Portland State University

PDXScholar

Spring 6-5-2014

\title{
Participation, Information, Values, and Community Interests Within Health Impact Assessments
}

Nicole Iroz-Elardo

Portland State University

Follow this and additional works at: https://pdxscholar.library.pdx.edu/open_access_etds

Part of the Environmental Public Health Commons, Transportation Commons, and the Urban, Community and Regional Planning Commons

Let us know how access to this document benefits you.

\section{Recommended Citation}

Iroz-Elardo, Nicole, "Participation, Information, Values, and Community Interests Within Health Impact Assessments" (2014). Dissertations and Theses. Paper 1846.

https://doi.org/10.15760/etd.1845

This Dissertation is brought to you for free and open access. It has been accepted for inclusion in Dissertations and Theses by an authorized administrator of PDXScholar. Please contact us if we can make this document more accessible: pdxscholar@pdx.edu. 


\title{
Participation, Information, Values, and Community Interests Within Health Impact Assessments
}

\section{by}

Nicole Iroz-Elardo

A dissertation submitted in partial fulfillment of the requirements for the degree of

\author{
Doctor of Philosophy \\ in \\ Urban Studies
}
Dissertation Committee:
Connie Ozawa, Chair
Sy Adler
Jennifer Dill
Stephanie Farquhar

Portland State University

2014 
(C) 2014 Nicole Iroz-Elardo 


\begin{abstract}
Health impact assessment (HIA) has emerged in the U.S. as one promising process to increase social and environmental justice through addressing health equity issues within planning. HIA practice is guided by values such as democracy and equity and grounded in broad social determinants of health. The most readily applied definition of democracy is problematic because it implies an element of direct, participatory engagement with the public. This is at odds with HIA practice that largely relies on stakeholder engagement strategies.

This dissertation critically examines the engagement strategies of three transportation planning HIA cases to more fully understand how the HIA process may or may not promote democratic values and protect community health interests. It employs a multi-case study design that uses qualitative content analysis to trace community health interests through the HIA process, HIA document, and target plan. It finds that while the field is overstating the participatory nature of HIA, commitments to health equity and broad determinants of health protect community health interests with and without robust engagement of community stakeholders.
\end{abstract}




\section{Dedication}

In loving memory of Patty Sue Stewart who fed my love of learning, introduced me to some of the worlds' great cities, and instilled values of justice and peace. 


\section{Acknowledgements}

Writing a dissertation is a decidedly solitary activity; yet a community of supporters shape and sustain such a large project. I owe Sy Adler for identifying HIA as a potential research topic long before I - or frankly many - realized it would become such a popular interdisciplinary practice. I am grateful for the support that he, Connie Ozawa, Jennifer Dill, and Stephanie Farquhar provided. I also want to thank Ellen Bassett whose fingerprints are all over this project; she provided emotional, conceptual, and editorial support from afar. I am appreciative of the financial support provided by an Oregon Transportation Research and Education Consortium (OTREC) Dissertation Fellowship. I am thankful for the collaborative nature of the HIA practice community. I am also appreciative of advice and editorial support from Loulie Brown. I also want to acknowledge the mentorship of Jyothi Nagaraja and Warren Strauss.

Words cannot express my love and appreciation for those who provided emotional support throughout this process. To Lauren Larin and Moriah McSharry McGrath who have become like sisters: thank you for providing sustenance, a place to sleep, shoulders to cry on, and laughter to accompany celebrations as we have plodded through this process. I must thank my parents and siblings, particularly my mother Renee, for indulging my academic endeavors throughout my life. Gratitude also goes to Robert and Rosalie who have welcomed my passion in their family. To my sweet boys Martin and Allen: thank you for grounding my life, even if the time I spent "type-typetyping on my book" cheated you of time with me in these special and formative years. Finally, I owe a debt of gratitude to Justin's abiding love and partnership; he pushed me to start this process and never once doubted I would complete it. 


\section{Table Of Contents}

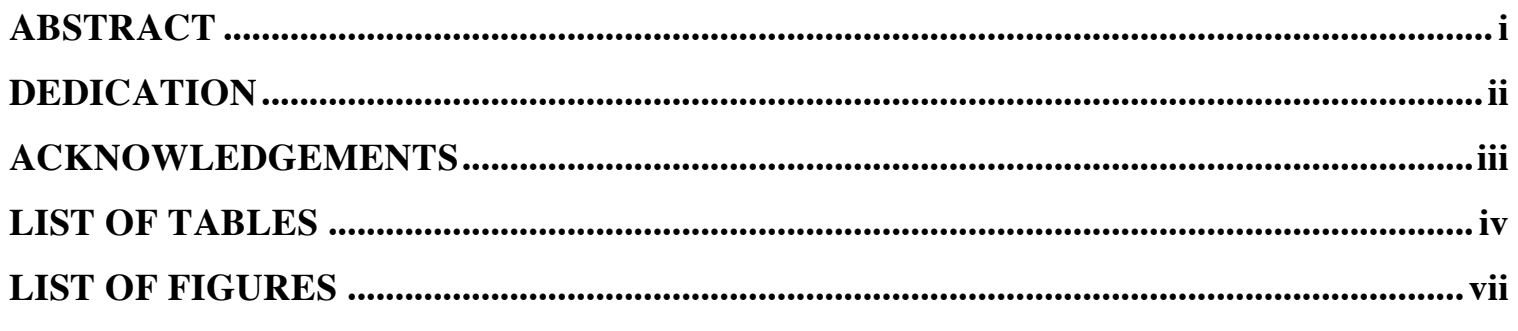

CHAPTER 1 - HEALTH, PLANNING, AND COMMUNITY .................................................. 1

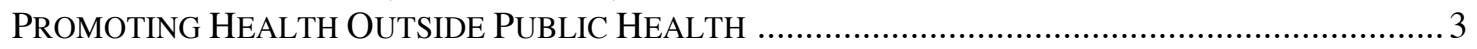

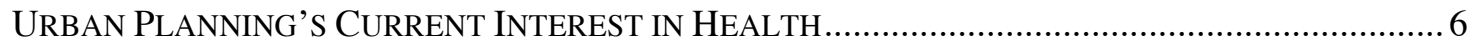

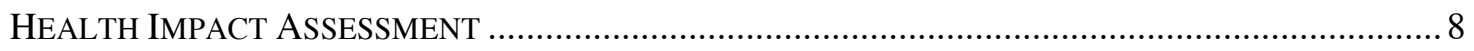

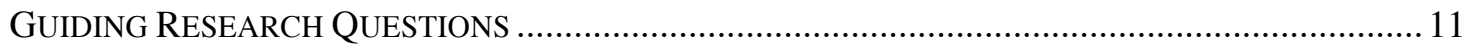

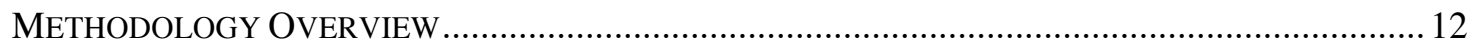

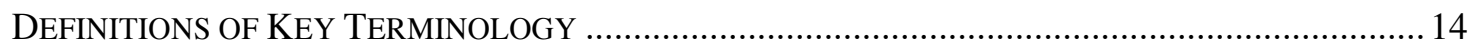

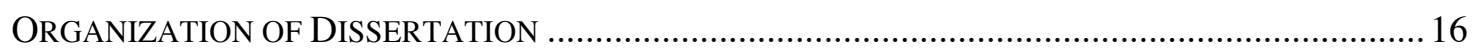

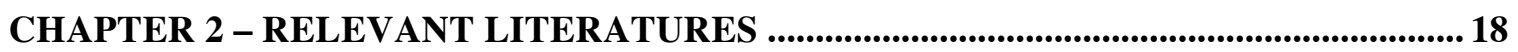

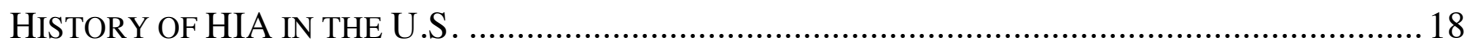

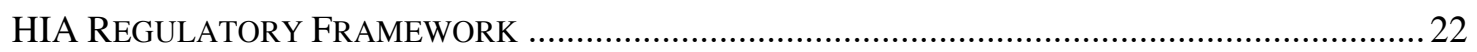

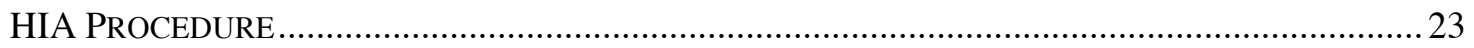

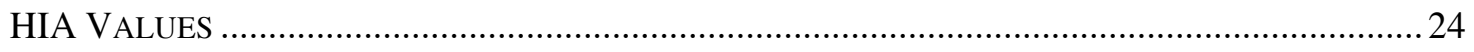

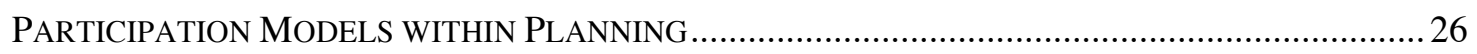

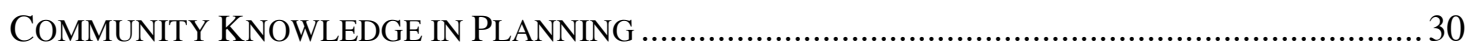

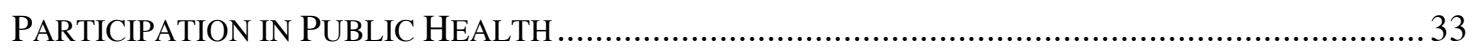

CBPR AS AN EXEMPLARY PARTICIPATORY STRATEGY IN PUBLIC HEALTH .................................. 34

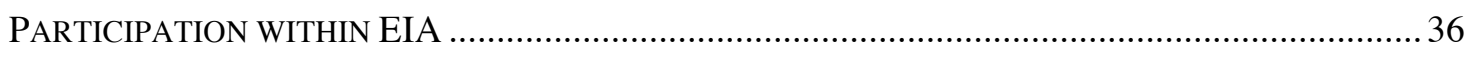

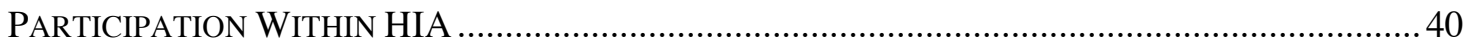

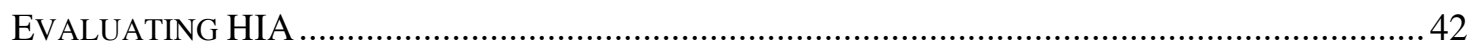

CHAPTER 3 - RESEARCH DESIGN AND METHODS ................................................. 49

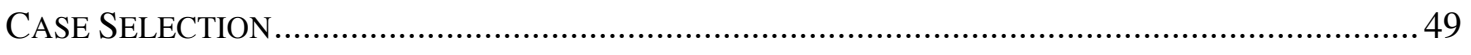

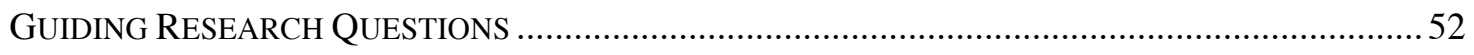

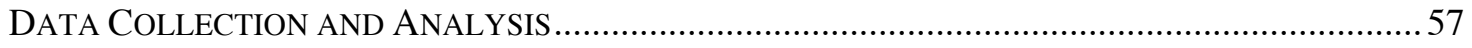

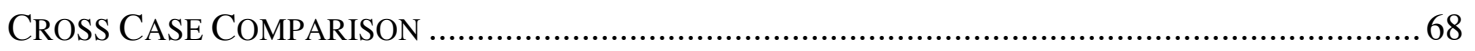

CHAPTER 4 - CLARK COUNTY BICYCLE AND PEDESTRIAN PLAN AND HIA ....... 69

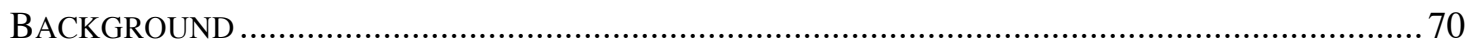

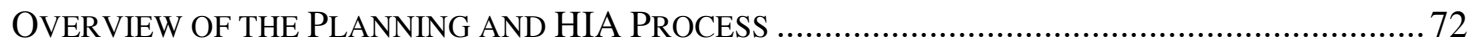

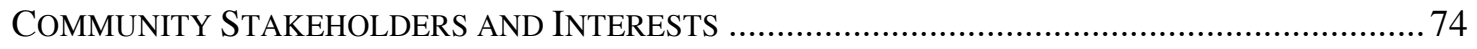

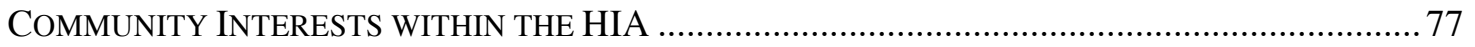

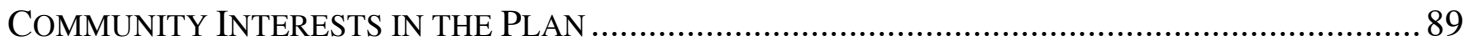

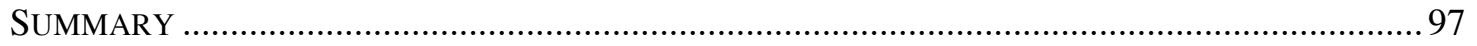

CHAPTER 5: CASE STUDY OF LAKE MERRITT BART STATION AREA PLAN .......98

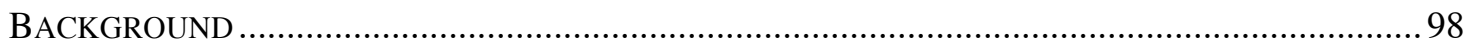

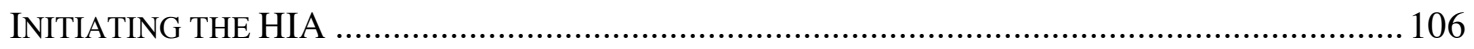

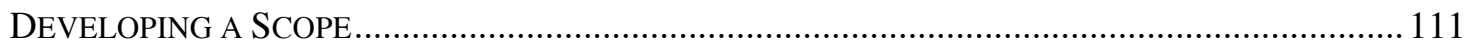

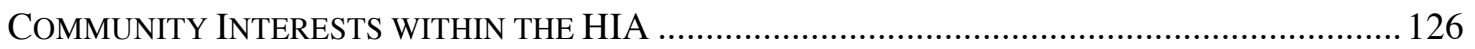




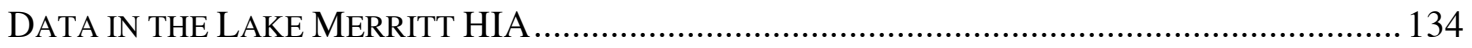

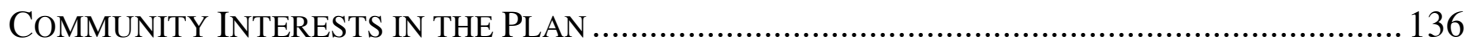

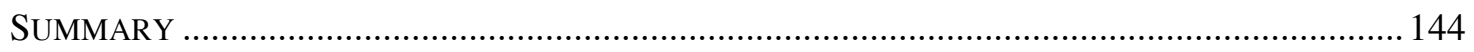

CHAPTER 6: CASE STUDY OF I-710 CORRIDOR PROJECT ..................................... 147

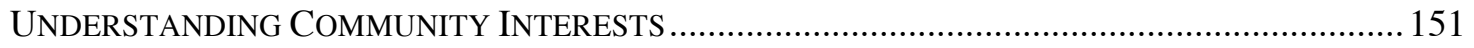

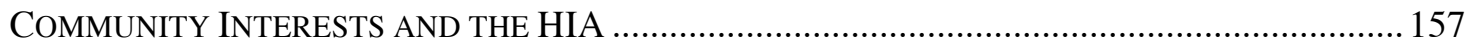

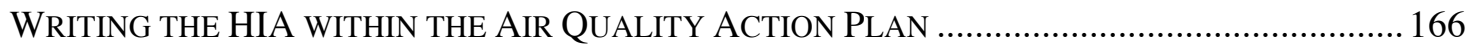

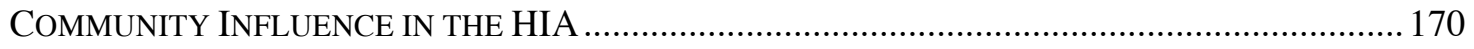

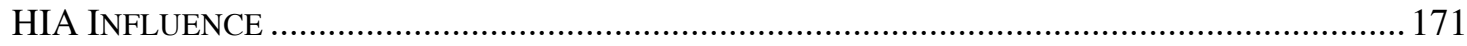

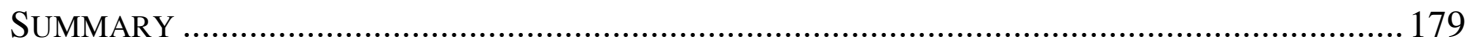

CHAPTER 7: PARTICIPATION NORMS AND IMPLICATIONS FOR THE FUTURE OF

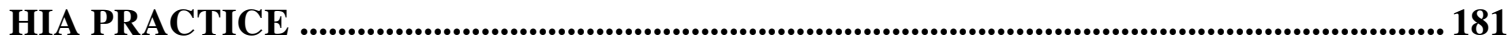

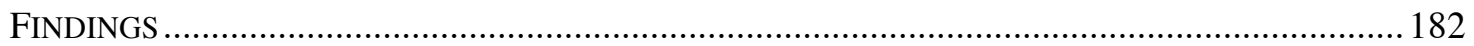

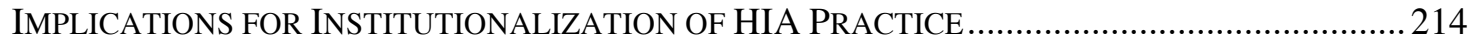

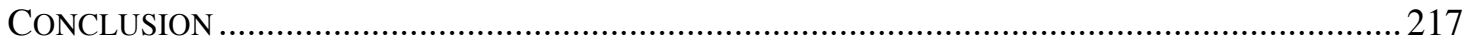

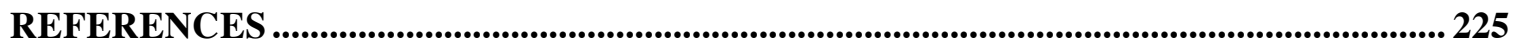

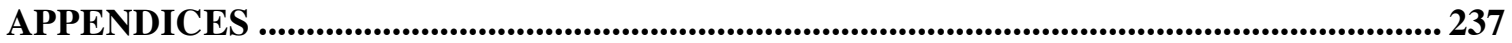

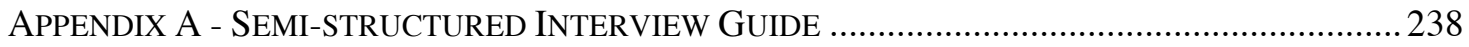

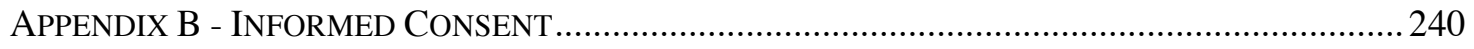

APPENDIX C - GUIDING PRINCIPLES GOVERNING LAKE MERRITT BART

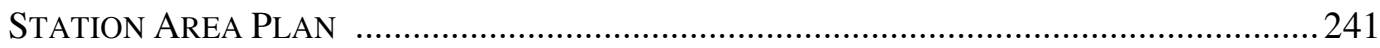




\section{List of Tables}

Table 4.1 Clark County Populations within Incorporated Areas ................................... 70

Table 4.2 2008 and 2012 Presidential Election Results ............................................... 71

Table 4.3 Membership Roles of the Bicycle and Pedestrian Advisory Committee......... 75

Table 4.4 Content Analysis of the HIAs for Pedestrian and Bicycle Interests ................ 82

Table 4.5 Clark County Rapid HIA and Inclusion in Final Plan ................................... 90

Table 4.6 Community Language in Clark County Comprehensive HIA......................... 92

Table 5.1 Organization Roles and Characteristics of the Lake Merritt HIA Stakeholder

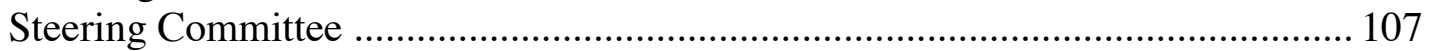

Table 5.2 Code Count of Guiding Principles within the Lake Merritt HIA Document.. 126

Table 5.3 Transportation Health Recommendations in the Lake Merritt Administrative

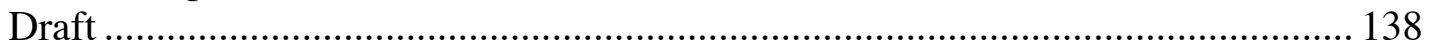

Table 6.1 Demographic Profile of I-710 Corridor Community (Coalition for Environmental Health and Justice, 2012, p. Attachment H)............................... 152

Table 6.2 Organizations Interested in the I-710 Corridor HIA ................................... 154

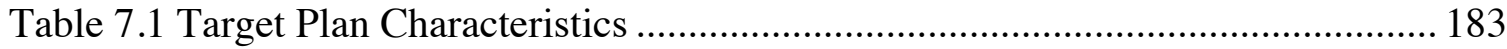

Table 7.2 Participation Structure Matrix ....................................................................... 187

Table 7.3 Problem Definition and Agenda Setting in the HIA .................................... 193

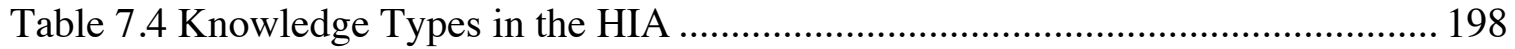

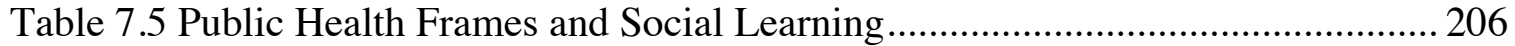

Table 7.6 Measures of Community Influence .......................................................... 209 


\section{List of Figures}

Figure 3.1 Diagram of Lake Merritt Station Area Plan Documents Available for Content

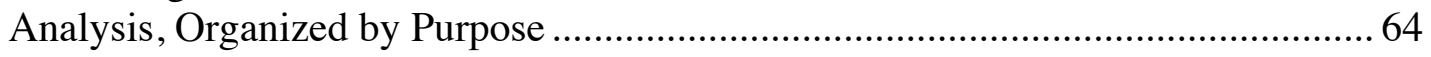

Figure 5.1 Map of Planning Area for the Lake Merritt BART Station Area Plan........... 99 Figure 5.2 Stakeholder Interest Diagram for Lake Merritt BART Station Area Plan .... 101 Figure 5.3 Interest Diagram of Organizations Participating in HIA Steering Committee

Figure 6.1 I-710 Corridor Project Area.................................................................... 148

Figure 6.2 I-710 Corridor Project Participation Structure ........................................ 150

Figure 6.3 Community Interests in the I-710 Corridor Project................................... 156

Figure 6.4 AQAP Participation Structure Corridor Project ........................................ 166 


\section{Chapter 1 - Health, Planning, and Community}

The leading causes of death in the U.S. are no longer communicable diseases; instead, chronic conditions linked to behaviors and shaped by environments are today's most pressing public health concerns (Center for Disease Control and Prevention, 2014b). Further, chronic disease does not affect all communities equally. Individuals living in communities characterized by high proportions of minority and low-income households are far more likely to succumb to disease and premature death than those living in a community of high socio-economic status (Marmot \& Wilkinson, 2003). For example, a 2010 project funded by the National Institutes on Health found massive disparities in life expectancy by census track: a difference of 24 years within Oakland; 30 years within Baltimore; and 33 years within Boston (Center on Society and Health, 2014). Those living within the Roxbury neighborhood of Boston, on average, do not see their $59^{\text {th }}$ birthday while those living in the Charles River Basin can expect to live to nearly 92 years old (Zimmerman, Evans, Woolf, \& Haley, 2012, p. 21). These vast differences in quality and length of life result from complex interactions of economic, social, and environmental factors across the life cycle (Marmot \& Wilkinson, 2003). Improving health in an equitable fashion will require aggressive collaboration across all public sectors including between public health and urban planning (Rudolph, Caplan, BenMoshe, \& Dillon, 2013).

Despite the significant interest in collaboration between the public health and planning fields over the past twenty years, incorporating and institutionalizing the inclusion of health interests in planning decisions and urban governance is an ongoing challenge. Recent collaborations between public health and urban planning are best 
understood in the context of each discipline's objectives and history. The two disciplines share historical roots in the sanitary movement of the late nineteenth century. Both fields began as a reaction to the poor environmental conditions that accompanied nineteenth century industrialization and urbanization and efforts by Progressive Era reforms (Corburn, 2007; Melosi, 2000; Rosner, 2006; Tarr, 1996). Yet they drifted apart in the early twentieth century. Public health turned to germ theory and the accompanying attention on individual cleanliness and vaccines to combat epidemics. Planning increasingly focused on protecting the single family home via zoning and on accommodating the automobile through rational, technical exercises (Frank, Engelke, \& Schmid, 2003).

The two disciplines maintained largely separate agendas in the U.S. for the greater part of the $20^{\text {th }}$ century, occasionally crossing over to address housing, urban renewal, and health planning. Public health professionals knew that urban form impacts physical and mental well-being and would occasionally weigh in on housing reform throughout the twentieth century; planners would at times include health as a planning goal and occasionally lend their planning expertise. Examples of these episodic collaborations include the "Basic Principles of Healthful Housing" released by the American Public Health Association's Committee on Hygiene of Housing in 1938, mid-century efforts to revitalize downtowns and address substandard housing, and federally mandated health planning efforts to allocate hospital bed capacity in the 1960's and 1970s (American Society of Planning Officials, 1968; Corburn, 2007; Sloane, 2006).

More recently, however, planners and public health officials alike have returned to examining the impact of the physical environment on health (Frank \& Kavage, 2008). 
Public health practitioners have attempted to integrate the built environment with the social environment's effect on physical health - particularly in Europe's "Healthy Cities" program (Awofeso, 2004; Barton \& Tsourou, 2000). Planners dipped their feet into the collaboration by exploring the role of land use and transportation modes in encouraging physical activity or "active living" in the earliest years of the twenty-first century (Boarnet, 2006; Frank, et al., 2003; Frank \& Kavage, 2008). Research agendas have since expanded, moving beyond transportation and housing to include topics such as access to food, healthy workplaces, social capital, and mental health (Dannenberg, Frumkin, \& Jackson, 2011)

Health impact assessment (HIA) has emerged in the U.S. as one promising process to increase social and environmental justice and fold health considerations into planning and urban decision-making. HIA's promise is its potential to address health equity by analyzing prospective policies, programs, and plans. HIA practice is explicitly guided by values such as democracy, equity, and broad social determinants of health and is able to flexibly integrate into diverse decision-making processes (North American HIA Practice Standards Working Group, 2009; World Health Organization, 1999). Yet it remains unclear what role HIA will play in solidifying the resurgence in the relationship between the two fields.

\section{Promoting Health Outside Public Health}

In late November 1986, the World Health Organization sponsored the International Conference on Health Promotion ${ }^{1}$ in Ottawa Canada. Those who gathered

\footnotetext{
${ }^{1}$ This conference is clearly linked to the World Health Organization's (WHO) 1978 "Health for All" initiative which sought to reduce inequalities in health by emphasizing disease prevention, primary health
} 
codified an international movement to promote health in its infancy through a document known as the Ottawa Charter for Health Promotion. The charter outlines health and equity rationales for addressing health in sectors outside of traditional public health applications. Specifically, participants pledged:

- to move into the arena of healthy public policy, and to advocate a clear political commitment to health and equity in all sectors;

- to counteract the pressures towards harmful products, resource depletion, unhealthy living conditions and environments, and bad nutrition; and to focus attention on public health issues such as pollution, occupational hazards, housing and settlements;

- to respond to the health gap within and between societies, and to tackle the inequities in health produced by the rules and practices of these societies;

- to acknowledge people as the main health resource; to support and enable them to keep themselves, their families and friends healthy through financial and other means, and to accept the community as the essential voice in matters of its health, living conditions and well-being;

- to reorient health services and their resources towards the promotion of health; and to share power with other sectors, other disciplines and, most importantly, with people themselves;

- to recognize health and its maintenance as a major social investment and challenge; and to address the overall ecological issue of our ways of living. (World Health Organization, 1986)

This pledge reflects a belief that health is a fundamental right that has an “inextricable link" to all other social goals (World Health Organization, 1986). Public health has increasingly articulated that an individuals' health is constrained by social and economic conditions at the household (micro), neighborhood and city (meso), and national and global (macro) scales (Galea, Freudenberg, \& Vlahov, 2006; M. E. Northridge, Sclar, \& Biswas, 2003). This ecological view of health suggests that health equity will require a diversity of action at all levels including advocating for public health outside the health services sector. Only then will individuals be able to "achieve their 1999). 
fullest health potential." The charter calls for "systematic assessment of the health impact of a rapidly changing environment - particularly in areas of technology, work, energy production and urbanization" to "ensure positive benefit to the health of the public" (World Health Organization, 1986).

In the nearly three decades since the Ottawa Charter was first articulated, the movement for health promotion in public policy has continued to grow. The World Health Organization rolled out the Health Cities Programme in 1986, a designation that continues today (Kenzer, 1999; Werna, Harpham, Blue, \& Goldstein, 1999; World Health Organization, 2014). Domestic efforts solidified in 1990 when the Centers for Disease Control and Prevention launched a health promotion and disease prevention agenda with Healthy People 2000. This program was extended with Healthy People 2010 and 2020 and continues to "encourage collaborations across communities and sectors" (Center for Disease Control and Prevention, 2014a).

With an emphasis on multiple factors and multiple levels influencing health behavior and outcomes, ecological models continue to play prominently within research and practice including health promotion. A key strength of this approach is that it "broadens options for interventions" (J. Sallis, Owen, \& Fisher, 2008, p. 479). The subfield of urban health explicitly acknowledges that environments - built, social, and natural - and the policies that shape them play an undeniable role in determining the health of communities and individuals (Corburn, 2009; Dannenberg, et al., 2011; Fitzpatrick \& LaGory, 2011; Galea, Freudenberg, \& Vlahov, 2005; Galea, et al., 2006; Lawrence, 1999; M. E. Northridge, et al., 2003; J. Sallis, et al., 2008; J. F. Sallis et al., 2006). 
In the U.S., the current iteration of the health promotion movement is the health in all policies approach to address the complexity of factors that constrain and influence individual choices about healthy behaviors (Rudolph, et al., 2013). Health in all policies asserts that improved health outcomes and decreased health disparities require collaboration across sectors because non-traditional partners have great influence over the social determinants of health. It suggests that public health practitioners seek opportunities to educate and partner with non-health professionals who shape the environment where people live, work, study and play. Health in all policies champions a diversity of activities ranging from informal partnerships to formal initiatives. This pragmatic approach to elevating health's profile claims that by repeatedly collaborating and working across sectors, consideration of health can be institutionalized and made a standard part of public decision-making processes (Gase, Pennotti, \& Smith, 2013; Rudolph, et al., 2013).

\section{Urban Planning's Current Interest in Health}

The interest in the intersection of health with other sectors is not limited to public health professionals. In the late $20^{\text {th }}$ century, planners also began to review the impact of the physical environment on health, primarily by exploring the role of land use and transportation modes to encouraging physical activity or "active living" (Boarnet, 2006; Frank, et al., 2003; Frank \& Kavage, 2008; Jackson, 2003; Sloane, 2006). Sustained collaborations between the two fields are resulting in a broadening of the research and practice agendas (Boarnet, 2006; Dannenberg, et al., 2011; Dannenberg et al., 2003; Jackson, 2003; Kent \& Thompson, 2014; Malizia, 2006; Ricklin, Musiol, \& Klein, 2012; Srinivasan, O'Fallon, \& Dearry, 2003). The development of theoretical models using 
ecological approaches has proved particularly fruitful in contextualizing the multiple spatial scales through which policy and design influence determinants and individual health (Galea, et al., 2006; M. E. Northridge, et al., 2003).

Like all planning and policy making, understanding the effects of the built and social environments on health and implementing interventions requires interacting with political processes (Hoch, 1994). Public health, recognizing the potential of urban planning to supersede market forces and guide development in a more healthy fashion through deliberation, has embraced the multi-disciplinary work to blend social, political, economic, and historical processes (M. Northridge \& Sclar, 2003). Public health professionals are particularly appreciative of planners' influence on urban governance and ability to "exert discretionary power" to shape agendas, public attention, evidence and deliberations (Campbell, 2006; Corburn \& Bhatia, 2007, p. 337; Forester, 1989, 1999; Ann Forsyth, 1999). Indeed, the 'communicative turn' in planning theory acknowledges multiple ways of coming to know the public interest; in doing so, it normatively invites a multitude of interests and knowledge types into planning process (Healey, 1996/2003; Innes, 1995, 1996/2004; Innes \& Booher, 2010). Yet both planning and public health struggle to democratize practice even as each seeks to identify the public interest and implement interventions that provide improved public coordination and input (Corburn, 2004, 2005b).

Today, both fields continue to search for innovative ways to advocate for and with communities while improving outcomes to reflect a more equitable, healthy, and just society (S. Fainstein, 2010; Gase, et al., 2013; Hofrichter \& Bhatia, 2010; Innes \& Booher, 2010, 2014; Minkler \& Wallerstein, 2008). This is a complex task that requires 
deliberation and collaboration across and between disciplines to identify imaginative solutions and address institutionalized power in creative ways (Innes \& Booher, 2010). Healthy planning demands a progressive practice that refuses to turn away from the political in order to advocate for populations at risk and the environments in which they live (Forester, 1989; Hoch, 1994; Krumholz, 1999/2003). Coburn (2009) believes planning and public health professionals are well-positioned to plan for a healthy city if they are willing to be multi-faceted and incorporate several political frames: population health, a relational view of place, process of governance, and power inequities. Only then will planners and public health professionals make significant progress in addressing health equity in the urban context.

\section{Health Impact Assessment}

Clearly planning intersects with and influences community and individual health, and both fields are committed to interdisciplinary research and practice. Yet questions remain about what form(s) this collaboration should take (A. Forsyth, Schively Slotterback, \& Krizek, 2010). This dissertation takes a critical look at a relatively new process - Health Impact Assessment (HIA) - as one particular form of interdisciplinary practice. HIA has been put forth as one of several structured approaches to implementing health in all policies, increasing interdisciplinary practice, and raising the profile of health in public decision-making (Collins \& Koplan, 2009; A. Forsyth, et al., 2010; Gase, et al., 2013; National Research Council, 2011; Rudolph, et al., 2013). It has been suggested that HIA "might bring together the built and social environmental factors that influence urban health" to inform public decisions outside of traditional public health applications (Corburn, 2007, p. 700) by "facilitating intersectoral action for health promotion" while 
also influencing decisions (Cole \& Fielding, 2007, p. 396; Cole et al., 2004). Because "HIA may offer a process for bringing together city agencies that rarely work together... HIA may be a method for breaking down disciplinary boundaries and other institutional barriers confronting efforts to reconnect planning and public health" (Corburn, 2007, p. 701).

HIA is a highly flexible approach that allows for applications in diverse settings and scales, but it is unlikely that it is suitable, successful, or efficient in all situations (A. Forsyth, et al., 2010; Gase, et al., 2013; Gottlieb, Fielding, \& Braveman, 2012; P. Harris, Sainsbury, \& Kemp, 2014). In particular, observers have raised significant concerns about effectiveness, democratization and governance, and the role of community in HIA practice (Cole \& Fielding, 2007; Corburn \& Bhatia, 2007; Dannenberg et al., 2006; A. Forsyth, et al., 2010; Mahoney, Potter, \& Marsh, 2007). HIA practitioners join a long democratic tradition of planning and other professionals supporting marginalized interests in current processes by advocating for new rules, procedures, and progressive outcomes (Davidoff, 1965/2003; Forester, 1994; Krumholz \& Forester, 1990). But does the HIA process and product deliver? HIA practitioners generally assume effectiveness, but since HIA practice is less than 15 years old, its ability to influence decisions is only now being documented (Charbonneau, 2013, Harris, Haigh, Baum, Harris-Roxas, Kemp, Chok, Spickett, Keleher, Morgan, Harris and Dannenberg, 2013, Pollack, 2013, Wendel, 2013). This dissertation attempts to add to this emerging body of work by recording whether HIA can shape and influence public decisions, and if so, how.

Second, it is unclear if HIA increases democracy and addresses urban governance as early proponents of HIA hoped. The HIA field builds upon the environmental 
activism of the 1950s and 1960s and borrows many concepts from environmental impact assessment (EIA) processes developed after the passage of the National Environmental Protection Act of 1969 (A. Forsyth, et al., 2010); however it remains committed to moving beyond EIA with an emphasis on the social determinants of health, health equity, and democracy (Cole \& Fielding, 2007; Harris-Roxas et al., 2012; Mahoney, et al., 2007; Ross \& Rao, 2013). HIA holds democratizing potential because it provides additional opportunities for stakeholders and communities to influence decisions (Cole \& Fielding, 2007; Negev, 2012; World Health Organization, 1999) and expands the body of information upon which a decision is made (Glucker, Driessen, Kolhoff, \& Runhaar, 2013; O'Faircheallaigh, 2010). However several recent evaluations have called into question the extent to which communities and stakeholders are incorporated and given power to control the HIA process (Harris-Roxas, et al., 2012; Rhodus, Fulk, Autrey, O'Shea, \& Roth, 2013). The heart of this dissertation is understanding how the HIA process may or may not overcome participation-related limitations often seen in planning applications, including some limitations that are inherent to impact assessment. It seeks to understand how HIA: tackles timing the process to both influence and analyze alternatives; integrates with planning processes without being co-opted by powerful parties; and incorporates community knowledge with technical information.

Finally, this dissertation specifically looks at the role of community within HIA practice. HIA is an attractive process to those interested in health promotion and urban health because it has the potential to place the community at the center of social and environmental public decisions. This reinforces community and social health frames essential to broadening beyond an individual conception of health (Minkler, 1999). Yet 
the role of the local community in the HIA process itself is not well documented or understood(Mahoney, et al., 2007). Early adopters of HIA in the U.S. came from participatory public health backgrounds, pushed significant stakeholder and community engagement, and provided some level of participatory involvement (Cole \& Fielding, 2007; Corburn, 2009; Corburn \& Bhatia, 2007; Dannenberg et al., 2008; Gihuly et al., 2011). Despite early examples and explicit guidance suggesting otherwise, U.S. HIA practice seems to have developed with minimal citizen participation and very uneven use of stakeholder engagement strategies. Additionally, "further study is needed to explore how HIA process might handle recurring conflicts over political power and health values such as when a state or private sector sponsored development project clashes with the health of the local community" (Corburn, 2007, p. 337). Thus a major aim of this research is to understand if and how HIA protects communities. It places community interests at the center of the analysis by specifically identifying and tracing community members' health interests and participation through three HIAs associated with transportation-planning cases. By doing so, it documents the promise and pitfalls of assuming HIA augments community participation in planning processes.

\section{Guiding Research Questions}

To study participation while also documenting general HIA effectiveness, six research questions guided the data collection and analysis. These questions are reproduced in Chapter 3 and developed further by adding associated hypotheses and factors for consideration.

1. Who is participating in HIAs and in what format?

2. Who is defining the problem and/or setting the agenda? 
3. How does the 'nature' of the plan affect the HIA problem definition, process and outcome?

4. Are communities able to influence decision-making?

5. Is local knowledge integrated with professional knowledge?

6. Does HIA increase the ability of health interests to influence urban governance?

\section{Methodology Overview}

This dissertation employs a multi-case study approach to describe and examine how HIA processes are treating diverse health interests and the extent to which HIA can influence the target planning and decision-making process. Three contemporary HIA cases were examined using six guiding research questions. The HIA cases were limited to those associated with transportation target plans as a type of control. Yet the scale, objectives, and stakeholder participation methods of the target plan and thus HIA varied greatly:

- Case 1: Clark County Bicycle-Pedestrian HIA addressed the planning process to update bicycle and pedestrian plans for the unincorporated areas of Clark County, Washington. Clark County is a primarily rural county and the plan is an uncomplicated Active Transportation effort. A HIA-specific advisory committee was not convened; instead, the target plan's stakeholder advisory committee provided regular feedback for a more integrated participation structure.

- Case 2: Lake Merritt BART Station Area HIA analyzes a planning effort in Oakland California to envision a transportation oriented development pattern around the Bay Area Rapid Transit (BART) station serving a densely 
populated Chinatown and a local community college. This HIA was completely controlled by an advisory council of six local community organizations devoted to social justice. This council chose to keep the HIA separate from the official planning process in order to protect its role as an advocacy document; the HIA clearly reflects this priority.

- Case 3: I-710 Corridor Project HIA analyzes the defined alternatives for expanding an 18-mile stretch of I-170 connecting the ports of Los Angeles and Long Beach to the greater Los Angeles region and running through largely poor, Latino communities. This HIA was initiated after extensive community advocacy efforts, and the HIA was integrated into a portion of the environmental planning processes. However, the completion of the HIA was largely divorced from community input. A robust environmental justice advocacy effort after the release of the draft Environmental Impact Statement relies heavily on the HIA and thus shows HIA can influence the decisionmaking process in diverse ways.

Data collection and analysis for each case generally occurred in three phases: initial document review, interviews, and analysis of final documents. Data was gathered from (1) public documents and media reports associated with the target plan and HIA, (2) semi-structured interviews with members of the HIA advisory committees, (3) and the HIA report and target plan. Analysis relied on qualitative content analysis of a diversity of data sources to trace participants, interests, knowledge sources, and plan outcomes and also account for the broader context of each planning exercise. A cross-case comparison 
was approached using standard qualitative methods documented by Miles and Huberman (1994).

\section{Definitions of Key Terminology}

Because this dissertation is multi-disciplinary, defining a few key terms may be helpful even though these topics are covered in-depth in Chapter 2. First, the definition of health is one embraced by the public health field: "health is a state of complete physical, mental and social well-being and not merely the absence of disease or infirmity" (World Health Organization, 1946). Community is generally defined as those with shared interests, goals, and culture including the group primarily impacted by decisions, with special attention to vulnerable populations. Defining public participation is particularly troublesome in the literature because it is universally desirable but it can take on many forms (Glucker, et al., 2013; Mahoney, et al., 2007) ${ }^{2}$. Accordingly, this dissertation uses engagement or participation to signify general involvement and participatory to signify more active roles such as data collection and decision-making authority by citizens. When possible, these terms are qualified with community, community-based organizations, or stakeholders to signify who is participating.

\section{Various types of interests and knowledge play a key role in both the framing} and the analysis of this research. The definition of interests comes from negotiation theory that posits interests are the underlying motivators of positions (Fisher, Ury, \& Patton, 1991). While distinctions between professional knowledge and all other types of knowledge may be unnecessarily divisive (Innes \& Booher, 2014), multiple scholars over

\footnotetext{
${ }^{2}$ Glucker et al (2013) discusses the challenges of defining participation within EIA. Mahoney et al (2007) suggests the lack of rigor and clarity in defining 'community participation' is a significant barrier to understanding its appropriate role in HIA.
} 
many years have documented that vulnerable communities struggle to engage technical planning processes due to their tendency to elevate and privilege technical, rational knowledge (Amy, 1987; Corburn, 2003, 2005a; Ehrmann \& Stinson, 1999; Innes \& Booher, 2010). Professional knowledge is widely defined to be scientific, rational, and often technical. More importantly, professional knowledge differs from community (or lay) knowledge in that the latter is grounded in the experiences of everyday life (Corburn, 2005a). Community knowledge is knowledge that comes directly from the community and is assumed to be tightly linked to community interests (Corburn, 2005a; N. Taylor, 1998). Community knowledge is generally assumed to be democratizing when it is gathered in a participatory manner (Corburn, 2005a). Finally, while academic understanding largely concedes there is no singular community interest (often termed 'public interest') or knowledge, it is important to recognize this is also true for professionals. In HIA, due to the multi-disciplinary nature, professional knowledge and interests often varies even among health professionals (Negev, 2012) and thus should not be assumed to be uniform across or within specific professions.

Other key terms relate to values and frames often employed by public health professionals practicing in the health promotion arena. First, the phrase social determinants of health encompasses the notion that health of individuals and communities is dependent on the greater social, economic, cultural, built and physical environmental conditions (Wilkinson \& Marmont, 2003). It explains public health professionals' desire to use HIA to influence policy areas outside their normal line of work (Harris-Roxas \& Harris, 2011). This notion also helps explain the concern about health for specific spatial communities because residential distribution is closely linked to 
socio-economic status in the U.S. Health inequities or health disparities (used interchangeably) describes uneven distribution of health outcomes based on race, class, age, and/or place of residence. Health equity describes the normative goal and outcome

of bringing all groups and communities to equal health status (World Health Organization, 2008a).

\section{Organization of Dissertation}

This dissertation seeks to critically evaluate community engagement in HIA practice and understand its potential and limitations as democracy tool using a comparative case-study approach. Before presenting the full cases, Chapter 2 reviews several literatures pertinent to this investigation including: the history, regulatory environment, procedure, and values of HIA practice; participation in planning; participation in public health; treatment of participation in EIA and HIA; and the state of evaluation in HIA. After reviewing case-selection criteria, Chapter 3 details the methodology used to understand how community interests interact with HIA using a three-phase approach: identifying community interests through document review, verifying interests and knowledge sources with interviews, and tracing community interests into the HIA documents and target plans. Analysis methods largely draw from qualitative content analysis informed by best practices in the negotiation and conflict resolution literature.

The next three chapters offer detailed individual case studies. Chapter 4 outlines the challenges and success of the Clark County (Washington) Bicycle and Pedestrian Plan and HIA. Chapter 5 presents the Lake Merritt BART Station Area Plan (Oakland, California) and HIA as an exemplar of a community-controlled HIA process. In Chapter 
6, the HIA associated with the I-710 Corridor Project (southern California) is presented; this HIA serves as a deviant case because the HIA author struggled to engage the planning process for the largest public works and freeway expansion in the U.S.

Chapter 7 returns to the research questions developed in Chapter 3 to help understand potential barriers and facilitators of community influence in HIA practice. Using a cross-case comparison approach, it documents findings including participation strategies used, types and use of knowledge, community influence, and HIA effectiveness. Included is a discussion of values governing HIA and how these values are demonstrated in HIA practice. Chapter 7 also includes a discussion of implications for HIA practice before turning to conclusions, limitations, and future research. It posits that participatory elements are not a fundamental element of contemporary HIA practice, but that democracy can still be bolstered with (1) good stakeholder engagement and (2) through continued professional commitment to the values of health equity and broad determinants of health. The implication is that HIA practitioners will need to be more explicit in their engagement plans in order to support and address health in vulnerable populations, particularly if increasing community capacity and democracy are overt goals of the HIA. 


\section{Chapter 2 - Relevant Literatures}

HIA is an interdisciplinary practice that has been influenced by a number of fields and literatures. This chapter begins by providing a history of HIA in the U.S. including the fields' regulatory framework, procedure and values. It then reviews how participation is treated in both planning and public health. It discusses the theoretical and practice norms in both disciplines for integrating community interests and knowledge. It then inspects how the broader impact assessment (IA) literature views participation with special attention to evaluative studies of participation within both environmental impact assessment (EIA) and HIA. Finally, it examines the current state of evaluation practice and methodology in HIA to understand general treatment of effectiveness and the narrower question of community influence.

\section{History of HIA in the U.S.}

HIA originates from three areas of public health activity: environmental health, the wider determinants of health, and health equity (Harris-Roxas and Harris 2011). While HIA shares many features and objectives with EIA due to its environmental health roots, HIA's origin is distinct because it is part of a larger professional movement in public health to promote more equitable health outcomes in policies outside the public health arena (Harris-Roxas, et al., 2012). HIA was initially promoted by the World Health Organization and used in both developing nations and European contexts in the 1990s (Kemm, 2013). The 1999 Gothenburg Consensus Paper was an attempt to bring much of the disparate European threads of HIA practice together by explicitly stating values and putting some boundaries on the field (Harris-Roxas, et al., 2012; World Health Organization, 1999) . 
HIA did not emerge in the U.S. until 1999. The San Francisco Department of Public Health was the earliest U.S. adopter of HIA because leadership within the Environmental Health Section believed it might allow public health to weigh in on social and environmental determinants of health historically outside a local health department's purview. Early topics for HIAs in San Francisco included a city-wide living wage ordinance, a land-use and zoning plan in an environmental justice neighborhood of Bayview, and a sick-pay ordinance (Bhatia, 2007; Bhatia \& Wernham, 2008; Corburn \& Bhatia, 2007; Farhang et al., 2008). As practitioners in San Francisco, California and Europe began documenting success with HIA, other public health practitioners took note. Academics at University of Southern California and University of California, Los Angeles began experimenting with more quantitative HIAs. In Alaska, tribes began using HIA to address resource extraction issues, often turning to the international community for examples and advice. In Atlanta, the Center for Quality Growth and Research Development at Georgia Institute of Technology used HIA to understand the health impacts of the region's BeltLine (Dannenberg, et al., 2006; Dannenberg, et al., 2008).

By 2007, at least 27 HIAs had been completed in the U.S. (Dannenberg, et al., 2008) and talk began of attempting to institutionalize the field in the U.S. (Dannenberg, et al., 2006). In October 2008, a small group of two-dozen practitioners met in Oakland, California to share successes and challenges of using HIA. A major outcome of this "HIA of the Americas" event was establishing practice standards based upon European, early Californian, and Alaskan experiences (North American HIA Practice Standards Working Group, 2009). In October 2009, the Robert Wood Johnson Foundation and The 
Pew Charitable Trusts joined together to support the growth of HIA with the Health Impact Project ${ }^{3}$. The Bay Area has remained an HIA leader even if the San Francisco Department of Public Health has replaced HIA work with a more regular seat at the planning table; Oakland is home to a consulting company specializing in HIAs called Human Impact Partners (HIP) ${ }^{4}$ (Dannenberg \& Wernham, 2013).

In 2011, Health Impact Project documented 75 completed and 40 in-progress HIAs (Ross \& Rao, 2013). In May of 2012, this had expanded to 103 completed and 89 additional in-progress HIAs (Dannenberg \& Wernham, 2013). A March 2014 query of the Health Impact Project clearinghouse showed 244 completed HIAs with an additional 85 in progress (Health Impact Project). As the quantity of HIAs has expanded, so have the sectors HIA seeks to influence. Built environment issues including land-use and transportation planning still dominate HIA practice, but HIAs are beginning to address housing, economic development, criminal justice, climate change, and education. The scale at which HIAs are performed has also diversified. While most HIAs occur at a local scale, an increasing number address regional, state and federal plans and policies (Dannenberg \& Wernham, 2013).

Pew's Health Impact Project (www.healthimpactproject.org) and the U.S. Centers for Disease Control and Prevention (CDC) are today's dominant HIA funders. Between late 2009 and 2013, Pew funded 35 HIAs, six HIA programs - most of which completed multiple HIAs, and four HIAs in partnership with National Association of County and City Health Officials, and four HIAs in partnership with Blue Cross and Blue Shield of

\footnotetext{
${ }^{3}$ The Clark County HIA was part of the last round of HIAs to be funded by Robert Wood Johnson Foundation prior to the implementation of the Health Impact Project.

${ }^{4} \mathrm{HIP}$ is the author of two of the HIA cases examined in this dissertation: Lake Merritt and I-710 Corridor.
} 
Minnesota Foundation (Health Impact Project, 2014). Additionally, Pew has partnered with four public health institutes to provide training and support to grantees. The CDC has supported HIAs tightly linked to the built environment through their Healthy Community Design Initiative since 2006. (See www.cdc.gov/healthyplaces/hia.htm.) In 2011, the CDC funded six public agencies (state and county) to perform three HIAs between 2011 and 2013. Together, Pew and the CDC organized two National HIA Conferences in 2012 and 2013, and both maintain significant web presence to support HIA practice. With such a dominant presence in funding, training, and research, the Pew and CDC programs are highly influential in institutionalizing and pushing innovations in HIA practice. Both grant programs require clear target decisions and adherence to HIA Minimum Elements and Practice Standards (North American HIA Practice Standards Working Group, 2010).

The HIA profession has also solidified in the past few years. In the fall of 2011, HIA practitioners from across the U.S. and Canada organized the Society of Practitioners of Health Impact Assessment (SOPHIA). (See www.hiasociety.org.) For several years, Human Impact Partners had been hosting "HIA of the Americas Workshop" in Oakland, California where the notion of an organization for practitioners to guide standards, coordinate peer review, and provide mentorship was often discussed. The establishment of SOPHIA helped institutionalize the structure of the HIA of America's workshops and workgroups. SOPHIA remains active on the HIA scene today and will be hosting the fifth HIA of the Americas Workshop in the fall of 2014.

It is notable that the three cases in this dissertation predate the rollout of Pew's Human Impact Project and none of the three HIAs were funded through the CDC's 
Healthy Community Design Initiative. The cases also predates SOPHIA, although Human Impact Partners - the I-710 Corridor and Lake Merritt HIAs author - is the primary organization behind SOPHIA. In a way, the cases represent the last of an era when HIA practitioners were truly scrambling for funding and defining the field as they produced HIAs. This has significant implications on the generalizability of this dissertation including the extent to which it is able to speak to the current trajectory of HIA practice.

\section{HIA Regulatory Framework}

Environmental impact assessment (EIA) began as a tool to guide decisions after the passage of the National Environmental Protection (NEPA) Act in 1970. The original intent of NEPA was to require EIA to analyze the quality of environmental impact as well as to "stimulate the health and welfare of man" (Sec. 101[42 USC § 4331]). Many in the public health field, however, feel that NEPA does not adequately address human health due to a narrow focus on pollution-related effects instead of describing human health outcomes (Dannenberg \& Wernham, 2013).

Unlike EIA, HIA does not generally enjoy a legal mandate ${ }^{5}$. Legislatures and decision-making bodies are requesting some HIAs on a project-by-project basis. The first such request was from the State of Washington in 2007 for an HIA on the State Route 520 bridge replacement in Seattle; the I-710 Corridor HIA analyzed in this dissertation was requested by the I-710 Project Committee. The legal argument for including HIA within EIA practice is strong, but the field continues to debate whether or not to push for inclusion of HIA within EIA (Dannenberg \& Wernham, 2013; Rajotte,

\footnotetext{
5 A notable exception is Massachusetts' 2009 mandate to perform an HIA on all large transportation projects; implementation of this mandate is still occurring.
} 
Ross, Ekechi, \& Cadet, 2011). Some argue that HIA can and should be demanded and integrated into EIA (Bhatia \& Wernham, 2008). Others argue that HIAs are effective because it is a flexible process independent of the EIA process (Cole, et al., 2004). This debate is unlikely to be resolved soon. Until then, "the degree to which the HIA and EIA analyses are integrated varies depending on the relationship of the team conducting the HIA and the agency responsible for leading the EIA" (Dannenberg \& Wernham, 2013,p. 213).

\section{HIA Procedure}

The HIA field has reached broad consensus on the procedural aspects of HIA (Harris-Roxas, et al., 2012). HIA follows a six-step process of screening to decide if an HIA is feasible and would add to the decision-making process; scoping health pathways important to the analysis and outlining an analysis plan; assessment including documenting existing health conditions and evaluating impacts; recommending strategies or changes to maximize health; reporting recommendations; and ongoing monitoring and evaluation of the process, influence and health outcomes (National Research Council, 2011).

While there is also broad consensus around values driving HIA (see next section), the expression of values is uneven. Nowhere is this more apparent than in the quantity and quality of stakeholder and community input as an expression of democracy. Some HIAs involve partner organizations in identifying and gathering data during the scoping and early assessment phase. A small proportion of HIAs - 18.5 percent in a recent study by the EPA - robustly engage stakeholders through an advisory committee. An even smaller proportion of HIAs appeared to engage stakeholders in HIA decisions as equal 
partners throughout the process (Rhodus, et al., 2013). While stakeholder engagement guidance is available, (Stakeholder Participation Working Group, 2012), many decisions including how to engage stakeholders are driven by expediency (UCLA School of Public Health, 2014). Without explicit attention to the procedural and decision-making role of stakeholders and community, HIAs may be ignoring values fundamental to HIA practice.

\section{HIA Values}

This dissertation attempts to understand the rhetoric and practice gap of participation and democracy within HIA. Three explicit values in HIA practice drive consideration of community health interests: democracy, equity, and a broad view of health. The first two values - democracy and equity - are linked to the Gothenburg Consensus in 1999 that sought to define HIA in the European context:

Democracy, emphasizing the right of people to participate in a transparent process for the formulation, implementation, and evaluation of policies that affect their life both directly and through elected decision makers.

Equity, emphasizing that HIA is not only interested in the aggregate impact of the assessed policy on the health of a population but also on the distribution of the impact within the population, in terms of gender, age, ethnic background, and socioeconomic status. (World Health Organization, 1999)

These two definitions were also adopted for the first edition of North American Practice Standards (North American HIA Practice Standards Working Group, 2009) ${ }^{67}$.

The third value - broad or comprehensive view of health - was also included in the first edition of the North American Practice Standards and defined as:

Comprehensive approach to health, emphasizing that physical, mental and social well-being is determined by a broad range of factors from all sectors of

\footnotetext{
${ }^{6}$ The values are referred to as "principles" in most North American contexts.

${ }^{7}$ In an effort to make the it more practice friendly, the current edition of Practice Standards (North American HIA Practice Standards Working Group, 2010) omits any mention of values/principles even though many (myself included) asked that the values - however aspirational - remain within the text.
} 
society (known as the wider determinants of health). In adhering to this value, the HIA method should be guided by the wider determinants of health. (North American HIA Practice Standards Working Group, 2009)

Other values routinely cited include sustainable development and ethical use of evidence, both of which were included in the Gothenburg Consensus; impartiality meaning that HIA advocates for increased public health by informing rather than advocating for specific alternatives; and openness or transparency in how the HIA was produced (Kemm, 2013; North American HIA Practice Standards Working Group, 2009). Approximately two-thirds of HIA guidance documents world-wide include some or all of these values (Hebert, Wendel, Kennedy, \& Dannenberg, 2012). Merging social determinants of health with the Gothenburg Consensus' definition of equity to drive adoption of HIA practice and may protect community health interests. This dissertation shows that these two values may have a more instrumental role in protecting community health because each value prompts expanding the communities and health pathways under consideration.

Inclusion of "directly" in the democracy definition suggests and has usually been understood as a participatory element in HIA circles (Kemm, 2013). This reflects a standing tradition within public health that views community engagement, organization, and empowerment as normatively desirable and instrumental in promoting individual and community health (Minkler, Wallerstein, \& Wilson, 2008) ${ }^{8}$. Thus, supporting empowerment in a community through participatory elements is a near universal ideal in HIA circles. Yet HIA practice - as this and other evaluative research is beginning to show - is not necessarily participatory and may not even engage stakeholders at all. This

\footnotetext{
${ }^{8}$ See subsection 'Participation Within Public Health' for a more detailed explanation of contemporary thought surrounding participation within the health promotion field.
} 
suggests HIA practice needs to re-evaluate the demonstration of democracy and participation within the field.

\section{Participation Models within Planning}

Because planning problems and solutions assume collective intervention for the common good, the public interest has been and remains an important consideration within the field (Altshuler, 1965/2004; Campbell, 2006). Conventions about the level and form of public participation have varied as planning has moved from a rational, bureaucratic activity towards a deliberative process. As planning continues to grapple with combining rational and deliberative process, the scale and scope of citizen participation remains somewhat contested (Innes \& Booher, 2014). Evaluations of participation in planning applications also remain thin (Day, 1997; Laurian \& Shaw, 2009). Still, planning remains heavily dependent on accurately identifying a non-singular public interest in order to inform, frame and analyze decisions. Avoiding mistaken interests is both necessary and difficult. Mistakes in empirical judgments, inability to recognize course of life issues, and social-individual tensions make accurate interest identification difficult even for the trained, professional planner.

Political philosophers suggest a "privileged status to people when they are identifying their own interests (thus avoiding the danger of third-party authoritarianism)" as long as the individual is doing so "under conditions of rational deliberation and choice (Connolly)... [and] relative personal autonomy [Lukes]" through collective discourse (N. Taylor, 1998, p. 68). This suggests the centrality and normative role of planning activities to provide a participatory platform. Doing so increases citizens' self-autonomy 
and civic capacity and results in plans and policies that are more reflective and sensitive to various public interests (N. Taylor, 1998).

The spectrum of participation strategies and its relationship with community power has been discussed at length since Arnstein's (1969/2005) influential paper describing citizen participation as a ladder. More recently, Quick and Feldman (2011) distinguished participation from inclusion in public engagement processes. In their view, participation increases the input (or information) for the decision while inclusive engagement increases connections among people and issues. Thus an engagement process can be highly participatory with many citizens providing information but do little to expand the ability of that community to engage each other or the decision. Quick and Feldman find that inclusion engages in multiple ways of knowing, co-produces process and content of the decision-making, and sustains temporal openness of past context and future sustainability of the plan. Inclusive planning efforts thus "support developing communities in which people defined public issues jointly and continuously and developed processes for addressing them" (Quick \& Feldman, 2011, p. 282).

Participatory processes are difficult to sustain. Aside from the difficulty of deciding "who" the public(s) are, participatory processes are resource and time intensive. Ordinary citizens have limited ability or desire to engage in civic life, particularly when the decisions require highly technical elements. Collaborative or stakeholder processes are a popular alternative to direct participation in planning processes. In stakeholder processes, interests surface through representatives, often self-selected, of various groups. Majority rule is often replaced with more collaborative efforts - sometimes with consensus as an explicit goal - which lead to group deliberation. 
Stakeholder processes can be inclusive, particularly if communities collaboratively grapple with and coproduce knowledge (Quick \& Feldman, 2011). This requires a well-designed process that includes the range of potential impacted stakeholders to allow most interests to surface through the process of group deliberation. The negotiation and conflict resolution literature is particularly instructive to understanding how to design such a process. This literature places significant emphasis on interests rather than positions to bring about joint or mutual gains (Fisher, et al., 1991). It acknowledges that identifying representatives within the stakeholder model is an important and powerful step and that the circle of possible stakeholders and interests should include all appropriate stakeholders. Enlarging the circle of participants is critical to a meaningful and fair process, strong agreement, smooth implementation, perceived legitimacy, and challenges from non-participating parties (Carlson, 1999; Potapchuk \& Crocker, 1999). Because of the critical nature of identifying representatives, guidelines have been developed to assist in the task. Conveners and mediators should (1) identify all possible representatives who are affected, can implement or can block a potential agreement; (2) invite obvious representatives and assist poorly organized interests in identifying a representative; and (3) ask all stakeholders if anyone has been omitted (Carlson, 1999). There is little evidence to suggest HIA practitioners are explicitly identifying stakeholders in this fashion; this may be limiting the circle of interests included in HIA.

Inclusion in the process is not enough; good processes encourage all stakeholder to articulate their interests and equitably participate (Rauschmayer \& Risse, 2005). All stakeholders need the ability to influence the agenda and problem definition by 
unpacking interests early on in the process, perhaps before the first meeting with the help of the mediator (Carlson, 1999). While many HIAs are supported by some sort of stakeholder or advisory committee, best practices are still emerging (Stakeholder Participation Working Group, 2012). There seems to be a theoretical commitment to "deliberative methods" within stakeholder participation strategies, but it is less clear to what extent deliberation and/or stakeholder power and control occurs within HIA (National Research Council, 2011; Rhodus, et al., 2013; Stakeholder Participation Working Group, 2012).

It is also unclear if HIA practice will be able to fend off cooptive pressures inherent in many planning processes. HIA practice is reminiscent of advocacy (Davidoff, 1965/2003) and its offshoot, equity (Krumholz \& Forester, 1990; Metzger, 1996) planning. Just as the advocate planners of the 1960s and 1970s provided technical expertise to poorly organized and disenfranchised groups with little capacity to engage the rational planning practice in order to attempt to shift power relations, HIA practitioners are providing technical information about determinants of health in the hopes that the dominate planning process will better mitigate health risks for vulnerable populations. HIA practitioners are often, although not always, employees of local and state government agencies. In this state role, HIA practitioners seem to be seeking ways to navigate the political nature of planning to demand more equitable outcomes through information provision. Yet both advocacy and equity planning have been criticized as a mechanism for placating and diverting the precious energy of the vulnerable and thus contributing to the status quo (Piven, 1970). If HIA practitioners are to avoid the HIA process being coopted, they must explicitly explore how their practice and participation 
norms interact with greater social movements and actively seek to provide as authentic and linked participation as possible.

\section{Community Knowledge in Planning}

The primary objective of impact assessment is to provide and integrate additional information into the target plan. Impact assessment, like much of planning, tends to elevate technical expertise (Innes \& Booher, 2014; O'Faircheallaigh, 2010). Yet technical and community knowledge are not mutually exclusive; processes that use both types of knowledge are the most likely to reframe problems in an emancipatory way (Innes \& Booher, 2014). The ability to integrate and co-produce many types of knowledge is important when sorting through objective criteria and tradeoffs, and is often required to move from potential to concrete agreements and solutions (Elliott, 1999; Fisher, et al., 1991). Some of the attraction of HIA seems to be the process' potential to integrate community, public health, and planning knowledge to improve public decisions. HIA stakeholder advisory committees potentially increase democracy to the extent that all stakeholders have the ability to present evidence and analyze information.

Scientific or technical knowledge and expertise are routinely utilized as objective criteria in stakeholder processes. For those stakeholders with less comfort and familiarity with scientific jargon, inclusion of this type of information represents a serious power deficit; those more comfortable with scientific language often use scientific details as leverage and ignore the universal element of scientific uncertainty (Amy, 1987; Ehrmann \& Stinson, 1999). Since community members are least likely to be equipped to share in information exchange and analysis, negotiation scholars have developed several best practices to guide objective criteria deliberations in a more power neutral manner. Joint- 
fact finding including (1) joint determination of technical issues of concern, (2) questions for experts, (3) specific experts to include, and (4) the best information gathering process is routinely suggested (Ehrmann \& Stinson, 1999). Mediators and facilitators are in a good position to manage the merging of technical and non-technical debates through both introducing technical information before alternatives and supporting resource sharing coalitions (Ozawa, 1993).

Corburn's (2005a) recent notion of 'street science' explicitly extends the notion of joint-fact finding to include the community's local knowledge. Corburn (2005a) defines local knowledge as communities "drawing on their firsthand experience" (p. 4) and encourages 'co-production' of expertise in environmental problem solving in the tradition “'local,' 'public,' and bottom-up, as opposed to top-down, approaches to research and decision making" (p. 7). Local knowledge allows for citizens and professionals integrated within the community ${ }^{9}$ to provide knowledge "grounded in a combination of media reports, firsthand experience, conversations with those with direct knowledge, conversations that help individuals make sense of what is happening and logic based on familiarity with comparable situations" (Innes \& Booher, 2010, p. 171) ${ }^{10}$. In this sense, the presence of community representatives well versed in the needs, conditions, and interests of the community potentially expands the information base due to the social learning that occurs in an advisory committee conversation.

\footnotetext{
${ }^{9}$ Examples of such a professional in an HIA setting include local CBO professionals or citizens who bring relevant professional but non-planning or public health expertise. Every effort is made to tease out planning, public health, citizen, and "other" professional knowledge and information. ${ }^{10}$ Innes \& Booher (2010) use the term "lay knowledge" in part because it is not spatially situated. This proposal will utilize local knowledge because of the spatial emphasis but acknowledges that HIA process studied may draw on knowledge, largely from professionals, with tenuous spatial links to the project.
} 
Local knowledge, which varies by community and context, is one of the most direct links to community interests. This knowledge is desirable because it (1) adds context, (2) allows non-experts to participate and influence decisions, and (3) increases the likelihood of good implementation due to better solutions and increased public buyin. Linking back to rationales for stakeholder and direct participation rationales, local knowledge expands the information base upon which decisions are made. Local knowledge in most cases also increases both levels of civic engagement and selfdetermination by allowing representatives and in some cases citizens - often in disadvantaged communities that have limited voice and influence - to define and address problems in their communities (Corburn, 2005a; Innes \& Booher, 2010). It also allows neighboring communities of (often cultural) differences to express conflict in a therapeutic manner (Sandercock, 2000). Examples of both planning and public-health practice that elevate community-based information in decision making include Healey (1997), Forester (1999), Minkler (1997), Israel et al (1998).

Avoidance of local knowledge may occur due to (1) epistemological differences, (2) anxiety about such difference and (3) uncertainty about how lay knowledge will affect process and outcomes (Innes \& Booher, 2010). Like direct participation strategies, soliciting local knowledge may be pragmatically ignored because of the increased resource burden on citizens who have more immediate needs and priorities reflective of their everyday lives and may not have the capacity to effectively participate. It also increases the resource burden on professionals shaping the engagement process since face-to-face deliberation can become unwieldy with a large group of participants. The increased burden on both the community and process provides one explanation as to why 
community members - a traditionally marginalized group - are often left out of decisionmaking processes even though they hold unique and critical information (Amy, 1987; Carlson, 1999; Innes \& Booher, 2010; Rauschmayer \& Risse, 2005).

Beierle \& Cayford's evaluation of 239 public participation cases echoes the challenges of soliciting local knowledge, identifying the "overall tendency of public participation to resolve conflict by leaving out participants or ignoring issues" (2003, p. 60). Decisions that occurs at the expense of adequately addressing the public interests and/or representation is extremely problematic particularly because advocacy and community groups with limited resources and power are those most likely to be excluded. Those shaping and mediating public processes only strengthen the position of the most powerful when they fail to intervene on behalf of less powerful parties by extending invitations, providing technical and financial support when needed, and requiring the consideration of absent stakeholders' interests (Amy, 1987; Carlson, 1999; Laws, 1999). Amy's (1987) documentation of how easy and frequently interests with limited resources are omitted thereby increasing the power of those with resources cannot be overstated. This is particularly true in light of understanding HIA as a tool to augment the information base during public decisions. The inclusion of community interests in HIA - by direct representation or through representatives such as professionals working in community-based organizations - are easily brushed aside due to the difficulty of including all possible parties and the pressure to resolve conflict quickly and efficiently. Thus, without explicit and careful consideration of how to include community interests, HIA may not address community health interests as much as proponents suggest.

\section{Participation in Public Health}


Public health has continually grappled with community participation and empowerment since the 1980s (Minkler et al., 2008). Examples include the WHOinitiated Healthy Cities movement from the 1985 Ottawa Charter for Health Promotion (Kenzer, 1999; Werna, et al., 1999); developing and applying empowerment theory in public health (Schulz, Israel, Zimmerman, \& Checkoway, 1995); understanding and applying models of community organizing to promote health (Minkler, Breechwich Vasquez, et al., 2008); and developing its own brand of action research - community based participatory research (Minkler \& Wallerstein, 2008). Each of these traditions privileges participation of individuals and community representatives to more accurately shape health interventions, improve community and self-efficacy, and in some cases shift power relations.

\section{CBPR as an Exemplary Participatory Strategy in Public Health}

The most likely authors of HIA are public health professionals who may have limited knowledge of negotiation and conflict resolution. Instead, HIA practitioners are likely to turn to community based participatory research (CBPR) as a source of best practices for participatory engagement of community stakeholders. CBPR, which reflects the influence of emancipatory traditions of social theory, directly tackles foundational public health notions of health equity and social determinants of health. It does so by advocating collaborative partnerships between researchers (often academic) and the community affected and elevating community interests, needs, and knowledge within the partnership (Cargo \& Mercer, 2008; Minkler, 2010; Wallerstein \& Duran, 2003).

Israel, Schulz, Parker, and Becker (Israel, et al., 1998) codified the basic principles and elements of CBPR which include (1) recognizing the community as a unit; 
(2) building on strengths and resources in that community; (3) facilitating collaboration in all phases; (4) integrating knowledge and action for the benefit of the community; (5) promoting co-learning and empowerment; (6) using a cyclical and iterative process; (7) addressing health from both positive and ecological perspectives; and (8) disseminating knowledge and findings to all partners. The literature addresses challenges of partnerships between (academic) researchers and community including building relationships of trust, power inequities, addressing conflict in the partnership, balancing research and action, and integrating different types of (including local) knowledge (Israel, et al., 1998; Isreal et al., 2003).

Identifying and including the community and how to best include them is discussed within the CBPR literature. Community is often defined in terms of demographics including spatial characteristics even if researchers are aware that doing so inadequately addresses the "legitimacy of an individual's claim to represent the community" (Sullivan et al., 2003, p. 117). It is not uncommon for the public health researcher to partner with service providers. Yet "CBPR represents the view that community members themselves need to be brought into the research process as decisionmaking participants" (Wallerstein \& Duran, 2003,p. 34). Thus both end-users and their network (representatives from community-based organizations) through which research is put into action are considered appropriate partners (Cargo \& Mercer, 2008).

Relevant best practices to address the complex and power-laden relationship between researchers and the community include attention to defining the community, identifying appropriate representatives, and providing equal opportunity for each partner to participate. When community-based organizations (CBO) serve as the main link to the 
community, the nature and link of the $\mathrm{CBO}$ including its mission, agenda and capacity should be considered. Even though grassroots organizations may provide a more direct link to the community, "strong, autonomous" CBOs may be in a better position than grassroots organizations to advocate for policy change stemming from CBPR practice (Isreal, et al., 2003; Minkler, 2010; Minkler, Breechwich Vasquez, et al., 2008; Sullivan, et al., 2003). Recognizing the differing needs, capacity, and resources of various partners, community members should have the power to choose when and how they participate throughout the process (Cargo \& Mercer, 2008; Isreal, et al., 2003; Stoecker, 2003). Every effort should be made to involve community members in the shaping the research questions, project trajectory, and interpretation of results (Stoecker, 2003). Involvement in data collection and analysis, while not required, should also be available for community involvement in CBPR practice (Cashman et al., 2008).

HIA has not implicitly or explicitly adopted CBPR principles, and HIA standards and guidelines surrounding community engagement are very vague when compared to the CBPR literature (Stakeholder Participation Working Group, 2012). Yet public health professionals concerned about community interests and engagement are likely to draw from CBPR literature and practice when confronted with questions of community participation within HIA practice (Stakeholder Participation Working Group, 2012).

\section{Participation within EIA}

Because HIA joins the impact assessment tradition of accounting for additional interests and information to guide public decision-making, it is appropriate to review the treatment of public participation in EIA. There is broad consensus that public 
participation is both a goal and a facilitator of effective EIA. However, the consensus quickly evaporates when digging into details:

most scholars are divided over the precise meaning of public participation in the context of EIA... [what it] involves and requires. Furthermore, there is no consensus on who should be allowed to participate in EIA [and] there is large disagreement as to the specific objectives of pubic participation in EIA (Glucker, et al., 2013, p. 104).

There has been a recent resurgence in efforts to define and understand public participation in EIA (Dietz \& Stern, 2008; Glucker, et al., 2013; Hourdequin, Landres, Hanson, \& Craig, 2012; O'Faircheallaigh, 2010; Salomons \& Hoberg, 2014). Nearly all attempt to outline rationales for including public participation in EIA.

Glucker and colleagues (2013) provide the most coherent discussion, dividing the rationales into three categories: normative, substantive, and instrumental. Normative rationales for participation connect to underlying social values such as democracy or empowerment. Reflecting fundamental democratic ideals, participation in EIA provides individuals and communities the ability to influence decisions, resolve conflict, and add to social learning. Public participation also has the ability to empower and at times emancipate marginalized groups. The second rationale is substantive and acknowledges that participation can often improve the quality of information and thus decisions. Substantive gains from participation in EIA include the ability to harness local information and knowledge, incorporate value-based knowledge, and test the robustness of the information. Finally, instrumental rationales for participation in EIA include generating legitimacy and reducing conflict (Glucker, et al., 2013).

Hourdequin and colleagues (Hourdequin, et al., 2012) recently suggested that public participation within EIA could be evaluated using ethics grounded in democratic 
ideals. Based upon Rawls fundamental values of equality of persons and autonomy, they developed four ethical principles for public participation: equal opportunity to participate, equal access to information, genuine deliberation, and shared commitment to the success of the process. They note that there is a big disconnect between theory and NEPA practice in supporting equal opportunity to participate and access information. NEPA fails to support deliberation and due to ongoing issues of trust, often is void of shared commitment. Because of this, they suggest that EIA should reconsider and possibly link to more collaborative processes that often run in parallel to the official NEPA process.

A National Academies of Science sponsored study provides empirical evidence to augment the theoretical wrangling with public participation in EIA (Dietz \& Stern, 2008). The report evaluated the extent to which participation improved the quality of decisions, enhanced the legitimacy of decisions, and built the capacity of participants to contribute. Its conclusion was "substantial evidence shows that effective public participation does a better job in achieving public purposes" but can also "do more harm than good" if not adequately designed or resourced (Dietz \& Stern, 2008, pp. 226, 230). This suggests that HIA may also struggle to adequately design and provide resources for public participation that is effective and authentic.

Several characteristics driving the participation structure and community outreach in EIA - the largest practice and literature base - also influence the structure of HIA practice. First, project and plan-based EIAs often have a spatial component that generally corresponds to a spatially defined public(s). Second, impact assessment processes are primarily designed to inform but not necessarily make or implement decisions. This suggests that impact assessment, including HIA, stress information gathering and 
reporting; engagement with the community must acknowledge this primary objective. To some, this means that the purpose of participation within EIA is "to obtain consent of those affected by proposed projects" by creating a forum in which community interest(s) can influence and compete with a plurality of other interests (O'Faircheallaigh, 2010,p. 22). This occurs in EIA through bi-directional transfer of information at public meetings and open houses where information is provided and public comment recorded, officials are able to learn of public concerns and the community can better evaluate whether or not to further engage the process.

The tendency of community and public involvement in EIA to only be "selective consultation" that provides minimal transparency of decision-making has been both acknowledged and critiqued. Some argue that including community within impact assessment should also support shifting power relations in the direction of the marginalized. Power shifting requires supporting the marginalized by structuring the process as community accessible as possible including providing resources to participate fully (O'Faircheallaigh, 2010). This approach may be troubling to those concerned about providing managed information to decision. The result is that while EIA has the potential to shift the locus of decision-making and thus power relations, most EIA processes have limited opportunities and avenues for community influence. The question for marginalized groups becomes whether the provided EIA process is adequate enough to advocate for their interests. The alternative - to respond with a parallel or separate process - might make sense for certain groups who have not traditionally been included in the development and EIA process (O'Faircheallaigh, 2010). 


\section{Participation Within HIA}

It has been suggested that HIA is an alternative avenue of participation for marginalized interests. Indeed, with HIA not legally mandated, the choice to pursue an HIA process is evidence of health interests not entirely satisfied with available planning and/or EIA process. Pursuing an HIA provides the ability to move EIA discussions beyond threshold exposure and to explicitly address human impacts. By shedding the institutionalized norms of EIA, HIA may be able to document human impacts in a more holistic fashion and thus expand the opportunities for communities to express more distal community health concerns.

The small body of HIA theoretical literature echoes themes in the EIA participation literature. Participation allows for soliciting information from stakeholders, informing the community, facilitating community self-determination, increasing the odds of implementation through community participation and ownership, and increasing social capacity and learning (Kemm, 2005). Participation in HIA is challenged by a diversity of knowledge, data, interests, and languages held by various stakeholders (Negev, 2012). This diversity does not, however divide neatly along laypersons and professionals; instead, the multi-disciplinary nature of HIA means advisory committees often contain diverse professional backgrounds even among public health practitioners. This means it cannot be automatically "expected to easily find a common ground between stakeholders in the framework of HIA, especially in a diverse society and when environmental health disputes are involved" (Negev, 2012, p. 53).

Contemporary U.S. HIA practice is an extension of HIA guidelines provided by WHO (World Health Organization, 1999, 2008b). These guidelines are a flexible 
template for a community group to sort through health information, particularly when partnered with public health professional expertise. These WHO guidelines also explicitly adopt a participation notion of democracy as a fundamental value; this expression of democracy was also included in the first U.S. Practice standards (North American HIA Practice Standards Working Group, 2009). At least one trajectory of U.S. HIA practice advances a partnership between community and professionals. Several documented HIA cases tell of significant community involvement augmenting a stakeholder process driven by public health professionals (Corburn, 2009; Corburn \& Bhatia, 2007; Dannenberg, et al., 2008).

Yet a quick inventory of HIAs shows that the levels and purposes of participation vary widely. Recent research suggests that only a small proportion of HIAs - 18.5 percent the EPA meta-evaluation and 42 percent in the Australian meta-evaluation - robustly engage community members and stakeholders in decisions including the advisory committee (E. Harris et al., 2013; Rhodus, et al., 2013). The EPA evaluation further showed that only one-quarter of those stakeholder advisory committees "actually oversaw or guided the HIA process and were engaged as decision-makers in equal partnership with the HIA team or as the primary decision-makers" (Rhodus, et al., 2013, p. 82). While the EPA meta-evaluation likely under-reports stakeholder engagement because it relied on documentation of engagement strategies within the HIA report something the field is very inconsistent about providing in reports - this indicates a significant shift from the rhetoric of HIAs supporting democracy.

Harris-Roxis and Harris (2011) suggested that certain participation concepts such as the role of stakeholders and value judgments are often matched to the purpose of the 
HIA. Their HIA typology posits that mandated HIAs that occur within EIA, meet a regulatory requirement, and minimize health risks are likely to be conducted by technical consultants with little room for stakeholder knowledge or values. Voluntary decisionsupport HIAs that minimize health risks and maximize health impacts through improved decision making are far more likely to incorporate value judgments and information from stakeholders. Advocacy HIAs, often conducted by outside groups, are far more explicit in incorporating value judgments and welcome stakeholders to guide the assessment.

Finally, community-led HIAs, conducted and controlled by the communities with the aid of HIA practitioners, elevate community values and power to make decisions in the HIA in order to ensure that community health concerns are identified and addressed (HarrisRoxas \& Harris, 2011). Current HIA practice in the U.S. largely falls in the decisionsupport and advocacy types. Notably, this dissertation includes a mandated HIA (I-710 Corridor), a decision-support HIA (Clark County), and a hybrid between the advocacy and community-led HIA (Lake Merritt).

\section{Evaluating HIA}

Evaluation, along with monitoring, is routinely listed as the last step in the HIA process. Despite this prominence, evaluation of participation within HIA processes is non-existent in the U.S. and limited in Europe. Instead, better understanding of participation is routinely listed as a "next step for HIA" including more clearly defining the roles of stakeholders and HIA within the greater policy arena (Putters, 2005). Kemm (2005) is particularly vocal about the challenge to develop and "be very clear [about] what it seeks to achieve through participation" because "too much of what has been called participation in the past has been tokenism and in many HIAs it would probably 
have been preferable to recognize that resources did not allow the inclusion of meaningful participation rather than do it very inadequately" (p. 805). The lack of evaluation in HIA played prominently in developing this dissertation as it seeks to both add to the evaluative research addressing effectiveness and operationalize an evaluation process that could tease out community interests and influence.

Evaluating Effectiveness and Participation The gap in documenting HIA effectiveness is quickly closing. Adding to a 17-case meta-evaluation of European HIAs in 2007, U.S. and Australian meta-evaluations were released in late 2013 (E. Harris, et al., 2013; Rhodus, et al., 2013; Wismar, Blau, Ernst, \& Figueras, 2007). Several additional U.S.-based meta-evaluations are expected in 2014 (Charbonneau, 2013; Pollack, 2013; Wendel, 2013). Each of these evaluations provides concrete evidence of HIA influencing decision-making.

The evaluative research is also beginning to document stakeholder engagement strategies in contemporary U.S. HIA practice. An EPA-sponsored U.S. evaluation found the level and quality of stakeholder participation var[ies] greatly. In many of these HIAs, stakeholder input was solicited to inform the scoping and assessment steps of the process,... but the stakeholders themselves were not involved in the actual HIA decision-making (Rhodus, et al., 2013, p. 82).

Only a small proportion of HIAs - 18.5 percent -robustly engage stakeholders in decisions including the advisory committee; however only a quarter of those stakeholder advisory committees "actually oversaw or guided the HIA process and were engaged as decision-makers in equal partnership with the HIA team or as the primary decisionmakers" (Rhodus, et al., 2013, p. 82). A recent Australian meta-evaluation affirms community involvement in developing recommendations and making decisions during 
scoping facilitates direct effectiveness. It also found only 42 percent of HIAs had community members on a steering group and only 25 percent allowed community members to make decisions about the HIA (E. Harris, et al., 2013). This suggests that HIAs are not automatically democratic, much less participatory, as proposed by the Gothenburg Consensus Paper (World Health Organization, 1999).

Evaluations specific to participation are difficult to find in the HIA field. Kearney (2004) provides a rare exception by interviewing twelve stakeholders (officials, representatives and local residents) associated with the UK equivalent of a redevelopment master plan. Kearney's research identified five substantial barriers, many institutional, to community participation within HIA including (1) capacity to engage undermined by anger and mistrust; (2) limited skills in engaging communities on the part of officers (or professionals); (3) professionals belief that community capacity is limited; (4) existing structures favor established representative groups; and (5) system dynamics of short timescales with crowded agendas and limited financial resources lead to risk aversion among all and undermine the process.

A literature review of participation evaluations within EIA reveals little more. Dietz and Stern's shows evidence of effectiveness but is also clear that participation can "do more harm than good" if not adequately designed or resourced (2008, p. 230). Steinemann's (2001) participation evaluation of U.S. EIAs utilizes a combination of content and context analysis including interviews with multiple stakeholder groups. This study takes a path dependency view of the process to develop alternatives in EIA, showing that alternatives are narrowed early due to (largely agency) problem definitions that are often defined to justify predetermined solutions. In this context, larger agency 
agendas are incredibly influential while public involvement occurs too late in the decision-making to influence the development of alternatives.

Echoing Steinemann, Hartley and Wood (2005) attempt to understand the extent to which EIA in the UK follows a 1998 'early' and 'effective' participation imperative. Through 22 interviews with a variety of stakeholders (planners, developers, local action group members and members of the public) in four case studies, Hartley and Wood (2005) evaluate early and effective participation through interviewees' ranked criteria of communication, fairness, timing, accessibility, information provision, influence on decision-making, competence, interaction, compromise, and trust. Evaluation led the authors to identify eight key barriers to effective public participation including:

1. poor public knowledge of planning, legal and waste licensing issues;

2. poor provision of information;

3. poor access to legal advice;

4. mistrust of the waste disposal industry;

5. not in my backyard (NIMBY) syndrome;

6. failure to influence the decision-making process;

7. poor execution of participation methods; and

8. regulatory constraints (Hartley \& Wood, 2005, p. 333)

This led the authors to conclude (1) the participation structure is a significant driver of effectiveness and (2) legislative time provisions of EIA public participation (within the UK and likely also within the US) are inadequate to allow for meaningful participation.

HIA Evaluation Methodologies The empirical gap in HIA evaluations is somewhat a result of a thinly developed evaluation methodology - even in Europe where HIA is more developed and routine (Quigley \& Taylor, 2003) ${ }^{11}$. The field widely

\footnotetext{
${ }^{11}$ HIA joins other impact assessments in a lack of conceptualization of effectiveness of process. For a recent effort at addressing this gap across all impact assessments, see Chanchitpricha, C., \& Bond, A. (2013). Conceptualising the Effectiveness of Impact Asessment Process. Environmental Impact Assessment Review, 43, 65-72.
} 
acknowledges evaluation needs to happen to show HIA is worth the effort, but practical advice is almost non-existent (Dannenberg, et al., 2006; Kemm, 2005, 2013). There is consensus that evaluation in HIA can occur on one of three endpoints: process, influence or impact on decisions, and changes in health outcomes (Parry \& Kemm, 2005; Ross, Orenstein, \& Botchwey, 2014). Most practitioners admit large methodological and practical barriers in linking health outcomes directly to HIAs. However, process evaluations are occurring a little more often in U.S. HIA practice. Researchers have been busy evaluating influence/impacts as a measure of effectiveness (see previous section).

For process and influence evaluations, HIA practitioners tend to piece together various methodologies even as they build evaluation best practices and guidance (HarrisRoxas \& Harris, 2012; Ross, et al., 2014; L. Taylor, Gowman, \& Quiigley, 2003). A current trend in the HIA field in the U.S., particularly for process evaluations, is to evaluate the extent to which the HIA met "minimal elements" within the fields' practice standards (North American HIA Practice Standards Working Group, 2010). It is also not unusual for such evaluations to exist only as internal documents instead of being released and providing lessons learned to the greater practice community. Other methodologies for evaluating process are drawn from evaluations of health policy or public health interventions such as the PRECEED-PROCEDE model used in health promotion (Green \& Kreuter, 2004).

Understanding effectiveness in influencing decisions has largely been patterned on an early meta-evaluation of European HIAs released in 2007. Wismar (2007) created a two-by-two typology that states directly effective HIAs are those that are considered by decision makers and result in a modification. Consideration by decision makers without 
a modified decision is called "general effective" by Wismar and often referred to as indirectly effective in the greater HIA field. If the HIA is not considered, alignment with HIA recommendations is a 'happy accident'; lack of consideration and change in decision suggests the HIA was ineffective.

Harris-Roxas and Harris $(2013 ; 2012)$ found Wismar's typology too simplistic to adequately explain the effectiveness of HIA. They expanded Wismar's typology by emphasizing three domains: context, process, and impacts. Context covers the decisionmaking context and the HIA purpose and goals. Process addresses both inputs such as available resources and procedures including the involvement of stakeholders. Impacts are divided into proximal - influencing decisions, implementation, health determinants, effectiveness at predicting impacts - and distal impacts such as increased understanding and social learning.

Kemm (2013) recently outlined parameters to consider when evaluating HIA. Questions specific to participation include:

1. Have the relevant stakeholders been identified?

2. Has the HIA explained how and why those who participated were selected and why those who did not participate were not selected?

3. Could those who did participate be deemed to be representative?

4. What process was used to involve stakeholders and how have their views influenced the HIA conclusions? (Kemm, 2013, p. 78).

Due to a lack of best practices in HIA evaluation at the time this dissertation was proposed in 2010, a major element of the research was to bridge this methodological gap and to isolate effectiveness of community and stakeholder participation. This was done using Lasker and Guidry (2009) as a conceptual guide. Lasker and Guidry document opportunity for communities to participate, the ability to express and communicate or 
"voice" ideas, and if those ideas are used to investigate influence in community development partnerships in a health policy setting. Similarly, this dissertation evaluates three HIAs by documenting opportunities for community participation, understanding the extent to which communities or community interests are voiced in the HIA process and report, and then looking for the community interests in HIA recommendations and target planning documents. 


\section{Chapter 3 - Research Design and Methods}

The primary purpose of this research is to describe and analyze the participation structures within current HIA practice with particular attention to engagement opportunities for citizens, community based organizations, and public health professionals. Through a cross-case comparison approach, this research also describes how HIA processes are treating diverse health interests and the extent to which HIA can influence the target planning and decision-making process. Three contemporary HIA cases were examined using six guiding research questions. Data collection and analysis for each case generally occurred in three phases: initial document review, interviews, and analysis of final documents. Data was gathered from (1) public documents and media reports associated with the target plan and HIA, (2) semi-structured interviews with members of the HIA advisory committees, (3) and the HIA report and target plan. Analysis relied on qualitative content analysis of a diversity of data sources to trace participants, interests, knowledge sources, and plan outcomes and also account for the broader context of each planning exercise.

\section{Case Selection}

Early adopter and training patterns resulted in HIA practice spatially clustering in a few distinct regions in the late 2000's with regional variation in practice norms. The context for legally integrating HIA also seems to be particularly salient to current HIA literature questioning legislative legitimacy (Bhatia \& Wernham, 2008; Cole, et al., 2004; Rajotte, et al., 2011). Sampling three regions acknowledged the importance environmental, legal and practice context. This project sampled cases from three distinct regions with at least basic prior history with HIA. The two of three cases selected were 
supported, but not legally mandated, by governing planning bodies. The I-710 Corridor Project HIA was mandated by the decision-making body for the planning effort with intent to integrate it with the EIA; inclusion of this case specifically speaks to the challenges of integrating with decades of experience and institutionalization of NEPA (federal) and CEPA (California) environmental law.

Each HIA is also distinct and "unique," with the scope and content of the HIA influenced by many variables. This includes the general nature, specific objectives and goals, and scale of the project ${ }^{12}$.

Nature Because a central question of this research is to understand the extent to which HIAs are meeting community interests and preferences regarding their environment, the nature of the plan has been limited to those where the subject of the plan is firmly within traditional spatial urban planning activities. This decision was further impacted by observing that project and plan oriented HIAs seem, thus far, to have drastically different community outreach rationales and practices than spatially diffused policy or program oriented HIAs; limiting to project/plan HIAs should narrow the variation. To address differences in sector, cases were limited to transportation related target plans.

Specific objectives and goals of the target planning exercise likely influence the process and content of the HIA through two mechanisms.

\footnotetext{
${ }^{12}$ While unavailable at the time of case selection, two recent articles are salient to context and participation norms in HIA. Harris-Roxas \& Harris' (2011) typology of HIAs explicitly acknowledges different roles of stakeholders and values depending on the purpose - ranging from minimizing negative health impacts to maximizing positive health impacts - of the HIA. Negev (2012) aptly notes challenges associated with multiple approaches to health including risk reduction, wellbeing, etc.
} 
Health promotion versus harm reduction When goals of the planning exercise are to plan the infrastructure required to promote healthy activities, an associated HIA is likely to focus on maximizing health promotion through the activity in question (i.e. increased biking and walking). Planning exercises associated with projects harmful impacts will require a harm reduction lens for the HIA.

Concentration of impacts The more concentrated an impact, the more likely a public is to gravitate towards a planning and HIA process. In a planning activity where the primary objectives create visibly concentrated health harms (i.e. a highway expansion), a NIMBY response from citizen and activists is likely and an HIA focused on harm reduction should follow. An HIA may have more opportunities to focus on health promotion through design options in cases where the impacts - negative and positive are more diffuse and thus the public response minimal.

Objectives vary among the cases: Clark County is a health promoting bike-ped plan, Lake Merritt BART is a transit oriented redevelopment plan with elements of both health promotion and harm reduction, and the I-710 Corridor Project a highway expansion plan that clearly requires harm reduction.

Scale Resources, money, and effort of the planning project also likely affects participation norms. Narrow plans may not create enough public interest to solicit participation from anyone but the most passionate advocate or activist. Large-scale plans - even those with a very clear spatial community such as those along a highway corridor - may limit community input and participation opportunities out of practical necessity of coordinating such a large public. The three cases proposed vary along scale: Clark County is a small and geographically diffuse bike-ped plan; Lake Merritt BART is a 
larger transit oriented redevelopment plan in a small (1/2-mile radius) but dense urban center; and I-710 is one of the largest public works projects in the country with impacts largely concentrated within a mile of the 18-mile highway expansion.

After identifying full HIAs targeting a spatial urban planning issue and sampling for varying specific objectives, goals, and scale, cases were selected for region accessibility, anticipated timeline, and funding considerations. The cases were just beginning HIA work at the time of dissertation proposal to minimize to some extent bias associated with retrospective interviewing. All cases had secured HIA funding. Additionally, a cooperative public health professional to serve as a point of was identified in each case.

\section{Guiding Research Questions}

The following six research questions guided the data collection and analysis. Each question includes an associated hypothesis and factors that were considered in evaluating the question in both the case and cross-case analyses. Next to each factor is an italicized abbreviation(s) for the anticipated data source $-C A$ for content analysis, $Q x$ for specific semi-structured interview questions found in the Appendix A.

\section{Research Question 1 - Who is participating in HIAs and in what format?}

Participation can range from direct participation to more collaborative stakeholder forms. Facilitated primarily by public health professionals and generally engaging in larger multi-stakeholder land-use decision- making processes, HIA participation opportunities likely take a stakeholder format but are not necessarily participatory. Understanding the democratizing aspects of HIA, particularly answering the "who" is participating aspect, 
requires fully characterizing the nature of both the general HIA process and the portion, if it exists, that is meant to include direct citizen or community participation.

Hypothesis: HIA processes will be stakeholder processes with little explicit attention to direct community outreach/participation. Community representation will likely be in the form of representatives from community-based organizations.

Factors to examine to understand general participation structure for HIAs include

- Character of the methods(s) and techniques of overall and participation process $C A, Q 2$

- Explicit and implicit objectives of participation and community outreach

- A broad rule of thumb is that participation forms should match the objectives of the participation. To what extent are the objectives of participation articulated? $C A, Q 3$

$\circ$ What objective(s) are elevated in the process? $C A, Q 3$

- Organizers of participation and community outreach

- Those who are organizing and controlling the participation process have a great deal of discretion and thus power.

- Are organizers public health or planning professionals? $C A$

- Do community groups have any role in convening the HIA? $C A$

- Are outside facilitators involved? $C A$

- Participants

○ How are participants identified? $Q 2$

- Who is invited/participates? $Q 6, Q 7$

○ Are participants speaking for themselves or are they representative? How is feedback to the community occurring? Q17

- What is the public health/planning/public ratio? $C A$

$\circ$ What resources are available to those with few resources to facilitate participation? $Q 8$

\section{Research Question 2 - Who is defining the problem and/or setting the}

agenda? In both participatory and stakeholder models of participation, democratizing practice require that all members of the process, including the community, are able to influence the agenda and problem definition in order to have the participation process reflect community concerns and interests. 
Hypothesis 1: The public health professional(s) shaping the process will set HIA agendas and problem definitions in both the screening and scoping phases of the HIA.

Hypothesis 2: If community representatives are not participating in shaping the HIA process, community interests will not be addressed.

Factors to examine control of the HIA process include

- Agenda setting

- Who sets the initial agenda? $C A, Q 1, Q 4, Q 10$

$\circ$ Is there opportunity for the community to influence the agenda? How? Q11, Q12

- Problem definition

- How are the problems defined? By whom? CA, Q1, Q10

- Is the problem definition reflective of community interests? $C A$, $Q 1, Q 4, Q 10-Q 12$

\section{Research Question 3 - How does the 'nature' of the plan affect the HIA}

problem definition, process and outcome? HIA processes are attempting to engage planning processes and their contexts. Naturally, HIA will be impacted by the 'nature' specific objectives and goals, scope - of the plan.

Hypothesis 1 (Attracting participants as a function of concentration of impacts):

Plans with concentrated health impacts, particularly negative, are more likely to draw the attention and participation of the community.

Hypothesis 2 (Scale): Smaller scale plans allow for an HIA to address the entire plan while large scale plans prompt the HIA to either (a) focus on a narrow slice of the plan or (b) broad rather than deep analysis of many health interests. Narrow slices are more likely to mirror an involved community group.

Hypothesis 3 (Nature): Planning activities where the objective is to create health promoting activities (such as the bike-ped plan with a focus on walkability) will result in 
a positive tone surrounding health interests and draw community 'boosters' into the

process. Conversely, planning activities that require attention to harm reduction (such as freeway building and associated pollution and noise) will result in health interests and community participants that are reactionary (i.e. environmental/health justice participants).

Factors to examine and understand the contextual nature of HIA include

- Scale

- Proportion of plan addressed by HIA $C A$

- Proportion of health interests scoped and/or voiced that appear in the HIA document $C A$

- Breadth/depth of analysis associated with each health impact within the HIA report $C A$

- Nature/Objectives

- Types of participants $C A$

- CBO agendas/mission statements $C A$

$\bigcirc$ Classify health interests identified in planning stages and HIA report as health promoting or harm reduction $C A$

\section{Research Question 4 - Is local knowledge integrated with professional}

knowledge? A primary objective of participation is to broaden the knowledge base in order to increase the quality of decisions. The knowledge carried by the community may not be in a form traditionally utilized in impact assessment. HIA practice is more likely to accurately address community interests when integrating local knowledge with traditionally privileged technical science.

Hypothesis: HIA processes will not ignore local knowledge but may struggle to integrate local knowledge with technical knowledge. The most prominent examples of integration will occur when: (a) local interests and knowledge align with professionally held technical knowledge; (b) professionally trained CBO representatives serve as the 
bridge between types of knowledge. Factors to examine the integration of knowledge include

- Control for educational/professional background of participants D1-D7

- Local information Q13-Q15

- How is local information treated?

$\circ$ What is the position of technical information?

- Joint-fact finding Q13-Q15

$\bigcirc \quad$ Is joint-fact finding employed?

- Do communities with limited resources or experience in privileged scientific information receive help? $Q 8$

\section{Research Question 5 - Are communities able to influence decision-making?}

The primary outcome of an HIA process is a document addressed to decision makers outlining concerning evidence of (primarily negative) health impacts and mitigation suggestions. In a democratizing HIA process, community interests as identified throughout the process should be present in the final HIA document.

Hypothesis 1: HIAs, as written by public health professionals, will reflect community interests inasmuch as those interests align well with those held by the public health professional.

Hypothesis 2: Health interests/HIA recommendations that are directly linked to design options of the proposed plan are most likely to be present in the final plan documents.

Factors to examine influence and thus effectiveness of HIA include

- Presence of previously identified interests, community and otherwise, within final HIA document(s) $C A, Q 1, Q 4, Q 5, Q 18$

- Final plan/EIS documents will be analyzed for presence of community interests identified via the HIA process. $C A, Q 1, Q 4, Q 5, Q 19$

Research Question 6 - Does HIA increase the ability of health interests to influence urban governance? Much has been made about the ability of HIA to provide 
an avenue for increasing long-term influence of both public health professionals and community groups in urban governance and policy. The formation of long term HIA workgroups in both regions as well as meeting the long-term HIA goal of “institutionalizing" public health considerations within urban development and land-use decisions provide some evidence of influencing urban governance.

Hypothesis 1: $\mathrm{CBO}$ and other formalized representation of community interests will continue to be involved with HIA-like activities including convening and partnering in future projects with public health professionals met through the HIA process.

Hypothesis 2: As a result of newly formed relationships during the HIA, public health professionals will regularly advise urban planning activities regarding health concerns.

Factors to examine to understand increased governance include

- $\quad$ Past and future project partnerships between community groups and HIA associated public health professionals $Q^{9}$

- Standing participation of public health professionals in local government planning activities as measured by regular working group and committee attendance. D5

\section{Data Collection and Analysis}

Data collection and analysis for each case took place in three phases: initial document review, interviews, and analysis of the HIA and target planning documents. Each sequential phase built upon the previous, refining the understanding of various actors, their health and competing interests in the case, and influence on the target plan. A case-study approach allowed for retaining a holistic and contextual view of the target plan and HIA processes. It also increased construct validity by providing multiple opportunities for community interests and participation concepts to appear. Each case 
incorporated multiple types of primary and secondary sources to support triangulating data and increase validity in findings when evidence converged (Yin, 1994). The three cases are found in Chapters 4-6.

Phase 1: Initial Document Review The purpose of the first phase was to (1) understand the contextual background of the case including, (2) how planning exercises usually incorporate health interests, and (3) construct an initial map of participants and interests. A search and retrieval record was initiated and maintained for each case. Data in this phase included plans and community engagement completed before the initiation of HIA as a type of control, a media/newspaper archive search for background information, community organization websites, and HIA process documents such as meeting agendas, minutes, and notes.

Prior Plans Reviewing prior plans helped gauge how planning exercises historically addressed health interests. In the Clark County case, the Clark County Bicycle Commute Plan (1996) and the Vancouver-Clark Parks and Recreation's Regional Trail and Bikeway Systems Plan (2006) were reviewed for content and themes. The BART Transit Oriented Design (TOD) Policy (2005) and Lake Merritt BART Station Area Community Engagement Report (2009) were reviewed for the Lake Merritt Case. In the I-710 Corridor case, previous efforts in engaging the community encapsulated in 2004 report by the Tier 2 Community Advisory Committee.

Community Based Organization Websites Each community-based organization's mission statement and history were documented to understand the relationship of its interests with the target planning effort. Websites were also mined for HIA materials to understand what, if any, role the HIA played in major campaigns. 
Media Regional and local news sources, primarily print newspapers, were searched for (1) background information on the plan, (2) competing public health issues, and (3) mention of the HIA work. Archives were searched for the previous 10 years (2000 onward) via GoogleNews; automated electronic notifications were set up for the research project. In the case of the I-710 Corridor, YouTube was also searched for videos featuring active community-based organizations to understand the community's position on environmental justice issues related to freeway and port expansion.

HIA and target plan process documents HIA agendas and meeting notes were collected to document participants and their associated interests. Documentation was scarce for the Lake Merritt BART HIA, thin for the Bicycle and Pedestrian Advisory Committee for the Clark County HIA, and plentiful for the I-710 Corridor Project. In the I-710 case, the quantity and detail of meeting minutes from the I-710 Project Committee and the Air Quality Action Plan was plentiful enough to justify minimal interviews ${ }^{13}$. In addition, the I-710 HIA author wrote a case study to unpack challenges and lessonslearned (Human Impact Partners, 2012). This case study and a 90-minute interview provided an outline of the process that was then corroborated with meeting minutes.

Analysis in Phase I Analysis of the documents collected in this first phase was accomplished through qualitative content analysis with open coding by hand. The coding was supplemented with analytical memos to trace participant and health interests within documents and track initial researcher reflections. All analytical memos were compressed into larger draft data displays for each case to conceptually map HIA participants and interests (Berg, 2007; Huberman \& Miles, 1998).

\footnotetext{
${ }^{13}$ See Interviews subsection below for details about difficulty in obtaining interviews for the I-710 Corridor case.
} 
Phase 2: Semi-Structured Interviews The participants and health interests identified in the first phase guided the second phase of semi-structured interviews with HIA participants. Those interviewed were directly involved in the HIA process. The interviews focused on themes of (1) participation structure, (2) perceptions of community interests, and (3) treatment of information. It also included questions regarding the educational and professional experience to help tease out various types of knowledge and interests. Questions were informed by best practices as documented in the negotiation and CBPR literature. The interview guide is provided in Appendix A.

Interviews were generally sought with those involved in the advisory committee associated with the HIA and included five main types of stakeholders: (1) public health professionals, (2) planning professionals, (3) other government agency professionals such as sanitation or transportation engineers, (4) representatives of community based organizations, and (5) citizens. Interviews with public health and planning professionals assigned to the process were particularly rich in providing information regarding participation and community engagement strategies and identifying health and competing interests. Interviews with professionals that actively participated but did not shape the engagement process provided more critical insights into the process. Interviews with representatives of community-based organizations involved in the process were helpful in validating community health interests, representation, and feedback issues.

Interview Scheme The number of interviews varied according to the number of the participants in the HIA and plan. The dissertation proposal grossly overestimated the number of interviews - approximately twenty per case. In the Lake Merritt BART HIA, there were only six members on the HIA advisory committee - much smaller than 
originally anticipated. Interviews were requested with all six; one had moved on in employment and declined. Interviews were also sought but not granted with at least one City of Oakland planner for a final response rate of five out of seven.

In addition to interviewing the Clark County Public Health professional and HIA author, interviews were sought with at least two members of each constituency on the Bicycle-Pedestrian Advisory Committee: planners, public works, public health professionals, community at large, cyclists, and school districts. Advisory Committee members were contacted multiple times for an interview for a total of eleven requests and six completed interviews. Notably, the bicycle advocates either did not respond or were outright hostile to talking about health. School district representatives were unwilling to be interviewed, asking that the HIA author be interviewed instead. A public works and public health employee each responded that an interview with their alternate would be more appropriate. Four county government employees and two community members were generous in their response.

It proved difficult to interview advisory committee members in the I-710 Corridor case because the HIA author was contractually prevented from convening a stakeholder/community advisory committee. Thirty attendees of an HIA training that pre-screened and pre-scoped the topic served as a replacement pool of potential interviewees. These attendees were contacted via email, but only two responded and both stated they had not kept up with the project. This was followed up with attempts to contact training attendees via social media with little success. Finally, letters of introduction by the HIA author were sent to three key informants; this resulted in one interview and two email exchanges. Another brief discussion occurred with the NRDC 
representative after his presentation about the case at an HIA conference. The HIA author was particularly generous with his time; two informal and one formal 90-minute interview were augmented by a written case study.

The dismal interview response rate (five of thirty) for the I-710 Corridor case can be explained in a couple of ways. First, nearly five years had passed between the HIA training and the initial requests for interviews and many of the interviewees were purposefully kept at a distance during the Air Quality Action Plan by the planning agency. Second, the entire project has been drawn out over thirteen years, resulting in participant fatigue - particularly on the part of many of the community members. Third, searching for the community members on social media indicated there was potentially a language barrier - an unsurprising finding given $92 \%$ of the Corridor is Latino (Coalition for Environmental Health and Justice, 2012). Finally, the project remains highly politicized; organizations involved enough to know about an HIA may be guarding responses in anticipation of a possible legal strategy. More in-depth investigation of the meeting minutes, meeting notes, and media coverage of the community-based organizations was conducted to substitute for interviews.

Interview Data Management Each interviewee was initially contacted by email and/or phone to request a 45- minute interview. Upon scheduling an appointment, a confirmation email including the human subjects form (see Appendix B) was sent electronically. Most interviews took place in person although three were performed via phone. Interviews ranged from 30 minutes to 90 minutes, were obtained with appropriate consent, digitally recorded, and fully transcribed. A summary document with transcripts was available to study participants upon request. 
Analysis A qualitative analysis of the interview transcripts occurred using openended hand coding to (1) verify the extent to which interests previously identified in documents during Phase 1 emerged in interviews, (2) identify any emerging interests, and (3) understand knowledge sources within the HIA process. This allowed for further refinement of the conceptual map of participants and interests developed in the first phase. It also allowed for the conceptual map to be augmented with sources of information linked to interests and conflicts.

Phase 3: Influence on HIA Document and Plans After refining community health interests through analysis of HIA process documents and interviews, the third phase involved a computer assisted (Altas.ti) qualitative content analysis of two final documents: (1) HIA report or document(s) to ascertain the extent to which community health interests were surfacing in final documents and recommendations; and (2) a target planning document to trace interests identified in Phase 1 and 2 and look for HIA recommendations as a measure of HIA's influence. This phase also included an open, hand-coded analysis of media reports on the HIA to understand the degree to which the process was influencing public discourse.

HIA report and other interim work products Interviews with HIA authors and other advisory members indicated that HIA final reports are summative documents reflecting health interests. However, interviewees questioned if the comprehensive or final HIA reports were influential for a variety of reasons. This required careful consideration of health documents as data on a case-by-case basis.

In the Clark County case, most interviewees from the Bicycle-Pedestrian Advisory Committee were familiar with the contents of the Rapid HIA - essentially a 
'draft' version of the Comprehensive HIA written by the public health professional. The majority of interviewees reported they had not looked at the Comprehensive HIA.

Additionally, the Rapid HIA was included as an appendix in the target plan while the Comprehensive HIA was released concurrently with the target plan. This suggested that the target plan was more likely to contain recommendations of the Rapid HIA than reflect the Comprehensive HIA. The Comprehensive HIA remained a valuable document to analyze because its recommendations outlined where Clark County Public Health professionals felt the planning process was falling short.

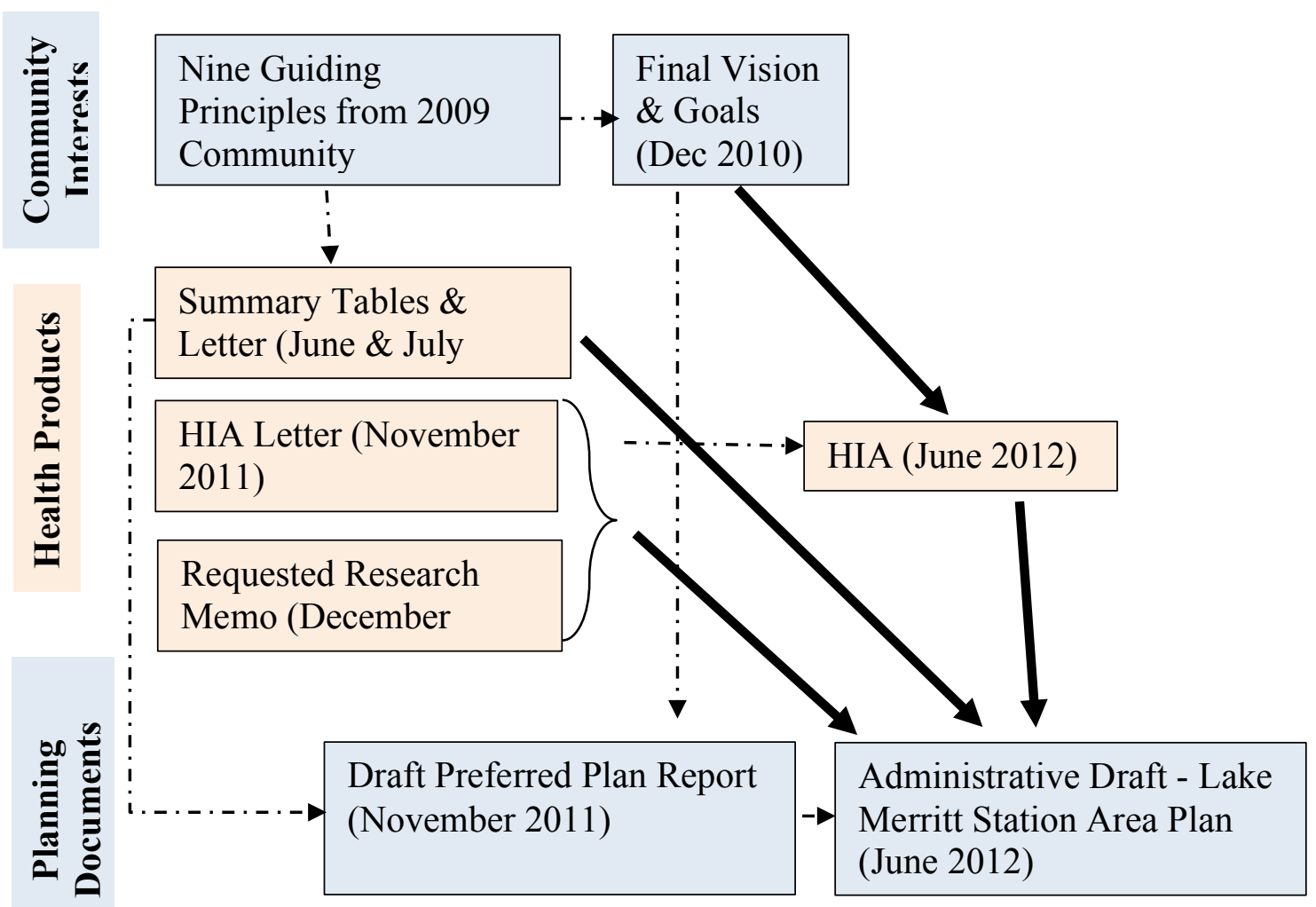

Figure 3.1 Diagram of Lake Merritt Station Area Plan documents available for content analysis, organized by purpose. Dotted lines represent intended influence; solid lines represent content analyses. 
In the Lake Merritt case, there was a lapse in work on the HIA between late-2011 and mid-2012. During January 2012 interviews, it was apparent that the group was primarily completing the HIA because it was required by the grant. The HIA author and group facilitator had approached the Senior Planner early in the process to ask if /when the HIA Advisory Committee could provide formal feedback. The Senior Planner asked for feedback at specific times well ahead of when the HIA could be feasibly completed. The HIA team honored the requested times by submitting three separate letters to the City with detailed feedback (see Figure 3.1) and these letters were included as appendices in the Comprehensive HIA. The HIA was completed prior to the finalization of the preferred alternative ${ }^{14}$. Because of this, the letters and the HIA were both analyzed for community interests; the target plan was searched for evidence of influence from all available health documents.

In the I-710 Corridor case, the HIA was unavailable for approximately 8 months between completion and the release of the draft EIS. While the public position of GCCOG planning staff was that the HIA had been forwarded to Caltrans for review and possible inclusion in the draft EIS/EIR, community members saw little evidence of consideration. Even if Caltrans did review the HIA, its position to not include it in the draft EIS as initially promised was based - in part - on the premise that the community impact and air quality impact reports already contained the information in the HIA. Because of this, the sheer magnitude of the HIA (over 400 pages) and draft EIS (thousands), and the readily apparent influence of the HIA in draft EIS/EIR public comments, the draft EIS/EIR was not analyzed line-by-line for HIA recommendations.

\footnotetext{
${ }^{14}$ The City of Oakland chose to work towards a single preferred alternative before launching the EIS process.
} 
Instead, the I-710 Corridor HIA was analyzed for general themes, use of GIS/maps, and specific mentions of community needs.

Content Analysis of HIA documents For the other two cases - Lake Merritt and Clark County - content analysis of the HIA documents was organized by health pathway (safety, resources, etc.) using the auto-code feature of ATLAS.ti. Every phrase of the HIA text identified by the auto-code feature triggered a re-reading of the surrounding text where complete thoughts were coded as individual segments; uses of the phrase with alternative meanings were discarded. Any other key words that repeatedly surfaced during this process were then entered into the auto-code feature, and the process was repeated until appropriate saturation was achieved.

For example, while searching for "business" in the Lake Merritt case, references to business in a purely employment context were discarded because the community defined "Business Principle" addressed creating an appropriate environment for owners and consumers. Also references to "merchants" repeatedly surfaced; even though merchants were not utilized in previous outreach efforts, it was obvious that the author(s) of the HIA were using the word as a synonym for business owner. Thus, the auto-coding process was repeated with "merchants."

Target planning document To address the issue of influence on the planning process, target plan documents were analyzed for community interests and HIA recommendations. The target plan was searched for each HIA recommendation, noting which recommendations were included verbatim and which were paraphrased but consistent with the HIA recommendation intent. The dissertation proposal recognized the fluid nature of planning and potential timing issues would require careful identification of 
the target-planning document. The target plan document was obvious in the Clark County case; the final plan was analyzed even though the Comprehensive HIA was critical of the final plan. The draft EIS/EIR was the obvious target plan document for the I-710 Corridor case.

In the Lake Merritt case, the first health letter to Oakland planners was meant to influence a November 2011 Administrative Draft Plan Report. The remainder of the health documents, including the HIA, were meant to influence the Administrative Draft released in June 2012 (see Figure 3.1 above). The Administrative Draft was chosen for content analysis because it incorporated much of the November 2011 Plan Report. However, certain issues around community benefits - and not always in the way the HIA Advisory Committee hoped - between the two planning documents. These nuances are noted inside the case studies when appropriate.

Content analysis of target plan documents To adequately understand influence using the available documents, the following steps were taken in the Clark County and Lake Merritt cases:

1. Using ATLAS.ti, the target plan was searched for all references to 'health.'

2. Using the target plan documents' table of contents, chapters/sections most pertinent to each determinant of health were identified and quickly confirmed using the auto-search function of ATLAS.ti.

3. The recommendations in the HIA were isolated and printed. Any 'interim' health documents were also printed.

4. Working by health pathway and then by each individual recommendation, the target plan was coded by hand to match HIA recommendations to planning designs and/or policies.

5. Special note was made of matches where health recommendations were relatively specific or unique. Health recommendations that seemed left out were also noted. 
For the I-710 Corridor case, the content analysis was much less detailed because of the sheer magnitude of the draft EIS/EIR was prohibitive and the political influence of the HIA could be ascertained through other documents and methods.

\section{Cross Case Comparison}

In addition to triangulating data to provide internal validity within each case, the three cases were compared to systematically look for key barriers and facilitators in using HIA as a community participation tool. After completing all three individual case studies, data was entered into cross-case displays using the approach outlined by Miles and Huberman (1994). Guiding research questions and factors were utilized as initial constructs and variables within each matrix; displays were reordered and at times split to adequately understand the extent to which certain phenomena were driven by individual case context, scale, and target-plan objectives. While some difference is expected in cross case comparisons, the deviant nature of participation for the I-710 Corridor case and exemplar nature of Lake Merritt HIA Advisory Committee were considered throughout the process of contrasting, comparing and drawing casual conclusions. The results of the cross-case analysis can be found in Chapter 7. 


\section{Chapter 4 - Clark County Bicycle and Pedestrian Plan and HIA}

In early 2009, Clark County, Washington initiated updating their Bicycle and Pedestrian Master Plan governing unincorporated areas to address a requirement of Washington State law. ${ }^{15}$ The lack of a pedestrian plan was a barrier to grant applications for state and federal level pedestrian programs and projects (Columbian Editorial Board, 2010). The Clark County Public Health Department viewed the planning exercise as an opportunity to perform its second HIA. Upon receiving a Robert Wood Johnson grant, a full time staff member was hired; this public health staff member was welcomed by the senior planner and integrated into the Bicycle and Pedestrian Advisory Committee. As a result, both a Rapid (desktop) HIA and Comprehensive HIA were produced over a oneyear period.

This case was chosen to understand how HIAs might address community needs in a small city or suburban setting with a narrow but geographically dispersed topic. It also was chosen to better understand how acquiring community feedback through the greater planning process impacts community voice in the HIA. Despite the willingness to work across disciplines within the county government, the HIA remained primarily a 'professional' version. Even so, the HIA provides an important equity lens through attention to the social determinants of health, health equity, and the use of GIS to document social and health conditions. As the planning exercises struggled to address varied interests in a quickly urbanizing community split about the role of current and

\footnotetext{
${ }^{15}$ Washington State's Growth Management Act (Chapter 36.70A RCW) requires that "the [mandatory] transportation element of a [local] comprehensive plan shall include collaborative efforts to identify and designate planned improvements for pedestrian and bicycle facilities and corridors that address and encourage enhanced community access and promote healthy lifestyles." See page 71 for more information.
} 
future bicyclists and pedestrians, the HIA was able to fill important participation gaps for unorganized groups such as pedestrians, future and utility bicyclists, and children. It was also able to influence decisions and infrastructure criteria in specific and important ways.

\section{Background}

Planning in Clark County, Washington can be challenging due to significant demographic shifts. Understanding these demographic shifts is helpful in contextualizing the challenge of addressing infrastructure for alternative modes of transportation within unincorporated areas. Clark County is a quickly growing and urbanizing area in southwest Washington across the river from Portland, Oregon. Long a rural, farming community north of the Columbia River, Clark County has seen significant growth over the past two decades. In 1990 , the population of the county was slightly under 200,000 persons; the population had increased to 345,238 by 2000 and 425,363 in 2010 .

Table 4.1 Clark County Populations within Incorporated Areas

\begin{tabular}{|c|c|c|c|}
\hline \multirow{2}{*}{ Year } & \multirow{2}{*}{ Population } & Population Living within Incorporated Areas \\
\cline { 2 - 4 } & 3,081 & 0 & Pount \\
\hline 1870 & 5,490 & 1,722 & 31.4 \\
\hline 1880 & 11,709 & 3,545 & 30.3 \\
\hline 1890 & 13,419 & 3,126 & 23.3 \\
\hline 1900 & 26,115 & 11,901 & 45.6 \\
\hline 1910 & 32,805 & 16,552 & 50.5 \\
\hline 1920 & 40,316 & 22,332 & 55.4 \\
\hline 1930 & 49,852 & 25,531 & 51.2 \\
\hline 1940 & 85,307 & 49,343 & 57.8 \\
\hline 1950 & 93,809 & 43,132 & 46.0 \\
\hline 1960 & 128,454 & 54,267 & 42.2 \\
\hline 1970 & 192,227 & 57,168 & 29.7 \\
\hline 1980 & 238,053 & 64,115 & 26.9 \\
\hline 1990 & 345,238 & 178,959 & 51.8 \\
\hline 2000 & 425,363 & 203,339 & 47.8 \\
\hline 2010 & & & \\
\hline
\end{tabular}

Source: U.S. Census 
Complicating this growth pattern is jurisdictional control and identity associated with incorporation. As shown in Table 4-1, the percentage of people living within incorporated areas has significantly shifted in the past 15 years. In 1990, 73 percent of Clark County's population was living in unincorporated areas; with a population boom and significant annexation in the late 1990s by Vancouver, nearly 50 percent live in incorporated areas today. These population statistics are both indicative of the infrastructure, including transportation facility, pressures and shifting character of the area. It also helps contextualize this planning exercise and its focus on unincorporated areas of Clark County.

Planning within Clark County is also challenging due to social norms and ideology. Clark County's largest city, Vancouver, is the fourth largest city in Washington. Yet the county and city have long played second fiddle to Seattle to the north. It is also directly across the Columbia River from liberal Portland, Oregon. Even though Clark County is considered a swing vote on the national stage, it trends conservative compared to its major urban neighbors. For instance, in 2012, 48.58 percent of Clark County voted for Obama compared to 68.72 percent in King County (Seattle) and 75.37 percent in Multnomah County (Portland, Oregon). Politics in Clark County, including transportation policy, are often reactionary; public opinion often exhibits open

Table 4.2 2008 and 2012 Presidential Election Results

\begin{tabular}{|l|c|c|c|c|}
\hline \multirow{2}{*}{ County } & \multicolumn{2}{|c|}{$\mathbf{2 0 0 8}$} & \multicolumn{2}{c|}{$\mathbf{2 0 1 2}$} \\
\cline { 2 - 5 } & Obama & McCain & Obama & Romney \\
\hline Clark & $52.17 \%$ & $46.08 \%$ & $48.59 \%$ & $48.37 \%$ \\
\hline King (Seattle) & $70.30 \%$ & $28.17 \%$ & $68.72 \%$ & $28.36 \%$ \\
\hline Multnomah (Portland, OR) & $76.69 \%$ & $20.61 \%$ & $75.37 \%$ & $20.65 \%$ \\
\hline
\end{tabular}

Source: city-data.com $(7 / 11 / 13)$ 
disdain for the social and political norms - including norms surrounding alternative transportation modes - of both Seattle and Portland.

\section{Overview of the Planning and HIA Process}

In early 2009, Clark County, Washington initiated updating their Bicycle and Pedestrian Master Plan governing unincorporated areas. Two previous bicycle plans addressing the entire county were completed in 1972 (Bicycle Plan) and 1996 (Bicycle Commute Plan). Vancouver-Clark Parks and Recreation adopted an additional Regional Trail and Bikeway Systems Plan in 2006. Clark County, however, had yet to address the pedestrian network despite local and national attention to 'walkability' as a health promotion measure (Alta Planning + Design, 2010). The lack of a pedestrian plan was also a barrier to grant applications for pedestrian programs and projects (Columbian Editorial Board, 2010). Further, Clark County was not in compliance with Washington State Law. The Engrossed Substitute Senate Bill (ESSB) 5186, passed in 2005 by the Washington State Legislature, included an amendment to the Growth Management Act to address alternative transportation modes. The amendment mandates Washington communities and counties include a bicycle and pedestrian component in the Transportation Element of its comprehensive plan.

The Clark County Bicycle and Pedestrian Plan was one of the last large planning efforts prior to the Great Recession. Funding for the Clark County Bicycle and Pedestrian Plan was provided primarily through the county's Public Works department. The planning process was headed by Clark County 'Community Planners' with the help of consultants at Alta Planning + Design - a Portland, Oregon firm with bicycle planning expertise. The community engagement strategy initially consisted of three separate 
stakeholder committees: the Bicycle Advisory Committee ${ }^{16}$, the Bicycle and Pedestrian Advisory Committee, and a Technical Advisory Committee. The Bicycle Advisory Committee was a long-standing advisory committee that supported Public Works in designing bicycle facilities. The approximately 20-member Bicycle and Pedestrian Advisory Committee was convened in 2009 with input for the Clark County Bicycle and Pedestrian Plan as its primary purpose. It included representatives from public works, parks and recreation departments, the local school districts, local and national community-based organization representatives, and private citizens. The Bicycle and Pedestrian Advisory Committee met fourteen times over a sixteen-month period in 2009 and 2010. These stakeholder advisory meetings were augmented with four open houses, a work session and hearing with the planning commission, and three work sessions with the county commissioners. The 3-member County Commission unanimously adopted the plan in November 2010 (Rice, 2010).

A Clark County Public Health representative attended nearly every Bicycle and Pedestrian Advisory Committee meeting. Having just finished the County's first HIA on a corridor plan (Hwy 99), the Clark County Public Health Department employees attending initial Bicycle and Pedestrian Advisory Committee meetings recognized an opportunity for supporting the planning effort by applying for and receiving a Robert Wood Johnson Active Living Grant (Melnick, 2010). The grant covered one FTE for the 2010 calendar year and was written to include a ‘desktop' or rapid HIA by a public health professional to guide public engagement followed by a 'full' HIA of the target plan and

\footnotetext{
${ }^{16}$ The Bicycle Advisory Committee remained active and distinct from the Bicycle and Pedestrian Advisory Committee throughout this planning process and continued its historic role of advising on bicycle issues on a variety of plans and issues throughout the county. After completing the plan, all bicycle and pedestrian committees were folded into a single Bicycle and Pedestrian Advisory Committee.
} 
an evaluation at the end. Both the evaluative and 2-step or iterative HIA process were and remain novel to HIA practice. The iterative HIA has particular implications for understanding how to time and stage an HIA to maximize influence and how to shape methods used in evaluation.

Clark County Public Health Department hired a newly minted urban planner from Portland State University to complete the HIA. Due to the established relationship between the planning and public health departments and ongoing presence of a public health representative on the Bicycle and Pedestrian Advisory Committee, the author of the HIA chose to rely on the greater planning public outreach rather than establishing a separate community engagement plan. A Clark County Public Health Department representative continued to attend all Bicycle and Pedestrian Advisory Committee meetings and use that stakeholder forum for community feedback.

The Clark County Public Health Department staff member leading the HIA was the primary author in consultation with other Clark County Public Health Department professionals. While the entire Bicycle and Pedestrian Advisory Committee was invited to review the HIA at various points, only one community group - Community Choices consistently reviewed and edited the HIA. The Clark County Senior Planner also provided significant feedback. Upon completion of the Rapid HIA, Clark County Public Health Department presented HIA findings to the Bicycle and Pedestrian Advisory Committee. Clark County Public Health Department also presented HIA findings during various planning and county commissioner work meetings. The Rapid HIA was then revised and included in the final adopted plan as an Appendix.

\section{Community Stakeholders and Interests}


Community participation and input for the Plan primarily surfaced in the Bicycle and Pedestrian Advisory Committee. Table 4.3 lists the organizations and their roles in the Bicycle and Pedestrian Advisory Committee. Composed of approximately 23 individuals and narrowing to a core group of ten, the Bicycle and Pedestrian Advisory Committee "made all decisions in the Plan" $(\mathrm{CC} 01, \mathrm{p} 3)$. Government representatives dominated the stakeholder group. Nearly half of the members were from Clark County governments: Planning, Public Works, Public Health, and Parks and Recreation. Vancouver and Evergreen School Districts were also represented. Three community organizations - Volksmarch, Bike Me, and Community Choices - were involved

Table 4.3 Membership Roles of the Bicycle and Pedestrian Advisory Committee

\begin{tabular}{|c|c|c|c|c|}
\hline Category & Organization & Members & Active & Roles/Interests \\
\hline \multirow[t]{5}{*}{$\begin{array}{l}\text { Government } \\
\text { Representatives }\end{array}$} & $\begin{array}{l}\text { Planning (Clark County, } \\
\text { Alta) }\end{array}$ & 3 & 2 & Coordinate plan \\
\hline & $\begin{array}{l}\text { Clark County Public } \\
\text { Works }\end{array}$ & 3 & 1 & $\begin{array}{l}\text { Funded Planning Efforts; } \\
\text { Implementing sidewalk infill }\end{array}$ \\
\hline & $\begin{array}{l}\text { Clark County Public } \\
\text { Health }\end{array}$ & 2 & 1 & Public Health \\
\hline & Other Municipal/County & 3 & 3 & $\begin{array}{l}\text { Congruency with Vancouver- } \\
\text { Clark Parks \& Recreation and } \\
\text { Vancouver Plans; personal } \\
\text { significant AMERICAN } \\
\text { WITH DISABILITIES ACT } \\
\text { interests }\end{array}$ \\
\hline & $\begin{array}{l}\text { School Districts } \\
\text { (Vancouver \& Evergreen) }\end{array}$ & 2 & 2 & $\begin{array}{l}\text { Minimize busing cost; } \\
\text { Child pedestrian safety }\end{array}$ \\
\hline \multirow[t]{3}{*}{$\begin{array}{l}\text { Community } \\
\text { Organizations }\end{array}$} & Community Choices & 1 & 1 & $\begin{array}{l}\text { Strong links to Clark County } \\
\text { Public Health }\end{array}$ \\
\hline & Volksmarch & 1 & 0 & Pedestrian \\
\hline & Bike Me & 1 & 0 & $\begin{array}{l}\text { Bicycle Advocacy and } \\
\text { Education }\end{array}$ \\
\hline \multirow[t]{3}{*}{ Citizens } & $\begin{array}{l}\text { Bicycle Advisory } \\
\text { Committee }\end{array}$ & 3 & 2 & $\begin{array}{l}\text { Bicycle Advocacy and } \\
\text { Feasibility }\end{array}$ \\
\hline & Youth Commission & 1 & 0 & $\begin{array}{l}\text { Youth perspectives; } \\
\text { coordinated through Clark } \\
\text { County Office }\end{array}$ \\
\hline & Citizen & $3^{17}$ & 2 & \\
\hline
\end{tabular}

\footnotetext{
${ }^{17}$ Two of the three citizens listed could also be described as public health professionals; one began as a Community Choices staff member before switching employment and the other was a County Public Health employee.
} 
although only Community Choices was active throughout. One-third of the Bicycle and Pedestrian Advisory Committee was composed of citizens; three of those were from the long-standing Bicycle Advisory Committee, one from the Clark County Youth Commission, and three were citizens at large.

Table 4.3 also provides a list of initial roles and interests of various non-health stakeholders. Clark County Public Works funded the planning efforts and was primarily interested in developing a prioritized list for sidewalk infill and new bike lanes. Vancouver-Clark Parks and Recreation representatives had just finished a Regional Trail and Bikeway Systems Plan in 2006 and were interested in connectivity to the trails. One of the Vancouver-Clark Parks and Recreation representatives was interesting because that person works on trails for the U.S. Forest Service and is wheelchair bound; this representative has become very active in universal design nationally and brought a distinct Americans with Disability Act lens to the group. The school district representatives were invited in anticipation of addressing active transportation for children. These representatives strongly resisted the initial framing of active transportation to school, but recognized the value in reducing busing costs.

Three community organizations were represented on the Bicycle and Pedestrian Advisory Committee. Community Choices ${ }^{18}$ is a long-standing public health non-profit with strong ties to Clark County Public Health; its work revolved around reporting health disparities in a way to increase community engagement around health issues. Volksmarch, a national pedestrian advocacy organization, was invited but provided

\footnotetext{
${ }^{18}$ Due to a lack of funding, Community Choices dissolved in late 2012.
} 
minimal interaction and feedback. Bike Me, a local advocacy group for bicycle education, was also involved to a limited degree.

Seven individuals on the Bicycle and Pedestrian Advisory Committee are listed as citizens. Three of those individuals have served on the Clark County Public Works sponsored Bicycle Advisory Committee for many years. One citizen was a teenager who also served on a Clark County sponsored Youth Commission but provided limited input. Only three citizens were not affiliated with another Clark County advisory committee. However, upon further investigation, one of these citizens began as the former director of Community Choices and stayed on after changing employment. Another was also an employee of Clark County Public Health. Thus even the 'citizen' component of the stakeholder group is best characterized as active citizens who came to the process familiar County governance, particularly for the issues in which they have traditionally engaged.

\section{Community Interests within the HIA}

The HIA relied heavily on the Bicycle and Pedestrian Advisory Committee for community input. The HIA author never

"fully considered doing our own public outreach process for the grant... [which] came far to late to do something like that. We had really meaningful input on the [Rapid] HIA, taking it to one [Bicycle and Pedestrian Advisory Committee] committee meeting.... Committee members, to my surprise, read it, and discussed it and had meaningful questions" (CC01, p5).

Beyond "raising visibility of health and having input," the goals of the HIA were initially driven by the Robert Wood Johnson (RWJ) Active Living grant application. The RWJ grant, written and submitted after the initial kick-off of the planning activities, is primarily focused on pedestrians including active transportation to school. For example, 
the proposal title for the grant was "Planning for Active Walkable Neighborhoods." The text describes a "20-year Pedestrian Master Plan" where "the HIA would provide planners with input into projected youth and adult health impacts of proposed implementation strategies, including STRS [Safe Routes to Schools] projects” and other pedestrian related activates (Melnick, 2010).

Treatment of bicycles in the RWJ grant application is extremely limited. The words bike or bicycle appear in the text only three times: first to acknowledge a separate process for updating the 20-year Bicycle Master Plan (presumably with the Bicycle Advisory Committee), second to acknowledge low-income areas have less active transportation facilities including bike paths, and third to state a long-term national decline in walking and biking to school. As dominant as walking is in the RWJ grant, it also "anticipate[s] future changes with input from a Pedestrian Committee, numerous neighborhood meetings, and interviews with stakeholders" ( $p$ 1). By the time the grant was awarded, the Pedestrian Advisory Committee had changed to the Bicycle and Pedestrian Committee, and the HIA's goals were expanded to address both modes of active transportation (Melnick, 2010).

As the planning process grew to incorporate more than a narrow view of pedestrian and bicycle facilities, the HIA also began to evolve. The HIA author reported that from initial hire, he hoped to augment the active transportation positions with "access to parks which is part of access to physical activity, access to healthy food, and safety from traffic crashes" (CC01, p3). Clark County Public Health Department welcomed the opportunity to address additional health pathways in the HIA. In doing so, Clark County Public Health Department also played a critical role in (1) addressing the needs of 
populations with little representation on the Bicycle and Pedestrian Advisory Committee. Clark County Public Health Department was also instrumental in emphasizing equity components of the Plan through basic demographic, GIS, and social determinants of health analysis. The following subsections draw on content analysis of stakeholder interviews, the Rapid HIA, and the Comprehensive HIA to show how each theme interacted with the inclusion of Clark County Public Health Department in the planning process.

Active Transportation One way that the Clark County Public Health Department and the HIA influenced the Clark County Bicycle and Pedestrian Plan was by consistently helping to

"re-orient or reframe the discussion from focusing on recreational walkers and cyclers who are currently walking and cycling to recreational as well as transportation or utility users far into the future" $(\mathrm{CC} 01, \mathrm{p} 10)$.

The active transportation literature emphasizes 'utility' forms of transportation such as riding a bike to work, walking to another form of public transit, walking or riding to the grocery store, and walking or riding to school. By leveraging transportation to a community destination to which someone is already headed, physical activity is integrated fairly seamlessly into everyday life. This type of physical activity is distinctly different than recreational exercise including recreational transportation such as a Saturday ride on the trails or an evening 2-mile run starting and ending at a household residence. Recreational activity is good; however public health officials have consistently shown that active transportation, as a utility activity, is more likely to result in life-long healthy behaviors for most individuals. 
As shown in the previous section, bicyclists drawn from a long-standing Bicycle Advisory Committee were the dominant citizen contingent on the Bicycle and Pedestrian Advisory Committee. "The bikers were a little bit more organized in terms of a community bicycling group, and they came in with a much clearer picture of what they wanted" (CC04, p 3). They were not particularly interested in supporting utility trips for inexperienced users and were indifferent to pedestrian needs. The Bicycle Advisory Committee had been in place for over a decade to serve as an advisory committee for select Clark County Public Works bike-lane restriping projects. Members of the Bicycle Advisory Committee were firmly entrenched in long-term efforts to provide such facilities and expand recreational possibilities. Further, they felt they had an ally in Public Works. Public Works was the county department funding the planning exercises and was primarily interested in bolstering sidewalk infill and bike-lane stripping prioritization.

Interviews with stakeholders clearly indicated that the citizens from the Bicycle Advisory Committee were experienced bicyclists who believed the plan should support facilities for recreational purposes. One participant pointed out that "this contingent of older cyclists and recreational cyclists" was not interested in talking about kids, health ${ }^{19}$ and density $(\mathrm{CCO}, \mathrm{p} 10)$. Another participant was more direct in describing the citizens from the Bicycle Advisory Committee:

"self-selected and old school, mainly male, Caucasian, older who had their own focus on 'I want to get from A to B' and 'you need to learn how to ride safely.'.... Pretty much recreational, not very much for commuting. .... I don't remember

\footnotetext{
${ }^{19}$ It is important to note that not a single Bicycle Advisory Committee member on the Bicycle and Pedestrian Advisory Committee was willing to be interviewed for this analysis. One immediately responded to requests asking not to be contacted again, stating he had nothing to say about the HIA. The other two ignored multiple attempts at contact and requests for interviews.
} 
them specifically talking about health issues. That wasn't their focus. They were on a leash from Public Works on what they wanted public input from. The way that program was run, they had specific things that Public Works was working on and they wanted their input on those projects" (CC05, p2).

One professional member summed up the challenges from such an intense interest in recreational cycling:

“Frankly, if you're biking right now in Clark County, you're a diehard.... [the problem with] planning for more diehards, is it isn't going to reach a lot of health improvements. Those guys are going to go exercise one way or another" (CC01, p10).

Another professional further elaborated about the challenges of the self-selected Bicycle Advisory Committee citizens:

"some of them were really engaged. But then there were some who just didn't care. Just didn't understand why we were talking about this. They were like 'I want a new bike lane now. I don't really care about this.' There were a couple of people that were just like 'why are we talking about kids and promoting this stuff?' They were really indifferent" (CC03, p11).

When asked what was done to resolve this indifference, the planner explained that they explicitly tried to link today's children cyclists as tomorrow's recreational cyclists.

However, the Bicycle Advisory Committee cyclists were primarily interested in supporting their serious recreational rides by placing bike lanes on major arteries in order to improve their ride to the weekend trail. They "didn't really see where [addressing children] was relevant to projects" (CC03, p13).

Another Bicycle and Pedestrian Advisory Committee member stated "it seemed at times the bike people were almost hijacking the process and the sidewalk people needed a little bit of help" (CC04, p 3). Pedestrians were not well organized. Volksmarch was invited but barely interacted with the Bicycle and Pedestrian Advisory Committee. The planners "looked to the schools [and] tried to reel them in with the Safe Routes to School 
program" $(\mathrm{CC} 05, \mathrm{p} 2)$ but quickly ran into barriers with the word 'safe.' (See next section for analysis of schools as a destination.) One member of the Vancouver-Clark Parks \& Rec board was intently interested in Americans with Disability Act issues but struggled to link disability to health or even pedestrians at large. Interviews showed that planners came to rely on the public health representatives - the HIA author and Community Choices - as an important way to bring in the pedestrian frame.

Because the evidence for active transportation is strong and well developed, the HIA was able to formalize pedestrian and utility bicycling perspectives. A content analysis of the two HIAs shows that health information is presented for bicyclists and pedestrians in an even manner; a summary is provided in Table 4.4. Even though the HIA began with the intent for pedestrian analysis, the Rapid and Comprehensive HIAs both show there are nearly an equal number of quote segments devoted to both pedestrians (189) and bicyclists (197) concerns.

Table 4.4 Content Analysis of the HIAs for Pedestrian and Bicycle Interests

\begin{tabular}{|c|c|c|c|}
\hline \multirow{2}{*}{ Type of Segment } & \multicolumn{3}{|c|}{ Number of Segments } \\
\cline { 2 - 4 } & Rapid HIA & $\begin{array}{c}\text { Comprehensive } \\
\text { HIA }\end{array}$ & Total \\
\hline Pedestrian & 37 & 152 & 189 \\
\hline Bicycle & 39 & 158 & 197 \\
\hline Pedestrian \& Bicycle & 23 & 83 & 106 \\
\hline
\end{tabular}

The overlap between pedestrian and bicycle segments was large; 106 of the 280 segments were coded as both pedestrian and bicyclist information. However, upon closer examination, the concurrent appearance of pedestrian and bicyclist segments was larger for the Rapid HIA (30.3 percent) than the Comprehensive HIA (26.8 percent). This can be explained in at least two ways. The Rapid HIA states that the walkability index is able to capture bikability, particularly for inexperienced riders; consistent with this statement, 
the Rapid HIA often links some variation of 'walk and bike' (or 'pedestrian and bicyclist') throughout the document. Fewer instances of concurrent treatment of bicycles and pedestrians may also be explained by the analysis deepening and becoming specific to certain populations and modes over time.

It is more difficult to identify quotes as only utility or recreational because many treat both aspects. However themes from the HIA text clearly support utility bicycle riding and walking with specific emphasis on vulnerable populations. For instance, the Comprehensive HIA analyzes proposed bikeways and sidewalk network density by socio-economic status, percent minority, youth, and older adult populations. The Comprehensive HIA also systematically evaluates plan policies for impact on physical activity (positive, supportive, or negative), strength of evidence from the literature, and the potential to address disparities of vulnerable populations.

Perhaps more importantly, several interview respondents described a significant shift in attitudes towards a pedestrian supportive environment and attributed this shift, in part, to work associated with the HIA. One particular interviewee described involvement with the Bicycle and Pedestrian Advisory Committee prompting a personal walk just to see what pedestrian conditions were truly like.

"After I joined the Bicycle and Pedestrian Advisory Committee, I took a fourmile walk and had to cross the road at least four times to stay on a sidewalk. It never even dawned on me before. It was never an issue. But I started thinking 'if my mom were here?' And it wasn't that they were really busy roads, but it was roads where there are not designated crosswalks and it is not easy. I live in East County were there are sidewalks, but [the Bicycle and Pedestrian Advisory Committee] made me start to think 'huh, it might be a barrier' [in other parts of the county]. The awareness... a lot of increased awareness of things that I took for granted or just didn't pay attention to" (CC06, p9). 
This individual made a similar statement about facilities that support all types of bicycle riders:

"People who ride here accept the inherent risk. I bike a little bit - enough to know that it is not easy to bike. Sometimes I bike nine miles from my house to here and it is not an easy ride. Again, I've learned so much - so much of what I've taken for granted. [Public Health] is not where I come from, so I'm telling you straight up that the way-finding signs, I always thought those were a waste of money. But then I got on my bike and realized they were really important because you can't just bike like you are in a car. You just can't get on Mill Plain and get into town on a bike. And then I got the signs. NOW, I understand that sign" (CC06, p3).

The HIA's primary author concurred:

"To the extent that [the skeptics] continued to participate, they came around. I would say the more common case was they maybe just had not thought of it. Once it was presented, a lot of [participants] described it as an 'Aha!' moment... Mapping conditions on the ground was really engaging and helped people visualize differences throughout the county. There were a couple of occasions that I can recall that people just lighted up with fascination at that. They wanted to know how [the built environment] affected obesity and what conditions were present where walkability was strong" $(\mathrm{CC} 01, \mathrm{p} 6)$.

Access to Parks, Food, and Schools By framing the HIA with 'Active Living Research' as its underlying theoretical construct, public health also expanded the types of destinations considered within the plan. The central theme of Active Living Research is the built environment can encourage or discourage behaviors that affect obesity and related health outcomes. One way in which Active Living Research is evident within the HIA is the emphasis on pedestrian and bicycle access to parks, food outlets, and schools.

Park access can significantly increase the activity levels of individuals. Parks within walking or biking distance can entice individuals to choose an active form of transportation to and exercise at the park. Both HIAs address this through GIS analysis of walking distance to parks, and it is readily apparent that only those who live in the City 
of Vancouver have parks within walking distance of their home. The Comprehensive HIA also uses the number of people with additional access to parks as a metric to analyze the magnitude of impact for projects prioritized within the Plan.

Active Living Research also recognizes that access to healthy food is an important pathway to decreasing obesity. Shopping for food is a routine activity, making it a good candidate for an active transportation destination. The county senior planner directly attributed the inclusion of food access in the Plan to the HIA. "Food access... would not have come up, but Public Health made some presentations to our committee and showed the map where there is very little [access]" (CC03,p7). Both HIAs augmented the Plan by describing baseline food access conditions with $1 / 2$-mile and 1-mile buffered maps to fast food and grocery stores. Additional correlation analysis in the Comprehensive HIA shows that the nearest food store is often a less nutritious food outlet, particularly for low-income communities. The Comprehensive HIA analysis labels policies increasing bicycle and pedestrian routes to nutritious food sources and farmers markets as 'supportive' of increased activity levels.

As an active transportation destination, schools were surprisingly contentious. The RWJ grant clearly shows that Clark County Public Health Department envisioned Safe Routes to School - a popular national program currently being rolled out in the State of Washington - as a prominent pedestrian program. Yet half way through the planning process, it was clear that inclusion of Safe Routes to Schools was problematic. Several participants brought up Safe Routes to Schools as a contentious issue; one even described it as "a huge one" (CC05, p4). 
"Schools did not want the [phrase] 'Safe Routes to Schools' in any shape or form - the Vancouver School District said absolutely not because they felt that [Safe Routes to Schools] implies that when you send your child out, it is a safe route and nothing is going to happen. Unfortunately, that is where a litigious society comes into play. The school district was adamant even though I've attended several Safe Routes to Schools seminars and workshops and most people do not feel that way" (CC06, p 9).

This ‘very strong position' was absolutely firm. For a while, the planners and public health professionals "continued to call it Safe Routes to Schools and [the school district representative] continued to say 'no, you can’t say that!"” (CC06, p9).

Concern about stranger danger is acknowledged in Active Living Research and active school transportation literature. The active school transportation literature tends to focus on built environment interventions for increasing walking and biking to school; however it is clear that social factors including parental perceptions of safety are often stronger predictors of behavior than the built environment. Faulkner (2010) described the decision about a child's mode of travel to school as two separate decisions: (1) whether to allow the child to transport themselves independently and (2) what mode to take if accompanying the child. Acting as gatekeepers, parental concerns about safety result in the decision to accompany the child; family logistics often dictates accompaniment in a vehicle.

The surprising part of stranger danger surfacing in the planning process is that the concern was voiced and held firm throughout by a school district representative. Parents, emotionally attached to their child's safety, often choose to be overly risk-adverse, but school districts should understand the statistical probability of a stranger utilizing Safe Routes to School maps to prey on children is small. Yet however small the risk, the 
consequences of a lawsuit could potentially be large for the school district; in this case, the Vancouver School District was firm in its position that publishing maps was predator friendly.

Several interviewees suggested that, despite

"lots of Bicycle Advisory Committee back and forth, why is this so important, what can we use so we can get this out there so people can know they can walk, they don't have to ride the [school] bus, that it is a functional way to get to school?" (CC05, p4)

The contention about Safe Routes to School was never resolved. Meeting minutes from Bicycle and Pedestrian Advisory Committee Meeting 7 clearly record Vancouver School District's objections about publishing maps of safe routes as a part of the plan. Accordingly, Safe Routes to School language is also stripped from the final plan with three exceptions. The first is a mention in the executive summary to provide two local examples upon which a school active transportation education program should build. The second is a mention in the text of educational programs and refers to Portland's 'Safer Routes to School' program as a model program. Finally, Appendix D of the target plan briefly catalogs much of the knowledge about Safe Routes to School and includes a Portland Public School District (Multnomah County, Oregon) map as an example.

The HIA was able to help salvage some of the intent behind Safe Routes to School in a number of ways. Both HIAs maintained access to schools as a central point of GIS analysis; the HIAs map current conditions of distance to a neighborhood school to make the point that many children would have to walk or bike more than a mile. More importantly, the Comprehensive HIA analyzed the extent to which proposed prioritized 
facility improvements would be near schools; this analysis was further stratified by school SES status to investigate equity issues. Finally, the Comprehensive HIA nimbly changed Safe Routes to School to more generic forms such as Recommendation 11 that states, "use proven approaches in schools programs."

Further, the child frame remained important when addressing broader audiences prior to presenting the plan to council. When asked about the most influential part of the HIA, one planner responded, "I think it was the kids" issue that spoke to various constituencies" $(\mathrm{CC} 03, \mathrm{p} 11)$. Specifically, the planners spoke about the health costs and benefits while emphasizing children when presenting the draft plan to various commissions and public meetings. Framing reducing obesity and diabetes by reducing busing costs seemed to gain traction in front of a lot of audiences including the three county commissioners.

Bicycle and Pedestrian Safety Perceived and real safety concerns are often a significant barrier to bicycling and walking and most Bicycle and Pedestrian Advisory Committee participants were quick to understand the importance of safety.

"It's almost the first thing that comes up sometimes. When you talk about health and bicycle planning, people think helmets... it seemed like an obvious or boiler plate kind of think to include" information about safety (CC01, p 4).

Another pedestrian-oriented participant stated that the

"ability for individuals to be able to walk throughout their area in a safe environment is obviously the very first [health] thing [to address]. The second thing for me is the ability for children to walk to school in a safe manner also. Safe means that a person does not have to walk down the street. We have many areas in Clark County that were developed early on, that only have one sidewalk on one side or some that have no sidewalks at all. So therefore kids have to walk out on the street and mixing it up with vehicles. Not safe." (CC02,p3). 
The most problematic safety issue for bicyclists and pedestrians is clearly collisions with automobiles. Crashes can be minimized with well-designed facilities.

Yet bicycle and pedestrian safety was "much harder" to elicit and address in the HIA and Plan than the lead HIA author anticipated:

"I kind of expected there to be an assessment of crashes produced by Public Works or Planning, a Sherriff's Department, or someone. But those actually were never mapped or included as any kind of project prioritization criteria before we jumped in. So the map of bicycle and pedestrian crashes in Clark County is included as part of the HIA. It was a surprise to me, but it was also something that took so much time. We weren't able to have it done really very much in advance. And so I don't think it ultimately had a lot of impact other than to say that people need to feel safe from - because perceived safety is an important issue - traffic collisions" (CC01 p3-4).

To this end, the Comprehensive HIA augments the Plan by providing four years of injury and fatality rates for both bicycles and pedestrians. It also maps crash densities, noting the most problematic intersections.

\section{Community Interests in the Plan}

The HIAs clearly supported expanding the vision of the plan to support active living for pedestrians, utility, and future users. The HIA did so by emphasizing the creation of programs and safe facilities that support and link a spectrum of users to a variety of destinations. The Plan attempts to incorporate a diverse set of pedestrians and bicyclists, but falls short at times. Tracing the HIA recommendations of the Rapid HIA shows where inclusion of health information played an important role in the planning process. Similarly, analysis of the Comprehensive HIA that was released concurrently with the final Clark County Bicycle and Pedestrian Plan at the end of the process clearly indicates areas where the HIA struggled to influence. 
The Rapid HIA was included as Appendix I of the final Plan. The

recommendations from the Rapid HIA were meant to influence the final plan and thus

were analyzed for this project as a measure of HIA influence. Table 4.5 quotes the

Table 4.5 Clark County Rapid HIA and Inclusion in Final Plan

\begin{tabular}{|c|c|c|}
\hline \multicolumn{2}{|c|}{ Rapid HIA Recommendation } & Final Plan Inclusion \\
\hline 0 & $\begin{array}{l}\text { Recommended Geographic Focus - Public Health recommends } \\
\text { focusing the plan impact on moderate-to-high density geographic } \\
\text { areas that: } \\
\text { - Are disadvantaged in terms of social determinants of } \\
\text { health } \\
\text { - Have unfavorably distributed health outcomes } \\
\text { Have measures of the built environment that constitute a } \\
\text { high need or a high potential for enabling physical activity }\end{array}$ & $\begin{array}{l}\text { Partially addressed. See } \\
\text { criteria for sidewalk } \\
\text { prioritization for example of } \\
\text { including geography-based } \\
\text { social determinants of health } \\
\end{array}$ \\
\hline 1 & $\begin{array}{l}\text { Include low-speed roadway designs as bicycle and pedestrian } \\
\text { projects }\end{array}$ & Action 6.1 .2 (Exact) \\
\hline 2 & Implement a variety of bikeway facility types & Action 1.1.5 \\
\hline 3 & Include temporary street closures (ciclovias) in programs & $\begin{array}{l}\text { Action 4.1.3 (Exact); } \\
\text { Implemented Summer } 2013\end{array}$ \\
\hline 4 & Add programs that manage automobile parking & $\begin{array}{l}\text { Action } 1.3 .2 \text { - Partially } \\
\text { addresses by suggesting } \\
\text { reduced parking standard } \\
\text { minimums in trade for } \\
\text { bicycle parking }\end{array}$ \\
\hline 5 & $\begin{array}{l}\text { Declare measureable targets for project objectives. The plan should } \\
\text { include: (a) Numeric objectives that define a desirable level of } \\
\text { service (b) Which government agency is responsible for } \\
\text { implementation and when (c) Benchmarks and performance } \\
\text { measures for assessing progress }\end{array}$ & $\begin{array}{l}\text { No. Targets are minimal } \\
\text { throughout, benchmarks are } \\
\text { not addressed and mentioned } \\
\text { only once }\end{array}$ \\
\hline 6 & $\begin{array}{l}\text { Prioritize projects and adopt policies that increase the following } \\
\text { measures of walkability: connectivity, urban design, land use mix, } \\
\text { and residential density. Specific proposals for consideration (not } \\
\text { mentioned in the plan) include: limit construction of new cul-de- } \\
\text { sacs; connect existing cul-de-sacs; limit block size; design for } \\
\text { imageability, enclosure, human scale, transparency, and } \\
\text { complexity; encourage a dense mix of land uses; encourage higher } \\
\text { density housing }\end{array}$ & $\begin{array}{l}\text { Action 6.1.3 (Exact); } \\
\text { Action 6.1.4 (cul-de-sacs); } \\
\text { Action 6.1.5 (increased } \\
\text { density and mix of uses) }\end{array}$ \\
\hline 7 & $\begin{array}{l}\text { Create policies to increase bicycle and pedestrian access to } \\
\text { nutritious food }\end{array}$ & $\begin{array}{l}\text { Objective } 6.2 \text { (Exact) } \\
\text { including Action } 6.1 .1 \& \\
6.1 .2\end{array}$ \\
\hline 8 & Design for inexperienced cyclists & $\begin{array}{l}\text { Action } 1.1 .5 \text { (Note } \\
\text { Recommendation \#3 of } \\
\text { Comprehensive HIA suggests } \\
\text { the Plan does not go far } \\
\text { enough.) }\end{array}$ \\
\hline 9 & Include health and equity in project evaluation criteria & Action 1.1.6 (Exact) \\
\hline 10 & $\begin{array}{l}\text { Recognize increased numbers of bicyclists and pedestrians as a } \\
\text { safety strategy }\end{array}$ & Action 4.3.2 (Exact) \\
\hline
\end{tabular}


eleven Rapid HIA recommendations and summarizes the extent to which they were addressed in the final plan. Most of the Rapid HIA recommendations were explicitly included in the Plan's policy recommendations. Ten of the eleven Rapid HIA recommendations were addressed. In five of those cases, the exact HIA language was maintained. The HIA recommendation to include measurable targets was largely ignored; the plan remained aspirational with less than a handful of references to data or benchmarks. In three of the cases, the recommendations were partially addressed. Places the plan started to but did not adequately address HIA concerns includes the overarching recommendation that the plan frame and focus through spatial analysis to target areas that are disadvantaged in both health outcomes and social determinants of health, exploring parking incentives and programs, and designing for inexperienced bicyclists.

Because the Comprehensive HIA was meant to analyze the Final Plan for health concerns, examination of the Comprehensive HIA's recommendations is another way to understand the inverse of influence. Each recommendation in the Comprehensive HIA is an area where health interests did not, in the opinion of the public health contingent, gain enough traction. To the extent that these recommendations are community centered also speaks to public health's unsuccessful attempts to expand the planning process to consider a greater public.

Table 4.6 below lists the eleven Comprehensive HIA recommendations, any Rapid HIA recommendations that tracked closely, and quotes within the recommendations that explicitly link to major community themes. Five Comprehensive HIA recommendations are variations on four previous recommendations in the Rapid 
Table 4.6 Community Language in Clark County Comprehensive HIA

\begin{tabular}{|c|c|c|c|}
\hline \multicolumn{2}{|c|}{$\begin{array}{l}\text { Comprehensive HIA } \\
\text { Recommendations }\end{array}$} & \multirow[t]{2}{*}{$\begin{array}{c}\text { Rapid HIA } \\
\text { Recommendation } \\
\text { Reference } \\
\end{array}$} & \multirow{2}{*}{$\begin{array}{c}\text { Community Specific Language in } \\
\text { Comprehensive HIA Recommendation }\end{array}$} \\
\hline 1 & $\begin{array}{l}\text { Update the plan } \\
\text { within five years. }\end{array}$ & & \\
\hline 2 & $\begin{array}{l}\text { Use data to prioritize } \\
\text { proposals and track } \\
\text { progress. }\end{array}$ & $\begin{array}{l}5 \text { - Declare } \\
\text { Measurable targets }\end{array}$ & \\
\hline \multirow[t]{2}{*}{3} & \multirow{2}{*}{$\begin{array}{l}\text { Respond to the needs } \\
\text { of a continuum of } \\
\text { users and trip types. }\end{array}$} & $\begin{array}{l}2-\text { Implement a } \\
\text { variety of bikeway } \\
\text { facility types }\end{array}$ & \multirow[t]{2}{*}{ "a continuum of users and trip types" } \\
\hline & & $\begin{array}{l}8 \text { - Design for } \\
\text { inexperienced cyclists }\end{array}$ & \\
\hline \multirow[t]{2}{*}{4} & \multirow{2}{*}{$\begin{array}{l}\text { Use innovative } \\
\text { designs and a variety } \\
\text { of facility types. }\end{array}$} & $\begin{array}{l}2-\text { Implement a } \\
\text { variety of bikeway } \\
\text { facility types }\end{array}$ & \multirow[t]{2}{*}{ "attracting new cyclists" } \\
\hline & & $\begin{array}{l}8 \text { - Design for } \\
\text { inexperienced cyclists }\end{array}$ & \\
\hline \multirow{2}{*}{5} & \multirow{2}{*}{$\begin{array}{l}\text { Create a } \\
\text { comprehensive } \\
\text { inventory of } \\
\text { sidewalks. }\end{array}$} & $\begin{array}{l}0 \text { - Recommended } \\
\text { Geographic Focus }\end{array}$ & \multirow{2}{*}{$\begin{array}{c}\text { "Without a clear picture of existing conditions, it is } \\
\text { difficult to identify the highest priority pedestrian } \\
\text { projects" }\end{array}$} \\
\hline & & $\begin{array}{l}5 \text { - Declare } \\
\text { Measurable targets }\end{array}$ & \\
\hline 6 & $\begin{array}{l}\text { Fully implement } \\
\text { policies. }\end{array}$ & & \\
\hline 7 & $\begin{array}{l}\text { Target zero bicycle } \\
\text { and pedestrian } \\
\text { crashes. }\end{array}$ & $\begin{array}{l}5 \text { - Declare } \\
\text { Measurable targets }\end{array}$ & $\begin{array}{l}\text { "Given that such crashes are preventable, we } \\
\text { envision a future for Clark County free of pedestrian } \\
\text { and bicycle crashes. Adopting a target of zero } \\
\text { pedestrian and bicycle injuries and fatalities by } 2030 \\
\text { would be consistent with Washington State goals as } \\
\text { articulated in Washington State's Strategic Highway } \\
\text { Safety Plan (2010)" }\end{array}$ \\
\hline \multirow{2}{*}{8} & \multirow{2}{*}{$\begin{array}{l}\text { Use crash data in } \\
\text { project prioritization. }\end{array}$} & $\begin{array}{l}0 \text { - Recommended } \\
\text { Geographic Focus }\end{array}$ & \multirow{2}{*}{$\begin{array}{c}\text { "Using crash data as criteria in project list generation } \\
\text { could lead the county to identify hazardous locations } \\
\text { and target solutions to reduce crashes" }\end{array}$} \\
\hline & & $\begin{array}{l}5 \text { - Declare } \\
\text { Measurable targets }\end{array}$ & \\
\hline 9 & $\begin{array}{l}\text { Focus on low SES } \\
\text { neighborhoods. }\end{array}$ & $\begin{array}{l}0 \text { - Recommended } \\
\text { Geographic Focus }\end{array}$ & $\begin{array}{c}\text { "One way to address this disparity is to increase } \\
\text { opportunities for physical activity in lower SES } \\
\text { neighborhoods" }\end{array}$ \\
\hline 10 & $\begin{array}{l}\text { Develop criteria for } \\
\text { selecting programs. }\end{array}$ & $\begin{array}{l}5 \text { - Declare } \\
\text { Measurable targets }\end{array}$ & \\
\hline 11 & $\begin{array}{l}\text { Use proven } \\
\text { approaches in school } \\
\text { programs }\end{array}$ & & $\begin{array}{l}\text { "A substantial body of research exists demonstrating } \\
\text { the effectiveness of Safe Routes to School programs. } \\
\text { The national Safe Routes to School Partnership } \\
\text { emphasizes the success of the 4-E approach widely } \\
\text { recognized for its effectiveness. This approach goes } \\
\text { beyond safety education and encouragement, citing } \\
\text { the reinforcing effects of combining Encouragement, } \\
\text { Enforcement, Engineering, and Education. Adopting } \\
\text { evidence-based approaches will protect children, } \\
\text { maximize Safe Routes funding, and prepare the } \\
\text { county for future competitive grants." }\end{array}$ \\
\hline
\end{tabular}


HIA. Closer examination of both sets of recommendations suggests that the planning process did not adequately (1) define data and criteria for prioritization, (2) plan for a diversity of users including inexperienced cyclists through a diversity of facilities, or (3) focus enough on low-income neighborhoods.

For example, recommendations three and four of the Comprehensive HIA are still addressing the request for the Plan to "respond to the needs of a continuum of users and trip types" through a diversity of facilities. This recommendation encapsulates the HIA's efforts in expanding the community under consideration to pedestrians, utility trips, and future users. Its inclusion reveals that the Rapid HIA - which included two separate recommendations addressing a range of users and bicycle facilities - and continued attendance by Clark County Public Health Department at Bicycle and Pedestrian Advisory Committee did not completely overcome resistance by the vocal recreational bicycle citizen contingent. The HIA text is critical of this continued emphasis on recreational bicycling for current users. In the analysis section, the HIA reads:

Although the best practices matrix [in Chapter 6 of the Plan] identifies numerous facility types and treatments, such as bike boulevards and cycle tracks, the plan recommends only two designs, lanes and trails, as prioritized bikeway projects. It is unlikely that such a limited variety of designs will attract any new cyclists (Comprehensive HIA, p 46).

In the end, the plan "talked about the potential [for all], but the majority of the plan focused on those who were already riding and how to make it safer and more convenient" (CC06, p8).

Another theme in the recommendations of both HIAs - relying more heavily on data, guidelines, and criteria for prioritization of policies and infrastructure improvements 
- speaks to the type of plan public health felt would best protect a variety of communities.

The plan does not link the best practices matrix to any proposed facilities or policies. Instead, the best practices matrix is presented in the plan as a basis for future committee work [to develop standards or guidelines]... Development of such guidelines could increase opportunities for physical activity, but the current plan falls short of guaranteeing any changes to design standards (Comprehensive HIA, p 46).

Comprehensive HIA Recommendations 5 (sidewalk inventory), 7 (target zero bike and pedestrian crashes), 8 (use crash data in project prioritization), and 10 (develop criteria for program prioritization) all indicate that Clark County Public Health Department felt the Plan did not move beyond aspirations in a way that would make protecting health a reality.

Two specific data gaps were identified by the HIA process and addressed in the Comprehensive HIA. First, several sidewalk inventories existed but were inconsistent. It was difficult to address Public Works' interests for sidewalk infill criteria with such poor data. As a result, the HIA and Plan struggled to protect pedestrians. Another example, adding crash data, would also help protect pedestrians and bicyclists. The HIA includes traffic crash maps to illustrate that point. Yet Public Works resisted incorporating crash data, claiming that the current use of a measure of magnitude of separation was more 'objective' and thus defensible. The Comprehensive HIA specifically called out this approach to safety as important but inadequate:

The emphasis on separation is appropriate given the importance of perceived safety in cycling and walking, but failing to include and respond to data on specific existing safety hazards may lead to missed opportunities to identify and correct [existing hazards] (Comprehensive HIA, p 51). 
Further, Comprehensive HIA Recommendation 7 states that the plan ought to "target zero bicycle and pedestrian crashes" (p 56); this is a more rigorous benchmark than the Plan's recommendation of a ten percent reduction in crashes and more consistent with Washington State Planning goals. More importantly, it is far more protective of the bicycle and pedestrian communities.

Given the relatively scarcity of data, geographic focus, and criteria, it is somewhat surprising that inclusion of health factors - neighborhood socio-economic profile and walkability scores - in sidewalk infill criteria is the most noticeable and measurable influence of this HIA. The HIA author's narrative about integrating health into the criteria is instructive about the value of health 'being at the table.'

"We has an enormous list of potential projects - 350 to 400 projects - and the planners wanted to get to an arbitrary number of 'Top 10 projects in 4 categories.' As the consultants brought draft prioritization criteria, we tried to merge it with existing sidewalk prioritization criteria [which] prioritized complaint driven database of sidewalk infill. At that meeting, I said 'Hey, how about a criteria for health?' and they said 'Ok, you can have 20 points. Tell us how you ant to use them.' I mean, it was kind of straight forward"' (CC01, p 10).

The HIA author, somewhat caught off-guard about these new 20 points, went to a larger

Clark County Public Health Department team and

"essentially debated for a couple of days how to assign the 20 points. We ended up assigning them based on the social determinants of health and the predictors of physical activity that has emerged from the Active Living Research" (CC01, p $11)$.

Eventually, the 20 points in the "Health Outcomes" criteria were ten points for socioeconomic status, four points for increasing walkability, five points for increasing connectivity, and one point for low stress facilities. 
Identifying measures for each of those factors, however, proved more

challenging. During interviews, Public Works called out these health criteria as a

'perfect example' of the plan leaning towards subjective criteria.

"One of the things that was recommended was a walkability survey... which requires physically going out and walking roads and making subjective judgments such as 'do you feel safe' without really delving into why you do or do not feel safe. Is it a narrow walkway? Is it a barking dog? Is it the neighborhood? Is it something that has absolutely no bearing on the sidewalk provided, an external factor?

So when it came to coming up with a measurement for that, I had to come up with something different. I decided to use two maps that Clark County Public Health Department created. One shows HUD's definition of the economic profile of the neighborhood and assigned points based on quintiles. I let Clark County Public Health Department determine walkability and used their map to assign points based on quintiles" (CC04, p 4).

The continued belief that a walkability scale is subjective, even though it has been

developed and validated repeatedly in an effort to minimize the surveyor's bias, illustrates that public health and transportation professionals still have some disciplinary barriers that were not overcome by the presence of the HIA.

In fairness to the HIA and the efforts of Clark County Public Health Department to integrate health into criteria, Public Works struggled with all attempts to develop criteria:

"[The Bicycle and Pedestrian Advisory Committee] attempted to pull together proposed measurements for criteria and take a stab at assigning point values to the criteria to develop weighting factors. My personal view was it was less successful because much of what was developed is not really usable from a public works standpoint. So while the criteria and general thrust of the committee was respected, the measurements that came up pretty much had to be totally thrown out to be workable with our existing, ongoing program.

One reason for this was because the people involved had a planning focus that wasn't really balanced by a construction focus.... They did not understand and 
see the need to have very objective criteria so that choices could be explained and reasonably defended to two [conflicting] neighborhoods" (CC04, p4).

Interviews with almost every other Bicycle and Pedestrian Advisory Committee member suggested Public Works representation struggled to understand the visioning goals of the

planning process. Still, Public Works' perception that walkability is 'subjective' and not particularly defensible suggests that health will need a seat at the table for a long time to overcome disciplinary silos.

\section{Summary}

The Clark County HIA is a good example of a decision-support HIA on a relatively tight and health promoting planning objective of active transportation. While the HIA did not maintain a separate community or stakeholder engagement strategy, it was able to collaborate with the main planning engagement process. Notably, the Clark County HIA author was able to use professional knowledge to expand both the publics and interests considered. Finally, the iterative approach to a Rapid HIA followed by a Comprehensive HIA successfully addressed the timing tension and influenced the target plan. 


\section{Chapter 5: Case Study of Lake Merritt BART Station Area Plan}

The HIA field was propelled forward in the U.S., in part, by several HIAs that elevated community concerns through excellent stakeholder participation structures. The Lake Merritt case was chosen primarily to investigate the extent to which a robust stakeholder advisory committee with complete control over HIA decisions could support community interests, particularly in a planning process where significant competing cultural and economic interests were likely to appear. The Lake Merritt HIA was initiated by local community advocacy organizations that maintained significant control over the HIA throughout the process. As such, this case serves as an exemplar of community-led and advocacy HIA practice.

\section{Background}

The Lake Merritt BART Station Area Plan in Oakland, CA is a planning effort led by the City of Oakland with partners Bay Area Rapid Transit (BART) and Peralta Community College District (Laney College) through a grant from the Metropolitan Transportation Commission. The plan focuses on a half-mile radius around the Lake Merritt BART Station that includes Chinatown, Laney College, civic buildings of Alameda County and Oakland and the channel connecting Lake Merritt to the estuary (see Figure 5.1). The planning activities began in 2010 and are scheduled to finish in 2014. This planning effort has triggered California Environmental Protection Act (CEPA) regulations requiring EIA; the City of Oakland has chosen to work towards a single preferred alternative to analyze for EIA requirements.

In 2009, in anticipation of the planning process starting, Public Health Law \& Chinatown Coalition to apply for a Federal Transportation Administration grant; 


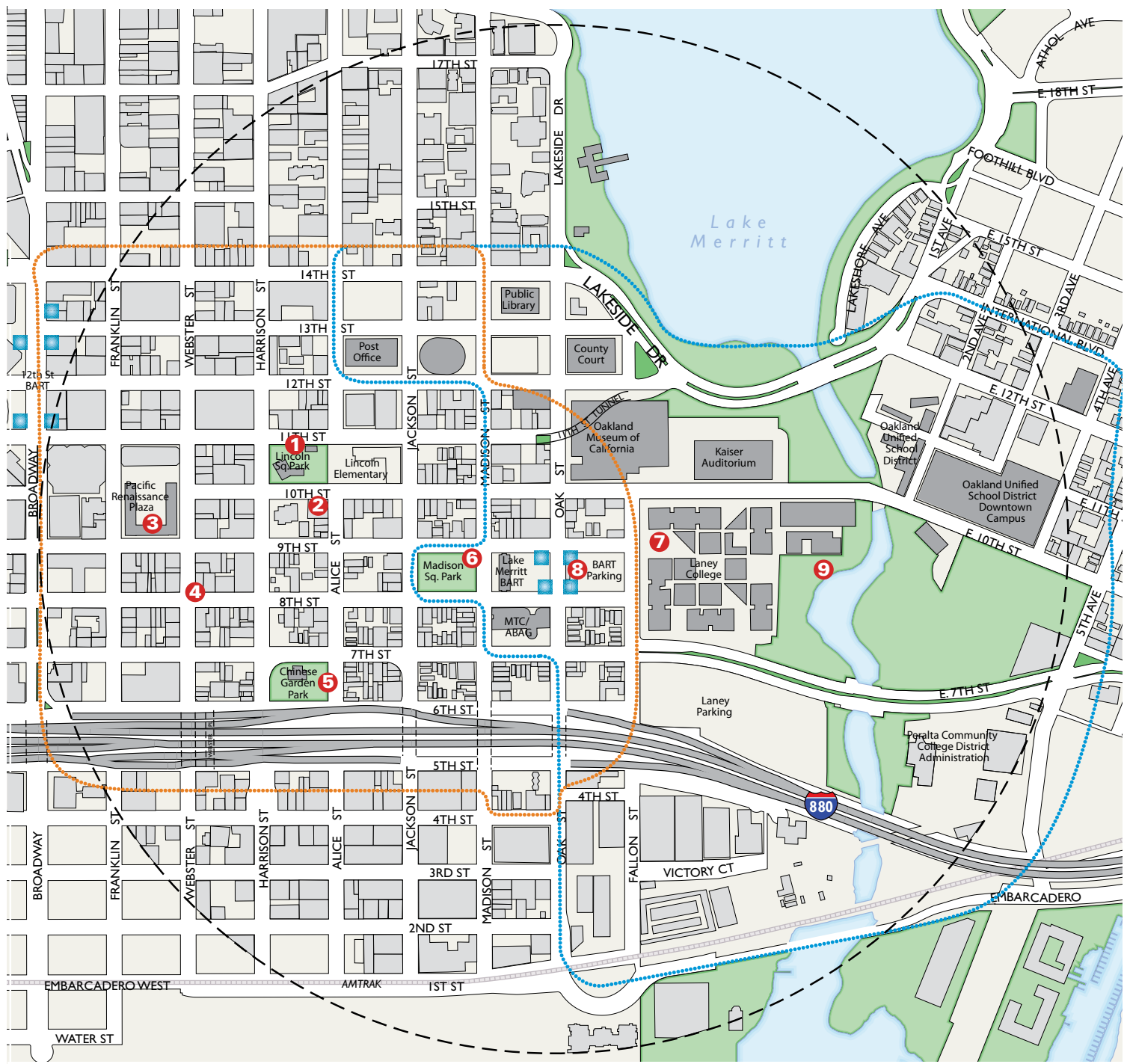

Figure 5.1 Map of Planning Area for the Lake Merritt BART Station Area Plan

the group hoped to explore HIA as a potential participation avenue. The grant was awarded and combined with additional funding to support a HIA Steering Committee and process.

The central objective of the Lake Merritt BART SAP is to identify appropriate Transit Oriented Development (TOD) projects for the BART Station and other publicly owned lands nearby. Much of the developed land is well below City of Oakland density guidelines. Approximately half of the planning area is publicly owned, which is why 
government-led redevelopment efforts could be vast and greatly influence the composition and character of the neighborhood. Only fifteen percent of the buildings are residential, and nearly all (95\%) are considered multi-family. The projects should increase housing and employment opportunities while providing additional mixed-use retail and services, preserving open space, and increase capacity of the regional BART station (City of Oakland, 2010).

Equitable planning in this context is particularly challenging given the diverse set of stakeholders: students, faculty and staff at Laney College; the Asian (immigrant, refugee, and Asian-American) community in neighboring Oakland's Chinatown and associated small businesses; the Kaiser Convention Center; the Oakland Museum of California; various Alameda County and other government office buildings; and a variety of commercial businesses. Summarizing a Stakeholder Interview Report, Figure 5.2 provides a diagram of major interests as reported in 50 interviews - 28 with members of the Chinatown Coalition - with various stakeholders (Dyett \& Bhatia, 2010). According to this report, every stakeholder recognized problems of crime and perceived safety. Beyond safety, interests and positions varied depending on the group. For instance, parking demand and transportation management is a key issue for many of the stakeholders; the position on parking (increase, decrease, or shift to transit) varies depending on the group. The Chinatown Coalition along with the local businesses represented primarily by the Oakland Chinatown Chamber of Commerce made it clear that preserving - if not expanding - Chinatown and its character was their primary concern. 


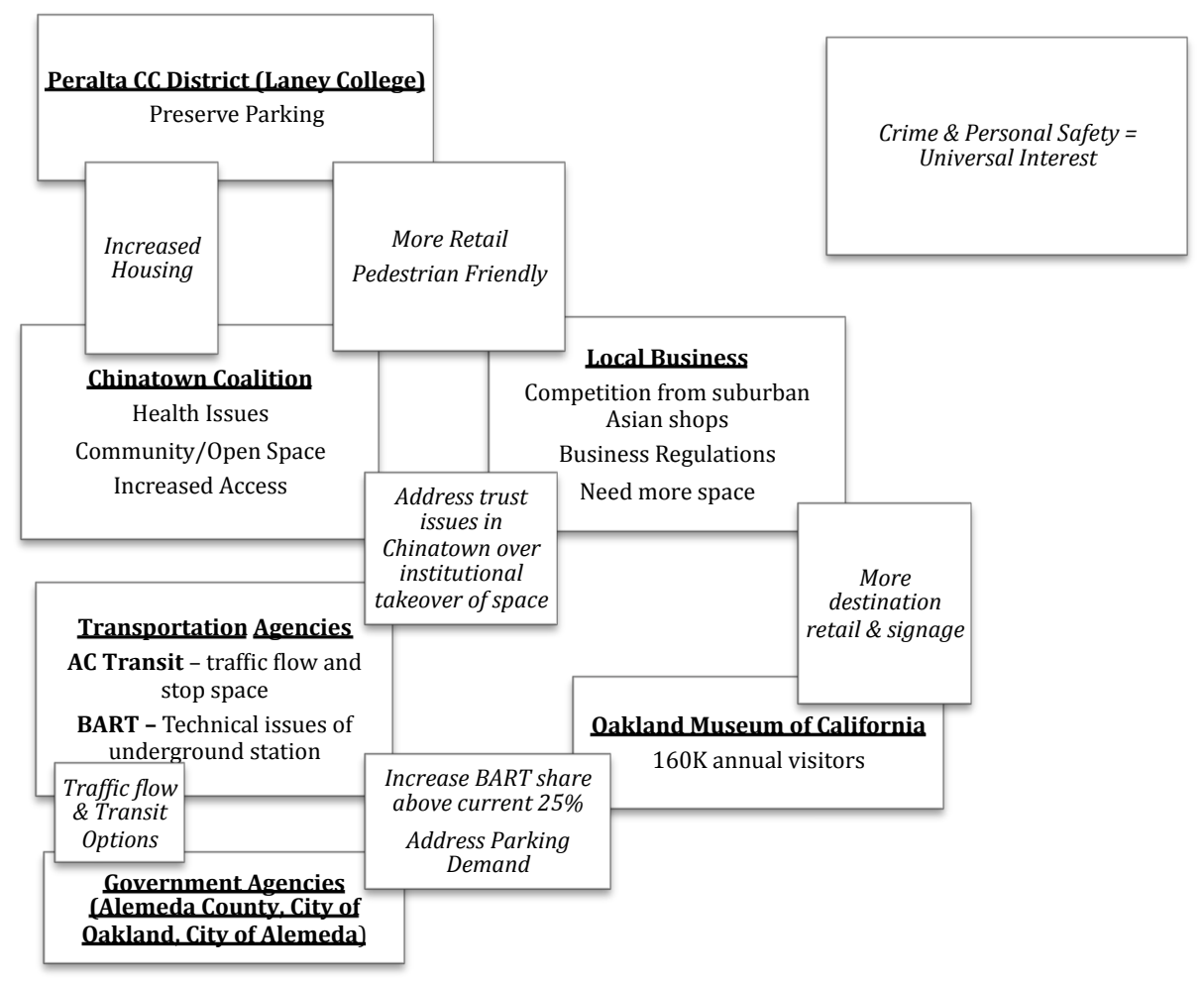

Figure 5.2 Stakeholder Interest Diagram ${ }^{20}$ for Lake Merritt BART Station Area Plan

Chinatown and Displacement The demographics of those residing in Chinatown are particularly challenging: a highly concentrated and impoverished minority community dependent on language-specific social services. Sixty-four percent of the population is Asian and eighty-four percent of that population is Chinese. The median age is 46 years; nearly thirty percent is over the age of sixty. One-third of households in the plan area have an income less than $\$ 15,000$ (City of Oakland, 2010).

A long history of displacement has led to considerable mistrust among the Chinatown community. The three blocks at the center of the planning effort bounded by Jackson, $9^{\text {th }}$, Fallon, and $8^{\text {th }}$ were claimed for a BART station through eminent domain in

${ }^{20}$ Diagram summarizes over 50 interviews with stakeholders as reported by Dyett \& Bhatia (2010). Stakeholder groups are bolded and underlined, main interests are in regular print, and shared interests are italicized. 
the mid-1960s. Today, "there remains a sense of loss" (Dyett \& Bhatia, 2010, p. 17) associated with the demolishment of 75 homes and the Chinese True Sunshine Episcopal Church (Huang, 2011). Stakeholder interviews clearly indicate that the Chinatown Coalition is counting on BART to address historical displacement through the planning process:

There is a sentiment in the community that BART has a moral and political obligation to give the blocks back to Chinatown, and therefore, the Station Area Plan must set up a system to ensure that what goes on those blocks enhances the Chinatown community and is approved by the Chinatown community (Dyett \& Bhatia, 2010, pp. 17-18).

Government entities, particularly BART, recognize "the mistrust in the Chinatown community...[and] BART is attempting to right past wrongs" (Dyett \& Bhatia, 2010, p. 29).

Overcoming Mistrust In an effort to confront historic mistrust and engagement challenges, the City of Oakland made three distinct efforts to address the concerns of the community. First, the City of Oakland "initiat[ed] the process with a robust outreach program" two full years prior to the start of the official planning process (Asian Health Services, Oakland Chinatown Chamber of Commerce, \& City of Oakland, 2009a, p. 1). The partnership with Asian Health Services, Oakland Chinatown Chamber of Commerce, and Asian Pacific Environmental Network was meant to inform the community, begin visioning, prepare the community for planning, and draft a community platform and guiding principles. It held four well-attended meetings in late 2008 and early 2009 where the community expressed concern about increasing density, gentrification for limitedEnglish speakers and seniors, public safety, and traffic; the need to restore Chinatown as central to the neighborhood was a unifying vision (Asian Health Services, et al., 2009a). 
The partnership also administered a 16 -question survey ${ }^{21}$ to over 1,150

community members, 59\% of whom were residents, in March and April of 2009. When asked to list the three most 'urgent needs,' respondents overwhelmingly ranked safety from crime (53 percent) and employment (50 percent) as top priorities. Housing issues (37 percent), environmental quality (35 percent), access to services (30 percent), and access to parks and open spaces (30 percent) ranked high. Thirty-one percent of survey respondents walked to work and identified improved sidewalks, reduced truck traffic, and improved pedestrian facilities as important issues that the plan could potentially address (Asian Health Services, et al., 2009a).

The results of the survey also show a strong community desire for neighborhood improvements that increase health:

Many of the specific concerns cited have significant impact on community health. Crime and violence (cited by $64 \%$ of the respondents), air pollution (38\%), unsafe public spaces $(32 \%)$, noise $(27 \%)$, and insufficient parks and recreational facilities $(20 \%)$ are conventionally viewed as health hazards. Almost half voiced the desire for additional parks, athletic fields (including space for tai chi) and public indoor recreational facilities.

Almost a third of the respondents have a serious or chronic health condition. It was not surprising, therefore, that $35 \%$ identified the need for additional health and medical services as one of the top three needs for services, and the $38 \%$ are concerned about air pollution. An even larger number identified a need for healthful restaurants.

Other needs can also be viewed through a public health lens. For example, employment opportunities, affordable housing, access to healthful foods, and good transit services also contribute to exercise, balanced household budgets, good diet, and stress reduction that are the building blocks of a healthy, active, and engaged life. (Asian Health Services, et al., 2009a, p. 12)

\footnotetext{
${ }^{21}$ Survey was developed with input of Oakland Chinatown Chamber of Commerce, APEN, HIP, TransForm, and AHS
} 
From the meetings and survey, Nine Guiding Principles ${ }^{22}$ were produced to "translate the community values into preliminary goals and objectives" for the planning process. The final version of these are provided in full in Appendix $\mathrm{C}$ and are summarized below:

1. Public Safety - safe public spaces and streets; increased police services

2. Jobs -number and quality for community profile; job training

3. Housing - affordable housing; potential displacement; healthful homes

4. Community Facilities \& Open Space - preserve/improve access, number and quality of parks, recreations centers, libraries, and open space

5. Business - new healthy food options, attract community needed businesses

6. Transportation - preserve/strengthen transit and walkability by reducing auto, expanding modes, and ensuring pedestrian safety; address parking needs

7. Cultural Preservation - public services and spaces should reflect cultural history of Chinatown

8. Community Engagement - opportunities for effective participation and monitoring of plan

9. Health - improve air quality; increase health/medical services; clean up air, soil and water including trash; reduce noise levels; clean public spaces; provide public bathrooms and trash containers; anti-liter campaigns. (Asian Health Services, et al., 2009a, pp. 13-16).

With slight variations, the Principles continued to inform the planning process through several community input avenues, served as a starting document for Great Communities Collaborative work spearheaded by TransForm, and became the starting point in for building the HIA scope and analysis.

A second way in which the City of Oakland attempted to overcome historical mistrust in Chinatown was by initiating a robust citizen advisory committee at the beginning of the official planning process. Named the Community Stakeholder Group (CSG), a representative of one CBO described the convening and makeup of the CSG in detail:

${ }^{22}$ The Nine Guiding Principles continued to undergo revision and ended up as 10 'Goals'; for simplicity, I refer to them as 'Principles' throughout the analysis. 
There is a history that is there... a high level of distrust. Some shake-ups in the beginning [were] required [so] the community could push their way into the process a little more than they were being involved. But the city responded and we have to give [senior planner] credit for that - for carrying this process forward in a manner that was much more meaningful to the community and engaging the community.

There is always a citizens advisory committee, but it is rarely as diverse as this one is. We advocated early on that these different groups be given a seat at the table when they were putting together the process because we felt they would be essential in producing a good plan. Typically, the CSG might consist of local architects, developers, maybe some chairs of neighborhood organizations and that would probably be about it, if that much. Because [CBOs] were able to get in early on and say we really need to change these things, I think that helped to transform the overall community engagement. It has resulted in multiple workshops in multiple languages, really catering to the community in ways that have been unsurpassed (LM03, p 9-10).

The CSG is clearly a stakeholder strategy with robust community representation instead of a direct participatory avenue for community input. Yet publicly available CSG meeting minutes suggest that between twenty and thirty people attended ten working meetings over two years; at least one-third of those present represented community-based organizations from the Chinatown Coalition. Additionally, three community workshops and four 'teas' augmented input provided by the CSG.

The third strategic decision made by the City of Oakland to help address historic mistrust was the overall intention to work towards a single preferred plan prior to environmental analysis. Doing so acknowledged that approaching the community for input at the environmental review stage after alternatives were already established was too late for meaningful participation. Instead, the City set out an iterative process where a near-consensus draft Preferred Plan would emerge through feedback and input from the Technical Advisory Group, three workshops, and several neighborhood teas. 


\section{Initiating the HIA}

Given the efforts by the City of Oakland to address historical mistrust with Chinatown through a robust outreach and advisory group effort, the decision to utilize a Health Impact Assessment may seem superfluous. Yet members of the Chinatown Coalition viewed their first HIA as an additional opportunity to sort through and advocate for their community needs. The early engagement process had identified "health" as one of the Principles for the plan; several Chinatown community-based organizations felt that exploring the health aspect further would increase their ability to successfully advocate for a good plan.

Community-driven and advocacy HIAs require a careful process to adequately address a diversity of interests. Interviews suggested this HIA was successful due to the collaborative process that informed its writing. Table 5.1 provides an overview of the actors in the HIA portion of the Lake Merritt case including information about their organization, role in the HIA, and involvement in the planning process outside of the HIA work. It shows that besides the HIA author, Health Impact Partners (HIP), and the facilitator Public Health Law \& Policy (PHLP) ${ }^{23}$, the other four members of the Steering Committee were community-based organizations drawn from the Chinatown Coalition. These organizations all had previous experience and strong commitment to advocacy and organizing the Oakland Chinatown community: Asian-Pacific Environmental Network (APEN) is a grassroots environmental justice organization with climate and housing major campaigns; TransForm is a transportation equity non-profit devoted to community

\footnotetext{
${ }^{23}$ The original grant was awarded to PHLP as a subsidiary of Public Health Institute in 2009; mid-grant, PHLP became an independent entity. In 2012, PHLP rebranded itself as Change Lab Solutions.
} 
Table 5.1 Organization Roles and Characteristics of the Lake Merritt HIA Stakeholder Steering Committee

\begin{tabular}{|c|c|c|c|c|c|c|c|}
\hline & 焉 & 焉 & 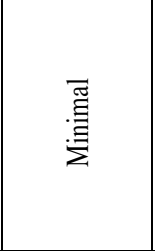 & 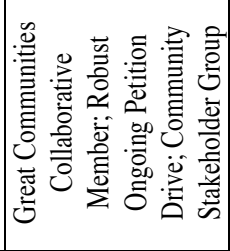 & 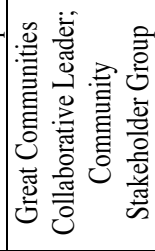 & 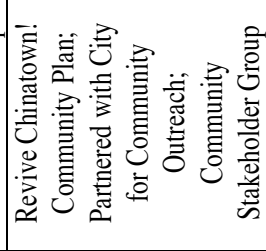 & 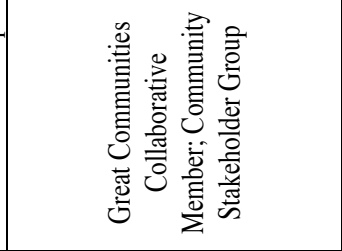 \\
\hline & 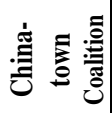 & ¿̊ & 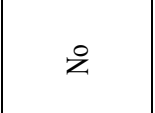 & $\approx$ & 之 & $\stackrel{\Xi}{2}$ & $\stackrel{\Xi}{\sim}$ \\
\hline & 离 & 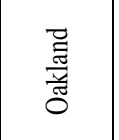 & 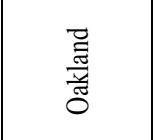 & 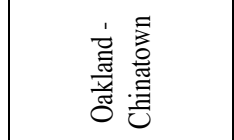 & 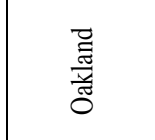 & 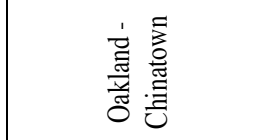 & 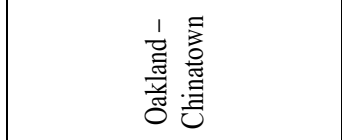 \\
\hline & 嘅 & 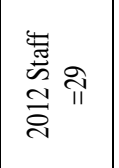 & 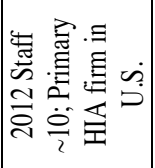 & 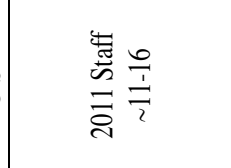 & 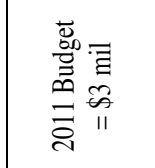 & 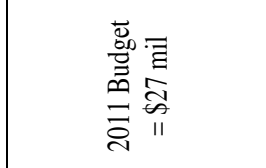 & 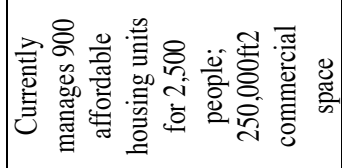 \\
\hline & 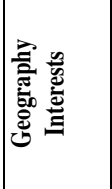 & 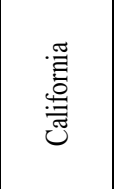 & $\dot{\sim}$ & 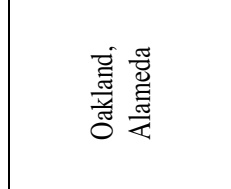 & 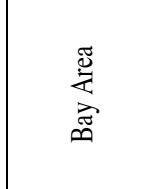 & 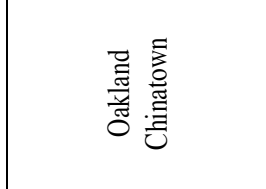 & 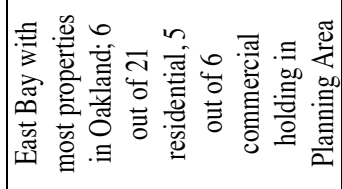 \\
\hline 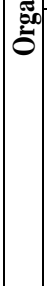 & 䍿 & 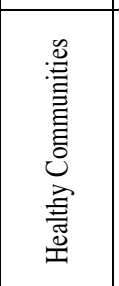 & 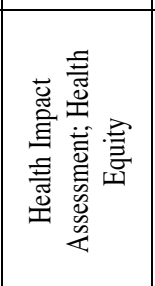 & 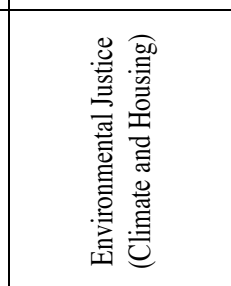 & 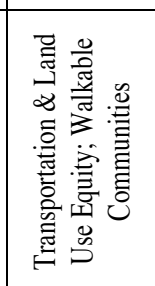 & 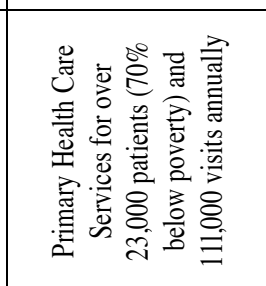 & 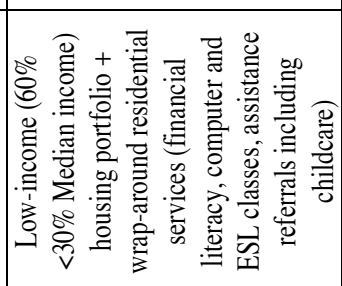 \\
\hline & $\underset{:}{\stackrel{D}{*}}$ & 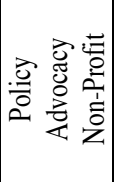 & 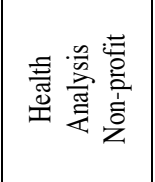 & 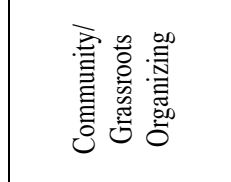 & 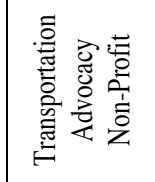 & 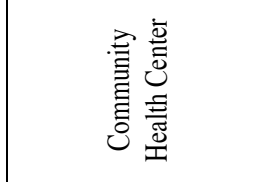 & 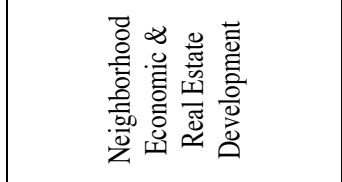 \\
\hline & 猿 & 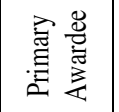 & 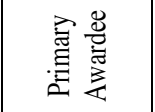 & $\stackrel{\varpi}{2}$ & $\succsim$ & z & z \\
\hline 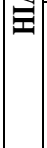 & 䒕 & 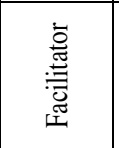 & 屴害总 & 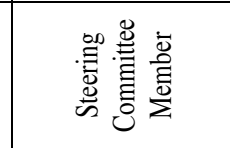 & 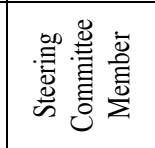 & 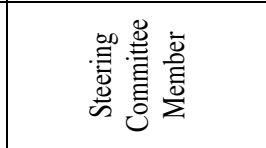 & 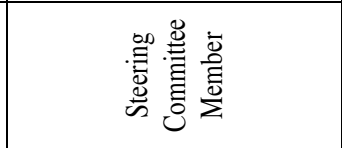 \\
\hline . & 蒙 & 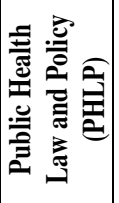 & 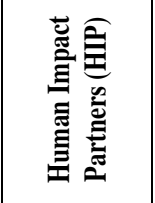 & 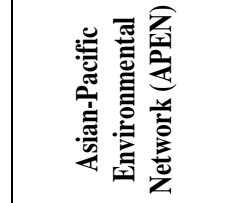 & 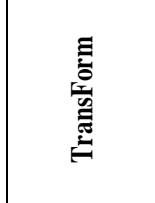 & 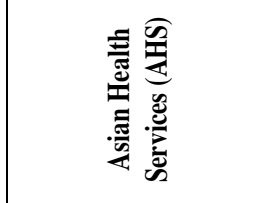 & 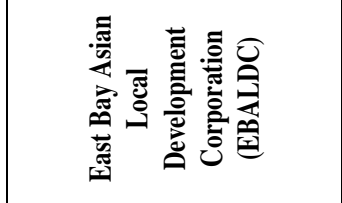 \\
\hline
\end{tabular}


control and improving walking and cycling opportunities; Asian Health Services (AHS) is a community health center providing primary health care services for Chinatown and other East Bay residents living in poverty; and East Bay Asian Local Development Corporation (EBALDC) is a neighborhood economic and real estate development company with a significant low-income housing portfolio committed to providing wraparound residential services.

PHLP, with little direct organizing experience and as the lead on the grant, played the role of convener and facilitator throughout the HIA process. PHLP had identified Round 4 (2009) Federal Transportation Administration's Public Transportation Participation Pilot Program funding as a possibility.

"The goal of the Public Transportation Participation Pilot Program is to get nontraditional audiences engaged in the transportation decision-making process... [PHLP seeks to increase] public health specifically for populations that have to bare chronic disease inequities - a lot of low-income, minority communities. It so happens that in any sort of land-use or technical decision-making processes, those are the kinds of people left out. The [Lake Merritt BART] station is [in] very close proximity to Oakland Chinatown and a community made up of predominantly low-income seniors. So there was a lot of concern about how this was going to impact this community" (LM02, p2).

Working quickly, PHLP and HIP screened the project through a series of informal discussions: they reviewed how the community viewed the plan and health, the context of the target plan, and the potential stakeholders with interests in participating. Together, PHLP and HIP identified key organizations active in Oakland Chinatown land-use decisions:

"We knew the people at HIP and we knew the folks from APEN (Asian Pacific Environmental Network), but we hadn't formally worked together in any capacity. TransForm helped a lot in identifying who the key partners would be because they do a lot of work locally and specifically in Oakland Chinatown.... Frankly, we approached all the community-based-organizations including AHS 
and EBLDC at the very beginning, but you know how timing and proposal processes work - the timing didn't work out" (LM02, p 2).

PHLP and HIP applied for the FTA grant in partnership and with support from APEN and TransForm. Once the FTA grant was awarded and after just one or two meetings, APEN and Transform "made the case for [AHS and EBALDC] because they were stakeholders; they were never intended to be excluded from funding. It was just that they weren't in a position to respond in time to the calls" (LM03, p5) for grant writing. Yet because all had been "working so closely" there was an agreement that "these are the common partners and their voices should be here too" (LM01, p1).

TransForm facilitated funding for AHS and EBLDC to participate through another grant; yet the late addition of the two community-based organizations ended up creating a great deal of duplicate work and cost in the HIA scoping phase.

Before moving onto the scoping phase, it is important to evaluate stakeholders who were not included. All participants of the HIA Steering Committee were asked in interviews to reflect if certain interests or organizations should have been involved. In general, answers reflected satisfaction with those represented at the Steering Committee. Alameda Public Health Department, Oakland Public Schools, and youth groups were mentioned as possible candidates for augmenting the process. Given its partnership with AHS in public outreach, Oakland Chinatown Chamber of Commerce would also have been a reasonable stakeholder. When pushed as to whether or not the HIA should have included representatives of the City of Oakland, Laney College or BART - the three sponsors of the greater planning process - most members of the HIA Steering Committee bristled at the idea of potentially giving up control and advocacy power. 
The HIA field continually struggles how to legitimize the need for HIA. HIP's response to potentially including the large, institutional and governmental stakeholders in the HIA was particularly instructive in understanding the strategic nature of HIA as a parallel process for community groups seeking to engage the planning process as community advocates:

"We were coming in from the outside and deferring to the community groups. I seem to remember they felt that they weren't as satisfied with the City's process, especially early on... I don't really remember them wanting to go with the city process. They wanted to push the city from the outside" (LM01, p 1-2).

Another representative framed it in terms of geography:

"protecting those who were most vulnerable and are dealing with the most exposure to health determinants - proximity to the freeway, low access to affordable housing, and high amounts of traffic. [The Chinatown] neighborhood stood to lose or gain the most from anything. We really wanted to focus on the place that was most sensitive to decisions" (LM03, p 5).

PHLP recalled this strategic decision as a little less ideologically driven and more pragmatic. PHLP reported that the City of Oakland planning department was asked for a letter of support for the initial FTA grant. Support seemed reasonably likely because the City of Oakland was attempting to be more robust in its outreach and the initial RFP for the planning process included a request for an analysis of health impacts. The City of Oakland may have considered an HIA superfluous; expanded outreach efforts through the City sponsored CSG were primarily geared towards the Chinatown community including many of the organizations participating in the HIA. The City of Oakland may have hesitated for fear of the HIA being used as an obstructionist tactic given the strong advocacy groups involved. In the end, the City of Oakland declined to provide a letter of 
support for the grant but eventually came to appreciate and integrate many of the HIA Steering Committee's efforts.

\section{Developing a Scope}

Despite previous relationships and shared interests of the Chinatown Coalition members, the community groups differed in 'language' and priorities; these differences proved particularly challenging in the scoping phase of the HIA as agenda and priorities were set. This sub-section addresses how the group overcame these differences. In doing so, the extent to which community interests were authentically voiced becomes more obvious.

Previous to starting the HIA work, TransForm had played a significant role in facilitating the development of community priorities through its through its Great Community Collaborative ${ }^{24}$ effort. The Great Community Collaborative is a reflection of TransForm's commitment to social justice through both participation and equitable outcomes. Through the Collaborative, TransForm "engages people - particularly lowincome people and people of color - in local land use planning so they can shape future growth and create great communities with good public transportation options" (TransForm, 2012).

TransForm believes that the area around the Lake Merritt BART station holds "strong potential as a new model for a transit-oriented, walkable community." Thus its stated goal was to

\footnotetext{
${ }^{24}$ TransForm is one of five founding organizations of the Great Community Collaborative which acts as a progressive Bay Area transportation and land use coalition. The Collaborative works by identifying specific areas ripe for TOD development; there have been 25 such areas identified thus far. TransForm currently manages three of eleven specific efforts including the Lake Merritt BART Station Area Plan Collaborative.
} 
maximize community involvement by helping local stakeholders identify their own community needs and assets, helping them to understand the potential of transit oriented development, and help to facilitate as much local resident, merchant and worker participation in the planning process as possible (TransForm, 2012).

Through the Great Communities Collaborative, TransForm was able to anticipate the plan and engage the community very early.

"When we found out that the local MPO [metropolitan planning organization] was having a round of station area planning grant opportunities made available and that the City of Oakland had applied for one [for Lake Merritt], we started to build awareness in the community that this might eventually happen. From the very beginning, even before this process was awarded, we were anticipating it happening because it is such a terrific opportunity and super-ripe for redevelopment. As soon as the grant was awarded, we encouraged the City and neighborhood groups to apply for another grant through Caltrans to provide deeper community outreach. [That sub-grant] was a small amount, but it was enough to help fund community groups to get engaged in this greater planning process. We helped pair groups that typically aren't involved in the planning processes... and started to create a sort of partnership between local community groups that were already working on this effort. That turned into a survey and strategy to more deeply engage the community early on" (LM03, p2-3).

Although TransForm had never participated in an HIA prior to the Lake Merritt

HIA, TransForm decided early on that a health lens could be helpful in translating land-

use issues for the community:

"Before we had an opportunity to do the HIA, we brought in HIP to help make the connection for the community so they could understand what was at stake... help the community understand that some of the problems they were grappling with had their root cause in land-use decisions. It helped them understand the value of the planning process overall" (LM03, p3).

This set the stage for shared learning and language during the HIA scoping phase as the stakeholders attempted decide which aspects of health were most important to discuss.

Other Steering Committee members were also deeply involved in defining community priorities prior to the target plan and HIA. For example, Asian Health Services (AHS), a federally qualified community health center specializing in health care 
provision to the immigrant and refugee Asian and Pacific Islander community in Oakland's Chinatown, had already partnered with the City of Oakland at least two times to help understand the health interests of its low-income clients. AHS' partnership in community outreach was particularly important because most of its clients ( 85 percent) speak one of eight different non-English languages as a primary language (Asian Health Services, 2010).

AHS also has a long history in advocacy for the population it serves and recognizes that "reaching out to bring in those needing care, educating the community, and advocating for equal access to rights [is] just as important as treating patients" (Asian Health Services, 2006, p. 7). This advocacy role has taken many forms over the years including two area initiatives: Revive Chinatown! and a community engagement process prior to the official launch of the Station Area Plan.

Revive Chinatown! was a pedestrian safety plan that started in reaction to a personal tragedy in 2001 when a former AHS executive director's elderly father was killed crossing the street in Chinatown. This incident was galvanizing because it reflected a larger trend of high pedestrian-vehicle accidents; from 1998 to 2002, there were 50 incidents in the neighborhood (City of Oakland, 2004, p. 33). Through extensive outreach and citizen participation, the community identified the most dangerous intersections in Chinatown and perceived reasons for the danger. This resulted in six short-term pedestrian improvements: scrambled crosswalks allowing for diagonal crossing, pedestrian lighting, pedestrian countdown signals, expanded sidewalk corners/bulbs especially at the scrambled crosswalks, bilingual signage, and the addition 
of bike racks and trash receptacles throughout Chinatown (Asian Health Services, 2006; City of Oakland, 2004).

AHS's extended its relationship with the City of Oakland and Oakland Chinatown Chamber of Commerce to engage the community prior to the official launch of the LMBSA planning activities by reaching out to Chinatown residents and businesses, churches, youth groups, schools, tai chi exercisers, and other community based organizations and non-profits such as APEN. Other institutional stakeholders such as BART, AC Transit, Laney College, Oakland Museum and Oakland Library were consulted at various points. Many local policy non-profits - PolicyLink, TransForm, HIP, Reconnecting America - provided technical expertise when required; the University of California Berkeley Center for Community Innovation partnered with AHS to provide finer spatial demographics for Chinatown (Asian Health Services, Oakland Chinatown Chamber of Commerce, \& City of Oakland, 2009b). The resulting report was quoted several times in the HIA to frame the analysis in community-defined priorities.

APEN also had previous experience with organizing the Chinatown community before joining the HIA effort. APEN “strive[s] to build grassroots organizations that will improve the health, well-being and political strength of our communities" (APEN, 2008). APEN also runs the Asian American Climate Coalition which states that 'healthy, green, just communities' are created through 'healthy, affordable, culturally vibrant neighborhoods' that have clean air, green living-wage jobs, and an engaged community (APEN, 2010).

APEN's two main organizing efforts reflect their commitment to environmental justice. The first, known as the Laotian Organizing Project, started in the mid-1990s and 
addresses environmental justice and housing issues in Richmond, CA among Laotian immigrants; it has also been instrumental in pressuring the Richmond Chevron refinery to addresses pollution and safety through legal and political action. The second, Power in Asians Organizing (PAO), began in 2002 to address housing justice for the various immigrant and low-income Asian communities in Oakland.

APEN's participation in the HIA was meant to augment PAO's work to ensure that transit oriented development (TOD) 'renewal' efforts in Oakland's Chinatown reflected the vision of the current Asian community and that redevelopment occurred in an equitable fashion. As APEN's Vivian Huang wrote

The push to develop housing, jobs, and neighborhoods near transit is an opportunity to create green, walkable, transit-friendly communities that will reduce car usage and greenhouse gas emissions. However, development without equity can result in the displacement of core transit users, such as renters and lowincome households... Given the history of displacement, there is a lot of fear in Chinatown of being excluded from the decision-making during this round of development. (2011, pp. 64-65)

APEN's early efforts to address this fear included partnering with the City of Oakland, AHS, and EBALDC prior to the HIA process to organize community members through surveys and workshops (Huang, 2011). APEN was also active in various city sponsored stakeholder group activities throughout the planning process; it started a petition drive to elevate community interests and needs that garnered 1,400 signatures as the Draft Plan went before planning and city council.

EBALDC rounded out the Steering Committee as a local community development corporation whose target population is the Asian Pacific Islander community and diverse low-income populations in the Oakland area. As of 2009, the population served by EBALDC was 45 percent African American and 40 percent Asian/Pacific Islander; 60 
percent of their clients are extremely and 25 percent very low income (EBALDC, 2010).

EBALDC has a long history in Oakland's Chinatown. Their first project in 1975

revitalized a Chinatown warehouse into the Asian Resource Center. Today EBALDC

manages a large real estate portfolio that includes both commercial and residential rental properties. Through their residential portfolio, EBALDC houses at least 2500 people in varied situations from single-room-occupancy hotels to single-family housing. EBALDC assists thousands more through community services and outreach including the ongoing sponsorship of the Asian Resource Gallery, financial literacy programs, and residential services such as assistance referrals programs and computer and ESL courses (EBALDC, 2010).

Although EBALDC was not written into the initial HIA grant proposal, as a major property owner and community services provider in the planning area and a member of the Chinatown Coalition, it quickly became clear that the organization should be included in health discussions. EBALDC hoped to see a plan that created a "place where people choose to live and have the ability to afford to live regardless of their economic condition." The organization strongly felt that "the plan should provide the kind of cultural, business, public, and educational amenities that would make people want to live here' (Huang, 2011, p. 65).

Each community-based organization joining HIP and PHLP on the HIA Steering Committee has a clear and direct link to social justice and to the Chinatown Coalition. The expression of this commitment to social justice, however, differs by organization. Figure 5.3 provides more detail of the Chinatown Coalition by identifying each 


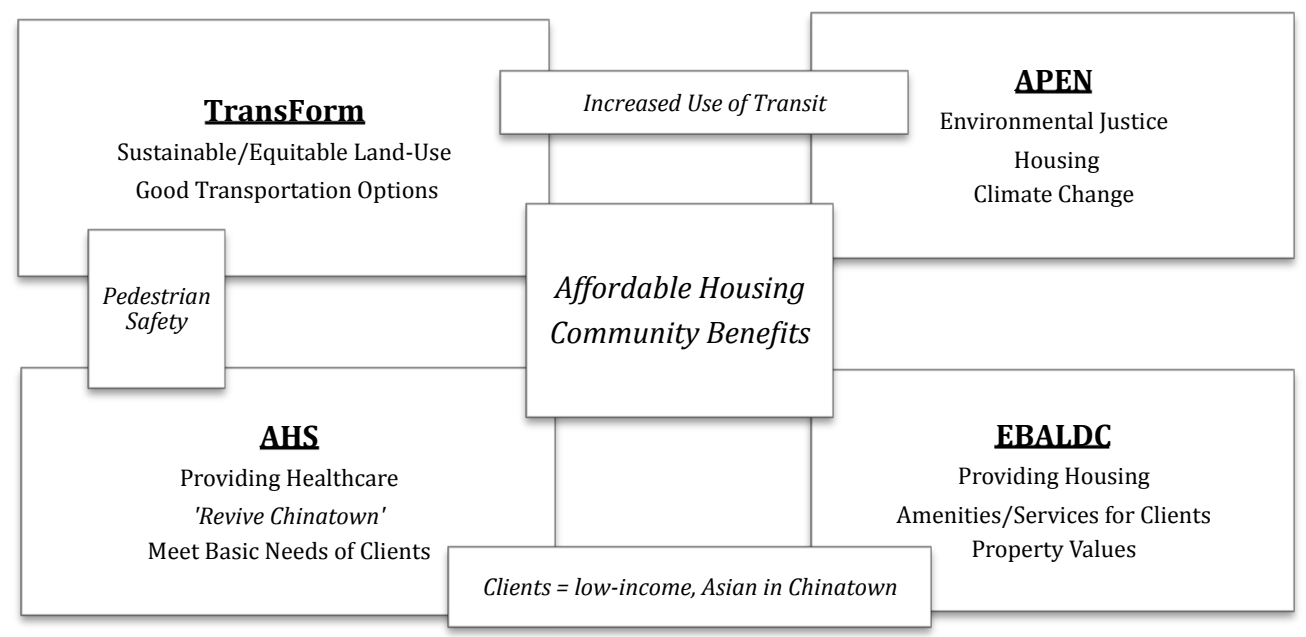

Figure 5.3 Interest Diagram of Organizations Participating in HIA Steering Committee

organization's primary purposes and areas where interests overlap. When taken as a group, interests are diverse: land-use, transportation, environment, healthcare, property, and housing; yet clear shared interests exist. These shared interests were clear to each participant and in many cases represented past partnerships.

Social justice brought the group together, but would it be enough to hold the minicoalition together through the HIA scoping phase? Interviews with each organization suggested that the diversity of advocacy positions and expertise resulted in challenges in terms of time, language, and advocacy priorities during scoping. The "reality is we didn't have enough [time or resources] to do everything, but scoping helped" sort through everyone's positions, explain the connection to health, and narrow the health pathways considered (LM06, p 2). Yet most members of the HIA Steering Committee "were convinced that [scoping] took too long and ate into the overall budget" (LM03, p 4). HIP, an organization that specializes in HIAs and has years of experiences in HIA, stated that scoping took 'longer than most.' 
The time allotted for scoping in the initial work plan was one month; PHLP reported that it took closer to six months:

"[Scoping] took a lot of time. It turned out to be probably the most challenging piece of the HIA. All the partners were approaching it from their advocacy priorities. That is what we wanted. We wanted the group to have a fuller representation of the issues. But then again, we had all these constraints: time, budget, and data. Not only that, was this an appropriate process to be talking about some of the priorities? Maybe not, maybe somewhere down the road. People came with what people came with" (LM02, p 5).

The Principles that everyone had already invested so much time in defining turned out to be a double-edged sword. It served as a baseline document defining potential priorities, but it was difficult for the various representatives to narrow priorities further.

"Because I think the community had already started with those guiding principles and there were a lot of them, so they were all really eager to continue with what they had already started. It totally makes sense. They had already done this process to hone in on their priorities and then for an HIA, we didn't have enough budget to analyze all of them. It was a longer process of narrowing done what we would look at in the HIA" (LM01, p 2).

Another reason given for the extended scoping period was that adding AHS and EBALDC triggered a 'restart' of sorts. Everyone agreed that adding the two groups was appropriate and needed. Yet, the addition of the direct-service providers after a couple of meetings understandably changed the nature of the scoping conversation as the two new organizations grappled with what they wanted from the process. It was difficult to narrow down priorities "with the first group - the funded partners - and then the new ones came on and we started over. It was really hard" (LM01, p 2).

One reason it was hard, was the diversity of interests offered a lot of opportunities for shared interests but made it difficult to focus.

"With enough imagination and passion, you can connect health to everything. Unfortunately, we didn't have the capacity to do everything. We had to narrow 
down the focus to the most important issues to be addressed.... There was a lot of 'how do we use this HIA to further or make sure our concerns are being addressed' in all of the different categories. That was the cause for some tension." (LM03, p 4).

The tension from using health to address different advocacy positions was exacerbated by different academic and professional backgrounds: environmental science, medical provision, housing and real estate, transportation and community development, community health, and environmental planning. None of the community members had formal public health background or expertise as a trained planner; yet each person was being asked to reframe their positions in health language.

"The other piece that I think that made scoping much lengthier than we thought was that none of us had a public health background except for HIP; they were the only scientists and they were the only ones who had a clear understanding of the pathways and how indicators related to health outcomes and how that related to vulnerable populations. For the folks at the table, it was a learning process. Built into the scoping process was not just identifying what we wanted to analyze and prioritizing that, but also building up peoples' understanding of [public health outcomes and pathways]. It took a couple of tries to get it to the point where people were 'oh, ok.' Even me. It was a matter of translating for ourselves what it meant before we could decide what we wanted to do" (LM02, p 5).

How did the HIA Steering Committee sort through all of this? Interviews suggest that scoping proceeded as verbal discussions of potential health pathways for each of the Nine Guiding Principles.

"The visioning that [the community] did - they identified nine priorities for this area - they wanted the LM station area plan to be consistent with. As you can imagine, those nine priorities are really health related: they wanted to preserve their culture, wanted pedestrian safety, affordable housing, social services - that kind of thing. Because we already had all of this vision summarized in a document - they prepared a report - we decided to maximize that, to use that as a jumping off point. So, that's what we did. Very early on, together with the group, we prioritized which one of the 10 vision elements they felt were the most critical. Just saying that, you can probably imagine what sort of conversations were there. All Nine were very important" (LM02, p 2-3). 
Through group deliberation, decisions were made about which pathways were most important and relevant to advocacy efforts: public safety, transportation, economic development, housing, and community facilities and open space. "Something that everyone agreed upon right away was safety. Safety not just from crime or perceived crime, but safety from a pedestrian standpoint - there are a lot of people walking around Lake Merritt, Oakland-Chinatown... just a lot of traffic. They wanted to preserve the people walking around but wanted to get rid of all the accidents" (LM02, p 3). The group agreed to keep transportation as a separate pathway to deal with some design features such one-way vs. two-way streets; angled parking; and bike path placement.

Economic development encompassed both employment and business concerns. "Access to living wage jobs - I mean it is an economic issue that quickly turns into health issue if you just dig a little" (LM03, p 3). But

"no one knows what it looks like [in a station area plan setting]. There doesn't seem to be data for some of the things that people wanted. Like people wanted to know what kind of jobs would come in and would they pay benefits and would they pay a living wage. And that, you just can't - there is no way to know, right?" (LM02, p 3).

Scoping business through the HIA was also difficult. It quickly became apparent that everyone was concerned about community appropriate business.

"At the onset, there were people really concerned about preserving local, smallbusiness owners serving existing clientele and not having a bunch of national retailers come in a replace the small-business owners. Then there was a discussion about food; there has been a lot of media attention of food deserts and lack of grocery stores in low-income communities. To a certain extent, that doesn't hold true for Oakland because there isn't a grocery store, but there are a lot of small-business shops that are culturally appropriate shops" (LM02, p 3). 
While the plan clearly would influence the direction of business, direct links between the HIA, the plan, and outcomes was tenuous; most agreed this would need to be tabled. Instead, the group decided to focus on employment.

Access to open space and thus passive and active recreation was a straightforward pathway for most members of the HIA Steering Committee. Everyone understood that "there is already too much competition over existing space; to bring more folks in [due to increasing density] would make achieving recreation that much more difficult" (LM03, p 3). The group wanted to enhance residents' experiences by emphasizing active space instead of the long, narrow 'public' spaces of the proposed plan. There was some tension about the extent to which HIA could leverage community services under community facilities.

"Services was kind of like the one thing were everyone in general had an idea that 'sure, we want complete services.' But what did complete services really mean?...There was this whole discussion of what sort of services that we want to keep given that the station area plan is probably going to help make OaklandChinatown a destination as opposed to just a neighborhood. So, there was a lot of tension about what that would look like" (LM02, p 3).

After perhaps general safety, affordable housing was the single-most agreed upon shared interest. "Everything is pointing to this [area] being at high risk for gentrification for this particular station and this particular plan" (LM02, p 10). The group hoped the HIA and public health evidence could bolster their advocacy position that the city needed to buffer the current community from gentrifying pressures. Despite widespread agreement that housing mix, including deeply affordable housing, was a shared concern, it became clear in scoping meetings that it was problematic in similar ways to jobs, businesses, and services. 
"I'm most nervous about the affordable housing issue just because at this stage of the planning process, I can't tell by what means we are going to have to have a monitoring plan that delegates who watches and when" (LM02, p 10)

The possibility of a community benefits mechanism surfaced when discussing increased density and housing. TransForm and APEN were aggressively pursuing (in and out of the HIA) the inclusion of a community benefits fund tied to the loosening of building height restrictions. The intention was "to call for more affordable housing as a part" of the community benefits mechanism. To that end, these advocacy groups felt the

"HIA is going to help us make that fight and will call for community benefits that are related to health that can only be mitigated through the heights because there is no other opportunity" to capture and redistribute the value added by increased heights (LM03, p 7).

Notably, cultural preservation was a challenging priority to screen in as a heath pathway. "It was a very important issue for the community as a whole for the community to hold onto [cultural character]" (LM03, p 4). Eventually, everyone agreed to it using it as an overarching concern. Similarly, the group was very committed to expanding engagement opportunities to the community, but saw few avenues within the HIA as a response to the plan for increasing engagement. Instead, the group saw the HIA as one of many avenues to "maximize the different community engagement processes that were going to be kicked off by virtue of the city's own planning process" (LM02, p 2).

As a starting document, the Principles allowed the group to build upon previous work and relationships. It provided a safe space to grapple with public health concepts, shared values, and how health pathways could be used to articulate positions. It allowed the group to "really turn the screws and tighten up our argument and concerns to define 
the scope in such a way that reflected things that were comprehensive enough to address concerns without overextending the potential reach and effect of an HIA" (LM03, p 4).

Some of the HIA success can be attributed to treating the scoping step as a collaborative process. PHLP entered the process cognizant of their role "more as a facilitator... We came to the project with this idea that we really want to come out of this with some policy tools that can help mitigate health issues and they did come up. But we wanted to be the people who facilitated" (LM02, p 4). This allowed PHLP to appropriately address current and historical positions with each organization through "a lot of massaging, a lot of education, a lot of conversations about the materials as they were being produced” (LM03, p 4). PHLP “did a lot of back preparation and strategic planning with HIP. A lot of the language was scientific and diagrams were confusing. We had a lot of conversations between our two organizations on how to present the information" (LM02, p 5). PHLP often utilized specific facilitation tools in both group and one-on-one settings to help the group reach consensus:

"I think it is safe to say that Oakland has had a lot of very challenging equity stuff that has historically surrounded redevelopment and BART. There is a lot of baggage in Oakland and rightfully so. And we knew that and we wanted to be respectful of that and we wanted to respect the consensus. We wanted to arrive at a consensus. That took a while. It took a lot of group meetings; it took a lot of one-on-one meetings with each of the parties. And sometimes you have staff from each of the organizations participating and there was at some point in time, we had needed to call on the leadership of the different organizations to sit down and weigh in. And obviously, we got through it and I think the coalition is stronger for it" (LM02, p 5).

Group meetings during the scoping step consisted of "active discussion" where the "outcome was agreement" (LM05, p 2). At first, "people were struggling to feel heard. It took a while to help people understand that your priority related to their priority 
and it wasn't "we are framing it one way and marginalizing yours"” (LM02, p 5). Over time, things shifted. "Even though it was kind of hard to hone in on priorities, the whole experience was really worthwhile because while we were doing that, our relationships in the group were able to be developed" (LM01, p 2). Later, as analysis decisions were being made, "everyone felt that we were united at that point. We had the same priorities. Everyone trusted each other by then" (LM01, p 4). Through scoping, both shared learning and trust had developed.

In the end, the efforts to facilitate consensus were successful. The community organizations “made sure [scoping] matched our community members' interests ... and there was a lot of consensus among the three [Chinatown] community organizations (APEN, AHS, EBALC) about priorities" (LM06, p 2). Every person interviewed on the HIA Steering committee agreed with the statement that scoping decisions were arrived at 'through consensus. As happens with many consensus-based processes, the time needed to arrive at such a point was lengthy. PHLP specifically noted that "if I had to do this again, I would have a much more realistic perception of what scoping really does, especially in terms of time and just giving people the time that they need to sit with this" (LM02, p 5).

The analysis step of the HIA was primarily performed by HIP with input and review from various HIA Steering Committee members as needed. "HIP did all the technical pieces, data collection and it is nicely laid out in the HIA framework. We used a lot of census, information that the city had already shared through their existing conditions report. We did a lot of connecting with the literature review" (LM02, p 5). 
Even with the lengthy scoping process, HIP started cutting out pieces due to

resource constraints:

"We had a couple different rounds of narrowing down and then HIP internally had another round - there was still too many indicators - discussing what data was available and feasibility technically and budget. And then we shared what that process was with the group. And then we narrowed it down even more because then we realized we had run out of a lot of budget from the scoping process because it had taken longer than we thought. So we went back to the Steering Committee and we talked about really what are the highest priorities and narrowed down even more. There was a lot of narrowing down!" (LM01, p 4).

The analysis stage was multi-faceted and resulted in multiple products (see Figure

3.1). These interim health products were provided to the City of Oakland early in the process at points in time identified by City planners as optimal for influence. HIA Steering Committee members requested a couple of meetings expecting resistance; instead, they were met with sincere consideration by the planning staff:

"We called [city planners] up. It took a couple of tries to get them. We met and said "we have this HIA framework and it is ready to go....How can we help you?" is how we framed it. The first conversation was a little bit like scoping. We sat down with [the principle planner] and his staff and talked about what an HIA was and what we were really trying to measure. Things you would measure anyways - walkability and affordable housing - social determinants of health - but also very hot issues.... The [principle planner] said "I'm really glad we had this conversation because it has helped me understand what you are trying to do and I feel a little bit of trust of the process" - something like that. He was very frank and I was really surprised that he had just articulated that. Him saying that legitimized what we were doing.

So the next [meeting], it was actually to discuss how we could plug into the planning process, and they immediately whipped out the schedule pointing to it. "At this point, you can analyze this and at this point, that," suggesting or inferring that each time we submitted health impacts, they would tweak the plan. It unfolded in a very easy way that we had not expected it to unfold. This, being a very political process, I was the one - the HIP representative and myself - we were the ones who were not trusting that they were going to do this. It seemed so easy - it did. They ended up having us do it. It unfolded in a really nice way (LM02, p7)." 


\section{Community Interests within the HIA}

Due to its prominent role in guiding the HIA scoping process, the content analysis procedure was organized by Guiding Principle ${ }^{25}$. The results of the content analysis of the HIA document are presented below. Table 5.2 lists each Principle and, if appropriate, the corresponding Determinant of Health identified in the HIA.

Community Engagement Even though the HIA is clearly supportive of community engagement, this principle is integrated throughout the report instead of being treated as a health pathway ${ }^{26}$. The 25 quotes within the HIA that discuss engagement

Table 5.2 Code Count of Guiding Principles within the Lake Merritt HIA Document

\begin{tabular}{|c|c|c|c|}
\hline $\begin{array}{l}\text { Principle/Planning } \\
\text { Goal }\end{array}$ & $\begin{array}{l}\text { Primary HIA } \\
\text { Determinant of } \\
\text { Health }\end{array}$ & Key Words/Concepts for Coding & $\begin{array}{l}\text { Count of } \\
\text { Quote } \\
\text { Segments }\end{array}$ \\
\hline $\begin{array}{l}\text { Community } \\
\text { Engagement }\end{array}$ & & $\begin{array}{l}\text { community, engagement, participation, } \\
\text { tea(s) }\end{array}$ & 25 \\
\hline Public Safety & Public Safety & $\begin{array}{l}\text { (un)safe, crime, lighting, signage, } \\
\text { sidewalk, police, pedestrian safety }\end{array}$ & 160 \\
\hline Business & $\begin{array}{l}\text { Economic } \\
\text { Development }\end{array}$ & business(s), retail, merchants, zoning & 148 \\
\hline Jobs & $\begin{array}{l}\text { Economic } \\
\text { Development }\end{array}$ & $\begin{array}{l}\text { job(s), (un)employment, wage, labor, } \\
\text { income, hire, training }\end{array}$ & 145 \\
\hline Housing & Housing & $\begin{array}{l}\text { house(ing), home, gentrification, rental, } \\
\text { affordable }\end{array}$ & 139 \\
\hline $\begin{array}{l}\text { Community Facilities } \\
\text { and Open Space }\end{array}$ & $\begin{array}{l}\text { Parks and Open } \\
\text { Space }\end{array}$ & $\operatorname{park}(\mathrm{s})$, recreation(al), space, facility(ies) & 141 \\
\hline Transportation & Transportation & $\begin{array}{l}\text { transportation, transit, traffic, vehicle(s), } \\
\text { pedestrian(s), cyclist(s), intersection, } \\
\text { commute, air pollution }\end{array}$ & 373 \\
\hline $\begin{array}{l}\text { Community \& } \\
\text { Cultural Anchor and } \\
\text { Regional Destination }\end{array}$ & & $\begin{array}{l}\text { cultural(al), anchor, regional, destination, } \\
\text { historic, signage, mixed-use, heritage }\end{array}$ & 84 \\
\hline Health & & $\mathrm{N} / \mathrm{A}$ & $\mathrm{N} / \mathrm{A}$ \\
\hline $\begin{array}{l}\text { Redevelopment of Key } \\
\text { Publicly Owned Blocks } \\
\text { Near Bart }\end{array}$ & & $\begin{array}{l}\text { block(s), Madison Square Park, } \\
\text { MTC/ABAG, BART plaza }\end{array}$ & \\
\hline $\begin{array}{l}\text { Green and Sustainable } \\
\text { Urban Design }\end{array}$ & & $\begin{array}{l}\text { design, green, mixed use, sustainable, } \\
\text { activate, eyes, gateway }\end{array}$ & 40 \\
\hline
\end{tabular}

${ }^{25}$ There were multiple versions of Guiding Principles, HIA and Planning documents available for content analysis. The relationship between versions and types of documents and the rational behind document chosen for content analysis can be found in Chapter 3 and Figure 3.1.

${ }^{26}$ Two notable exceptions include explanations of how access to transportation and cultural amenities help individuals participate in their community and lead to better health. 
often utilize information from past community engagement efforts including the community engagement process initiated by the City of Oakland. There are nine subsections within the HIA devoted to "Community Perspectives" that highlight the wishes of the community as ascertained through community 'teas' during the City of Oakland's engagement process. In this respect, the HIA document meets the goal of 'ensuring opportunities for effective community participation by all stakeholders' by transparently addressing community concerns.

Public Safety The 160 segments addressing public safety is diverse but can be largely divided into two categories consistent with community goals: creating a safe environment by addressing pedestrian improvements and crime reduction. The Chinatown community holds historic pedestrian safety concerns; these include reducing auto-pedestrian collisions and maintaining open and safe public space to be utilized for activities such as Tai Chi. Current pedestrian conditions are documented through collisions and injuries (fatal and non-fatal). There is also detailed discussion about the way various environmental design of transportation facilities (roads, sidewalks, crosswalks), lighting, and signage affects health. The HIA appropriately notes that some design features, such as one-way streets, have mixed track records within the literature. Finally, the HIA weighs in with specific pedestrian recommendations for eight intersections.

There is also an overarching concern about safety from crime within the neighborhood Public Safety determinant of health. Similar, brief, treatment of public safety also occurs in the housing, open-space, and economic development sections. Multi-directional safety impacts associated with gentrification appear in the housing 
section. Design issues of individual parks and the health promoting aspects of a vibrant and culturally appropriate commercial district including signage are discussed. Current crime rates are mapped and linked to current conditions of land-use and transportation within the planning area. The HIA also describes the elements of Crime Prevention through Environmental Design and how such design principles interact with both health and the planning area.

The HIA stops short of unique recommendations for public safety due to time and resource limits. Instead it quotes the recommendations generated by AHS's community engagement process: create safer public spaces; promote safer streets; improve community police services; and include violence prevention programs and policies.

Business and Jobs These two categories are addressed together under the heading "Economic Development" in the HIA. The HIA takes the approach that business is an employment engine and does so by linking income to wages, relating the risks of unemployment, arguing for a living wage with benefits including sick pay and health insurance, and showing that income from employment constrains housing and transportation choices. The focus on jobs is also apparent in a lengthy discussion of current area employers and resident education levels. It identifies desirable fast growing industries and occupations for the area and spends considerable space with tables listing the wage, educational needs, and training opportunities needed to support well-paying jobs for local residents ${ }^{27}$. The HIA details the role of both green ${ }^{28}$ and small, independent businesses in expanding job opportunities appropriate for local residents.

\footnotetext{
${ }^{27}$ Over six pages of the HIA are devoted to various tables relating employment and occupation conditions and opportunities. For consistency, the content of these tables are not included in the content analysis count.
} 
The HIA also documents the potential for business to create a safer neighborhood by 'activating' the street through increased pedestrian traffic. It focuses on culturally appropriate and proximal close businesses - in this case Asian/Chinese language business - as such businesses provide unique social resources and thus create social cohesion. Labeling business in terms of activating the street and providing culturally appropriate services as health pathways is directly in line with the community formulated Principle of Business. The only HIA data collection effort - in the form of data of a business inventory in four sub-sections of the area - was used to gauge culturally specific businesses through signage. The results of that survey are presented in greater detail in Appendix $\mathrm{D}^{29}$ of the HIA.

Housing The urban health literature speaks of two ways in which housing can affect health: residence as a spatial determinant of access to resources and/or exposure to health risks; and housing costs as a significant portion of the household budget constraining other health-promoting resource choices. With 139 quotes, the HIA document mirrors these themes in the treatment of housing, paying close attention to the tradeoffs that development can bring to a neighborhood where many of the residents should be considered vulnerable due to their race, income, or both. Most of the links between affordable housing and health focus on gentrification, documenting planning area conditions of low rents and home-ownership rates.

\footnotetext{
28 'Green' is under the Jobs header in the Guiding Principles. In the HIA document, 'green' is consistently applied as 'green businesses' but in the context of job creation.

${ }^{29}$ Content analysis was performed only on the main text of the HIA document; yet the presence of an appendix devoted to expanding the information base about a specific community Principle is further evidence that the HIA was attempting to address community concerns.
} 
The HIA also addresses overcrowding even though the literature separates density from overcrowding and further suggests that density levels in the U.S. - even the densest urban areas - do not warrant concern in terms of health. Interviews suggested the overcrowding issue was addressed in the HIA because there was community resistance for increased density in Chinatown due to overcrowding fears. In all other respects, recommendations in the HIA regarding housing are largely consistent with community concerns.

Housing is also addressed in other sections. Within the transportation section, the HIA repeatedly documents the relationship(s) between proximity to roads and exposure to air pollutants, noting that the most vulnerable - those who have the least ability to pay - are disproportionately clustered near freeways and highways ${ }^{30}$. It also notes that residence and transportation are linked to health; the closer home is to work or the bus stop, the more likely a resident will walk, take transit, and ultimately reduce greenhouse gas emissions. Finally, it notes that proximity of housing to health-promoting resources such as grocery stores and cultural amenities can greatly influence health behavior.

Community Facilities and Open Space At least 141 quote segments address community facilities and open space by clearly advocating for increasing both the quantity and quality of park and open space accessible to residents. It does so by linking park and open space to physical activity; documenting health effects of social cohesion from gathering in both green space and community centers; and describing environmental health issues including the psychological effects of green space, long-standing environmental justice issues of disparities in available space, and impacts of climate

\footnotetext{
${ }^{30}$ The HIA is largely silent on issues of housing quality standards including that of indoor air-quality.
} 
change. The section on public safety also addresses open space through documenting how well designed public space can facilitate social cohesion and inhibit social deviance.

Transportation Health impacts related to transportation are the largest topic in the HIA; 373 quote segments - more than twice that of any other health principle - are devoted to the subject. Three-fourths of the quotes are found within the determinant of health section labeled 'Transportation,' and most address the pedestrian, bicycle, and traffic concerns voiced in the Transportation Principles. The HIA details how walking, biking, and transit use lead to increased activity levels and thus decreased cardiovascular risk; other health determinant pathways associated with alternative modes of transportation mentioned include increased social cohesion and the household income effect of a less costly mode. Current conditions of various transportation facilities for all modes are provided; various data describing mode split within the planning area and/or Oakland are also presented. Some quotes connect transportation modes and their effects on safety, housing, and park access. For instance, pedestrian oriented design and volume plays a prominent role in discussions of public safety and open space. A few quotes also address air-quality concerns - something addressed under 'health' in the Nine Principles document.

Historic knowledge and advocacy of the HIA steering organizations are reflected in both the detail and content of the impacts and recommendation portion of the Transportation section. AHS had previously performed extensive survey work regarding pedestrian safety, and TransForm, as an alternative transportation advocacy group, was prepared with specific bicycle design approaches. The HIA addresses proposed design options for eight specific intersections with high collision and injury rates, and it 
recommends a page-long list of general transportation design principles that are health promoting. The HIA relists transportation related recommendations from the AHS Community Engagement Report and from Merchant and Family Tea outreach exercises.

Community and Cultural Anchor and Regional Destination In many ways, the HIA's treatment of the planning area as a cultural anchor and regional destination is sparse; only 84 quotes were coded and it did not rise to the top of priority determinants of health in the HIA. Yet cultural aspects are laced throughout three of the priority determinants of health sections: community development addresses Asian specific businesses as a resource; parks and open space details Asian specific community centers and spaces; and public safety links cultural preservation to social cohesion.

Understanding treatment of the culture requires a careful reading of the places where cultural resources were addressed. For instance, consider the following quote addressing the health supporting aspect of social cohesion due to Chinatown as a regional asset:

HIA Steering Committee members and participants in the focus groups... felt strongly that the social and cultural benefits of the Asian resident community, culturally focused retail, and cultural resources contribute to a sense of social cohesion and are a great health asset of the Planning Area. The presence of Asian-targeted goods and services, destinations and recreation, and cultural centers contribute to social cohesion because they draw Asian residents from nearby and more distant locations... [which] creates and encourages a sense of community, or more specifically, a sense of mutual aid, neighborhood security, of belonging, and shared values. (HIA, p 52)

Another quote about a seemingly minor design choice - streetscape improvements again argues for cultural preservation because of social cohesion for the community:

We support the inclusion of the area-wide streetscape improvements in the Planning Area that preserve and celebrate the cultural, linguistic, and historical significance of Chinatown residents and visitors. Such improvements can 
maintain and encourage the growth of the area as a regional destination for the Bay Area Asian residents and can contribute to social cohesion, which has health benefits. (HIA, p 42)

The group also applied scarce data collection resources to survey four blocks to gauge business activity, pedestrian usage, and cultural assets, counting Asian characters in signage for both independent business and for national chains. Findings from this survey conclude, "Chinatown represents a cultural draw to this commercial area that may be contributing to successful business operations and economic vitality" (HIA, p 55).

The HIA clearly supports cultural amenities and recognizes the economic driver of the Chinatown community; yet the emphasis is different than the Principles. The Principle treats Chinatown as a regional 'anchor' and 'destination' for a wide variety of stakeholders, many of them potentially 'visitors' or tourists ${ }^{31}$ to the area. Emphasis is placed on historic preservation and linking various institutions to create a lively business and entertainment district. The HIA is centered on people - specifically residents of the planning area - with no mention of historic preservation in the HIA.

Redevelopment of Key Publicly Owned Blocks Near BART While the topic of redevelopment of publicly-owned parcels is not prominent within the HIA, the document clearly recognizes that the blocks around the BART station are intimately connected to Chinatown. Madison Square Park is the only one of the blocks to be recognized in the HIA by name, but there are references to all of the publicly owned blocks in the safety section. Madison Square Park plays such a prominent role because it is largely utilized for Asian specific activities: Tai Chi, martial arts, and fan dancing as well as cultural activities such as qigong. The HIA also reminds that Tai Chi became a prominent

\footnotetext{
${ }^{31}$ A previous version of the Principles document labeled the content of this Principle under two different goals: 'Cultural \& Historic Preservation' and 'Community \& Tourist Destination'
} 
activity in Madison Square Park after exercisers were forced to move as a result of the demolition of the BART plaza and that residents would like to see more space in the area devoted to supporting Tai Chi. Focusing on this particular park allows the HIA to emphasize designing open space for the current community. The HIA also notes that a previous study suggests government owned super-blocks are "highly susceptible to gentrification" (p 48). Drawing on the Oakland Chinatown Coalition recommendation, the HIA restates "the Chinatown neighborhood should benefit from publicly-owned parcels, including the development of affordable housing, active park space, and community centers" (p 49).

Green and Sustainable Urban Design Although the case for urban health as a sustainable design strategy is beginning to appear in the literature, the HIA pays little explicit attention to green or sustainable design. There are only 40 quotes directly related to these two design strategies. 'Green' as a design strategy is absent; the primary use of 'green' is as a descriptor of businesses and therefore employment growth. Similarly, sustainability is largely absent from the HIA.

\section{Data in the Lake Merritt HIA}

HIA analysis relied heavily on existing data and was acquired from multiple sources. PHLP found others "were very generous with us" (LM02, p 6) and many government agencies provided various datasets: the State of California for collision counts, Alameda County Health Department for some public health data, San Francisco Public Health Department for air quality modeling, and AC Transit with bus routes data. Quantitative modeling is limited within the HIA, instead relying heavily on providing 
summary statistics such as prevalence or incidence rates for various geographies and populations.

Local Knowledge A previous community survey headed by AHS as part of the plan's community outreach was heavily mined. APEN started a survey of local merchants, although it was never fully integrated. The only primary data collection was a few business 'site visits' and a four-block survey of business and pedestrian activity that included an emphasis on Asian signage. This lack of primary data collection was very disappointing for some community members who had hoped the HIA would be an avenue to gather very specific, community-level data; for these community members, utilizing data they had previously collected was less than ideal. More broadly, though, everyone reported little or no conflict over data: “Once we got over the hurdle of what metrics are we interested and what indicators measure that, everyone was in agreement. I can't even tell you how smoothly after that point" (LM02).

GIS Capabilities While not heavily peppered with maps, there are eight Figures in the text, all of them maps. These maps were created specifically for this HIA and include the density of pedestrian injuries/fatalities, the density of bicycle injuries/fatalities, density of crime and overlay of transit stops using Oakland's Crimewatcher database. Other mentions of GIS include using the mapping feature of the California Department of Health Nutrition Network to discuss grocers and quantifying the number of residents living within 500 feet of a tunnel and thus too close for California Air Quality Board recommendations. 


\section{Community Interests in the Plan}

In July 2012, the City of Oakland released the Lake Merritt Station Area Plan Administrative Draft. It is a $300+$ page document. The first three chapters introduce the planning context, process and goals; document existing conditions; and outline a general vision for the plan. Of note, the vision chapter includes the Principles (termed goals) as developed by the community and utilized in the HIA analysis. The next six chapters are organized by planning area; each covers the conditions and recommended designs and policies.

With the HIA closely aligned with community interests, understanding community influence on the Lake Merritt BART SAP requires tracing HIA recommendations into the Plan. It also requires 'controlling' for community interests addressed through the City of Oakland public outreach including the visioning process that resulted in the Guiding Principles. Working by determinant of health, the Administrative Draft was hand-coded for recommendations in the HIA and specific language contained in the 'interim' health products ${ }^{32}$.

General Use of the Term 'Health' Health or healthy appears in the plan 64 times. Healthful or healthier appears an additional four. Of these, two are direct references to the Health Impact Assessment; one is a reference to Health Impact Partners; and three are in subsection or side box headings that include the words 'Public Health.'

Transportation Health Recommendations The 'Streetscape and Circulation' chapter of the Administrative Draft is generally attuned to community concerns with major concepts such as improve and expand the core of Chinatown; connect Chinatown

\footnotetext{
${ }^{32}$ See Chapter 3 for a more detailed description of the hand-coding procedure.
} 
to Jack London District; concentrate multimodal - pedestrian, bicycle, bus, and car access at the Lake Merritt BART Station; improve lighting, pedestrian crossings and street trees on all streets, connect Lake Merritt to the rest of the planning area; add unique wayfinding signage including expanding Chinatown's current bilingual signage system; reflect local character including that of Chinatown; and make the area a destination. The plan notes that the community's highest priorities are pedestrian safety improvements including lighting and street crossing, although the framing of pedestrian safety is troubling. The HIA and health documents' consistent position is that increasing pedestrian facilities decreases pedestrian injuries and fatalities; the concern about pedestrian fatalities can be directly traced to AHS' Revive! Chinatown work. It is therefore troubling to read about 'pedestrian conflicts' instead of pedestrian (and bicycle) injuries and fatalities within the Administrative Draft.

Specific policies and language also show the commitment to community interests. Table 5.3 provides ten examples of where health recommendations or language from the Transportation determinant of health are positively addressed in the Administrative Draft. For instance, community input 'Teas' (and the HIA) showed strong support for current 'scramble' system intersection crosswalks; this is reflected in Policy C-18 which proposes installing three more scramble systems in the Chinatown core. Other plan policies or language can be traced back even earlier to the interim health documents; examples of this include a section titled "Public Health and the Built Environment," the phrase "pedestrian-level lighting", the general approach to converting 1-way streets to 2ways, and the further study of bicycle safety with respect to commercial loading zones in the Chinatown core. 
Table 5.3 Transportation Health Recommendations in the Lake Merritt Administrative Draft

\begin{tabular}{|c|c|c|}
\hline \multicolumn{2}{|r|}{ Health } & \multirow[t]{2}{*}{ Administrative Draft } \\
\hline Document & Recommendation & \\
\hline $\begin{array}{c}\text { HIA and } \\
\text { Community } \\
\text { Teas }\end{array}$ & Add more scramble intersections & $\begin{array}{l}\text { Policy C-18 suggests } 3 \text { more scramble } \\
\text { intersections }\end{array}$ \\
\hline \multirow[t]{5}{*}{ HIA } & Widen sidewalks & Policy C-13 \\
\hline & Support festival streets & Policies C-8, C-17 \\
\hline & Emphasize youth and senior pedestrian safety & Policy C-16 \\
\hline & $\begin{array}{l}\text { Improve pedestrian linkages to Chinese } \\
\text { Garden Park }\end{array}$ & Policy C-16 \\
\hline & Improve pedestrian linkages to Laney College & Policy C-9 \\
\hline \multirow[t]{3}{*}{$\begin{array}{l}\text { July } 25,2011 \\
\text { Letter }\end{array}$} & $\begin{array}{l}\text { Streetscape improvements (general guidance } \\
\text { on vehicle lane width, sidewalk width, various } \\
\text { types of bike lanes, pedestrian crossings, 1- } \\
\text { way vs. 2-way streets, and angled parking) }\end{array}$ & $\begin{array}{l}\text { See section titled "Public Health and the } \\
\text { Built Environment" (p 6-54) }\end{array}$ \\
\hline & $\begin{array}{l}\text { "the proposal does not specify whether } \\
\text { lighting proposals are pedestrian or street- } \\
\text { scale. Benefits cited here pertain to } \\
\text { pedestrian-scale lighting" }\end{array}$ & $\begin{array}{l}\text { Lighting is consistently qualified with } \\
\text { 'pedestrian-scaled' }\end{array}$ \\
\hline & $\begin{array}{l}\text { To reduce speeds and improve pedestrian } \\
\text { safety: (1) lane reduction is good; (2) lane } \\
\text { reduction and conversion from 1-way to 2- } \\
\text { way would be better for pedestrians due to } \\
\text { lower speeds; and (3) pedestrian } \\
\text { improvements are good. }\end{array}$ & $\begin{array}{l}\text { Phase 1: lanes reduced, often to add a } \\
\text { bicycle lane. } \\
\text { Phase } 2 \text { : after requisite study mandated } \\
\text { by the state, turn a } 1 \text {-way into a } 2 \text {-way; } \\
\text { in cases where impractical, make lane } \\
\text { reduction permanent by sidewalk } \\
\text { widening. }\end{array}$ \\
\hline $\begin{array}{l}\text { November } 22 \text {, } \\
2011 \text { Letter }\end{array}$ & $\begin{array}{l}\text { "further study of bicycle safety on } 8^{\text {th }} \text { and } 9^{\text {th }} \\
\text { Streets in the Chinatown Core... [including] } \\
\text { separate vehicle loading/unloading from } \\
\text { bicyclist right-of-way" }\end{array}$ & Policy C-31 \\
\hline
\end{tabular}

A more detailed look sometimes shows less congruency with HIA

recommendations. For instance, the "Public Health and the Built Environment" section at times oversimplifies the relationships. Another example is pedestrian and bicycle injuries/fatalities generally occur at an intersection and he HIA is organized by problematic intersections. The Plan is organized by street and therefore does not explicitly address all problematic intersections. Some specific intersections mentioned in the Plan do agree in intent but downplay the priority of two-way conversion priority. One example in the Plan, $7^{\text {th }}$ Street west of Fallon, is particularly aggressive in rebutting the HIA. The HIA states that pedestrian improvements in this area, while welcome, are 
not enough: " $7^{\text {th }}$ Street is four one-way lands and traffic speeds tent to be fast. Lane reduction, two-way conversion, and narrowing would decrease vehicle speeds and thus improve pedestrian safety" (HIA, p 38). The Plan counters with "Phase II: The community would also like this segment of $7^{\text {th }}$ Street to be studied for possible future conversion to two-way traffic. However, this is highly unlikely due to traffic volumes" (Administrative Draft, p 6-42). Beyond the unclear writing of the second sentence, calling out community wishes and then not committing to further study stings.

It is important to note that many of these transportation and circulation elements may have come about without the HIA; a key stakeholder - TransForm - was active in both the HIA Steering Committee and the planning Stakeholder Advisory Committee. Similarly, Asian Health Services, who has a long history of advocating for pedestrian safety within the Chinatown core, sought to influence the planning process directly and through the HIA. Thus, while specific transportation health interests can be traced from health documents to the plan, many of these interests and details cannot be assigned to the HIA alone.

Housing The Land Use chapter of the Administrative Draft reflects community priorities in several ways: subsections devoted to public health, affordable housing, and developer incentives; repeated commitment to affordable and family housing; and a commitment to high-density development. Additionally, Section 4.6 of the Administrative Draft - Public Health and the Built Environment - explicitly acknowledges HIP before summarizing HIA concerns about land use including the resources and strain of new development, the need for affordable housing, and concerns about environmental hazards for residents near high-volume roads such as I-880. 
Affordable housing is specifically addressed in Section 4.5, "Affordable Housing Strategy," of the Administrative Draft and cites the HIA is cited twice to convey 45 percent of households in the planning area are overburdened in housing costs. Affordable housing goals in the plan are congruent with the $\mathrm{HIA}^{33}$ recommendations: encouraging family and affordable housing, preventing involuntary displacement and strengthening tenants' rights, preserve existing housing. Yet the benchmarks are less aggressive than the community would prefer. Finally, the central housing message of the HIA is that rent burden does not seem to be as much of an issue as cost for ownership; thus gentrification potential would be best addressed with developing permanently affordable housing for low-income homeownership. This interest in low-income homeownership is hardly present within the Administrative Draft.

Community benefits as a housing strategy is addressed in the Plan within both the Land Use and Implantation Chapters. The intent of the City of Oakland to move forward with a single alternative created a great deal of tension about establishing a community benefits program. Initially the community requested a conditional-use permit required for any building over 45 feet in order to capture, not stifle, value associated with rezoning areas for increased height and density. While initially written into an early plan draft, the 45-foot conditional permit was removed from the Administrative Draft because the City was concerned about unintended consequences such as developers choosing other areas in Oakland for large projects in the weak economy of the Great Recession. By the time the HIA was released, the community benefits approach reappeared with a watered down policy of 'develop' an incentive program. This approach is understandable but risky.

${ }^{33}$ The HIA quoted the recommendations provided by the Oakland Chinatown Coalition rather than develop its own. 
City "staff was frank in saying the issue with trying to get a community benefits or specific guidelines [into the plan versus] calling for them later [was] that future iterations of the plan won't necessarily include them. [Yet] if they don't include them, there won't be an opportunity to change them" further along in the planning process (LM03, p 1).

Open Space Both the HIA and the Administrative Draft acknowledge the community's desire for parks and recreation centers. The HIA recommendations include a request for an additional full block of park in the Chinatown core; this does not seem to be achieved in the Plan. The HIA also persuasively argues - and it is reiterated in the recommendations - that the planning area does not have enough local city parks to address the current population much less projected population need. Increasing area density will only increase the demands on the 4.1 acres of three city parks: Chinese Garden, Madison Square, and Lincoln Square. The Plan suggests the planning area meets the City of Oakland's targets for parkland once the 31 acres of regional open space is included in the tally. The HIA repeatedly suggests that health benefits of local parks are more important than access to regional parks on the far eastern edge of the planning area, because the usefulness of a park to promote healthy behavior primarily occurs with very close proximity to open space. Largely ignoring the proximity argument, the Plan remains committed to including regional parks as daily and accessible open space; it does make a marked improvement in identifying connectivity - current and potential between the residential areas and the regional open space.

Maximizing utilization of the three existing local parks is imperative. The HIA requests a community input process to plan current and new park programming and features to increase utilization; increased maintenance, accessibility and safety of current 
parks; and better connectivity to regional parks. The Plan recognizes this with an overarching policy to "maintain and enhance existing public parks to best meet community needs" (OS-1); expand well-utilized fitness facilities at Lincoln Square Park (OS-8); and provide pedestrian improvements including establishing a festival street next to Chinese Garden Park (OS-10, OS-11). Yet the plan does not address HIA air-pollution concerns associated with Chinese Garden Park backing up to I-880, speaking of health and safety in terms of sound and visual pollution instead of air-toxics.

One of the most significant community concerns was the City of Oakland's initial proposal to develop Madison Square Park due to its proximity to the BART station. The Chinatown community expressed adamant opposition to losing any space in Madison Square Park during early community meetings. Early health products aligned with community sentiment by recommending Madison Square Park remain completely open (ie - no new structures) to preserve it as an open space available for cultural and physical activities such as Tai Chi. The City of Oakland completely backed away from any development in Madison Square, acknowledging that “changes must preserve the park's usability for the Tai Chi community" (Policy OS-12). This about-face cannot be attributed directly to the HIA as many community members and organizations beyond the HIA Steering Committee made this particular interest in maintaining Madison Square as open space very clear. Still, it illustrates how an HIA can augment community concerns with a health lens.

Economic Development The HIA emphasizes that local, small businesses are the most likely types of businesses to hire local, multi-cultural, and multi-lingual residents of the planning area. To this end, the HIA explicitly draws the link between local hiring and 
five of the Administrative Draft's economic development objectives. The HIA also recommends: (1) incentivize the fee for the proposed Community Benefit District to support local hiring; (2) establish local hiring goals for the City of Oakland; (3) monitor and track local hiring in the planning area; and (4) include a local hiring service in the Community Benefit District. Items (1) and (3) are not evident in the Economic Development section of the Administrative Draft. However, the HIA recommendations to establish local hiring goals and include a local hiring service in the Community Benefit District are repeated almost verbatim in a subsection titled 'Local Hiring, Job Training, and Placement" and as policy ED-24.

Public Safety Public Safety is the only determinant of health that does not map directly onto a section of the Administrative Draft; instead it is integrated throughout the plan. Public safety was also the only determinant of health in the HIA without specific recommendations, instead reprinting Asian Health Services' recommendations from the community engagement process: create safe public spaces, promote safer streets, improve community police services, and include violence prevention programs and policies.

The treatment of safety in the Administrative Draft is consistent with community goals of creating safe public spaces and promoting safer streets but does not address violence prevention programs and policies explicitly. Of the 150 mentions of safety in the main text of the target plan, approximately 45 percent address public safety at large. This includes usage of safety in a list of desirable community or neighborhood attributes; descriptions of a vibrant and crime-free space as an economic development tool (see policies ED-8, ED-9, ED-10, ED-11, and ED-12); descriptions of safe parks and other open space (REC-4); design principles such as pedestrian lighting (ED-10) and Crime 
Prevention Through Environmental Design; and police presence (ED-8,ED-12). Seventy-seven mentions of safety address traffic safety; of those, two-thirds address pedestrian safety alone. Finally, there are a handful of mentions of safety to describe building, fire, and sanitation.

\section{Summary}

The Lake Merritt HIA was successful due to a number of factors: a diverse group of community stakeholders united by previous relationships and common core values such as a desire for social justice for the Chinatown community; PHLP playing an active facilitation role; and utilizing a previously created document - the Nine Guiding Principles - as a starting point for sorting and prioritizing interests best addressed by the HIA. Major challenges in the HIA scoping process included time and translating differences with and into a uniting health frame. Yet over the course of the scoping process, shared learning and trust occurred as the group worked towards consensus.

The Lake Merritt HIA is not simply an expansion of the community-determined health Principle. Rather it focuses on linking the physical and social determinants of health. This means that the other 'non-health' Principles seem to receive more treatment in terms of quote counts and space than the specific sub-goals in the health Principle. The various pathways have a decidedly community focus. The Transportation section addresses the perspective of the current community with emphasis on pedestrian safety, expansion of bicycle facilities, and addressing environmental justice issues of airpollution. Housing emphasizes affordable housing and preventing displacement. Some of the community defined Principles - community engagement; community and cultural anchor and regional destination; redevelopment of key publicly owned 
blocks near BART - that do not map directly onto primary social determinants of health in the HIA appear to be given minimal treatment. Analysis, however, suggests that the HIA writers were consistently committed to protecting residents in the planning area. This commitment is bolstered with the inclusion of nine community perspective subsections, strong community language, and deferment to prior community recommendations.

The HIA also exhibits a commitment to human health with various types of supporting data. The HIA discussion of park access is a good example of multiple types of data informing the community position. The HIA delineates between proximity and capacity using quantitative data to address supporting human health of residents and their access to parks. The HIA utilizes a common metric - percentage of residents within $1 / 4$ of a mile of a park - to show that most residents in the planning area already live in close proximity to a park. Proximity, however, belies the issue of inadequate park capacity as described by the acreage density. The need to match parks and recreational programing with resident preferences is a good example of HIAs speaking to qualitative aspects of human health supporting environments. Drawing on survey work by Asian Health Services, the HIA documents the current amenities, users, and design issues of existing parks and unofficial recreational spaces; it notes the demographics of users including stressing that many spaces are utilized by Asian Seniors for culturally specific games and exercise such as Tai Chi.

The target plan also shows an awareness of community needs throughout. The Principles are listed upfront and revisited section by section. Furthermore, it is attentive to the cultural uniqueness attributed to Chinatown. There are certain community interests 
that are arguably included a result of the influence of the HIA. This includes the two subsections and one topic box that specifically address 'Public Health'; the inclusion of 'pedestrian-scaled' lighting as a safety design strategy; Phase II of the circulation strategy which calls for study of two-way streets in order to decrease auto speeds and increase pedestrian safety; and almost identical language regarding local hiring as an economic development strategy. In each of these instances, the health documents influenced specific language within the planning document.

There are also examples of interests from the health documents aligning with the Administrative Draft. It is important to note that many of cases of direct influence can be attributed to the HIA process and interim products: pedestrian scaled lighting, Phase II and the study of two-way roads. This and other input was requested by the City of Oakland at points in time where planners anticipated the information would be most helpful. The early engagement with the City of Oakland also set the tone for inclusion of health more broadly. There are also examples of influence that likely occurred because specific organizations on the HIA Steering Committee were committed to the cause. Finally, there are examples where HIA issues gained little or no traction. Yet the HIA was largely successful in advocating for a healthy, community-centered plan. 


\section{Chapter 6: Case Study of I-710 Corridor Project}

The extent to which HIA can serve as a community tool in public planning processes is a function of the ability of the community to access and influence the HIA and the ability those within the HIA process to access and influence the planning process. In large-scale planning processes, the high stakes that make an HIA desirable to communities and public health professionals also serve as a barrier to HIA and community influence. This is particularly true when the planning processes are intersecting with environmental laws and processes to reduce risk such as environmental impact reviews as required by NEPA and the California Environmental Quality Act (CEQA). It was in this context that the I-710 Corridor Project HIA was selected as a case shortly after the I-710 Corridor Project Committee voted to include an HIA in the environmental planning process surrounding the expansion of the I-710 freeway to a proposed fourteen lanes.

This chapter catalogs how the community interacted with the HIA at various points leading up to the release of the draft Environmental Impact Report and Environmental Impact Statement ${ }^{34}$ (DEIR) and the eventual decision to recirculate the DEIR. The HIA was initiated with significant support from a coalition of local, community-based environmental justice organizations. Yet the scale of the planning process, politics, and funding structure resulted in the HIA being written with very little community input. Worse, the HIA was unavailable for many months, only to be released as a 'work-product' separate from the DEIR in an attempt to strip it from legal standing

\footnotetext{
${ }^{34}$ CEQA requires Environmental Impact Reports (EIR) while NEPA requires Environmental Impact Statements (EIS). DEIR is used throughout this chapter to refer to the joint report meeting both requirements.
} 
under state and federal environmental laws. Still, the HIA played a significant role in comments during the DEIR public comment period; as a result, Caltrans has promised consideration of a community defined alternative plan through a recirculated DEIR.

\section{Background}

The Long Beach freeway, or I-710, is approximately 24 miles long and generally six to eight lanes across. It connects the ports of Long Beach (to the east of the southern terminus) and Los Angeles (to the west of the southern terminus) to the greater metro region to the north by running through 15 distinct cities known colloquially as the "Gateway Corridor" (Figure 6.1). The ports of Los Angeles and Long Beach are the two busiest ports in the U.S.; together, the ports account for nearly 40 percent of all U.S. shipping trade. The cargo is increasingly transported by truck from the ports to the Inland Empire (Riverside and San Bernardino counties) via I-710 for further distribution. Due to an increase of traffic and projected cargo growth, Caltrans currently wishes to expand I710 to ten general-use lanes and four zero-emission freight lanes - an increase of six lanes. The effort to

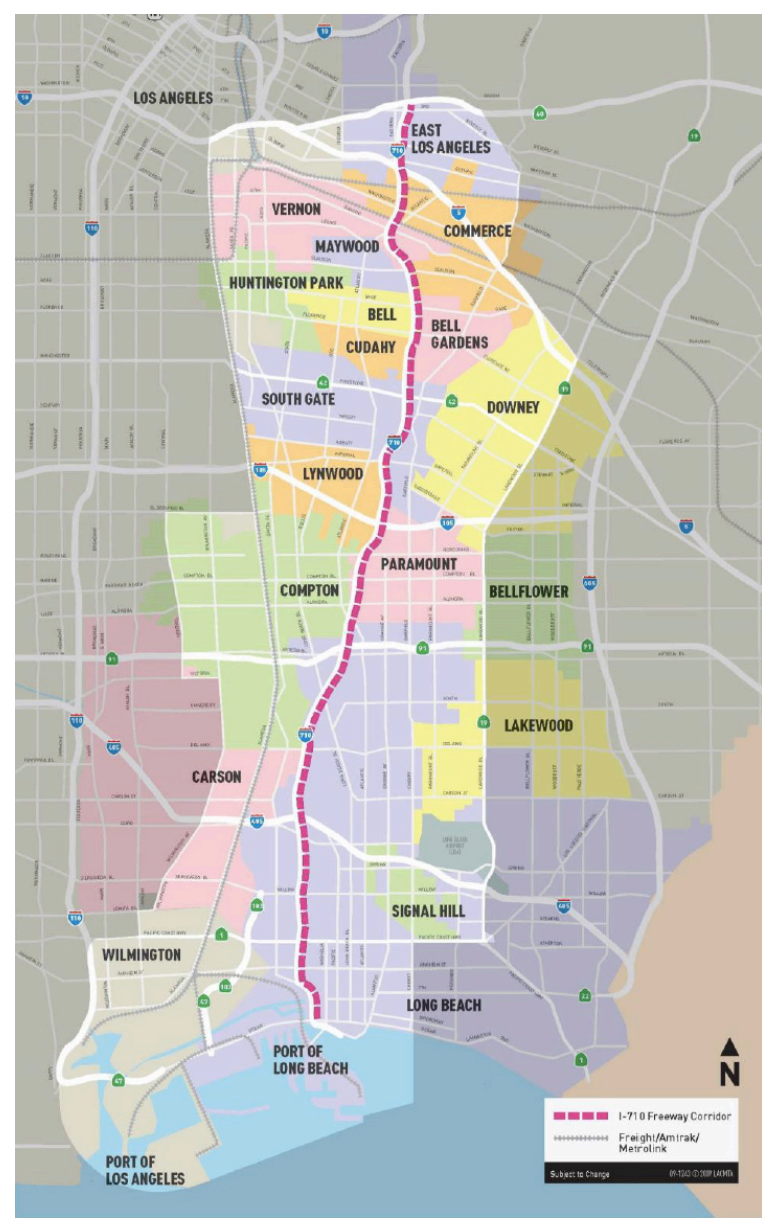

Figure 6.5 I-710 Corridor Project Area (LACMTA, 2014b) 
increase capacity of the freeway has been branded the I-710 Corridor Project.

Caltrans and Los Angeles County Metro Transit Authority (LACMTA) jointly lead the I-710 Corridor Project. Other agencies responsible for the I-710 environmental planning include: Gateway Cities Council of Governments (GCCOG) which represents 28 cities including Long Beach, I-5 Consortium Cities Joint Powers Authority, Port of Long Beach, Port of Los Angeles, and the Southern California Association of Governments. Plans to expand I-710 were originally fast tracked in early 2001 with little input from the historically marginalized communities within the corridor. Participation was largely a matter of public workshops, presentations, and open houses. Decisionmaking authority was given to an Oversight Policy Committee made up of elected officials from various affected cities and representatives of major agencies involved. Oversight Policy Committee committed to identifying the best alternative by early 2003 .

During Oversight Policy Committee's tenure, public health was folded into "safety" on a LACMTA community survey of priorities. Yet many argued that public health, including air pollution, should be given more design consideration and that community members should have more opportunities for input as well. By May 2003, with no alternative identified, LACMTA and the Oversight Policy Committee acknowledged (1) public health separately, (2) the need for more community participation opportunities and (3) that none of the current alternatives were acceptable. Thus, in mid-May 2003, the project started again.

The current community participation and governance structure for the I-710 Corridor Project process is provided in the figure below. GCCOG hosts the I-710 Corridor Project Committee that serves as the primary steering group for the 
environmental planning process. Final decision-making authority resides within the executive committee. The Project Committee gets regular feedback from the Corridor Advisory Committee (CAC) and the Technical Advisory Committee (TAC). Working groups and Local Advisory Committees (LACs) regularly report to CAC. Health was treated differently after the mid-2003 reset in the planning process. As a result of a consensus

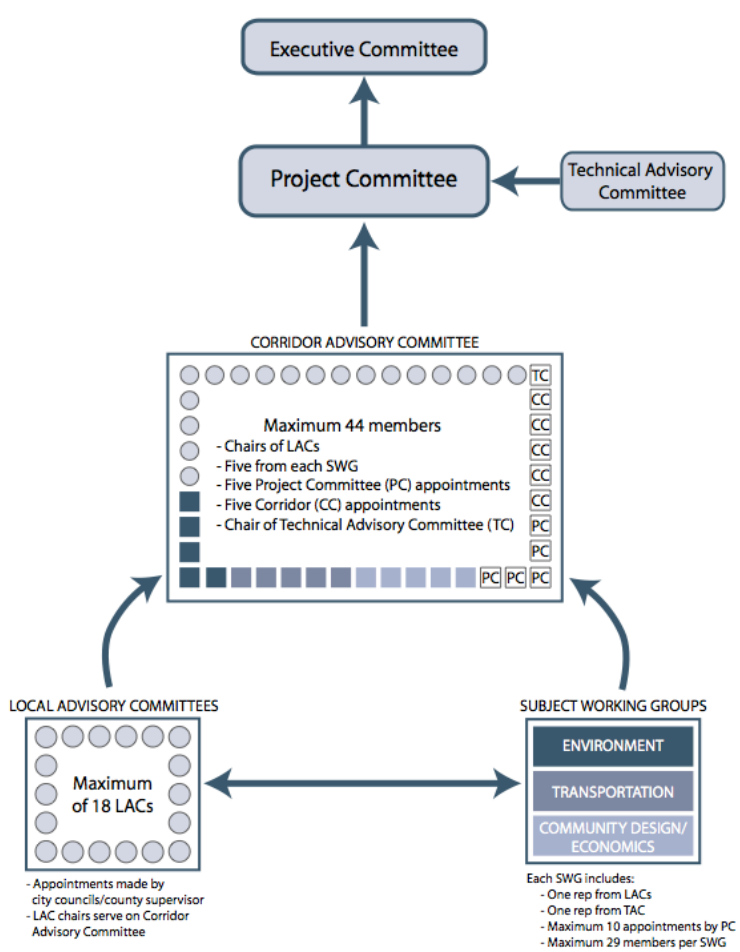

Figure 6.6 I-710 Corridor Project Participation Structure (LACMTA, 2014a)

process involving representatives of directly and less directly affected communities (known as the Tier 2 Community Advisory Committee), a report titled "Major Opportunity/Strategy Recommendations and Conditions" was released that acknowledged that "health is the overriding consideration" and "every action should be viewed as an opportunity for repair and improvement of the current situation" (Tier 2 Community Advisory Committee, 2004, p. 7)

An October 2009 recommendation by the I-710 Project Committee to include an HIA in the environmental impact work seemed to be a way to formalize the elevation of health in this planning exercise. Yet it was unclear at that time how the HIA was expected to blend into the participation and decision-making structure. Due to budget 
considerations, the HIA was eventually funded under a regional air quality analysis effort overseen by GCCOG with the intention to fold the HIA into Caltans' DEIR. A consultant hired by GCCOG subcontracted to Human Impact Partners (HIP) for the analysis, but it quickly became apparent that integrating the HIA into the DEIR was going to be a significant challenge.

\section{Understanding Community Interests}

The area surrounding the I-710 freeway is densely populated. Nearly 10,000 people live within census blocks with centroids within 500 feet of the freeway in the project area. Another 16,000 individuals live in census blocks with centroids between 500 and 1,000 feet. Over 80,000 live in census blocks with centroids less than 2,000 feet (approximately one third of a mile) from the freeway. The individuals who live near the I-710 freeway are, by every definition, a highly vulnerable population: Latino, lowincome, with a higher proportion of children. The 2010 Census recorded the area as 92 percent Latino. Individuals in the Corridor are nearly twice as likely to be Latino when compared to the rest of Los Angeles County, and many of these individuals are immigrants with limited English. Between nineteen and twenty-one percent are living in poverty and per capita income in the area is around $\$ 13,000$, less than half that of the greater Los Angeles County. The area is far younger than Los Angeles County: 33 percent of the population near the freeway are minors compared to 25 percent in the overall county (Coalition for Environmental Health and Justice, 2012, p. Attachment H).

Environmental conditions in the I-710 Corridor are poor. The I-710 Corridor area is home to industrial land-uses, many related to the Ports. I-710 runs parallel to the last 20 miles of the Los Angeles River. The Los Angeles River historically was a dry creek 
Table 6.1 Demographic Profile of I-710 Corridor Community

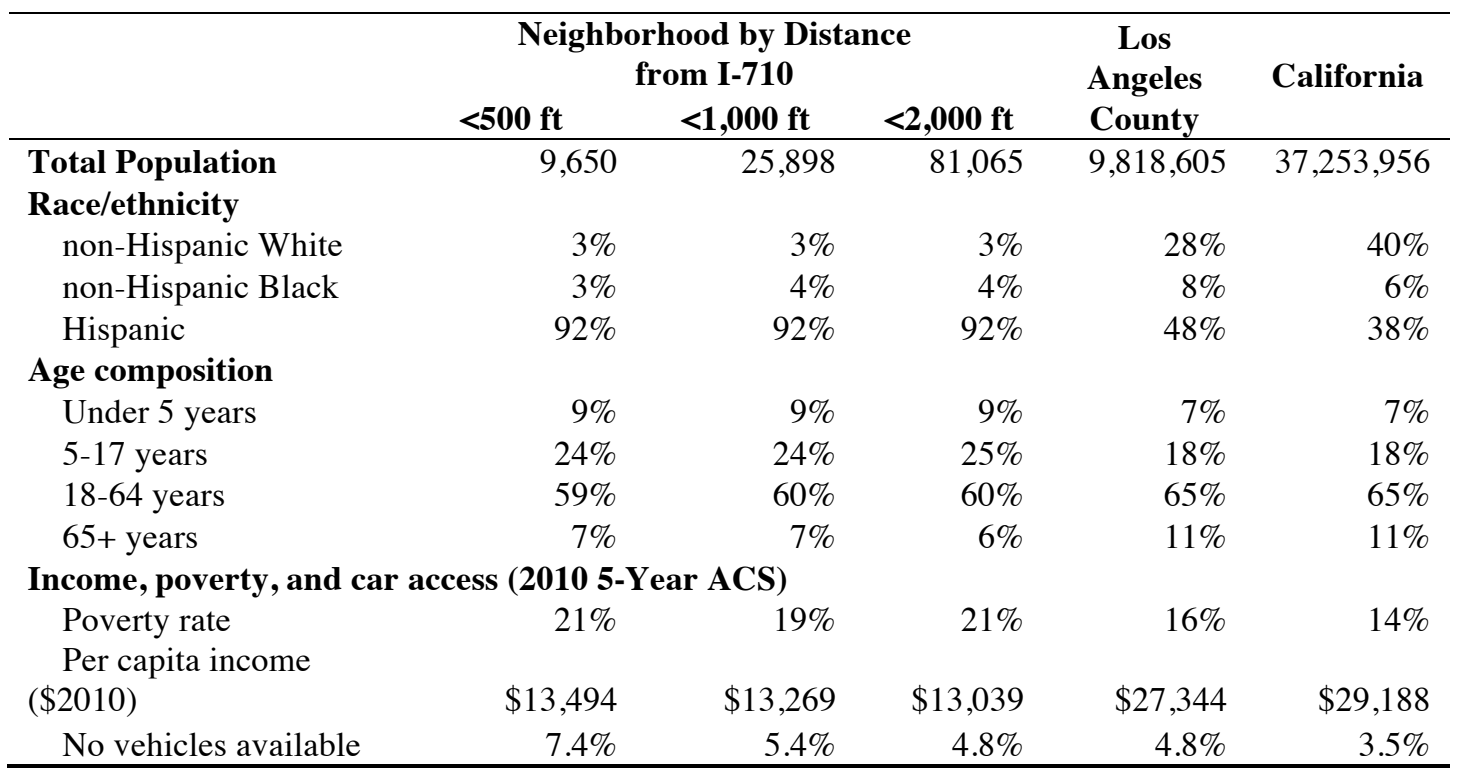

Source: Program for Environmental and Regional Equity (PERE) Analysis of data from the 2010 Census (SF1) and the 2010 5--Year American Community Survey (ACS). See Coalition for Environmental Health and Justice, 2012, p. Attachment H for original table.

bed that swelled during winter rains; today it runs all year with sewer and industrial discharge (Smith, 2013). Due to the freeway, the air quality in the Corridor is particularly troublesome, even for Southern California. For example, Los Angeles County's air is better than inland counties in the region such as Riverside and San Bernardino but is still unhealthy. From 2008 through 2010, Los Angeles County recorded 232 days where at least one 'background' ozone monitor was at or above National Ambient Air Quality Standards (NAAQS). In this same time period, Los Angeles County recorded 59 days with short-term $\mathrm{PM}_{2.5}$ levels above $35 \mu \mathrm{g} / \mathrm{m}^{3 .}{ }^{35}$ The long-term concentration for $\mathrm{PM}_{2.5}$ during this time was $14.4 \mu \mathrm{g} / \mathrm{m}^{3}$ - low enough to meet

\footnotetext{
${ }^{35} \mathrm{NAAQS}$ for 24-hour $\mathrm{PM}_{2.5}$ require no more than 7 days per year with concentrations above $35.0 \mu \mathrm{g} / \mathrm{m}^{3}$. The corresponding Air Quality Index, defined by the EPA, lists values over this level as "unhealthy for sensitive groups." There is significant evidence, however, that there is no levels at which $\mathrm{PM}_{2.5}$ is safe for human health. World Health Organization. (2013). Review of evidence on health aspects of air pollution REVIHAAP Project. Retrieved from http://www.euro.who.int/__data/assets/pdf_file/0004/193108/REVIHAAP-Final-technical-report-finalversion.pdf.
} 
long-term NAAQS regulations in 2009, but above current NAAQS of $12.0 \mu \mathrm{g} / \mathrm{m}^{3}$ (American Lung Association, 2012). Because air pollution is highly localized, populations along I-710 Corridor at are much higher risk for exposure to transportationrelated air pollutants. A study of pollution levels recorded in 2009 showed significantly higher average daily $\mathrm{PM}_{2.5}$ concentrations levels near I-710 when compared to the nearest 'background' station: 25 to 31 percent higher 15 meters (49 feet) and 15 to 20 percent higher 80 meters (262 feet) from the freeway (Polidori \& Fine, 2012, pp. A-10).

Given the environmental conditions, a significant environmental justice community has organized to address the burdens born by this low-income community of color. Table 6.2 lists the various organizations that played roles in advocating for a plan that addressed local environmental and health interests and/or participated in the HIA training. Many of these organizations formalized their relationship by joining the Coalition of Environmental Health and Justice (CEHJ). Of note are three local CBOs with an Environmental Justice mission that showed significant leadership in articulating and advocating for community concerns: East Yard Communities for Environmental Justice (EYCEJ), Coalition for a Safe Environment (CFASE), and Long Beach Alliance for Children with Asthma (LBACA). All three of these community-based organizations developed in the early 2000's to address port-related environmental justice.

EYCEJ was founded in 2001 to work "towards a safe and healthy environment for communities that are disproportionately suffering the negative impacts of industrial pollution." The founding was specifically in reaction to early I-710 Corridor plans and 
Table 6.2 Organizations Interested in the I-710 Corridor HIA

\begin{tabular}{|c|c|c|c|c|c|c|c|c|c|c|c|c|c|c|c|c|c|c|c|c|c|c|c|}
\hline 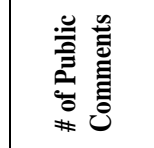 & & - & $m$ & & & -1 & & & & & & & $\infty$ & $\Omega$ & - & & & & & - & & & $\approx$ \\
\hline 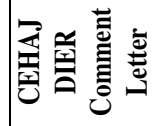 & & & & & & & & & $\rtimes$ & $\rtimes$ & $凶>$ & 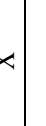 & $x$ & $\rtimes$ & $\rtimes$ & $\rtimes$ & & $x$ & $x$ & $x \mid x$ & & $x$ & $x$ \\
\hline 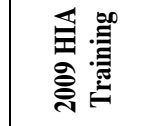 & $\rtimes$ & $\rtimes$ & $x$ & $\rtimes$ & $\rtimes$ & $\rtimes \mid$ & $x$ & $x$ & & & & $凶$ & $x$ & $\rtimes$ & $\rtimes$ & & & & & $\rtimes$ & $x$ & $x$ & \\
\hline 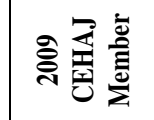 & & & & & & & & & & & & & $x$ & $\rtimes$ & $\rtimes$ & & $x$ & & & $x$ & & $x$ & $x$ \\
\hline 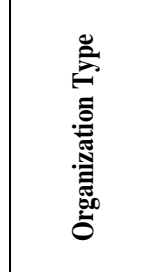 & $\begin{array}{l}\text { 急 } \\
\text { 言 } \\
\text { 产 } \\
\text { 产 }\end{array}$ & 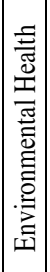 & 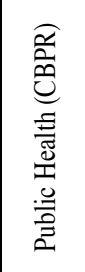 & 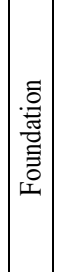 & 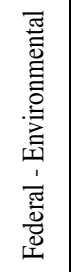 & 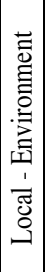 & 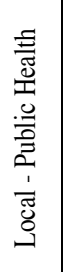 & 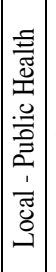 & 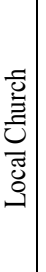 & 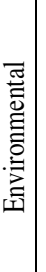 & 产 & \multicolumn{4}{|c|}{ 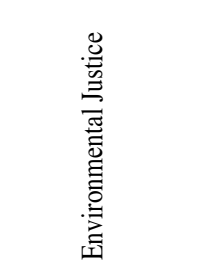 } & 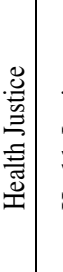 & 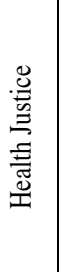 & 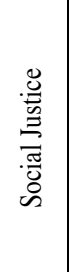 & 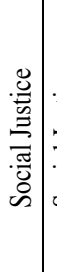 & & 氶 & 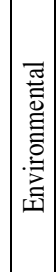 & 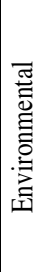 \\
\hline 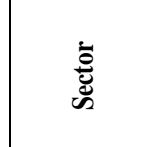 & & 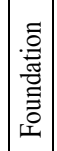 & \multicolumn{4}{|c|}{$\begin{array}{l}\overline{\bar{\Xi}} \\
\text { 产 } \\
\text { डे }\end{array}$} & 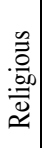 & \multicolumn{11}{|c|}{ 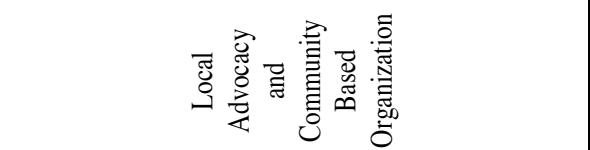 } & 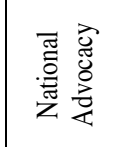 & \multicolumn{2}{|c|}{ 密 } \\
\hline 莺 & 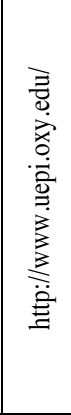 & 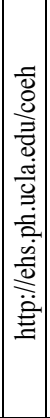 & 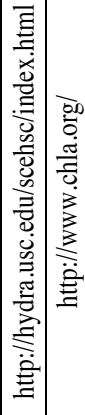 & 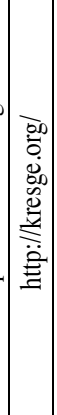 & 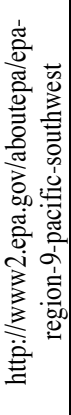 & 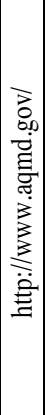 & 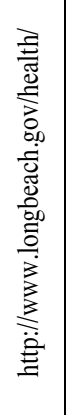 & 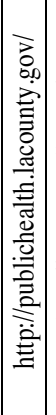 & 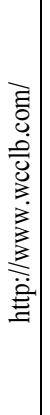 & 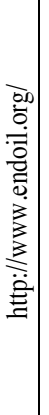 & 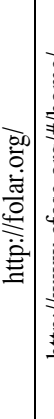 & 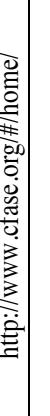 & 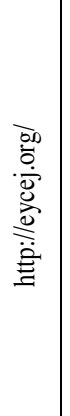 & 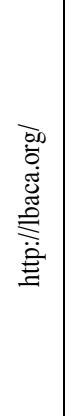 & 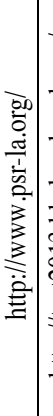 & 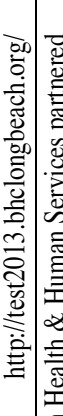 & 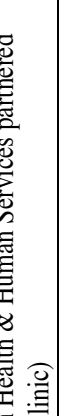 & 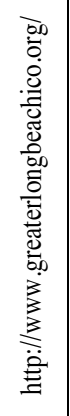 & 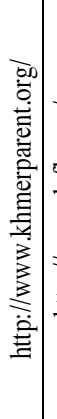 & 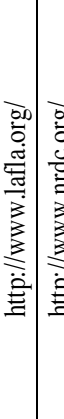 & 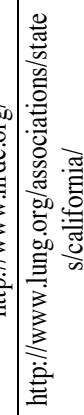 & 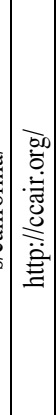 & 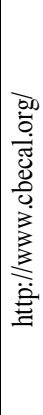 \\
\hline 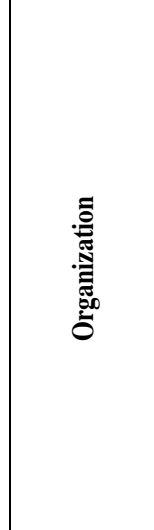 & 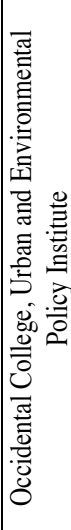 & 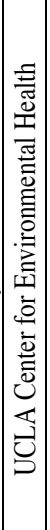 & 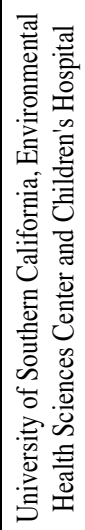 & 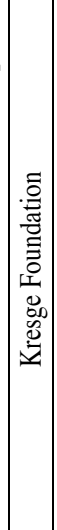 & 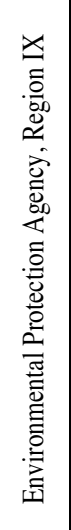 & 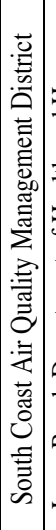 & 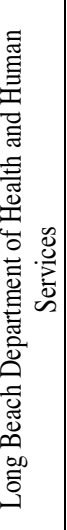 & 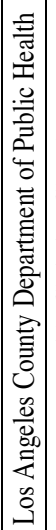 & 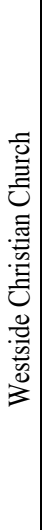 & 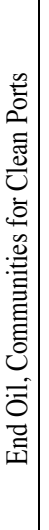 & 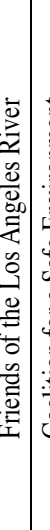 & 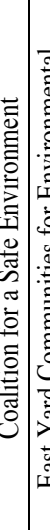 & 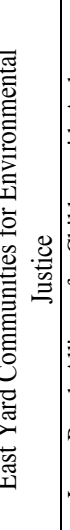 & 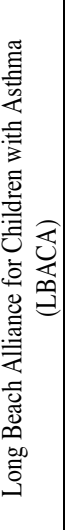 & 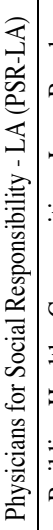 & 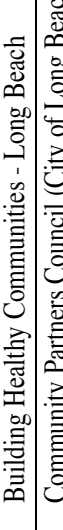 & 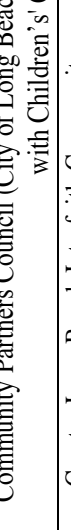 & 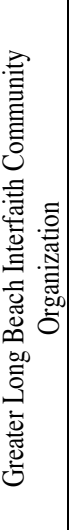 & 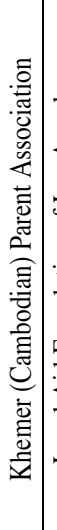 & 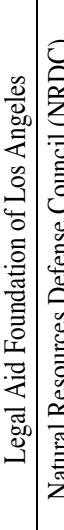 & 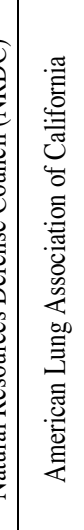 & 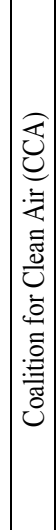 & 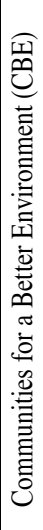 \\
\hline
\end{tabular}


the co-founder has aggressively sought to represent the community on advisory groups for the I-710 and Air Quality Area Plan. With a staff of around eight, EYCEJ takes a grass-roots approach to organizing (EYCEJ, 2014).

CFASE also formed in 2001 in response to expansion plans at the two ports. As a community-organizing group, CFASE targets the global goods movement in its campaigns. It specifically seeks to monitor health risk assessments for various projects at the ports of Long Beach and Los Angeles. CFASE favors HIA because it feels that traditional health risk assessments do not adequately document current conditions such as asthma or predict likely impacts well enough to adequately inform mitigation measures. (Alvarado, 2013; CFASE, 2014). CFASE has also been instrumental in rolling out a community-based participatory research project where citizen-scientists monitor and report pollution in the City of Wilmington (LACEEN, 2014).

LBACA formed as a coalition in 2000 with its primary purpose to reduce childhood asthma in the Long Beach community through "healthcare delivery and quality, outreach, education support systems, healthy living environments and, changes in policy at all levels" (LBACA, 2014a). Policy advocacy efforts include a robust community engagement campaign that brings "a strong community voice into the policymaking process, resulting in community education and empowerment" (LBACA, 2014c). The group has actively opposed I-710 expansion and uses the community demanding consideration of the community-defined alternative CA7 for the I-710 as an example of successful community power (LBACA, 2014b).

Several significant regional and national environmental organizations have provided ongoing support to these community-based organizations for the I-710 Corridor 
campaign and eventually joined CEHAJ. UCLA, USC and Occidental College have ongoing CBPR-type partnerships with the organizations. Communities for a Better Environment (CBE) and Coalition for Clean Air (CCA) are both California-based environmental groups that adopted the I-710 Corridor project as a major campaign. Physicians for Social Responsibility - LA (PSR-LA) has provided an authoritative health voice through media editorials. CBE and PSR-LA have previously and together to utilized litigation to force compliance with state and federal environmental laws. Legal Aid Foundation of Los Angles (LAF-LA) and the Natural Resources Defense Council (NRDC) also both provided significant support in building a legal case for opposing current alternatives in the I-710 Corridor Project.

The community has largely opposed any expansion of the I-710 freeway within the Corridor. Community concern about the I-710 Corridor Project is summarized in

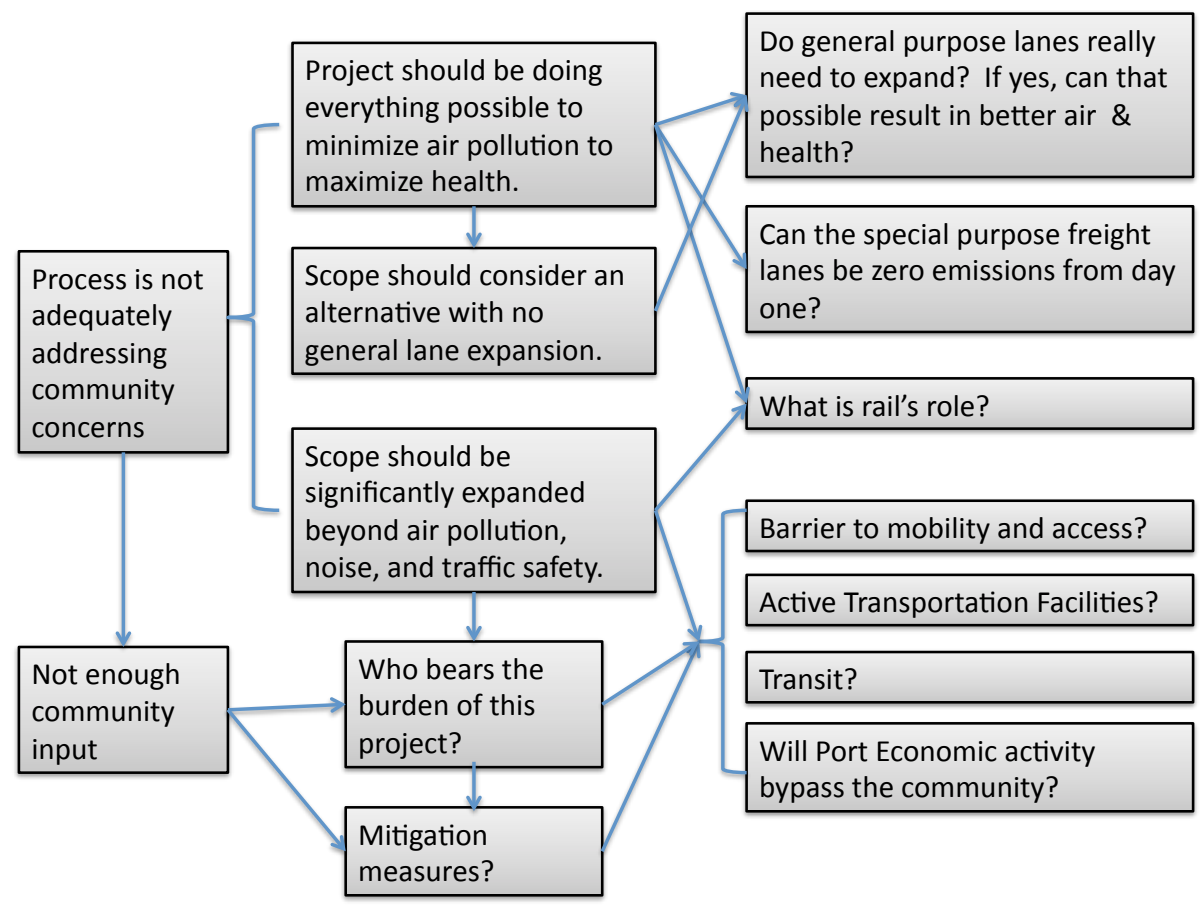

Figure 6.3 Community Interests in the I-710 Corridor Project 
Figure 6.3 above. At the heart of the anti-expansion position are both health and participation interests. The community is angry about a long history of environmental injustice and has vowed to not allow any more port, freight, or industrial development in the region unless it begins to address pollution-related health issues. Even though the Tier 2 Advisory Committee made this position clear as early as 2004, alternatives developed for the I-710 Corridor Project environmental review process did not contain a single scenario that did not widen general purpose lanes. The alternatives were also fairly non-committal about timelines for converting the four-lane special purpose freight lanes to zero-emission technologies. Finally, the environmental planning effort was focusing on noise and air quality with limited treatment of access to community and active transportation facilities. In environmental justice communities, this approach was deeply dissatisfying.

\section{Community Interests and the HIA}

Advocating for an HIA As Caltrans and LACMTA reconsidered the scope and alternatives of the I-710 Corridor Project after 2005, other agencies and communities concerned about health began to seek ways to make sure community health interests were considered. Through EPA guidance, an HIA training, and the community engagement structure, those with community health concerns worked to raise the prominence of the health issues in the planning process.

The first recommendation for an HIA on the I-710 Corridor Project came from the U.S. Environmental Protection Agency (EPA). The area through which the I-710 runs is considered one of the most toxic in the nation. It is also highly populated with low- 
income residents of color. In response to the proposed scope, EPA Region IX ${ }^{36}$

suggested in a 2008 letter that a HIA would be appropriate to address public health concerns:

Low-income and minority communities are potentially experiencing more health impacts than would be predicted using traditional risk assessments. An HIA is a potential tool for examining this complex issue. HIAs look at health holistically, considering not only the biophysical health effects, but also broader social, economic, and environmental influences. HIAs also explicitly focus on health benefits and the distribution of health impacts within a population. HIAs strive to anticipate potential impacts for decision-makers and to deliver a set of concrete recommendations targeted at minimizing health risks and maximizing benefits... Given the magnitude and complexity of potential health impacts related to Port projects and the critical role the I-710 Corridor serves accommodating freight traffic to and from the Ports, EPA recommends that Caltrans partner with the Ports, the Corps of Engineers, the local health department and the local community to conduct an HIA which encompasses this project and all upcoming Port expansion projects (U.S. Environmental Protection Agency Region IX, 2008).

In January 2009, Human Impact Partners (HIP) held a 2-day HIA training workshop for over 30 people in Southern California. This group included individuals from government environmental and public health agencies, academics with a focus on environmental health justice through participatory methods, representatives of national environmental justice agencies, and local CBOs. (See Table 6.2 in the previous section.) HIA trainings often use a case-study approach to teach the steps of HIA; the organizers of the January 2009 training requested that the I-710 Corridor serve as the training case. As a result, this large group of interested parties analyzed the ability of an HIA to address the I-710 Corridor Project by talking through each step of HIA. In other words, the group performed a soft screening and scoping of the project through the training process.

As the training ended, many participants decided they would like to move forward

${ }^{36}$ U.S. EPA Region IX is a cooperating agency for the I-710 Corridor Project 
with an HIA on the I-710 Corridor Project. Through the community engagement framework surrounding the I-710 Corridor Project, members of this group asked Caltrans and LACMTA for a fuller consideration of health impacts and offered HIA as a potential tool for such an analysis.

Requesting an HIA in the Environmental Review The community was instrumental in convincing decision-makers to authorize an HIA during the environmental planning process for the I-710 Corridor Project. Advocating for an HIA occurred primarily in the I-710 Project Committee hosted by GCCOG. The I-710 Project Committee was comprised of over 22 members representing most cities within the Corridor with additional seats for the County of Los Angeles, the Ports of Long Beach and Los Angeles, and several other regional governing the DEIR. The I-710 Project Committee met approximately twice a year to guide the environmental planning process. While the Project Committee was routinely seen as the decision-making body, Caltrans held ultimate decision-making authority.

Over 50 pages of meeting minutes are available to document the community's interests in the I-710 Corridor Project prior to the release of the DEIR/EIS. These public statements are summarized in Table 6.2. Between October 2009 and May 2012, 52 unique people attended seven Project Committee meetings. These citizens recorded 82 public comments. Most commenters were affiliated with three CBOs: LBACA, CBE, and EYCEJ. The vast majority of comments (71 percent) contained some sort of health element; another 23 percent were requests for a participation structure that reflected community concerns. One third of all public comments in this period explicitly addressed desires of the community to include an HIA in the environmental review. 
Table 6. 1 Summary of Public Comments in I-710 Corridor Project Committee Meetings

\begin{tabular}{|c|c|c|c|c|c|c|}
\hline \multirow[t]{2}{*}{ Date } & \multicolumn{2}{|c|}{ Commenters } & \multicolumn{2}{|c|}{ Concerned about } & \multirow{2}{*}{$\begin{array}{l}\text { Main Message From } \\
\text { Community }\end{array}$} & \multirow[b]{2}{*}{ Outcome } \\
\hline & All & Unique & Health & $\begin{array}{c}\text { Partici- } \\
\text { pation }\end{array}$ & & \\
\hline $\begin{array}{l}\text { October } \\
29,2009\end{array}$ & 19 & 19 & 18 & 1 & $\begin{array}{l}\text { Supporting the } \\
\text { recommendations of } \\
\text { CAC. }\end{array}$ & $\begin{array}{l}\text { Unanimous adoption of } \\
\text { CAC Recommendation \#2 } \\
\text { (HIA) through inclusion } \\
\text { in the draft scope for the } \\
\text { AQAP }\end{array}$ \\
\hline $\begin{array}{c}\text { January } \\
28,2010\end{array}$ & 20 & 15 & 14 & 3 & $\begin{array}{l}\text { Clarify the } \\
\text { relationship between } \\
\text { the HIA, EIR and } \\
\text { AQAP }\end{array}$ & $\begin{array}{l}\text { 10-7 to make HIA part of } \\
\text { EIR }\end{array}$ \\
\hline $\begin{array}{l}\text { July } 29 \\
2010\end{array}$ & 18 & 14 & 14 & 1 & $\begin{array}{l}\text { Thank you for } \\
\text { Including the HIA in } \\
\text { the EIR }\end{array}$ & \\
\hline $\begin{array}{c}\text { January } \\
31,2011\end{array}$ & 3 & 1 & 2 & & $\begin{array}{l}\text { Concern about not } \\
\text { including HIA in the } \\
\text { EIR with a request for } \\
\text { recommendation for } \\
\text { immediate } \\
\text { commitment from } \\
\text { Caltrans for HIA } \\
\text { inclusion in EIR }\end{array}$ & $\begin{array}{l}\text { Caltrans' representative } \\
\text { responded that it "has } \\
\text { taken that } \\
\text { recommendation under } \\
\text { advisement [and] legal } \\
\text { counsel has advised to } \\
\text { hold off consideration } \\
\text { until the HIA is } \\
\text { completed." }\end{array}$ \\
\hline $\begin{array}{c}\text { June } 30 \\
2011\end{array}$ & 6 & 3 & 1 & 6 & $\begin{array}{l}\text { Request } 180 \text { days } \\
\text { review period for EIR } \\
\text { plus Spanish } \\
\text { translation }\end{array}$ & $\begin{array}{l}\text { Issue tabled although } \\
\text { everyone seems ok with } \\
\text { executive summary in } \\
\text { Spanish }\end{array}$ \\
\hline $\begin{array}{c}\text { January } \\
31,2012\end{array}$ & 1 & 0 & 1 & 1 & $\begin{array}{l}\text { Concern about the } \\
\text { rollout of the HIA } \\
\text { including lack of time } \\
\text { in front of Project } \\
\text { Committee }\end{array}$ & \\
\hline $\begin{array}{l}\text { May } 31, \\
2012\end{array}$ & 15 & 0 & 8 & 7 & $\begin{array}{l}\text { Request } 120 \text { day } \\
\text { review period and HIA } \\
\text { in EIR }\end{array}$ & $\begin{array}{l}8-4 \text { to recommend } 120 \\
\text { day review to Caltrans; no } \\
\text { recommendation about } \\
\text { the HIA in EIR }\end{array}$ \\
\hline Total & 82 & 52 & 58 & 19 & & \\
\hline
\end{tabular}

The first formal requests for a HIA were at an October 2009 I-710 Project

Committee meeting. At this meeting, the Corridor Advisory Committee (CAC) - the advisory group that merged local advisory committee and technical committee information - recommended that the I-710 Project Committee include an HIA in the 
Environmental Impact planning efforts (GCCOG, October 29 2009). A member of the CAC who also served as the Director of Chronic Disease and Injury Prevention in the LA County Department of Public Health ${ }^{37}$ gave a short HIA presentation to the Project Committee. He justified the request for a HIA by explaining EIR scope is currently too narrow to account for all pathways that affect health: air quality, congestion and mobility, noise, mass transit, social and economic impacts. He also presented youth obesity by cities in the region to show the affected community is very vulnerable. Very few public comments in the September 2009 meeting explicitly mention HIA; however 11 out of 19 comments explicitly stated they support the CAC recommendations, implying support of the HIA. The I-710 Project Committee voted, unanimously, to include an HIA in the Air Quality Area Plan (AQAP) - a parallel process that was to be "linked" with the EIR/EIS in order to not duplicate effort in the Corridor(GCCOG, October 29 2009).

Another 20 public comments were recorded during the next I-710 Project Committee meeting held in January 2010 (GCCOG, January 28 2010). Fourteen comments addressed health with four of those specifically asking the I-710 Project Committee to "revisit the issue and place the HIA in the EIR/EIS [because the community] is confused by what linking the AWAP and EIR means." Three citizens stressed themes of community participation. After public comments, a member of the Project Committee thanked the community for "making it clear that the health of our residents is our priority" and moved to include the HIA in the EIR. Resulting discussion among members indicate a split in the I-710 Project Committee. Some strongly felt that the EIR for this project was more than exceeding CEQA regulations by including most

\footnotetext{
${ }^{37}$ This individual also attended the 2-day HIA training.
} 
health information anticipated to be in the HIA; these members were hesitant to add another hurdle to a drawn out process. On the other side were Members who felt the EIR should include the HIA even if it "slows down the project by six or seven months." Notably, the representative from Caltrans questioned the legal implications of including the HIA in the EIR. The motion to include the HIA in the EIR passed 10-7 (GCCOG, January 28 2010).

Six months later, at the next meeting in July 2010, the community came with a prepared message of 'thank you for including the HIA in the EIS' (GCCOG, July 29 2010). Of the 18 comments made, 13 explicitly mentioned the HIA. There were still concerns about the HIA's place in the AQAP and the relationship with the EIR; several of the commenters asked for clarification. However, there was no concrete action taken by the I-710 Project Committee.

Only three public comments were recorded in January 2011; however two explicitly and strongly addressed the need for the HIA(GCCOG, January 31 2011). A member of CBE was very concerned that "Caltrans seems to be equivocating as to whether the draft HIA will be included in the EIR/EIS." Another citizen and member of LBACA requested "Caltrans approve immediately the inclusion of the HIA in the EIR and send notices to the community." Caltrans' representative responded that the agency "has taken that recommendation under advisement [but] Caltrans' legal counsel has advised to hold off consideration until the HIA is completed." The members then 
unanimously voted to put HIA on the next agenda for discussion; however, this did not $\operatorname{occur}^{38}($ GCCOG, January 312011$)$.

In June 2011, six individuals attended the I-710 Project Committee meeting with a very clear request: the environmental review period on the draft EIS be extended to 180 days and translated in Spanish in order to allow the community time to adequately address it (GCCOG, June 30 2011). The normal CEQA review period is 45-60 days. While 180 days is permissible under CEQA, a review longer than 60 days only occurs under unusual circumstances. The recorded response of nine members show that most felt 60 days was sufficient. One member specifically asks the community why more than 60 days would be needed to which a community member replied, "a normal EIR is 800 pages and this document may be 10,000 covering many cities." Still, the committee decides there are too many unknowns and therefore moves to adopt the 60-day staff recommendation (GCCOG, June 30 2011).

Additional conversation among members ensued in the June 2011 meeting with claims that the process has "been going on for years and there has been public participation all along." Another member claimed that "the environmental documents by necessity [have] to be user-friendly... and that the executive summary would be no more than 25 pages with a total of 500 pages." Another member asserted, "almost every aspect of the document's development has been based on community involvement. It is basically a product of community involvement." Despite the clear message that the community

\footnotetext{
${ }^{38}$ The next meeting was scheduled for March 30, 2011; an agenda, without an item specifically for HIA, was created but the meeting never occurred. HIA was also not a specific item on the following meeting on June 30, 2011.
} 
wanted more involvement, the motion for a 60 -day review passes with a promise for a Spanish translation of the Executive Summary (GCCOG, June 30 2011).

The HIA was completed during the window between the June 2011 and January 2012 meeting; however the community had seen very little of the HIA. Even members of various AQAP advisory committees had been prevented from seeing the full report because of concerns about releasing DEIR data early. Further, concerns by various factions within the AQAP committees had resulted in a recommendation that the HIA be held until it could be externally reviewed; this resulted in a demotion from a technical report to a 'work product.' (See next subsection for elaboration.)

Because AQAP was not on the January 2012 agenda, only one community member from $\mathrm{EYCEJ}^{39}$ came prepared with a public comment. It was, however, a scathing assessment of the HIA process that had occurred that fall. This community member "expressed concern over the process of how the HIA was rolled out" with significant "gaps in communication and in the chain of decision-making." He pointed out "information has not been before the Project Committee to advocate that the HIA be included in the EIR/EIS." There is no recorded reply to the HIA comment in the meeting minutes (GCCOG, January 31 2012).

Members at the January 2012 meeting also discussed community participation. One member stressed that "even though the project has been going on for nine years, we must still be open to ideas and issues that come from newer people involved in the project." In response, two other members blamed the long timeline on "extensive outreach to the community" and "that the community has demanded a lot." Meeting

\footnotetext{
${ }^{39}$ This community member played a prominent role in both the CEHEJ coalition and in various community subcommittees for the I-710 and AQAP efforts.
} 
notes show intentions to translate the Executive Summary into five languages, but Caltrans remained convinced that 60 -days is adequate review time for the community (GCCOG, January 31 2012).

The last I-710 Project Committee meeting prior to the release of the DEIR was held on May 31, 2012. The community recognized this was their last chance to influence the terms of the DEIR. Fourteen out of fifteen public comments asked for a 120-day review period. Five of those comments explicitly advocated for the HIA including one commenter who was "troubled that the HIA is in the AQAP rather than the EIR [and] is troubled that Caltrans has the final say." In response to the community request for a 120day review, a member moved to recommend Caltrans extend the review period: "the community needs time to review the document and our [Project Committee] role is to represent the community." Three other members spoke and cited personal experience with asthma; one summarized his position as "when the public unanimously requests an extension, it carries a great deal of weight." Another member with familial asthma experience floated the idea of recommending once again that Caltrans include the HIA in the DEIR. This idea was rejected for the following reasons: the DEIR already contains most HIA info, the eventual release of the HIA, Caltrans legal limitations, and a preference for the Health Risk Assessment. By a vote of 8 to 4 with 2 abstentions, the motion of recommending Caltrans extend the review period to120 days passed without any HIA language. Caltrans chose to 'compromise' with a 90-day review period for the DEIR; the HIA was released concurrently but not included in the EIR (GCCOG, May 31 2012). 


\section{Writing the HIA within the Air Quality Action Plan}

In order to reduce duplicative effort and control costs in a massive planning effort, the Project Committee authorized the inclusion of the Air Quality Action Plan (AQAP) to cover the air quality aspects within the DEIR. This authorization happened around the same time as the community was demanding an HIA. Since the most pressing community health concern was air pollution, the HIA fell under the AQAP effort.

Completing the HIA within the AQAP had several negative implications including losing control of the participation process, reporting to the AQAP participation structure instead of the I-710 Project Committee and DEIS, and ongoing methodological conflicts.

Defining the Scope In summer 2010, GCCOG hired ICF International as the main AQAP consultant. HIP was hired as a subcontractor for the HIA work and a third firm - Arellano Associates - was hired for public outreach. HIP was consulted about the various committees in the HIA review process (see Figure 6.4), but was largely removed from any control of the participation

process. For example, HIP urged

Arellano to include fewer freight

representatives in favor of more

community representation; however

community representation continued

to be restricted to the AQAP

Advisory Roundtable. HIP's

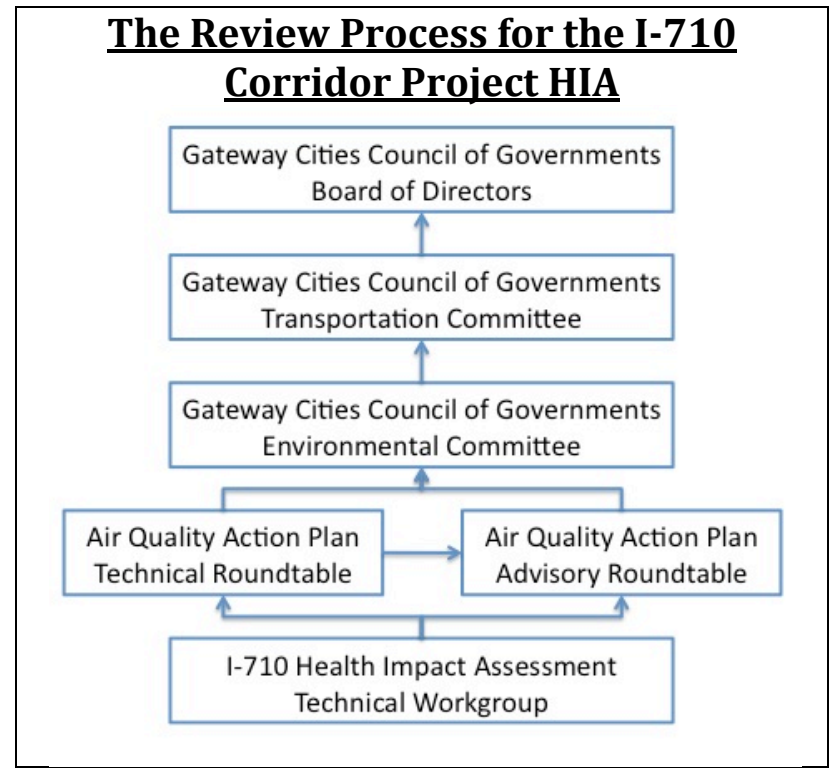

Figure 6.4 AQAP Participation Structure (Human Impact Partners, 2012, p 9) 
suggestion that committees be given greater decision-making power was also ignored.

Instead, the HIA Technical Working Group, Technical Roundtable, and Advisory Roundtable all provided ongoing, detailed support through six two-day meetings held over the course of six months but had no decision-making authority. The Environmental Committee and the Transportation Committee, relying heavily on short briefings from GCCOG staff, maintained the power to vote on various actions. Also problematic, none of the committees were ever provided drafts of the HIA for review due to DEIR data confidentiality concerns; questions and issues were often danced around without the ability to dig deep into data and conclusions (Human Impact Partners, 2012).

The HIA Technical Working Group composition and some of the resulting guidance was troublesome from the community's perspective. It consisted of six members from shipping, industry, and the ports; one from local government environmental health agency; one from LA County Department of Public Health; three regional government agencies including both LACMTA and the South Coast Air Quality Management District; and the U.S. Department of Transportation - Maritime Administration ${ }^{40}$. This group made two critical early scoping decisions: (1) only alternatives currently being considered in the DEIS would be given consideration in the HIA even if previously floated official alternatives proved to be more health promoting; and (2) assumptions in the DEIS would apply even if the HIA author and others such as the EPA believed assumptions such as lack of induced demand were flawed (Human Impact Partners, 2012).

\footnotetext{
${ }^{40}$ The HIA Technical Working Group also initially had representation from EPA but EPA removed itself due to public participation concerns.
} 
The remainder of the scope was largely adopted with minimal conflict in the HIA Technical Workgroup. Consistent with the previous two-day training, the HIA addressed 6 pathways: air quality, noise, mobility, traffic safety, jobs and economic development, and access to neighborhood resources. Data was provided from I-710 DEIS staff under a confidentiality agreement although it should be noted it did not include final PM2.5 modeling (a primary air-pollution concern) or final noise data. This limited the HIA's ability to predict mortality and morbidity from a major health pathway (Human Impact Partners, 2012).

HIA Findings \& Recommendations There was significant conflict over the findings of the HIA, much of which can be attributed to differences in expertise and previous experience with health risk assessment in environmental planning. Some of the conflict reflects tension between different sub-disciplines of public health: the HIA was using a social determinants of health approach and AQAP members were more familiar with the traditional noise and air pollution pathways analyzed through toxicology-based risk assessment. Yet feedback at times also seemed to reflect outside freight expansion agendas. HIP reports some of the feedback was "either vague or purely antagonistic and therefore more difficult to respond to... Some participants did not think specific findings were consistent with their own experiences and did not believe that the scientific literature was relevant" (Human Impact Partners, 2012, p. 16). These participants asserted personal experiences to argue the HIA was wrong. For example, one participant claimed she did not believe busy roads are a bicycling deterrent; she even declared "she enjoyed biking" in such conditions (Human Impact Partners, 2012, p. 16). Yet these 
same participants were uncomfortable with the HIA report because 'linkages' or pathway causation was not as clear as other impact assessment exercises.

The causation conflict continued well into the recommendation stage where the HIA made 72 recommendations based upon improving existing conditions. Many of the Technical Workgroup resisted the recommendations because there was no way to attribute 'proportionality' to the I-710 Corridor Project. For example, even though such a large public works project would be an opportune time to build out much needed active transportation facilities and linkages as a mitigation measure, representatives from the ports and industry were uncomfortable with this occurring under the I-710 Corridor Project (GCCOG, October 12, 2011).

The tension surrounding the HIA spilled out into the October 26, 2011 Environmental Committee meeting. In that meeting, GCCOG staff blindsided HIP with a six-page, single-spaced memo outlining GCCOG staff's areas of concern with the HIA. The HIA authors were not given a chance to preview the memo, resulting in it containing "false and misleading statements about the HIA and its findings" (Human Impact Partners, 2012, p. 18). GCCOG staff took issue with each and every pathway, often loosely invoking science. The memo suggests HIPs portrayal of the relationship between mode share and traffic volume and speeds is not supported by the literature; states the I710 will meet air pollution thresholds and thus has no responsibility to do more because communities will not be harmed, even in localized areas near warehouses; asserts that WHO noise targets are only guidelines; discounts the jobs and economic development analysis as qualitative and thus unfit for inclusion in the DEIS; and strongly disagrees 
with everything the HIA found about a major freeway affecting health-promoting neighborhood resources (GCCOG, October 26 2011a).

GCCOG staff then recommended that the Environmental Committee "forward the final HIA to the I-710 Project Team and Caltrans for their information only without comment from the Gateway Cities COG and to proceed to establish a peer review process to be completed as soon as is possible" (GCCOG, October 26 2011a, pp. 17, emphasis added). GCCOG wanted to be sure the HIA would not be included in the DEIS without significant changes. Everyone, including HIP, agreed to move forward with a peer review. However the HIA was shelved as the group argued about who could provide an unbiased review (GCCOG, October 26 2011b). At the same time, GCCOG removed many of the draft presentations from the Internet and changed the status of the HIA from a technical report to a "work product," thus stripping it of legal standing under NEPA, CEQA, and even Freedom of Information Act regulations.

The conflict over who would perform the peer review was never resolved, and the peer review never occurred. The HIA as a work product but not a technical study was sent on to the I-710 Corridor Project; GCCOG also sent along its memo of issues with the HIA. In the meantime, the full HIA report remained unavailable and not even community representatives serving on AQAP committees could access it until the HIA was released eight months later. Notably, the release of the HIA was concurrent with but not included in the DEIR.

\section{Community Influence in the HIA}

Even though the community had limited access while the HIA was being written, the HIA still contains important community elements. The HIA Technical Work Group 
adopted "identifying health concerns issues" and "increasing stakeholder participation and understanding" as two explicit goals of the HIA (p 1-3). Recommendations, particularly as they pertain to air quality, are framed around "primary concern[s] of the community" (p 1-13). Additionally, there are eight prominent subsections within the HIA that reference the Tier 2 Community Advisory Committee. These sections heavily quote the 2004 Tier 2 report as a framing device for analysis. This framing is further amplified with a commitment to the social determinants of health, over 50 geographic maps of current and expected conditions, and 19 photographs of the community as examples of good (or bad) design of the built environment.

\section{HIA Influence}

Despite being unavailable prior to the release of the DEIR, the HIA played a prominent role in public and agency comments for the DEIR. It also was influential in justifying the decision to recirculate the DEIR and include elements of a community alternative in future analyses. For example, the EPA cited the work of the HIA in their recommendation to not accept the DEIR/EIS. More importantly, the CEHAJ response to the DEIR relied heavily upon the HIA to bolster the legal case for DEIR inadequacy. CEHAJ also used the response to the DEIR to present a new alternative, Community Alternative 7 (CA7). Inclusion of CA7 marked a new effort, including the introduction of a state legislative bill, to increase the profile of community health considerations in the planning of the I-710 Corridor. Each of these avenues of HIA influence are described in detail below.

EPA DEIR Comments As both a cooperating agency and the agency with regulatory power to enforce NEPA, the U.S. Environmental Protection Agency's (EPA) 
opinion of the draft EIS is particularly important. EPA Region IX had shown concern for human health, particularly for vulnerable populations, throughout the planning process.

The letter filed as public comments continues this frame within the introduction:

EPA applauds Caltrans for declaring that "[improving] air quality and public health" is one of the key purposes and goals for the proposed I-710 expansion....The solution to moving freight in southern California must also balance the need to protect human health and the environment and we appreciate Caltrans recognizing this.... A well-planned and executed zero-emission freight corridor would contribute to improved air quality and reduced public health impacts for the already heavily burdened, low income and minority communities along the I-710 Corridor and for people throughout the Southern California Air Basin. (U.S. Environmental Protection Agency Region IX, September 28, 2012, p. 1)

However the review of the quickly turns sour with a rating for Alternatives $6 \mathrm{~B}$ and $6 \mathrm{C}$ as "Inadequate information" and the non zero-emission alternatives $5 \mathrm{~A}$ and $6 \mathrm{~A}$ as "Environmentally Unsatisfactory." With such ratings, the DEIR could not continue through the NEPA process without significant changes and additional recirculation of a DEIR for public review.

The justification for such a poor rating for the DEIR was primarily driven by the simple fact that all considered "build alternatives include increasing lanes along 710, potentially harming public health at many locations throughout the I-710 corridor" (U.S. Environmental Protection Agency Region IX, September 28, 2012, p. 3). With each alternative inducing traffic demand and presumably air pollution, the

EPA does not agree with the general statement in Section 3.13.4 of the Draft EIS that states "...the build alternatives will improve air quality and reduce public health risk in the South Coast Air Basin and the I- 710 AOI [area of influence]". As noted above, the existing analysis in the Draft EIS and AQHRA predicts an increase in adverse air quality impacts for all alternatives, and we have serious concerns that the existing analysis is inaccurate. Identifying mitigation is particularly important given that the Draft EIS indicates that disproportionate and adverse impacts are identified and would have to be mitigated. Additional impacts 
may be unintended or difficult to characterize without a methodology that comprehensively looks at the health of a population and the distribution of those effects within the population. (U.S. Environmental Protection Agency Region IX, September 28, 2012, p. 17)

The EPA comment letter is also notable in that it explicitly mentions the HIA in

the context of both public process and mitigation. It states that the

EPA provided extensive feedback concerning the validity of the scope and methodology of the health impact assessment (HIA) being completed as part of the Gateway Cities Air Quality Action in the I-710 Corridor Project.27 Although EPA's critique of that process reflects concerns that were not addressed, that process may result in identified mitigation measures. While Section 7 of the Community Impact Assessment presents the research questions for the separately prepared HIA, this discussion is not as robust as a fully completed HIA and it is unclear how the information presented here links with the HIA process. The recommendations for mitigation, either developed from the HIA that is being conducted as part of the Gateway Cities Air Quality Action Plan or through collaborations with citizens, could be funded through a creative method like one of the programs implemented by the ports. (U.S. Environmental Protection Agency Region IX, September 28, 2012, p. 18)

The letter continues by pointing out that mitigation measures have not been fully

explored and strongly recommending

a more aggressive approach for identifying air quality mitigation, and mitigation for other resource impacts, as described below, in a revised or supplemental Draft EIS. Caltrans should specifically identify where these impacts may disproportionately affect vulnerable populations (including children, seniors, low income, minority populations, and other sensitive receptors) and identify how these impacts will be reduced... EPA continues to recommend that further mitigation measures be developed through open, collaborative processes that include the public and affected citizens. (U.S. Environmental Protection Agency Region IX, September 28, 2012, p. 18)

Because the EPA supports "mitigation measures that provide a more holistic approach to protecting health," it also recommends that "to the extent that the separately completed HIA can inform mitigation measures, Caltrans should identify all feasible measures in a 
revised or supplemental Draft EIS" (U.S. Environmental Protection Agency Region IX, September 28, 2012, p. 19).

CEHAJ DEIR Comments and Legal Memo The community banded together through CEHAJ to address the inadequacies of the environmental review. On September $28^{\text {th }}, 2012$, CEHAJ provided an 833-page public comment package (Coalition for Environmental Health and Justice, 2012). Within the package are two sections of particular importance in understanding HIA influence. First, there is a 29-page alternative plan - Community Alternative 7 (CA7) - developed by the coalition; this alternative is discussed in greater detail in the following section. Second, Attachment B includes a 94-page legal analysis/memo from NRDC and CBE that draws heavily from the HIA.

The legal memo and analysis hinges on two main arguments. First, it shows why much of the analysis contained within the DEIR is flawed and therefore legally questionable. It then uses the HIA to show why the DEIR does not adequately address all sources of available information to protect the environment and human health. Specifically, it states

The I-710 HIA shows that the health and well being of communities lying nearby the I-710 will be disproportionately impacted by the Project, and identifies many impacts, mitigations and alternatives that are not adequately analyzed in the DEIR/S for the Project. The I-710 HIA, totaling over 450 pages with appendices, extensively critiques the conclusions and findings in the DEIR/S. These include impacts in areas such as: mobility, noise, traffic, air quality, jobs and economic development, and access to neighborhood resources. That is what the HIA specifically was designed to assess, and its findings and recommendations cannot be ignored. Despite this Caltrans' DEIR/S document unlawfully fails to formally include or incorporate the I-710 HIA, and in fact barely references the I-710 HIA at all. This makes the DEIR/S analysis a sham. 
The findings of the I-710 HIA must be included in the DEIR/S. A successful HIA requires decision makers' openness and responsiveness to new information, and we are very concerned that Caltrans has not demonstrated these characteristics. We are concerned that Caltrans first made up its mind that the I-710 should be expanded and that this would, if anything, impact health favorably - and no new data or knowledge from the HIA will change its view. This hostility to the I-710 HIA continues in the DEIR/S. This is not how the DEIR/S process is intended to function, and constitutes a violation of governing law, and the principles of transparency and well-informed public policy. (Coalition for Environmental Health and Justice, 2012, pp. 66-67, Attachement B)

For the next 24 pages, the legal memo argues for inclusion of the HIA in the official process using both NEPA and CEQA requirements. It also outlines the failure of the DEIR to address specific significant findings and recommendations include those related to the main pathways included in the HIA: mobility, noise impacts, air quality, traffic safety, job and economic development, and neighborhood resources. The HIA section ends with

The DEIR/S must be revised and recirculated to take into consideration the findings and recommendations of the I-710 Corridor Project Health Impact Assessment. We therefore respectfully urge Caltrans to include the I-710 HIA in the DEIR/S (Coalition for Environmental Health and Justice, 2012, pp. 91, Attachment B).

In sum, the legal analysis essentially argues that (1) the DEIR does not adequately address environmental and human health (2) or adequately incorporate available information. Thus, CEQA legally requires a recirculated DEIR instead of moving straight to a Final EIS to give the public adequate review of environmental health issues. In this legal position, the HIA is the primary exhibit of inadequate inclusion of available information and thus puts enormous pressure on LACMTA and Caltrans to recirculate the EIS with significant consideration of Community Alternative 7. 
Community Alternative 7 (CA7) CA7 is a community developed alternative plan to promote the community's definition of health. It was written by a coalition of non-profits, many local CBOs and state and national environmental groups, who are dedicated to making this historically marginalized community a healthy place for all. In particular, CA7 was developed to

[Protect] community health in an already overburdened part of the Los Angeles metro region; and [propose] an alternative that performs better environmentally than existing alternatives, while achieving traffic safety, enhancing goods movement, and reducing congestion (Coalition for Environmental Health and Justice, 2012, pp. 1, Attachment A)

Induced demand renders expanding general lanes of the freeway while adding four dedicated freight lanes to address air pollution foolish. CA7 firmly takes this position by leaving the eight general-purpose lanes in their current form, only modernizing on and off ramps for safety. CA7 also addresses increased port demand through other mechanisms, demands four freight lanes are zero emission from day one, and asks that the entire project be completed without taking property even if it means creating a double decked freeway in some areas. Finally, it calls for extensive active transportation facilities, extensive expansion of transit, and the inclusion of a number community benefits and mitigation measures including construction protections, tree plantings, air filtration systems, pedestrian bridges, park maintenance, and truck parking management within the corridor (Coalition for Environmental Health and Justice, 2012).

CA7 gained quite a bit of traction in early 2013. Most notably, on January $31^{\text {st }}$, 2013 the Project committee reconvened for the first time since September to decide how to proceed through the NEPA and CEQA processes and take recommendations from a number of reporting committees. In that meeting, the Project Team recommended that 
LACMTA and Caltrans recirculate the DEIR focusing on three alternatives: no build, and two refined versions of Alternative 6 dubbed Alternative 6C Modified and Alternative 6D. The project team legally justified the recommendation for recirculation by outlining changes in assumptions and information during the long, drawn-out planning process including the completion of the HIA (GCCOG, January 31 2013b).

The project team also included the corridor advisory committee (CAC) "recommend[ation] to the Project Committee, LACMTA and Caltrans that Community Alternative 7 be analyzed" and alternatives designed to not unduly impact residential, park, school, industrial properties, and providers of social services including shelters and senior housing. The CAC specifically requested inclusion of a public-private partnership for a mandatory zero emission freight corridor and consideration of all feasible mitigation measures (GCCOG, January 31 2013b).

While the project team did not recommend the inclusion of CA7 as a separate alternative in recirculation, it did acknowledge CA7 as a major source of community feedback. It also stated

With regard to the elements and design considerations presented above [for inclusion in the recirculated DEIS], Alternative 6D most clearly mirrors the design components included in the proposed Community Alternative 7. During alternatives refinement, an assessment will be made of the extent to which all three alternatives address the components of the proposed Community Alternative 7. A table (matrix) displaying the results of that analysis will be prepared and reviewed to show this assessment and provide coordination. (GCCOG, January 31 2013a, pp. 7, Item E)

The January 31, 2013 meeting minutes indicate that after the project team's presentation and during public discussion, the executive director of East Yards Communities for Environmental Justice pointed out that 
125 people were present [at this meeting] for this item and that he would like to present a PowerPoint on Community Alternative 7. It was the consensus of the Project Committee to receive the presentation on Alternative 7. [The executive director of EYCEJ] summarized the major elements of Alternative 7 as including no widening of I-710; a comprehensive public transit element; a committed zero emission freight corridor; a public/private partnership for an employer operated freight system; improvements to the Los Angeles River, a comprehensive bicycle and pedestrian element, and community benefits from expanded open space and other community enhancements. He asked that the recommendation from the Corridor Advisory Committee that Alternative 7 be included in the re-circulated EIR/EIS be approved (GCCOG, January 31 2013b).

After presenting CA7, five more community members representing four other CEHAJ organizations spoke up in support of including CA7 in the re-circulated DEIR. Following discussion between committee members regarding whether or not Alternative 6D adequately included elements of CA7 and was technically sound enough for consideration, the Project Committee ultimately adopted a motion to develop a Recirculated DEIR/Supplemental EIS with CA7 included (GCCOG, January 31 2013b).

The January 2013 Project Committee vote in support of CA7 was an amazing community victory. LBACA describes the meeting this way:

Community members came out to the meeting and testified about why they supported the CA7. The small room was filled beyond capacity with concerned residents. Once the vote was completed, residents cheered. After years of meetings, public testimony and commitment to their community, this was an example of community power and that people can really make a difference when uniting around a common vision of our communities. (LBACA, 2014b)

Despite the Project Committee's support of inclusion of CA7 and evidence that CA7 differs from Alternative 6D in significant ways, LACMTA and Caltrans would not commit to a including CA7 as a stand-alone alternative. Anticipating pushback, the community immediately started working other avenues to include CA7 in the recirculated DEIR. On February 22, 2013, state Senator Lara introduced SB811 to ensure 
that communities along the I-710 freeway had a meaningful mechanism to provide input about mitigation and local benefits, appropriate freight impacts, sustainability, and public health protections for the proposed I-710 Corridor Project

by requiring the lead agency - Caltrans - include CA7 within the recirculated DEIS

(Lara, 2013). SB811 passed both California legislative chambers in September 2013. On

October 11, Governor Brown vetoed SB811, citing unwillingness to set new precedent that CEQA analyze alternatives and mitigation measures outside an established scope (Belk, 2013). In response to the veto, SB811 sponsor Lara stated:

Last week, Malcolm Dougherty the Director of Caltrans, toured my district, met with members of the community and stakeholders, and assured me that the concerns of the community will be heard and Community Alternative 7 will be analyzed. Though this bill was not signed, we have a relationship and a seat at the table that will still enable us to advocate for clean air, safe roads and healthy communities. (Lara, 2013)

Today, the project team is moving forward with analysis on Alternatives 6C Modified and Alternative 6D under the position that Alternative 6D incorporates CA7. Even with the verbal promise of consideration from Caltrans' director, the community continues to aggressively push for inclusion of all elements of CA7 in the recirculated DEIR anticipated to be released in Fall 2014 (Belk, 2013).

\section{Summary}

The I-710 Corridor Project HIA is, in many ways, a deviant case. This case was selected, in part, to understand how stakeholder and community interests would be handled with HIA integrated into legally mandated environmental review processes. The I-710 Corridor Project HIA clearly shows that integration can be challenging, although the specific planning context may account for much of the conflict. In order to integrate the HIA into the environmental review process, community input into the HIA during the 
official scoping and analyses stage was severely limited. Yet the HIA clearly advocates for community interests. This case also shows that the community can interact with HIAs before and after the HIA process. Indeed, the influence of the HIA in public comments and in advocating for a community alternative is highly democratic. 


\section{Chapter 7: Participation Norms and Implications for the Future of HIA Practice}

HIA has only become popular in the U.S. in the last fifteen years. Early HIAs featured "community groups and city agencies collaborat[ing] in a participatory planning process" that included "new working relationships" and gathering of "new evidence" with community members (Corburn, 2009, p. 165). Public health professionals, often from a participatory research background, saw great potential in the "practice of HIA to address health inequities in urban policy and planning" (Corburn, 2009, p. 163). As public health practitioners began adopting HIAs in an effort to influence planning decisions, many cited five founding principles: democracy, equity, sustainable development, ethical use of evidence, and a comprehensive approach to health (World Health Organization, 1999). But few practitioners stopped to critically evaluate if HIAs routinely support democracy or "the right of people to participate in a transparent process for the formulation, implementation and evaluation of policies that affect their life, both directly and through the elected political decision makers" (World Health Organization, 1999).

Poor or misleading stakeholder participation and engagement quickly becomes tokenism and may actually harm the very communities HIA practice seeks to help (Arnstein, 1969/2005; Kemm, 2005). Thus it is disappointing to find HIA practitioners and academics overstating the participatory nature of the practice. However, a more complete understanding of how social determinants of health, health equity, and geography facilitate social learning suggests that the democratizing elements of HIA are less about participatory data gathering and more about enlarging the publics and health pathways considered in public decisions. Should HIA practitioners desire to provide a 
participatory outlet - a goal that may be appropriate in some situations - they will need to take a more active and explicit approach to stakeholder engagement in order to shape a process that empowers community members and/or their representatives.

\section{Findings}

The following subsections characterize the findings from this research. Patterns that surfaced during the cross-case comparison of target plan characteristics, HIA participation structure, problem definitions and agenda setting, and diverse knowledge types are documented in order to understand what is driving community influence and HIA effectiveness.

Target Plan Characteristics HIAs vary drastically; each is attempting to influence different target plans in differing political, demographic, and topical areas. Each HIA develops its own health pathways on which to focus. The three cases for this research were purposively selected in order to make appropriate comparisons. Table 7.1 compares the characteristics of the three target plans. All target plans were firmly within traditional transportation planning activities. Yet the target plans varied greatly in terms of scale, goals and objectives, and funding. This research began by hypothesizing that scale and objectives - health promotion versus risk reduction - could potentially change the HIA process and influence. Additionally, funding administration as a power differential emerged as a potential barrier to community participation and HIA influence. Each of these is discussed in further detail.

Scale Many of the challenges in the I-710 Corridor HIA are related to scale attributes. The community successfully advocated for an HIA with the I-710 Project Committee, but that same committee delegated the completion of the HIA to another 
Table 7.1 Target Plan Characteristics

\begin{tabular}{|c|c|c|c|c|c|}
\hline & Nature & $\begin{array}{c}\text { Goals \& } \\
\text { Objectives for } \\
\text { Health }\end{array}$ & $\begin{array}{l}\text { Concentrations of } \\
\text { Impacts }\end{array}$ & Scale & $\begin{array}{l}\text { Trigger Env. } \\
\text { Regulations }\end{array}$ \\
\hline $\begin{array}{l}\text { Lake } \\
\text { Merritt } \\
\text { Station } \\
\text { Area }\end{array}$ & $\begin{array}{l}\text { Transit Station } \\
\text { Area Plan } \\
\text { Urban mixed-use } \\
\text { neighborhood } \\
\text { including } \\
\text { Oakland's } \\
\text { Chinatown }\end{array}$ & $\begin{array}{l}\text { Promote health } \\
\text { through transit } \\
\text { oriented } \\
\text { development. } \\
\text { Harm reduction in } \\
\text { associated } \\
\text { redevelopment. }\end{array}$ & $\begin{array}{l}\text { Very } \\
\text { concentrated } \\
1 / 2 \text { mile radius } \\
\text { from station. }\end{array}$ & $\begin{array}{l}\text { Mid-sized } \\
\text { area plan } \\
\text { 4-year } \\
\text { planning } \\
\text { process }\end{array}$ & CEQA \\
\hline $\begin{array}{l}\text { Clark } \\
\text { County } \\
\text { Bike-Ped }\end{array}$ & $\begin{array}{l}\text { Bike-Ped Plan } \\
\text { Unincorporated } \\
\text { areas of quickly } \\
\text { urbanizing/ } \\
\text { suburbanizing }\end{array}$ & $\begin{array}{l}\text { Health promotion } \\
\text { through increased } \\
\text { active } \\
\text { transportation. }\end{array}$ & Very diffuse. & $\begin{array}{l}\text { Small, vision } \\
\text { plan } \\
\text { 18-month } \\
\text { planning } \\
\text { process }\end{array}$ & $\begin{array}{l}\text { No. However } \\
\text { mandated by } \\
\text { WA planning } \\
\text { regulations. }\end{array}$ \\
\hline $\begin{array}{l}\text { I-710 } \\
\text { Corridor }\end{array}$ & $\begin{array}{l}\text { Freeway } \\
\text { Expansion address } \\
\text { Ports of Long } \\
\text { Beach and LA } \\
\text { congestion. } \\
\text { Urban, low- } \\
\text { income, minority } \\
\text { cities with lots of } \\
\text { industry and } \\
\text { freight logistics. }\end{array}$ & $\begin{array}{l}\text { Harm reduction } \\
\text { particularly air } \\
\text { pollution by } \\
\text { adding 4-8 lanes } \\
\text { of freeway. }\end{array}$ & $\begin{array}{l}\text { Concentrated } \\
\text { over an 18-mile } \\
\text { section of I-710. } \\
\text { Analysis focuses } \\
\text { on populations } \\
\text { within 1-mile of } \\
\text { I-170. }\end{array}$ & $\begin{array}{l}\text { Currently } \\
\text { largest public } \\
\text { works } \\
\text { project in the } \\
\text { U.S. } \\
\text { 14+ years of } \\
\text { planning }\end{array}$ & $\begin{array}{l}\text { NEPA } \\
\text { CEQA }\end{array}$ \\
\hline
\end{tabular}

governing body under a completely separate plan. This was done to save money and effort, but the shift of oversight resulted in a loss of control and became a barrier for community input. It also sharply degraded the consideration of the HIA in the formal target plan. Conversely, the success of the Clark County HIA was attributable, in part, to ongoing inter-departmental relationships between the Public Health and Community Planning departments due to a relatively small county government setting. The relationships on the Clark County HIA were far more routine and friendly; this likely contributed to the collaborative approach. 
Planning Objectives Harris-Roxas and Harris (2011) recently recognized that the type of HIA is typically matched to planning objectives. This dissertation confirms that planning objectives intersect significantly with HIA strategy and influence. Health promoting plans such as the Lake Merritt and Clark County efforts appear to be more open to health input - likely because the HIA report provides non-threatening information. The two health-promoting plans studied were also visionary rather than an analysis of alternatives; this set a tone of cooperation across all disciplines and professionals.

Addressing risk reduction through HIA is potentially conflictual and practitioners should proceed with caution. HIA, with its holistic outlook, seeks to maximize health; this creates a tension with long-standing institutionalized practices of risk reduction in environmental and transportation planning. On face value, maximizing health and risk reduction may sound compatible, but each are from different sub-disciplines with different scientific toolboxes and objectives (Negev, 2012). When HIA practitioners advocate for the plan to move beyond regulatory minimums to address health, HIA, as the new process, is sometimes blamed for "moving out of health's lane." Much of the conflict about the I-710 Corridor HIA and conflicts over community benefits in the Lake Merritt case can be attributed to this phenomenon. Navigating the tension between maximizing health and risk reduction requires political savvy, good scientific understanding of risk reduction methodology, and a bit of good luck.

Funding Secure funding was controlled for in selecting cases. However the funding and administration mechanisms varied and were from sources that are not dominant funding sources today. The Lake Merritt case was funded through a federal 
USDOT participation grant with minimal oversight; this allowed the Lake Merritt Advisory Committee great latitude to shape the HIA as an advocacy exercise. Clark County funded its HIA through a Robert Wood Johnson grant in a highly supportive county health department. Caltrans instructed GCCOG to pay for the I-710 HIA.

GCCOG, in turn, contracted with a consulting firm who then sub-contracted with HIP for the HIA work. HIP mentioned multiple instances of both GCCOG and the consulting firm leveraging legal and financial power including: demanding a community member be removed from HIP's board, limited contact with the community during the HIA, withholding release of the HIA, and demanding that a non-flattering case study be removed from HIP's website. This should serve as a warning to those in HIA circles who envy the resources that come with the legal mandate of environmental review. HIA may be relatively cheap compared to environmental reviews, but demanding the project's sponsoring agency pay for the HIA may not be as straightforward as it appears.

Characterizing HIA Participation Structures One use of HIA is to coordinate the communication of health interests to the external stakeholder planning processes and thus force bureaucrats to consider the health implications of the public decision. Consistent with impact assessments' primary purpose to provide information, HIA leads to democracy by adding to the plurality of interests within a decision (O'Faircheallaigh, 2010). The HIA process also allows participants to engage by providing an alternative process than that of the target plan. Yet what kind of participation structure does the HIA process provide? This research finds that the participatory nature and robust community outreach seen in some early HIAs is an exception rather than a rule. The HIAs studied provided few opportunities for citizens to directly participate in the HIA or target plan. 
Conversely stakeholder forms of engagement were prominent. Further, strategies to engage stakeholders, including the community, varied widely: a community-led HIA advisory committee separate from the target plan where community representatives had control over nearly every decision; a collaborative strategy that combined efforts with the target plan's stakeholder model; and a highly technical stakeholder model over which the HIA had little control. Details about the structure, objectives, initiation, and relationship with the target plan are provided in Table 7.2 and in the subsections below.

HIA Participation Structure and Objectives Stakeholder engagement is a stated minimum element of HIA practice (North American HIA Practice Standards Working Group, 2010) and is often, but not always, conducted through an internal stakeholder advisory structure. HIA stakeholder advisory committees are potentially democratizing in a number of ways: identifying new health-related information; providing an additional participation opportunity for community representatives; supporting the growth of interdisciplinary relationships; and influencing public decisions (Stakeholder Participation Working Group, 2012). Yet communities often struggle to access and engage in stakeholder processes (Amy, 1987; Corburn, 2003, 2005a; Ehrmann \& Stinson, 1999; Innes \& Booher, 2010). Further, the negotiation, planning, and public health literatures all acknowledge that authentic, effective, and empowering stakeholder engagement requires an inclusive, well-facilitated, and well-resourced process (Carlson, 1999).

The three HIAs studied here relied heavily upon stakeholder engagement structures, but the strategies, including engagement and decision-making power of the 
Table 7.2 Participation Structure Matrix

\begin{tabular}{|c|c|c|c|}
\hline 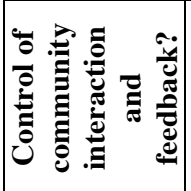 & 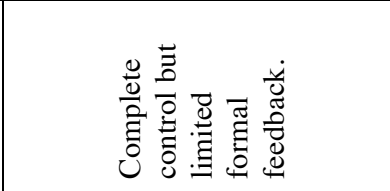 & 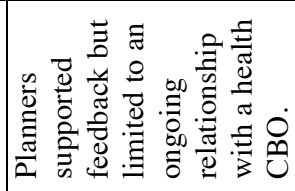 & 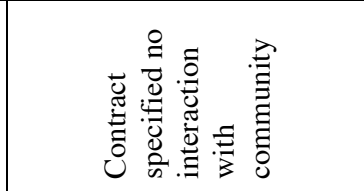 \\
\hline 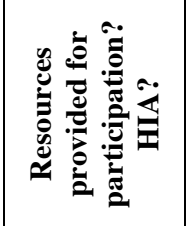 & 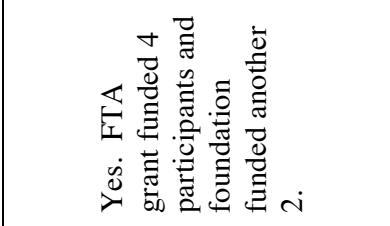 & 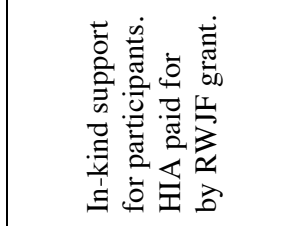 & 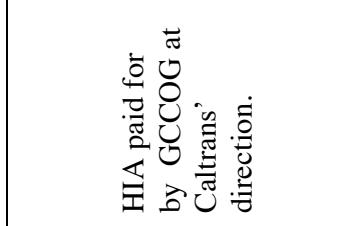 \\
\hline 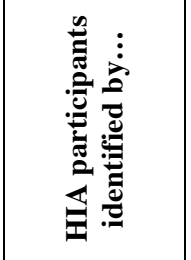 & 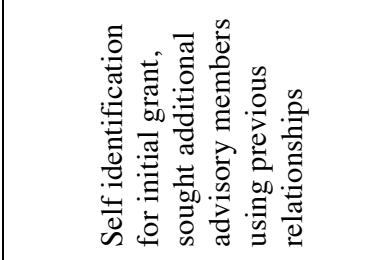 & 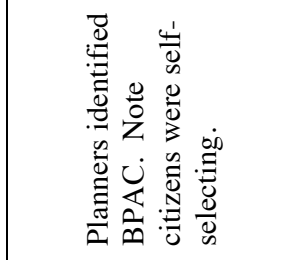 & 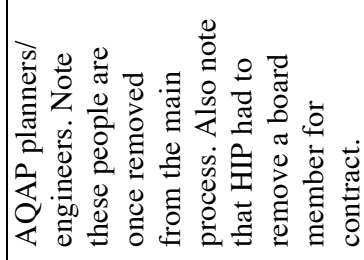 \\
\hline 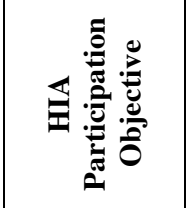 & 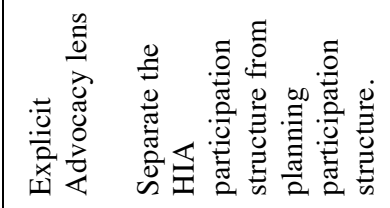 & 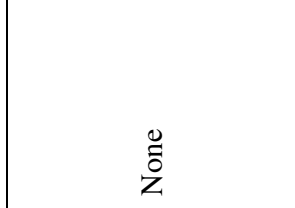 & $\stackrel{\circ}{\stackrel{0}{Z}}$ \\
\hline 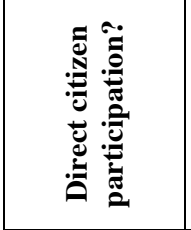 & 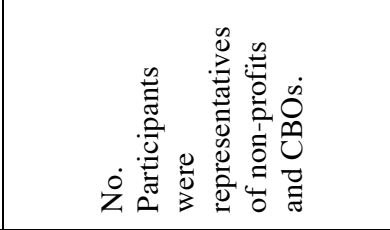 & 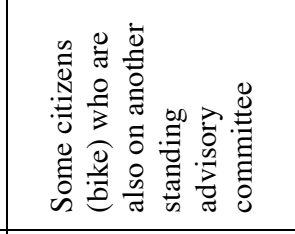 & 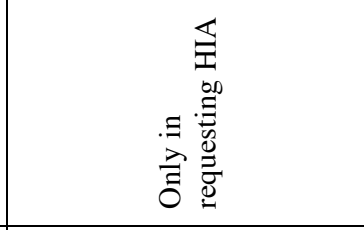 \\
\hline 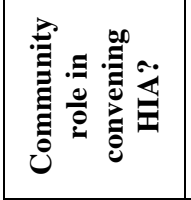 & 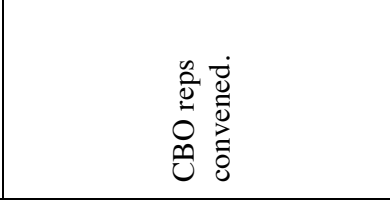 & $\begin{array}{l}0 \\
\overline{0} \\
z\end{array}$ & 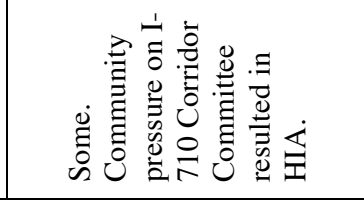 \\
\hline 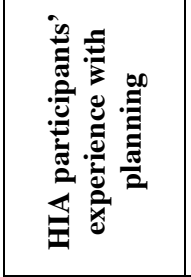 & 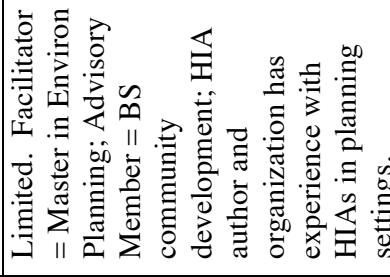 & 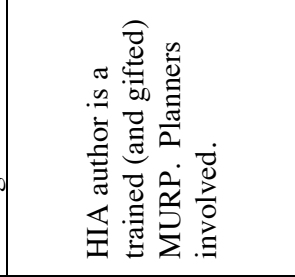 & 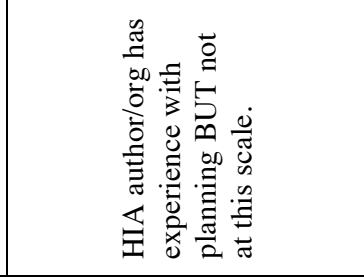 \\
\hline 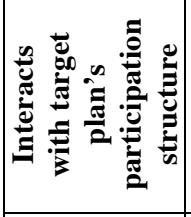 & 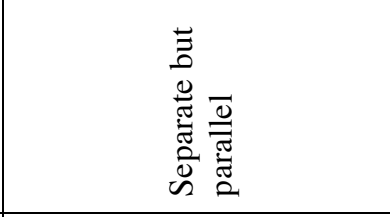 & 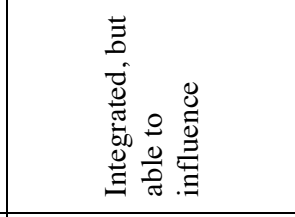 & 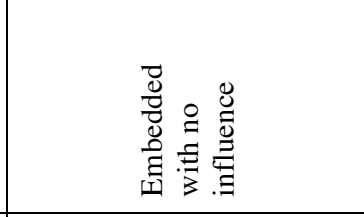 \\
\hline ש̋ & 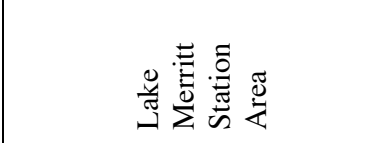 & 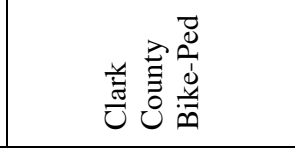 & 욤 \\
\hline
\end{tabular}


community, varied widely: the Lake Merritt HIA's six-member advisory council was explicitly selected to fully guide the HIA throughout the process; Clark County utilized the target plan's advisory committee as its HIA participation structure; and the I-710 Corridor HIA was forced to engage within the AQAP advisory committee structure that contained few avenues for community input. This variation is consistent with current HIA practice where

the level and quality of stakeholder participation var[ies] greatly. In many of these HIAs, stakeholder input was solicited to inform the scoping and assessment steps of the process,... but the stakeholders themselves were not involved in the actual HIA decision-making (Rhodus, et al., 2013, p. 82).

Recent Australian and U.S. meta-evaluations suggest that only a small proportion - 18.5 to $42 \%$ - of HIAs robustly engage stakeholders via advisory committees. Even fewer advisory committees "actually oversaw or guided the HIA process and were engaged as decision-makers in equal partnership with the HIA team or as the primary decisionmakers" (Rhodus, et al., 2013, p. 82). This suggests that the Lake Merritt HIA is a rare exemplar of advocacy and community-led HIA practice.

Initiation of HIAs Initiating an HIA is one way a community can exercise their democratic right to participate in and influence a planning decision. Doing so signals the community's uneasiness with both the content and participation avenues available in the official planning process. It also confirms the relevancy of the HIA and planning subject to the community. Both the I-710 Corridor and Lake Merritt HIAs were initiated by community members or organizations, although in drastically different ways. The community living in the I-710 Corridor advocated for the HIA through the existing democratic process, demanding that the planning body consider health. For the Lake 
Merritt HIA, community organizations committed to social justice worked with each other to start the HIA and later approached planners with health information. Community members in both cases continued to advocate for the HIA because they felt the planning process was inadequate and ignored important health issues.

The community will not initiate every HIA. The community did not initiate the Clark County HIA, but it is an exemplar of a decision-support HIA that accounts for community interests. This confirms that it is possible for an HIA to be community centered in the absence of an organized and engaged community as long as the HIA is relevant to the communities affected and emphasizes the pathways that affect the most vulnerable populations (Heller, Malakafzali, Todman, \& Wier, 2013). HIAs that are relevant are more likely to accurately gauge community interests and later engage the community. This is important because professionals within and without the community may be in a better position to accurately identify an opportunity where health can to influence and be integrated into decision-making. At other times, the health link may be so obvious that planners may invite public health professionals to start the HIA process to fill in a gap in the target plan's stakeholder process.

It is also important to clearly distinguish between community-initiated HIAs and participatory engagement strategies within the HIA. While the I-710 Corridor HIA came about because the community organized and demanded the target plan fund and consider the HIA, the HIA itself cannot be described as participatory. Even the Lake Merritt HIA, driven and controlled by community-based advocacy organizations with a history of participatory projects, was not able to provide participation opportunities for community residents. The lack of participatory elements is consistent with the greater HIA field; 
more than 275 HIAs have been completed in the U.S. at this time, but only a handful incorporate participatory processes as an engagement strategy.

Integrating with the Target Plan's Participation Strategy One immediate decision upon initiating an HIA is how to interact with the larger external stakeholder process. There was great variation in how the HIA practitioners navigated this decision. The Lake Merritt HIA explicitly chose a separate and parallel process, Clark County integrating with the greater planning Bicycle and Pedestrian Advisory Committee, and the I-710 Corridor HIA fully embedded within the technical planning process. While the Clark County HIA shows that collaborative relationships can support a combined HIA-planning engagement strategy, the I-710 Corridor HIA suggests caution in ceding control of community engagement.

Interviews with HIA authors all described the choice of integrating with the target plan as a combination of strategy and pragmatic expediency (UCLA School of Public Health, 2014). For example, Lake Merritt participants were clear that integrating with the target plan was a non-starter because the organizations involved wanted the process and HIA document to be free to forcefully advocate for the vulnerable communities living in Chinatown. Clark County described starting the HIA after already attending the Bicycle and Pedestrian Advisory Committee and choosing to integrate participation and feedback due to time and resource constraints. HIP told of being drawn to the I-170 project, in part, to push the field forward by showing an HIA could be integrated into the EIA/EIS process; but once that commitment was made, the participation structure was out of HIP's control. 
The initial decision about engaging the greater planning process is important because it generates path dependency and drastically shifts future options for interacting with the community. This finding can be thought of as an extension of Harris-Roxas and Harris' (2011) recent typology which suggests HIAs can be classified by their purpose: regulatory/integrated, decision-support, advocacy, and community-led. Most HIA practitioners are comfortable with a variety of HIA-types; it has long been lauded as a flexible practice (Cole, et al., 2004). The troubling part, however, is that path dependency potentially limits discretion, advocacy, power, and influence of both professionals and communities. For example, the Lake Merritt HIA is somewhere between community-led and advocacy on Harris-Roxas and Harris' (2011) typology. The advisory committee retained complete control over participants, resources, scoping, framing, and rollout of the HIA. Because the committee was composed of representatives from aggressive community advocacy organizations, the Lake Merritt HIA takes the tone of a community advocacy document and is a good example of an advocacy HIA with community-led elements.

On the other end of the spectrum, the I-710 would certainly be considered an integrated/regulatory HIA. In this setting, the HIA and accompanying engagement was funded and thus controlled by the same government entity controlling the target plan. Integrating the HIA into the regulatory framework came at a serious cost. Namely, the HIA author, HIP, was forced to back away from some of the more advocacy/communityled HIA strategies. For example, even before HIP signed the contract to do the I-710 HIA, it was asked to break ties with the community by removing a board member and limiting all community contact during the HIA. Retrospectively, this was a huge red flag; 
but HIP felt a sense of loyalty to advocate for the community by completing the HIA they so desperately wanted. HIP ceded control over the participation structure, invited participants, or decision-making authority. Further, the risk/harm reduction frame of the I-710 Corridor and AQAP plans conflicted with the health maximization objective of the HIA. When the HIA became adversarial, HIP had little power to reverse opposition that appeared in the official planning process. The HIA report essentially went from being an advocacy planning document initiated by the community to fully coopted by the powerful freight movement coalition (Piven, 1970) who have been perpetuating environmental, and by extension health, degradation for generations.

The Clark County case highlights an interesting middle ground where the HIA participation structure was integrated into the greater planning structure but was able to translate the combined structure into an effective HIA. The Clark County case suggests decision-support HIAs are likely be successful when the plan is more visionary than regulatory and the relationship between planning and public health is strong. Public health was treated as a significant partner in the process and offered the ability to engage stakeholder advisory group as needed. The HIA author and Clark County planners both attributed this to an ongoing relationship between Community Planning and Public Health at the county level.

Problem Definition and Agenda Setting Articulating community concerns when defining the problem and setting the agenda is a powerful act because it makes it more likely that the process and eventual outcomes will address interests as expressed by the community. Beyond making sure all community interests are invited to the process, HIA practitioners have an obligation to facilitate the process in such a way where community 
representatives can articulate their interests and equitably participate (Carlson, 1999;

Rauschmayer \& Risse, 2005). Table 7.3 compares how agendas and problems were defined in each of the cases. All cases provided opportunities - generally during the scoping phase - for the communities to define problems and set the agenda; however the time and circumstances varied widely. In general, as the HIAs became more intertwined with the official planning process, the ability for the community to freely influence the agenda and problem definition was reduced.

In the Lake Merritt case, there was a lot of grappling with individual CBO advocacy issues and how they fit with the HIA. This primarily occurred during the scoping phase. Almost all of the participants reported intense social learning curves as they struggled to understand each others' interests and how it all fit in with health constructs and frames. Scoping was facilitated by a priority consensus document that

Table 7.3 Problem Definition and Agenda Setting in the HIA

\begin{tabular}{|c|c|c|c|}
\hline & Who? & When? & Other factors \\
\hline $\begin{array}{l}\text { Lake Merritt } \\
\text { Station Area }\end{array}$ & $\begin{array}{l}\text { Advisory } \\
\text { committee } \\
\text { through } \\
\text { consensus }\end{array}$ & $\begin{array}{l}\text { Primarily during } \\
\text { scoping }\end{array}$ & $\begin{array}{l}\text { Applied previously defined by the } \\
\text { greater community document 'Nine } \\
\text { Guiding Principles' to make } \\
\text { scoping decisions }\end{array}$ \\
\hline $\begin{array}{l}\text { Clark County } \\
\text { Bike-Ped }\end{array}$ & $\begin{array}{l}\text { Public health } \\
\text { professional } \\
\text { with flexibility } \\
\text { to fold in other } \\
\text { stakeholder } \\
\text { concerns }\end{array}$ & $\begin{array}{l}\text { Desktop HIA guided } \\
\text { ongoing scope/analysis } \\
\text { of health issues. }\end{array}$ & \\
\hline I-710 Corridor & $\begin{array}{l}\text { Unofficial: } \\
\text { Community } \\
\text { representatives } \\
\text { Official: } \\
\text { Planners and } \\
\text { technical } \\
\text { advisory } \\
\text { committee for } \\
\text { AQAP }\end{array}$ & $\begin{array}{l}\text { Unofficial: A 2-day } \\
\text { training long before HIA } \\
\text { was a reality essentially } \\
\text { screened and scoped the } \\
\text { HIA. } \\
\text { Official: Rigid } \\
\text { definitions decided early } \\
\text { in the official HIA } \\
\text { process. }\end{array}$ & $\begin{array}{l}\text { The scope was very contentious. } \\
\text { HIA author felt severely limited to } \\
\text { unhealthy alternatives pathways by } \\
\text { what was included in the EIA/EIS } \\
\text { definition of the problem. } \\
\text { There was constant pressure on HIA } \\
\text { by AQAP to drop less proximal } \\
\text { pathways because a holistic look at } \\
\text { health doesn't play well in an } \\
\text { environmental regulatory context. }\end{array}$ \\
\hline
\end{tabular}


many, if not all, the CBOs had participated in creating to outline community priorities. The Lake Merritt advisory group strove for consensus and scoping took nearly four times the amount budgeted - although some of that time was required to bring late additions up to speed a few months into the process. The overrun is notable as the HIA author, HIP, is very experienced in advocacy community-led HIAs and still underestimated the time needed. More than one participant expressed frustration at the length and resources devoted to scoping; however, they also agreed that it had to occur in order to reach a point where everyone felt comfortable with each other and the analysis plan. The Lake Merritt HIA is consistent with the negotiation literature adage 'slow down to go fast ${ }^{41}$.' Stakeholder groups gather a diversity of interests, knowledge, and data and HIA is no exception (Negev, 2012). Good scoping takes time. The advisory committee for the Lake Merritt case was able to stretch out the scoping phase because they controlled the process and the target planning process was moving at a reasonable speed.

While it is more likely that the HIA will reflect community interests if the community is included in scoping, the Clark County and I-710 HIAs reveal that health professionals alone can accurately identify and expand the publics and health interests under consideration. This is particularly true when professionals remain committed to underlying values such as health equity, fully explore the social determinants of health, and use geographic tools when appropriate (see the following section on knowledge). Clark County and I-710 authors, however, were found themselves constrained in how to integrate the community in scoping because of dependency on the target planning process. When Clark County received a grant for the HIA approximately one-quarter of

${ }^{41}$ This phrase is attributed to Lawrence Susskind. 
the way through the planning process, the HIA author produced a quick, desktop HIA to guide discussions. When combined with a relatively narrow scope of the plan - active transportation from biking and walking - the rapid, desktop HIA allowed health to be quickly and accurately integrated with the greater planning process. It set the tone for expanding both the communities (utilitarian, future users, and pedestrians at large) and the health pathways (access to healthy destinations and food) considered. The scope was then tinkered with as things came up in the Bicycle and Pedestrian Advisory Committee. Examples of the scope changing midway due to stakeholder feedback include the change in framing Safe Routes to School and a late addition of mapping bicyclist and pedestrian fatalities.

In the I-710 case, community representatives were able to influence the HIA agenda upfront through the two-day training. The fact that the training conveners chose the I-710 Corridor as the example to use for the training indicates it was a problem of great concern to the community. The group of thirty professionals and community representatives were likely able to accurately identify broad community health interests in such a setting. Once HIP started official conversations with AQAP planners, interplay between the community and the HIA stopped. Yet HIP attempted to incorporate the community concerns brought up in the training by keeping the official scope fairly close to that which was defined by the community. Despite the fact that the community had advocated for the HIA precisely because they wanted a more holistic look at health, HIP was constantly under attack to limit the community-defined scope to look like a more traditional regulatory analysis of air quality. 
HIP suggested that conflicts over the scope were largely attributable to two reasons. First, because the HIA was funded under the AQAP effort, most people on the technical and environmental advisory committees were uncomfortable with any health pathway beyond air and noise. These advisory committee members were far more comfortable in a regulatory environment and never quite caught the HIA vision of maximizing health. The second issue that made fidelity to the community scope difficult is that by agreeing to integrate into the EIA process, HIP essentially agreed to limit alternatives to those under official consideration in the environmental process.

Agreeing to limit HIA analysis to official alternatives may seem reasonable to planners, but it is problematic for public health practitioners interested in health impact assessment for a number of reasons. First, public health practitioners advocating for an HIA process are likely to have a much broader systems view of health as dictated by the social determinants of health. For example, the AQAP technical advisory committee held a very narrow view of health as defined by air and noise and was uncomfortable with exploring air pollution outside standard presentations based on toxicological notions of regulatory thresholds that has been institutionalized by decades of NEPA practice. Second, HIA practitioners view their role as both analyzing and developing mitigation strategies to maximize health including strategies that may be outside the defined alternatives. HIA practitioners wish to maximize health, are not particularly concerned about other constraints such as cost or technical feasibility, and view the universe of pathways and alternatives much more broadly than planners and engineers experienced in NEPA. These scoping issues are likely to come up in almost any HIA embedded into an environmental review process. It is possible that better integration of community 
representatives could help, but it may not be enough to bridge the gap between the HIA and environmental planning worlds.

Finally, it is important to note that scoping with a supportive community is about more than accurately identifying the public interest; it helps set the stage for a shared understanding of problems and solutions. (See subsection below.) Scoping is the most common (Rhodus, et al., 2013) and reasonable point in which to insert community questions and concerns within a stakeholder format. If HIA practitioners wish to support increased participation opportunities for communities and their representatives through HIA, they need to be more explicit about the engagement process and goals. HIA practitioners should specifically consider allotting significantly more time and resources to support the extensive shared learning that occurs during the scoping stage of the HIA.

Knowledge Integration in HIA Planning, at its core, is about harnessing knowledge to make and implement decisions for the future. The primary objective of impact assessment is to provide and integrate additional information into the target plan. Despite an intertwined history with environmental advocacy, impact assessment tends to elevate technical expertise (Innes \& Booher, 2014; O'Faircheallaigh, 2010). Yet technical and community knowledge are not mutually exclusive; processes that use both knowledge types to co-produce shared knowledge are the most likely to reframe problems in an emancipatory way (Innes \& Booher, 2014). One important strand of this research was to understand if and how HIA integrates technical information with community knowledge. To the extent that community knowledge is limited, it also looked for technical knowledge that facilitated consideration of community interests. 
Table 7.4 Knowledge Types in the HIA

\begin{tabular}{|c|c|c|c|c|}
\hline & $\begin{array}{c}\text { Role of Local } \\
\text { Knowledge }\end{array}$ & $\begin{array}{c}\text { Role of Technical } \\
\text { Knowledge }\end{array}$ & Role of Geography & $\begin{array}{c}\text { Invokes community } \\
\text { concerns? }\end{array}$ \\
\hline $\begin{array}{l}\text { Lake } \\
\text { Merritt }\end{array}$ & $\begin{array}{l}\text { Little joint fact- } \\
\text { finding, something } \\
\text { that disappointed at } \\
\text { least one participant. } \\
\text { Survey of Asian } \\
\text { signage. } \\
\text { HIA drew heavily } \\
\text { from past inventories } \\
\text { and existing } \\
\text { conditions reports } \\
\text { written by involved } \\
\text { advisory committee } \\
\text { members. }\end{array}$ & $\begin{array}{l}\text { Supportive of } \\
\text { local knowledge } \\
\text { and concerns. } \\
\text { HIA is primarily a } \\
\text { heavy literature } \\
\text { review. }\end{array}$ & $\begin{array}{l}8 \text { maps to show specific } \\
\text { community concerns: } \\
\text { - bike/ped injuries and } \\
\text { fatalities } \\
\text { - crime w/ transit } \\
\text { overlay } \\
\text { \# of residents within } 500 \\
\text { feet of a tunnel. }\end{array}$ & $\begin{array}{l}\text { Nine subsections } \\
\text { labeled "Community } \\
\text { Perspectives." } \\
\text { Repeatedly returns } \\
\text { to the Nine Guiding } \\
\text { Principles. }\end{array}$ \\
\hline $\begin{array}{l}\text { Clark } \\
\text { County }\end{array}$ & $\begin{array}{l}\text { Some inventory of } \\
\text { bike-ped facilities in } \\
\text { greater BPAC }\end{array}$ & $\begin{array}{l}\text { Supportive, but } \\
\text { primarily a } \\
\text { professional } \\
\text { literature review. }\end{array}$ & \begin{tabular}{|l}
21 maps \\
$-\quad \begin{array}{l}\text { demographics } \\
\text { current health } \\
\text { conditions }\end{array}$ \\
- $\quad \begin{array}{l}\text { current network of } \\
\text { facilities }\end{array}$ \\
$-\quad$ access to resources \\
$-\quad$ crime rate \\
- $\quad$ bike/ped injuries and \\
fatalities \\
Overriding \\
recommendation in \\
Rapid HIA for more \\
geographic focus to \\
address health equity \\
issues.
\end{tabular} & No. \\
\hline $\begin{array}{l}\text { I-710 } \\
\text { Corridor }\end{array}$ & None. & $\begin{array}{l}\text { Literature review } \\
\text { with modeling. }\end{array}$ & 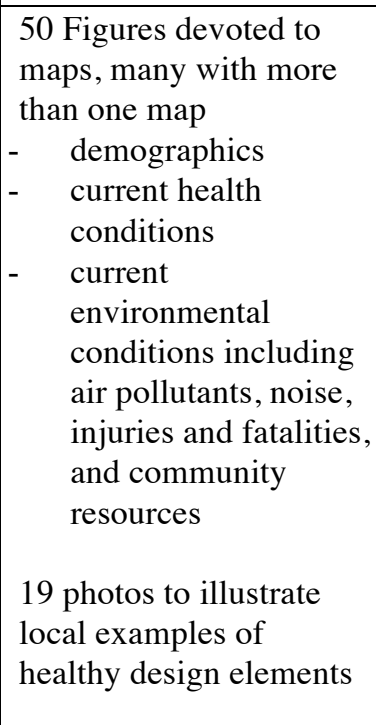 & $\begin{array}{l}\text { Nine sub-sections } \\
\text { highly quoting and } \\
\text { discussing concerns } \\
\text { from } 2004 \text { Tier } 2 \\
\text { Community } \\
\text { Advisory } \\
\text { Committee report; } \\
\text { one also cites } \\
\text { current community } \\
\text { participation } \\
\text { framework. } \\
\text { Note that these } \\
\text { subsections are } \\
\text { placed prominently } \\
\text { to frame the analysis } \\
\text { and/or } \\
\text { recommendations. }\end{array}$ \\
\hline
\end{tabular}


Table 7.4 provides an overview of the various types of knowledge seen in the cases studies. It reflects the finding that even with robust advisory committees, HIAs tend to be written by public health professionals who draw heavily from the literature to qualitatively describe the expected health impacts and increasingly use quantitative models to model health impacts. In this environment, it is fair to question the balance between local knowledge held by the community and technical knowledge generally held by professionals.

Co-production of Data Even more concerning, the reliance on stakeholder participation structures generally meant there was little evidence of co-production of data. One member of the Lake Merritt advisory committee was highly critical of the lack of joint fact-finding suggesting there may be a need to temper the participatory science expectations when beginning an HIA. Both the Lake Merritt and the Clark County HIA authors cited limited resources - time and money - as the primary reason for not undertaking more data collection. While funding - both at the time these HIAs were being completed and currently - is more readily available than the very early days of U.S. practice, the fact remains that resources are relatively scarce. In this environment, limiting community input and data collection is a realistic strategy for dealing with a small budget.

For example, the Robert Wood Johnson Foundation grant for the Clark County HIA was $\$ 100,000$ and is considered a large budget in the HIA world. This grant paid for 1.0 FTE for a pretty straightforward and defined topic with minimal quantitative modeling. But it also required completion of two HIAs (rapid and comprehensive) and an evaluation in about one year. In the Lake Merritt case, the budget and time went 
quickly, particularly as two additional community groups were added and the scoping process drew out over four or five months. Little remained to fund data collection during the analysis stage. Even with the project proponents - GCCOG - paying for the HIA ${ }^{42}$, the I-170 HIA authors struggled to manage resources and time. The I-170 HIA is highly quantitative and required a great deal of data and expertise; yet Caltrans and MTA's final modeled data required to feed air pollution concentrations and noise into the HIA models were not available at the time the HIA was being completed. The majority of the HIA was completed in just a few months - a feat that even GCCOG complemented HIP on successfully completing.

The lack of evidence of co-production of data seems to conflict with recent findings of an EPA meta-evaluation that found

collection of primary data is also a critical component of HIA. A variety of special collection methods were used in the HIAs to acquire new data, often at the local level.... Of the special collection methods utilized, those that involved and/or solicited information from stakeholder or the community and GIS or other mapping techniques were used most often (Rhodus, et al., 2013, p. 79).

Further examination of the EPA's evaluation suggests their conclusions may be driven by a particularly broad definition of data collection methods. This suggests more research is needed to fully understand the origin and use of primary data collection in HIA.

Co-production of Knowledge through Deliberation A lack of primary data collection, however, does not preclude community interests being identified or elaborated with local, community knowledge by community representatives. The community representatives participating with the Lake Merritt HIA obviously grappled with

\footnotetext{
${ }^{42}$ It is notable that having the project proponent pay for the HIA is one of several reasons why HIA practitioners are attracted to integrating HIA into the official process. What seems to be missing from this discussion is a firm understanding of the resources needed to address the scale and scope of NEPAtriggered planning process.
} 
community-specific knowledge in its scoping deliberations. The collaborative planning literature suggests the presence of community members and representatives allows local, community knowledge to surface through deliberation. This certainly seemed to be the case in all HIAs. Even the little interaction the I-170 community representatives had with the HIA at AQAP forums strengthened the HIA content and the Lake Merritt HIA certainly illustrates that community representatives can elicit community interests from each other.

\section{Supporting Community Health Interests with Professional Knowledge The}

HIAs studied also address community interests and concerns through professionals. Public health professionals are able to discover and support community interests by highlighting data, knowledge and concerns previously collected by the community. Two of the HIAs contained "community perspectives" subsections that drew heavily from previous community outreach efforts. These subsections, while short in length, are prominent in the framing of the analysis and recommendations in the HIA report. Generally, the community perspectives subsections quote reports from previous community outreach efforts. For example, the Lake Merritt HIA refers to information from the community teas and continually invokes the Nine Guiding Principles. This has the effect of anchoring the health analysis in community needs and priorities, even for the I-710 HIA with its emphasis on quantitative models and admittedly limited community outreach.

HIA practitioners also support community health interests through professional knowledge. Professional expertise in documenting existing environmental and health conditions and taking a decidedly geographic approach to the health analysis elevated 
equity in health outcomes in each HIA. This path to supporting community health interests is akin to advocacy planning (Davidoff, 1965/2003) where professionals support communities that may not be organized or powerful enough to otherwise influence the process. Thus their professional expertise helps identify and advocate for community health interests.

The most common types of professional and scientific knowledge used to frame and elevate community health interests in HIA include use of the social determinants of health to establish health pathways, health equity and disparities to identify issues salient to vulnerable populations, and an explicit geographic focus. The first two are particularly notable because each concept has been discussed as an explicit HIA value as well as in explaining the distinct nature of HIA (Harris-Roxas \& Harris, 2011). Yet relatively little has been written about how these particular professional knowledge types protect community interests or facilitate social learning. Thus each is discussed in more detail below.

Social Determinants of Health The social determinants of health is an anchor of contemporary public health practice, particularly for those who focus on community health and health promotion (Wilkinson \& Marmont, 2003). It also is an explicit HIA value (World Health Organization, 1999). By committing to the social determinants of health, HIA practitioners promise to look at a proposed plan in a holistic and multidisciplinary way. This helps HIA practitioners to think broadly and deeply about intended and unintended consequences of a proposed plan or policy during the early scoping phase. It is through the social determinants of health that public health professionals are able to accurately identify health interests for publics or communities 
even with minimal community involvement. This identification occurs by establishing multiple and detailed pathways linking non-health impacts of a plan to individual and community health. For example, the Clark County HIA was able to prompt the target plan to consider access to food within a bicycle and pedestrian plan after identifying access to food through active transportation networks as an important health pathway.

Health Equity Health equity is a second type of foundational knowledge in public health; it is also an explicit value in HIA practice (Heller, et al., 2013; World Health Organization, 1999). Striving for health equity acknowledges the uneven impact of the social determinants of health on various populations. There are multiple procedural best practices to increase health equity through relevant capacity building, but these generally require robust and authentic community engagement (Heller, et al., 2013).

In a stakeholder participation format, HIA practitioners use professional discretion as advocacy planners to address health equity. They initiate and facilitate equity conversations by sourcing and displaying data that features health equity themes. Public health professionals are well positioned to highlight the communities that need the most help when documenting current conditions. All three HIAs document differences in environmental conditions and health outcomes to frame the HIA. In doing so, each HIA advocates for communities that traditionally do not have a strong voice in decisionmaking processes.

Geographic Focus An unanticipated finding of this research was the extent to which a geographic focus - including utilization of basic GIS skills - helps HIAs remain community centered. GIS, as a visual representation of spatial distribution, can highlight health equity by mapping environmental and health disparities. All three HIAs used GIS 
to represent current conditions; had at least one analytical use of GIS, even though most were exceedingly simple; and strategically framed the spatial unevenness of exposure and health risks with GIS. This helped elevate community concerns.

For example, the Lake Merritt HIA report included the fewest number of maps only eight. These maps, however, emphasize that hazardous conditions for bicyclists and pedestrians spatially cluster in very specific areas around Chinatown. The Clark County HIA contains 21 maps that range from demographics to current access to resources such as parks, grocery stores, fast food, and schools. The author of the Clark County HIA expressed great surprise that no one in planning or public works was attempting to map bicycle and pedestrian injuries for a bike-ped plan. Inclusion of walkability scores and a geographic SES index in sidewalk infill criteria is another example where geographic information was folded into decision making. The 50 figures displaying maps in the I710 HIA also draw attention to the plight of specific spatial communities. Many of these maps compare the scenarios under consideration against current community conditions and undeniably show that expansion scenarios may not actually reduce specific air pollutants, areas of congestion, or noise levels. The I-710 HIA also provides 19 pictures from impacted neighborhoods to provide specific examples of good and bad design.

\section{Facilitating Social Learning and Equity with Professional Knowledge One} emergent theme was the extent to which public health frames such as the social determinants of health, health equity, and a geographic focus were bridging the gap between community and technical knowledge by facilitating social learning. HarrisRoxas and Harris (2011) have suggested that health equity and a social view of health make HIA roots distinctive from other impact assessment. These two concepts are also 
routinely cited as fundamental HIA values. This research also showed that both are protective of community health interests because each plays an important part in social learning among stakeholders and communities involved in the HIA. Similarly, geography, while greatly underutilized in HIA, brings health equity concepts into clear focus and thus promotes community health interests. HIA practitioners have a sense that social learning happens in HIA but tend to attribute and define social learning narrowly as educating participants in public health language and concepts. Yet it seems that health frames such as social determinants of health and health equity also served as a translational language that allowed communities with diverse interests to reach consensus about the most important aspects of the plan. Table 7.5 summarizes how this seems to have happened in both the Lake Merritt HIA and the Clark County Bike-Ped HIA. For example, in the Lake Merritt case, the scoping phase was lengthy because of strong advocacy positions by individual community organizations. Each came from different sectors with different concerns and languages. The health equity frame served to bind the group together and stick with sorting through the problem with a health lens. Combined with the social determinants of health, health equity helped assure the representatives that the HIA could maintain a community perspective and advocate for the Chinatown community. The social determinants of health also translated diverse interpretations of social justice into a single narrative that allowed the group to begin prioritizing and narrowing.

Through a strong commitment to health equity, the Clark County HIA author was able to expand the public under consideration. Future cyclists, cyclists of all levels, and 
Table 7.5 Public Health Frames and Social Learning

\begin{tabular}{|c|c|c|c|c|c|}
\hline HIA & \multicolumn{2}{|c|}{ Social Determinants of Health } & \multicolumn{2}{|c|}{ Health Equity } & Contested Views of Health \\
\hline \multirow[t]{2}{*}{$\begin{array}{l}\text { Lake } \\
\text { Merritt } \\
\text { Station } \\
\text { Area Plan }\end{array}$} & \multicolumn{2}{|c|}{$\begin{array}{l}\text { Narrowed large suite of interests } \\
\text { Bridged four different } \\
\text { advocacy positions }\end{array}$} & \multicolumn{2}{|c|}{$\begin{array}{l}\text { Helped translate diverse } \\
\text { community commitment to social } \\
\text { justice into health }\end{array}$} & \multirow[t]{2}{*}{$\begin{array}{l}\text { AHS was not sure HIA } \\
\text { pushed far enough }\end{array}$} \\
\hline & & & IAL & $\begin{array}{l}\text { community } \\
\text { perspectives }\end{array}$ & \\
\hline & \multicolumn{3}{|c|}{ LEARNING } & & \multirow{2}{*}{$\begin{array}{l}\text { Bicyclists didn't want to } \\
\text { expand the 'public' } \\
\text { ADA and a junior planner } \\
\text { didn't see added value of } \\
\text { HIA. } \\
\text { School District didn't want } \\
\text { Safe Routes to Schools }\end{array}$} \\
\hline $\begin{array}{l}\text { Clark } \\
\text { County } \\
\text { Bike-Ped }\end{array}$ & \multicolumn{2}{|l|}{$\begin{array}{l}\text { Expanded considerations } \\
\text { of access to } \\
\text {-food } \\
\text {-parks } \\
\text {-schools }\end{array}$} & \multicolumn{2}{|c|}{$\begin{array}{l}\text { Expanded the community } \\
\text { considered to pedestrians, future } \\
\text { and utility users } \\
\text { Seen in the sidewalk prioritization } \\
\text { criteria }\end{array}$} & \\
\hline $\begin{array}{l}\text { I-710 } \\
\text { Corridor }\end{array}$ & Guided the HIA & & $\begin{array}{l}\text { Overarchi } \\
\text { communi } \\
\text { was to ad } \\
\text { injustice } \\
\text { I-710 exte }\end{array}$ & $\begin{array}{l}\text { oncern for } \\
\text { nd some planners) } \\
\text { s the environmental } \\
\text { r-pollution and other } \\
\text { ities. }\end{array}$ & $\begin{array}{l}\text { Social Determinants of } \\
\text { Health conflicted with plan' } \\
\text { and AQAP's regulatory and } \\
\text { direct impacts emphasis }\end{array}$ \\
\hline
\end{tabular}

pedestrians became more prominent because the HIA was able to simultaneously address the near-universal nature of active transportation and the barriers often experienced by marginalized communities. Multiple individuals told of "ah-ha" moments when cycling or walking after discussing active transportation at Bicycle and Pedestrian meetings; design barriers that had seemed inconsequential all of a sudden became much more apparent. The social determinants of health framework also expanded the health pathways considered. Access to health food, parks, and education facilities were addressed because the HIA introduced the concepts to the greater group.

Geographic tools also prompt a closer look at equity and facilitate social learning. While GIS roots can be traced back to John Snow mapping cholera cases in London in 1854 , current HIA practice is largely limited to mapping and communicating current conditions. This understates the potential of GIS to support shared learning and is surprising given the elevated demand and role of health indicators in contemporary planning practice (Farhang, et al., 2008; A. Forsyth, et al., 2010) and effort of urban 
geographers to document and understand spatial injustice (S. S. Fainstein, 2014). Yet the HIA community is only beginning to recognize GIS as a way to "identify spatial disparities in health outcomes, evaluate health determinants and outcomes in a geographic context...[and] identify environmental justice communities" (Rhodus, et al., 2013, p. 88). Just over half of the HIAs in the recent EPA evaluation used GIS to display or represent data - primarily current conditions; $35 \%$ used GIS as an analytic tool (Rhodus, et al., 2013).

There is also inadequate understanding within HIA circles about how geographic representations can potentially empower communities by providing an approachable representation of disparities that reach across knowledge types and comfort levels. Public health professionals intuitively know that mapping conditions is a quick and effective way to display and communicate data but largely under-utilize maps as a conversation starter. Yet multiple interviewees across cases described the classic planning scene of stakeholders surrounding a map as a turning point in understanding the spatial distribution and disparities of environmental risk factors and health. HIA practitioners would likely benefit from exploring GIS as more than an analytical tool including studying how planners use maps to elicit deliberation.

Is Health Universally Accepted? Public health practitioners need to be aware that health is not a universally accepted frame. Citizen bicyclists from Clark County showed no interest in discussing the HIA or broadening beyond bicycle safety; another individual who was key in addressing access for those with disabilities also did not seem to understand the link to health; and a junior planner described the HIA as just another hoop through which to jump. A representative from the community-based health clinic in the 
Lake Merritt case also seemed less than enthused about the HIA, the lack of resources to collect local data, and noted constraints in the ability of the HIA process to push health equity for their highly poor and minority clients. Finally, much of conflict regarding the contents of the I-710 HIA can be attributed to dueling visions of health in impact assessment. Many of the air-quality and planning experts saw the environmental process as a regulatory, rational procedure that should use technical data; the HIAs' emphasis on health promotion through the social determinants of health was viewed as less than rigorous, not particularly logical, and irrational.

Understanding Community Influence and Effectiveness The primary outcome of an HIA process is an HIA report addressed to decision makers. This report typically documents existing conditions, outlines evidence of health impacts, and provides mitigation suggestions to maximize health. In an HIA process supportive of community, community interests should be incorporated into the HIA report. Because the primary goal of an HIA is to inform and influence decisions, an effective HIA should have evidence of HIA recommendations in the target plan. Ideally the target plan should also incorporate the community interests that surfaced in the HIA. A comparison of various measures of influence is provided in Table 7.6 and discussed below.

Community Interests Within the HIA Document Even with limited participatory opportunities, the HIAs studied showed evidence of community interests. The Lake Merritt HIA reflects a process controlled by a CBO advisory committee with the HIA report reframing a previous community-defined Nine Guiding Principles document in terms of community health. The other two HIAs are far more professionally driven but 
Table 7.6 Measures of Community Influence

\begin{tabular}{|c|c|c|c|c|}
\hline & $\begin{array}{l}\text { Community } \\
\text { Interests in HIA }\end{array}$ & $\begin{array}{l}\text { HIA Recommendations in } \\
\text { Target Plan }\end{array}$ & $\begin{array}{l}\text { Other HIA } \\
\text { Elements in } \\
\text { Target Plan }\end{array}$ & $\begin{array}{c}\text { Increased } \\
\text { Governance }\end{array}$ \\
\hline $\begin{array}{l}\text { Lake } \\
\text { Merritt }\end{array}$ & $\begin{array}{l}\text { Use of Nine } \\
\text { Principles } \\
\text { Document } \\
\text { overlaid with } \\
\text { Social } \\
\text { Determinants of } \\
\text { Health } \\
\text { Community } \\
\text { Perspectives } \\
\text { subsection } \\
\text { Geographic } \\
\text { information }\end{array}$ & $\begin{array}{l}\text { Widen sidewalks, } \\
\text { scramble intersections, } \\
\text { support festival streets, } \\
\text { emphasis on youth and } \\
\text { pedestrian safety, } \\
\text { improved pedestrian } \\
\text { linkages to Chinese } \\
\text { Garden Park and Laney } \\
\text { College } \\
\text { HIA citations in } \\
\text { "Affordable Housing } \\
\text { Strategy" subsection } \\
\text { More attention to } \\
\text { addressing current park } \\
\text { utilization. } \\
\text { Near verbatim quote of } \\
\text { establishing local hiring } \\
\text { goals and services }\end{array}$ & $\begin{array}{l}\text { July } 252011 \\
\text { letter: streetscape } \\
\text { improvements; } \\
\text { "pedestrian-scale } \\
\text { lighting"; phased } \\
\text { approach to } \\
\text { understanding } \\
\text { lane reduction } \\
\text { versus 1-way and } \\
\text { 2-way roads } \\
\text { November } 22 \text {, } \\
\text { 2011 letter: } \\
\text { further study of } \\
\text { bicycle safety and } \\
\text { loading/unloading } \\
\text { in Chinatown } \\
\text { core }\end{array}$ & $\begin{array}{l}\text { HIA advisory } \\
\text { committee served as } \\
\text { an ad hoc coalition } \\
\text { for ongoing } \\
\text { collaboration on } \\
\text { CBA and other LM } \\
\text { SAP issues. This } \\
\text { continued informally } \\
\text { post HIA. } \\
\text { TransForm \& HIP's } \\
\text { Oakland Bus Rapid } \\
\text { Transit HIA }\end{array}$ \\
\hline $\begin{array}{l}\text { Clark } \\
\text { County }\end{array}$ & $\begin{array}{l}\text { Geographic } \\
\text { emphasis } \\
\text { Expanded } \\
\text { consideration of } \\
\text { publics such as } \\
\text { utility, future } \\
\text { users, all levels } \\
\text { of cyclists, } \\
\text { pedestrians } \\
\text { Expanded } \\
\text { consideration of } \\
\text { health pathways } \\
\text { such as access to } \\
\text { food, parks, } \\
\text { schools }\end{array}$ & $\begin{array}{l}\text { Rapid HIA included as an } \\
\text { appendix in Plan. } \\
\text { Of the } 11 \text { Rapid HIA } \\
\text { recommendations, } \\
\text { - } 5 \text { verbatim } \\
\text { inclusions } \\
\text { - } 3 \text { partially } \\
\text { addressed } \\
2 \text { aspirational }\end{array}$ & $\begin{array}{l}\text { Comprehensive } \\
\text { HIA } \\
\text { recommendations } \\
\text { show where HIA } \\
\text { did not gain } \\
\text { traction. }\end{array}$ & $\begin{array}{l}\text { Health indicators } \\
\text { (walkability and } \\
\text { SES) in sidewalk } \\
\text { infill prioritization } \\
\text { Continued } \\
\text { partnership between } \\
\text { health and planning } \\
\text { (i.e. Aging effort) }\end{array}$ \\
\hline $\mathrm{I}-710$ & $\begin{array}{l}\begin{array}{l}\text { Builds upon 2- } \\
\text { day } \\
\text { training/screening }\end{array} \\
\text { Geographic } \\
\text { emphasis } \\
\text { Community } \\
\text { perspectives } \\
\text { subsections }\end{array}$ & Very little if anything & $\begin{array}{l}\text { Very little, if } \\
\text { anything }\end{array}$ & $\begin{array}{l}\text { CEHAJ public } \\
\text { comments \& CA7 } \\
\text { HIP, PSR-LA \& } \\
\text { LAFLA: Rapid HIA } \\
\text { for Farmers Field } \\
\text { HIP \& LAFLA: } \\
\text { Long Beach Housing } \\
\text { Element HIA on } \\
\text { General Plan }\end{array}$ \\
\hline
\end{tabular}


still communicate community interests. The Clark County HIA used the Active Living Research literature to expand the public considered and introduce more holistic health pathways. Even the I-710 Corridor HIA attempted to stay true to community concerns in the face of extreme pressure by retaining health concerns in the HIA that had been identified by community professionals and representatives in an earlier two-day training. Elements that help HIA documents remain community-centered include subsections that explicitly address community perspectives and the presentation of current conditions and expected health impacts with geographic maps.

Community Interests Within the Target Plan HIA practice continues to grow and mature, but documentation of HIA effectiveness is scarce. The EPA recently evaluated 81 HIAs using Internet data collection methods, but found it was difficult in such a format to determine if an HIA had influenced the target decision. When effectiveness could be ascertained, $60 \%$ showed direct effectiveness - meaning the HIA influenced the decision or details of the decision. In another $32 \%$, the HIA was at least considered. Only six percent showed no effectiveness at all (Rhodus, et al., 2013). A recent Australian and three forthcoming U.S. meta-evaluations also confirm that HIAs are able to influence decisions (Charbonneau, 2013; E. Harris, et al., 2013; Pollack, 2013; Wendel, 2013).

This dissertation adds to the growing body of evidence by providing specific examples of how HIAs are influencing decisions. Content analysis of the HIAs and the target plans revealed direct ways the HIAs are able to influence planning documents. Clark County's target plan addressed nearly all of the recommendations of the Rapid HIA and included the Rapid HIA as an appendix. The administrative draft of the Lake Merritt 
Station Area Plan contains HIA elements and mentions the HIA several times. In this target plan, concrete transportation design recommendations were more likely to be folded in than conceptual recommendations; notable exceptions include current park utilization and local hiring goals.

This research also illustrates that direct influence on decisions may occur in diverse and unexpected ways. Direct influence is highly dependent on timing. Impact assessments typically assess defined alternatives; yet the EIA literature suggests early input is ideal to avoid missing the period in the target planning process where problem definitions and associated construction of imaginative solutions occurs (Hartley \& Wood, 2005; O'Faircheallaigh, 2010; Steinemann, 2001). HIAs released concurrently with the target plan are unlikely to have as much, if any, influence. For example, the recommendations from the Clark County Comprehensive HIA and the I-710 Corridor HIA could not be folded into the target planning documents due to their late release. Waiting to perform an HIA until alternatives are all defined may result in missing an important window of influence. However providing early input requires a great deal of flexibility including willingness to provide interim work products.

Two novel solutions surfaced to address the timing tension. HIA authors in the Clark County and Lake Merritt cases stated they felt planners were much more willing to consider their input when the HIA could work within the planning time frame. Clark County addressed the timing tension with a Rapid HIA upfront to guide discussions followed by a Comprehensive HIA on the target plan. While most people did not read the Comprehensive HIA, working towards the Comprehensive HIA allowed the HIA author to remain actively engaged in advisory committee deliberations. The Lake Merritt 
HIA Advisory Committee provided a series of letters or memos addressing drafts of the plan to make sure input was early enough to guide alternative frames. For example, the use of "pedestrian-scaled lighting" in the administrative draft of the Lake Merritt Station Area Plan can be traced directly back to one of these letters. Both approaches suggest that information that surfaces during an HIA can be integrated into the target plan and thus influence decisions if HIA practitioners are flexible about the contents and timing of products. This flexibility has important implications for HIA evaluation methods and practice: evaluations seeking to document direct influence should gather all documents, even drafts, sent to planners to trace influence.

It is also important to note the diverse ways in which HIA products can influence public decisions including avenues outside the contents of the target plan. The I-710 Corridor HIA clearly struggled to engage the target planning process, yet the circumstances surrounding the HIA hint at its potential power as a community tool legal and otherwise - within the environmental review processes. The HIA report clearly bolstered the community position that the alternatives and environmental review were not adequate; it also was used in advocating for Community Alternative 7. The HIA report joined a chorus of dissent, and Caltrans was forced to rework alternatives and recirculate the draft Environmental Impact Statement - a win for the community.

Influencing Urban Governance with HIA Finally, much has been written about the ability of HIA to increase long-term influence of public health professionals and community groups in urban governance and policymaking. While this type of influence is more difficult to measure, the HIAs were shown to influence urban governance in important ways. First, ongoing relationships, including several subsequent HIAs, can be 
linked to the three HIAs studied. Additionally, relationships from the HIAs strengthened ongoing community and public health advocacy efforts in planning. For example, the Lake Merritt HIA report was used surprisingly little in advocacy efforts by the CBOs. However, representatives of the CBOs described using the HIA advisory committee meetings as ad hoc coalition meetings for developing strategy to engage in upcoming target planning events. This was particularly important in ongoing efforts to advocate for a community benefits mechanism. Clark County Community Planning routinely invites comment from professionals from Clark County Public Health. For example, Clark County Public Health was asked to join advisory committees for an Aging planning effort. To the extent that Clark County Public Works follows their sidewalk prioritization criteria, the addition of health indicators will influence urban governance far into the future.

Increased governance also redeems the I-710 Corridor HIA. This HIA was, by design of GCCOG planners and engineers, removed from the environmental process enough to have little if any influence on the target EIS/EIR documents. Yet the HIA had an important second act during and after the public comment period. The HIA was instrumental in a legal argument to add an additional community defined alternative to the planning process. Ironically, given the contractual requirements to limit community input in the HIA, the time period after the HIA was perhaps the most participatory and democratic element observed in this research. Citizens and community advocacy groups used the community alternative and its legal package to pressure Caltrans and LACMTA into a recirculating a draft EIS/EIR that truly addresses some of the most important health concerns of this traditionally marginalized community. 


\section{Implications for Institutionalization of HIA Practice}

HIA practice has been labeled "bureaucratic pragmatism" due to its tendency to select projects and methods based on regulatory context and expediency (UCLA School of Public Health, 2014). Canadian HIA practitioners recently noted that "to implement and sustain an HIA process... it is necessary to combine science and pragmatism and to take advantage of opportunities that support its introduction” (St-Pierre, 2013, p. 21). Further, HIA professionals are an example of Davidoff's (1965/2003) advocacy planner because they represent health interests for largely unorganized, vulnerable populations in pluralistic political processes. In order to advocate, HIA professionals require skill and discretion to navigate the power structures already present in the target planning process and greater political context. In such a pragmatic field, any research has HIA practice implications.

Are HIAs an Advisable Way to Address Health in Planning? The larger question of whether or not HIAs are valuable enough to justify the effort is somewhat unclear. Some have suggested planners may view HIAs as far too burdensome to be worth the effort (A. Forsyth, et al., 2010), and clearly HIAs are not well suited for all planning situations. HIAs, however, do have distinct value in highlighting and mitigating spatial health inequalities associated with projects and plans. HIA processes and products may also protect community health interests. To the extent the HIA authors are able to build a relationship with planners and get health concerns in front of decision makers, the practice furthers the over-arching health promotion goal of prompting consideration of health in sectors outside the traditional public health field (Collins \& Koplan, 2009; Rudolph, et al., 2013). Yet HIA practice is at risk for being coopted by the 
powerful who are deftly navigating, if not controlling, the environmental planning process associated with transportation plans (Piven, 1970). If HIA practitioners are to avoid the HIA process being coopted, they must develop a practice that provides good stakeholder engagement and navigates institutionalized political processes.

Best-Practices for Stakeholder Engagement in HIA The HIA process provides a deliberative space for stakeholders to share community concerns. This may be a traditional domain of planning, but planners should not underestimate the power of health frames in social learning and building consensus. The HIA field, however, needs to be careful not to oversell the promise of participation in HIA processes. In general, HIAs do not appear uniquely suited to gather information in a participatory manner. HIAs require broad and deep technical knowledge to navigate the science of multiple health pathways, suggesting a place of prominence for public health - and to a lesser extent planning professionals. Further, HIA processes do not create a natural forum for citizens to voice their concerns. Instead, HIA shows promise in providing a structure for community representatives to build capacity, engage in social learning, and address health inequities.

HIA professionals, as those shaping the discourse, have a responsibility to actively engage stakeholders including the community affected. Several practices would help guide HIA practitioners in successful stakeholder engagement. First, all HIAs would be significantly strengthened by explicitly planning for stakeholder engagement and outreach. HIA practitioners who view HIA as a democratizing practice will likely fall short of that goal without a specific strategy to integrate community into all steps of the HIA process. At a minimum, practitioners should set an explicit participation goal to guide outreach for each HIA; the most obvious time for setting stakeholder engagement 
goals is during the screening and early scoping phase. Second, to prompt explicit and elevated consideration of community, HIA practitioners should create a stakeholder outreach plan. The stakeholder outreach plan should include a list of potential stakeholders and representatives, foreseeable conflicts, the role of stakeholders in making decisions about the HIA, and a realistic budget in terms of resources and time. Both the first and second practices could be institutionalized simply by requiring a stakeholder plan within the minimum element describing stakeholder engagement in the HIA Practice Standards (North American HIA Practice Standards Working Group, 2010). Third, HIA practitioners should budget for a longer scoping period, particularly with diverse groups, to support the deliberation that naturally occurs in interdisciplinary practice.

To improve HIA effectiveness, this dissertation suggests that HIA practice should be more thoughtful about addressing differences within and between both the planning and public health fields. Allocating time for deliberation about concepts such as risk reduction, maximizing health, determinants of health, and health equity would likely lead to more cohesive collaborations. The cases presented here also hint that HIA practitioners are under-utilizing geographic information during both deliberation and analysis. Finally, this research suggests that HIA practitioners need to embrace their professional discretion in order to identify novel ways to provide early and relevant input.

Legal Status A recurring debate within the field has been whether or not to press for a legislative mandate including demanding inclusion within EIA as a way to institutionalize HIA practice (Bhatia \& Wernham, 2008; Cole, et al., 2004; Dannenberg \& Wernham, 2013; Rajotte, et al., 2011). This research suggests a legal mandate would both help and hurt community health interests. A legal mandate would help communities 
by making HIAs more routine, potentially shoring up funding, and signaling to decision makers that they must consider the HIA report. Since a commitment to social determinants of health and equity results in decision-support HIAs that address community health concerns even with minimal community contact, expanding HIA practice through a mandate would increase consideration of community health interests. A significant drawback to a legal mandate is that it may delegitimize HIAs outside of the legal parameters. This would likely result in less funding and consideration of community-led and controlled HIAs such as the Lake Merritt HIA.

The U.S. HIA field seems to recognize this quandary. Talk of legal mandates at recent conferences has largely been replaced with discussions about stable funding and HIA programs that can support and take advantage of a flexible HIA practice. The field seems content to hold off on this decision, especially now that Pew and the CDC are playing a major role in stabilizing funding, enforcing practice standards, and pressing for innovation.

\section{Conclusion}

Despite desire on the part of both public health and planning professionals to facilitate citizen control over decisions that affect their everyday lives, there are limits to democratizing transportation planning through HIA practice. Foremost, HIAs may not be as participatory as previously suggested. The HIAs studied were highly reliant on internal and external stakeholder participation processes; this was true even for the Lake Merritt HIA that had elements of both advocacy and community control. This suggests HIA democratizes to the extent that representatives on the HIA steering or advisory 
committees reflect community interests, are able to authentically engage the HIA process, and are able influence the target plan.

While many HIA processes engage stakeholders, not all are controlled by an advisory committee comprised of representatives from organizations best described as community advocates. The Lake Merritt HIA is an exemplar of a community-led approach and illuminates the success that can come with significant community engagement and control. The Clark County HIA illustrates that cooperation between planning and public health can facilitate successful merging of engagement strategies. In that setting, building relationships and collaborating with other stakeholders is a legitimate way to elevate health interests. Conversely, the I-710 case clearly serves as a cautionary tale that a contentious relationship with the planning agency can curtail if not coopt the influence of an HIA that was to be integrated into the target plan.

The challenge of timing an HIA to both shape and analyze defined alternatives is discussed at length in the literature, but the HIAs studied addressed this tension in flexible and novel ways: staging the HIA by starting with a Rapid HIA and following with a Comprehensive HIA on the target plan; providing memos and letters at points requested by the planning agency; and remaining active in the target advisory committees' engagement processes. The early input was particularly effective at influencing planning decisions and suggests that both HIA practitioners and evaluators need to be aware that other work products may be more influential than the HIA report. The I-710 case also illustrated that HIAs can serve a role in a community organizing campaign even in instances where the HIA becomes divorced from the official planning process. 
Even though HIAs may not be routinely participatory, the practice is flexible enough to support merging and elevating community health interests with technical public health knowledge and expertise. This dissertation distinguishes between technical knowledge divorced from community context and professional knowledge such as diverse pathways from the social determinants of health, documenting current conditions with demographics and health prevalence data, mapping data with GIS skills. These types of professional knowledge support community health interests in a stakeholder setting, even without significant community input. The Clark County HIA is notable in that it expanded both the publics and health pathways considered in the target plan. Even the I-710 Corridor HIA was able to include pathways relevant to the community.

This research clearly showed that the foundational public health values and frames of health equity and the social determinants of health elevate community needs and guide social learning. The social determinants of health provide the holistic frame to explore multiple health pathways and choose those most meaningful to the community and target plan. The health equity frame highlights vulnerable communities by documenting disparities in current environmental and health conditions. The power of GIS is largely unexplored in HIA literature and practice, but when combined with health equity tends to elevate community health interests in largely professional documents. Even technical, quantitative HIA reports such as the I-710 Corridor HIA can highlight community perspectives to frame the report.

Finally, this research adds to a body of forthcoming evidence of HIA process and reports' effectiveness in influencing planning decisions. The case study approach documented both direct and indirect influence of the HIA on the target decision. It also 
traced community interests at every stage in the process. Community interests are understandably more prominent with a strong community-based advisory committee; but largely professional HIAs can and do highlight community interests. Both types of HIAs can, in turn, be effective in influencing decisions, although the manner in which the HIAs influence target plans is diverse.

Several cautionary tales emerged from the cases. First, HIA authors reported that community and stakeholder engagement strategies were largely shaped by convenience. This places a great deal of discretionary power with the HIA practitioner to decide if and how stakeholders will be engaged. To make sure community voice is not overlooked, the field should adopt a minimum practice standard that requires an explicit stakeholder engagement plan for each HIA. Second, scoping may be the most meaningful point of entry for community representatives, but good scoping takes times and resources. Finally, while formal integration of the HIA and target plan process is possible, it can also lead to loss of control of community engagement and influence. HIA practitioners should carefully screen the controlling agency of the target plan and ascertain if it is open to the HIA promoting health equity and providing strategies to maximize health.

Limitations This research utilized a multi-case, qualitative design. The case study provided a holistic approach to understanding the context of participation within HIA. I engaged in several types of qualitative methods: interviews, document review, content analyses. The study relies heavily on retrospective recollections of stakeholders to identify their interests and contributions to the HIA process and the interview response rate was admittedly poor, particularly for the I-710 case. Outreach, timing, and interview questions attempted to minimize but may not have completely counteracted these 
limitations. A similar limitation applies to the use of meeting minutes to assess community interests. Even the detailed meeting minutes of the I-710 Corridor case are a poor proxy for underlying intent. In most cases, however, community interests were well triangulated with information about the community organizations actively involved. There was limited opportunity for participant observation. Future research that includes significant, real-time observation of HIA advisory groups and public meetings would greatly enhance the validity of the findings.

While the cases were selected for variability within transportation planning, the cases presented here are not necessarily representative of all HIAs. HIA is being applied to other fields within planning such as housing and to non-spatial fields outside of planning such as criminal justice and economic policies. These fields are not as tied to EIA and therefore may have different participation norms and needs. Further, over a 150 HIAs have been completed since these three HIAs were completed, and the field is moving very fast. The cases were identified right before Pew's Health Impact Project became the dominant funder of HIAs; thus the cases analyzed were not funded by the Health Impact Project ${ }^{43}$. There has been significant geographic dispersal in the HIA field in the past few years as well. Regional variation is not as pronounced as it was five years ago when HIAs were highly clustered and often performed by the same professionals within the cluster; still, care should be taken in assuming generalizability of these west coast cases to the overall field.

The cases studied were carefully identified and matched to provide for some regional, nature, and scale comparisons. Yet the very flexible nature of HIAs makes

${ }^{43}$ The Clark County HIA was funded by the Robert Wood Johnson Foundation, a key partner in the Health Impact Project. 
direct comparisons challenging. The three cases in this research revealed the extent to which an HIA will be a decision-support or an advocacy HIA with accompanying participation strategies is likely driven by a number of factors: the target plan's objectives, timeline, and engagement strategy; the goals, capacity, and political constraints of the organization leading the HIA; and the relationship between the public health and planning teams. Although care was taken to understand the context of each case, it is difficult to identify with certainty which factors are most important in influencing how communities engage with the HIA. However broad participation trends such as the clear reliance on stakeholder instead of participatory engagement methods are evident in both this research and the overall trajectory of HIA practice. This allowed for exploring potential barriers and facilitators in expressing community health interests within a stakeholder format.

Future Research The exploratory nature of this dissertation suggests that findings about community participation in HIA could be strengthened with additional research. First, case study research, while time and resource consuming, is particularly adept at tracing community interests and understanding HIA practice in the context of political processes that surround public decisions. Interviewing was incredibly fruitful in this research, but future case-study research should also include participant observation when possible. There is particular need for additional case studies in planning and policy sectors less influenced by environmental planning to understand the extent to which participation in transportation HIAs are affected by NEPA norms. There is also a need for understanding how health equity plays out in HIAs that are less geographically 
grounded such as economic policies or policies that affect identity groups such as felons or immigrants.

While survey instruments will likely miss the nuances surrounding community interests and political processes, the field still needs a better handle on stakeholder engagement norms, strategies, and participants. At the time of filing this dissertation, several recent large-scale meta-evaluations have been published with more scheduled for release in the coming months (Charbonneau, 2013; E. Harris, et al., 2013; Pollack, 2013; Rhodus, et al., 2013; Wendel, 2013). All but the EPA-led evaluation (Rhodus, et al., 2013) used a mixture of quantitative and qualitative methods including stakeholder interviews. The evaluations are best described as a broad looks at all aspects of the field with an emphasis on showing effectiveness. Since stakeholder participation and relationship building is a hallmark of HIA, the field needs to push forward in characterizing and showing the value in stakeholder engagement. There may be an opportunity to perform a meta-analysis to confirm validity and shed greater light on how participation strategies in HIA ultimately influence consideration of health in public policy. Doing so would also help address the range and intensity of participation types for community and non-community stakeholders and could be particularly useful in providing more insight into the power structure of advisory committees in contemporary HIA practice.

Several themes related to social learning emerged within this dissertation; these are largely ignored within contemporary HIA practice and theory. While there is some recognition that professional knowledge and methodologies vary both between and within the public health and planning professions, the extent to which this jeopardizes 
social learning within HIA remains largely unexplored. The theoretical links between health equity, the social determinants of health, and effectiveness are emerging in research and practice. However geographic and spatial issues are largely underdeveloped in HIA circles; understanding the ability to use HIA to address spatial injustice would likely benefit from applying constructs in social geography. Finally, it would be fruitful to verify that health equity, the social determinants of health, and GIS support social learning in other HIAs.

The dominance of stakeholder strategies within HIA is clear, but more work still needs to be done to develop best practices develop within the field. Evidence-based stakeholder best practices could largely be borrowed from the negotiation literature, but there is value in continued exploration of how to protect community interests specifically within the HIA context. Any future work on stakeholder engagement needs to differentiate between decision-support and community-led HIAs because community has vastly different roles and power in each. This dissertation is also well positioned to inform HIA practice standards for evaluation. In particular, this dissertation suggests that early documents may be more important in tracing influence than the HIA report. Compiling and analyzing all written and verbal communication is time consuming, but evaluators will need to adjust their methodologies to account for early influence of HIA on public policy. 


\section{References}

Alta Planning + Design. (2010). Clark County, WA Bicycle and Pedestrian Master Plan. Vancouver, Washington.

Altshuler, A. (1965/2004). The Goals of Comprehensive Planning. In J. M. Stein (Ed.), Classic Readings in Urban Planning - 2nd Edition (pp. 67-85). Chicago, IL: Planners Press.

Alvarado, M. (2013). Jesse Marquez: Coalition for a Safe Environment. 2014, from https://www.youtube.com/watch?v=19mDP_Dqt8U

American Lung Association. (2012). State of the Air. Washington DC.

American Society of Planning Officials. (1968). The Urban Planner in Health Planning. Washington DC: U.S. Department of Health, Education, and Welfare.

Amy, D. (1987). The Politics of Environmental Mediation. New York: Columbia University Press.

APEN. (2008). About Us: Background. Retrieved 02/07/2012, 2012, from http://archive.apen4ej.org/about_background.htm

APEN. (2010,02/07/2012). APACC: Asian Pacific American Climate Coalition Membership Form. from http://archive.apen4ej.org/download/APACC_membership_form.pdf

Arnstein, S. (1969/2005). A Ladder of Citizen Participation. In R. T. LeGates \& F. Stout (Eds.), The City Reader (pp. 244-254). New York: Routledge.

Asian Health Services. (2006). Annual Report. Oakland, CA.

Asian Health Services. (2010). Annual Report 2009-2010. Oakland, CA.

Asian Health Services, Oakland Chinatown Chamber of Commerce, \& City of Oakland. (2009a). Lake Merritt BART Station Area Community Engagement Final Report. Oakland, CA.

Asian Health Services, Oakland Chinatown Chamber of Commerce, \& City of Oakland. (2009b). Lake Merritt BART Station Area Community Engagement: Final Report. Oakland, CA.

Awofeso, N. (2004). What's new about the "new public health?". American Journal of Public Health, 94(5), 705-709.

Barton, H., \& Tsourou, C. (2000). Healthy urban planning : a WHO guide to planning for people London: Routledge for World Health Organization. Regional Office for Europe.

Beierle, T. C., \& Cayford, J. (2003). Dispute Resolution as a Method of Public Participation. In R. O'Leary \& L. B. Bingham (Eds.), The Promise and Performance of Environmental Conflict Resolution (pp. 53-68). Washington DC: RFF Press.

Belk, S. (2013, November 8, 2013). Environmental Groups Vow to Continue Push for Alternative I-710 Freeway Plan After Bill Vetoed. Signal Tribune. Retrieved from http://www.signaltribunenewspaper.com/?p=21569

Berg, B. L. (2007). An Introduction to Content Analysis. In B. L. Berg (Ed.), Qualitative Research Methods for the Social Sciences (6th ed.). Boston: Pearson. 
Bhatia, R. (2007). Protecting Health Using an Environmental Impact Assessment: A Case Study of San Francisco Land Use Decisionmaking. American Journal of Public Health, 97(3), 406-413.

Bhatia, R., \& Wernham, A. (2008). Integrating Human Health into Environmental Impact Assessment: An Unrealized Opportunity for Environmental Health and Justice. Environmental Health Perspectives, 116(8), 991-1000.

Boarnet, M. G. (2006). About This Issue: Planning's Role in Building Healthy Cities. Journal of the American Planning Association, 72(1), 5-9.

Campbell, H. (2006). Just Planning: The Art of Situated Ethical Judgment. Journal of Planning Education and Research, 26(1), 92-106.

Cargo, M., \& Mercer, S. L. (2008). The Value and Challenges of Participatory Research: Strengthening Its Practice. Annual Review of Public Health, 29, 325-350.

Carlson, C. (1999). The Importance of Convening: Two Examples. In L. Susskind, S. McKearnan \& J. Thomas-Larmer (Eds.), The Consensus Building Handbook. Thousand Oaks, CA: Sage.

Cashman, S. B., Adeky, S., Allen III, A. J., Corburn, J., Israel, B. A., Montano, J., et al. (2008). The Power and the Promise: Working with Communities to Analyze Data, Interpret Findings, and Get to Outcomes. American Journal of Public Health, 98(8), 1407-1141.

Center for Disease Control and Prevention. (2014a). About Health Poeple. Retrieved May 1, 2014, 2014, from http://www.healthypeople.gov/2020/about/default.aspx

Center for Disease Control and Prevention. (2014b). Chronic Diseases and Health Promotion. Retrieved May 1, 2014, from www.cdc.gov/chronicdisease/overview/index.htm

Center on Society and Health. (2014). Place Matters. Retrieved May 6, 2014, from www.societyhealth.vcu.edu/Page.aspx?nav=200

CFASE. (2014). Coalition for a Safe Environment. 2014, from www.cfase.org Chanchitpricha, C., \& Bond, A. (2013). Conceptualising the Effectiveness of Impact Asessment Process. Environmental Impact Assessment Review, 43, 65-72.

Charbonneau, D. (2013, 09/25/2013). Impact and success of HIAS: Highlights from a nationwide evaluation. Paper presented at the 2nd National HIA Meeting, Washington, DC.

City of Oakland. (2004). Revive Chinatown: Community Transportation Plan. Oakland, CA.

City of Oakland. (2010). Lake Merritt Station Area Plan Existing Conditions and Key Issues Report. Oakland, CA.

Coalition for Environmental Health and Justice. (2012). I710 Expansion Comments.

Cole, B. L., \& Fielding, J. E. (2007). Health Impact Assessment: A Tool to Help Policy Makers Understand Health Beyond Health Care. Annual Review of Public Health, 28, 393-412.

Cole, B. L., Wilhelm, M., Long, P. V., Fielding, J. E., Kominski, G., \& Morgenstern, H. (2004). Prospects for Health Impact Assessment in the United States: New and Improved Environmental Impact Assessment or Something Different? Journal of Health Politics, Policy, and Law, 29(6), 1153-1186. 
Collins, J., \& Koplan, J. P. (2009). Health impact assessment: a step toward health in all policies. JAMA : the journal of the American Medical Association, 302(3), 315317.

Columbian Editorial Board. (2010). In Our View: Riding into the Future. Columbian.

Corburn, J. (2003). Bringing local knowledge into environmental decision-making: Improving urban planning for communities at risk. Journal of Planning Education and Research, 22, 422-433.

Corburn, J. (2004). Confronting the Challenges in Reconnecting Urban Planning and Public Health. American Journal of Public Health, 94(4), 541 - 549.

Corburn, J. (2005a). Street Science: Community Knowledge and Environmental Health Justice. Cambridge, MA: MIT Press.

Corburn, J. (2005b). Urban planning and health disparities: Implications for research and practice. Planning Practice and Research, 20(2), 111 - 126.

Corburn, J. (2007). Reconnecting with Our Roots: American Urban Planning and Public Health in the Twenty-first Century. Urban Affairs Review, 42(5), 688-713.

Corburn, J. (2009). Toward the Healthy City: People, Places, and the Politics of Urban Planning. Cambridge, MA: MIT Press.

Corburn, J., \& Bhatia, R. (2007). Health impact assessment in San Francisco: Incorporating the social determinants of health into environmental planning. Journal of Environmental Planning and Management, 50(3), 323-341.

Dannenberg, A. L., Bhatia, R., Cole, B. L., Dora, C., Fielding, J. E., Kraft, K., et al. (2006). Growing the Field of Health Impact Assessment in the United States: An Agenda for Research and Practice. American Journal of Public Health, 96(2), 262-270.

Dannenberg, A. L., Bhatia, R., Cole, B. L., Heaton, S. K., Feldman, J. D., \& Rutt, C. D. (2008). Use of Health Impact Assessment in the U.S.: 27 Case Studies, 19992007. American Journal of Preventative Medicine, 34(3), 241-256.

Dannenberg, A. L., Frumkin, H., \& Jackson, R. J. (2011). Making Healthy Places: Designing and Building for Health, Well-being, and Sustainability. Washington DC: Island Press.

Dannenberg, A. L., Jackson, R. J., Frumkin, H., Schieber, R. A., Pratt, M., Kochtitzky, C., et al. (2003). The Impact of Community Design and Land-Use Choices on Public Health: A Scientific Research Agenda. American Journal of Public Health, 93(9), 1500-1508.

Dannenberg, A. L., \& Wernham, A. (2013). Health Impact Assessment in the USA. In J. Kemm (Ed.), Health Impact Assessment: Past Achievement, Current Understanding, Future Progress (pp. 208-223). Oxford, UK: Oxford Press.

Davidoff, P. (1965/2003). Advocacy and Pluralism in Planning. In S. Campbell \& S. Fainstein (Eds.), Readings in Planning Theory - 2nd Edition. Malden, MA: Blackwell.

Day, D. (1997). Citizen Participation in the Planning Process: An Essentially Contested Concept? Journal of Planning Literature, 11(3), 421.

Dietz, T., \& Stern, P. (2008). Public Participation in Environmental Assessment and Decision Making: National Academies Press.

Dyett \& Bhatia. (2010). Lake Merritt Station Area Plan: Stakeholder Interview Report. 
EBALDC. (2010). Community. Retrieved 05/01/13, 2013, from http://www.ebaldc.org/pg/14/about-ebaldc/community

Ehrmann, J. R., \& Stinson, B. L. (1999). Joint Fact-Finding and the Use of Technical Experts. In L. Susskind, S. McKearnan \& J. Thomas-Larmer (Eds.), The Consensus Building Handbook. Thousand Oaks, CA: Sage.

Elliott, M. L. P. (1999). The Role of Facilitators, Mediators, and Other Consensus Building Practitioners. In L. Susskind, S. McKearnan \& J. Thomas-Larmer (Eds.), The Consensus Building Handbook. Thousand Oaks, CA: Sage.

EYCEJ. (2014). Fighting for Life: East Yard Communites for Environmental Justice. 2014, from www.eycej.org

Fainstein, S. (2010). The Just City. Ithica, New York: Cornell University Press.

Fainstein, S. S. (2014). The Just City. International Journal of Urban Sciences, 18(1), 118.

Farhang, L., Bhatia, R., Scully, C. C., Corburn, J., Gaydos, M., \& Malekafzali, S. (2008). Creating Tools for Healthy Development: Case Study of San Francisco's Eastern Neighborhoods Community Health Impact Assessment. Journal of Public Health Management and Practice, 14(3), 255-265.

Fisher, R., Ury, W., \& Patton, B. (1991). Getting to Yes: Negotiation Agreement Without Giving In. New York: Penguin.

Fitzpatrick, K. M., \& LaGory, M. (2011). Unhealthy Cities: Poverty, Race, and Place in America. New York: Routledge.

Forester, J. (1989). Planning in the Face of Power. Berkeley: University of California Press.

Forester, J. (1994). Bridging Interests and Community: Advocacy Planning and the Challenges of Deliberative Democracy. Journal of the American Planning Association, 60(2), 153-158.

Forester, J. (1999). The Deliberative Practitioner: Encouraging Participatory Planning Processes. Cambridge, MA: MIT Press.

Forsyth, A. (1999). Administrative Discretion and Urban and Regional Planners' Values. Journal of Planning Literature, 14(1), 5-15.

Forsyth, A., Schively Slotterback, C., \& Krizek, K. (2010). Health Impact Assessment (HIA) for Planners: What Tools Are Useful? Journal of Planning Literature, 24(3), 231-245.

Frank, L. D., Engelke, P. O., \& Schmid, T. L. (2003). Health and Community Design: The Impact of the Built Environment on Physical Health. Washington: Island Press.

Frank, L. D., \& Kavage, S. (2008). Urban Planning and Public Health: A Story of Seperation and Reconnection. Journal of Public Health Management and Practice, 14(3), 214-220.

Galea, S., Freudenberg, N., \& Vlahov, D. (2005). Cities and population health. Social Science \& Medicine, 60(5), 1017-1033.

Galea, S., Freudenberg, N., \& Vlahov, D. (2006). A framework for the study of urban health. In N. Freudenberg, S. Galea \& D. Vlahov (Eds.), Cities and the Health of the Public (pp. 3-18). Nashville, Tenn: Vanderbilt University Press. 
Gase, L. N., Pennotti, R., \& Smith, K. D. (2013). "Health in All Policies": taking stock of emerging practices to incorporate health in decision making in the United States. Journal of public health management and practice : JPHMP, 19(6), 529-540.

GCCOG. (January 28 2010). Minutes of the Meeting. of the I710 EIR/EIS Corridor Project Committee, from www.gatewaycog.org/meeting-agendas/i-710-eireisproject-committee-agendas/

GCCOG. (January 31 2011). Minutes of the Meeting. of the I710 EIR/EIS Corridor Project Committee, from www.gatewaycog.org/meeting-agendas/1-710-eireisproject-committee-agendas/

GCCOG. (January 31 2012). Minutes of the Meeting. of the I710 EIR/EIS Corridor Project Committee, from www.gatewaycog.org/meeting-agendas/i-710-eireisproject-committee-agendas/

GCCOG. (January 31 2013a). Agenda. of the I710 EIR/EIS Corridor Project Committee, from www.gatewaycog.org/meeting-agendas/i-710-eireis-project-committeeagendas/

GCCOG. (January 31 2013b). Minutes of the Meeting. of the I710 EIR/EIS Corridor Project Committee, from www.gatewaycog.org/meeting-agendas/i-710-eireisproject-committee-agendas/

GCCOG. (July 29 2010). Minutes of the Meeting. of the I710 EIR/EIS Corridor Project Committee, from www .gatewaycog.org/meeting-agendas/i-710-eireis-projectcommittee-agendas/

GCCOG. (June 30 2011). Minutes of the Meeting. of the I710 EIR/EIS Corridor Project Committee, from www .gatewaycog.org/meeting-agendas/i-710-eireis-projectcommittee-agendas/

GCCOG. (May 31 2012). Minutes of the Meeting. of the I710 EIR/EIS Corridor Project Committee, from www .gatewaycog.org/meeting-agendas/i-710-eireis-projectcommittee-agendas/

GCCOG. (October 12, 2011). AQAP Technical Roundtable - Meeting Summary. from http://www.gatewaycog.org/meeting-agendas/aqap-committee-agendas-andminutes/

GCCOG. (October 26 2011a). Environmental Committee Agenda. from www.gatewaycog.org/meeting-agendas/environmental-committee-agendas-andminutes/

GCCOG. (October 26 2011b). Environmental Committee Meeting Minutes. from www.gatewaycog.org/meeting-agendas/environmental-committee-agendas-andminutes/

GCCOG. (October 29 2009). Minutes of the Meeting. of the I710 EIR/EIS Corridor Project Committee, from www.gatewaycog.org/meeting-agendas/i-710-eireisproject-committee-agendas/

Gihuly, K., Purciel, M., Farhang, L., Lucky, J., Harris, E. C., Heller, J., et al. (2011). Using health impact assessment in community development to improve air quality and public health. Community Development, 42(2), 193-207.

Glucker, A. N., Driessen, P. P., Kolhoff, A., \& Runhaar, H. A. (2013). Public Participation in Environmental Impact Assessment: Why, Who, and How? Environmental Impact Assessment Review, 43, 104-111. 
Gottlieb, L. M., Fielding, J. E., \& Braveman, P. A. (2012). Health Impact Assessment: Necessary but Not Sufficient for Healthy Public Policy. Public Health Reports, 127, 156-162.

Green, L., \& Kreuter, M. (2004). Health Program Planning: An Educational and Ecological Approach (4th ed.). New York, NY: McGraw-Hill.

Harris, E., Haigh, F., Baum, F., Harris-Roxas, B., Kemp, L., Chok, H. N., et al. (2013). The effectiveness of Health Impact Assessment: New Zealand and Australia 20052009. Sydney: Centre for Primary Health Care and Equity, University of NSW.

Harris, P., Sainsbury, P., \& Kemp, L. (2014). The fit between health impact assessment and public policy: Practice meets theory. Social Science \& Medicine, 108, 46-53.

Harris-Roxas, B., \& Harris, E. (2011). Differing Forms, Differing Purposes: A Typology of Health Impact Assessment. Environmental Impact Assessment Review, 31, 396403.

Harris-Roxas, B., \& Harris, E. (2012). The Impact and Effectiveness of Health Impact Assessment: A Conceptual Framework. Environmental Impact Assessment Review, In press.

Harris-Roxas, B., Viliani, F., Bond, A., Cave, B., Divall, M., Furu, P., et al. (2012). Health Impact Assessment: the State of the Art. Impact Assessment and Project Appraisal, 30(1), 43-52.

Hartley, N., \& Wood, C. (2005). Public Participation in Environmental Impact Assessment - Implementing the Aarhus Convention. Environmental Impact Assessment Review, 25, 319-340.

Healey, P. (1996/2003). Planning through debate: The communicative turn in planning theory. In S. Campbell \& S. Fainstein (Eds.), Readings in Planning Theory - 2nd Edition. Malden, MA: Blackwell.

Healey, P. (1997). Collaborative planning: Shaping places in a fragmented society. London: Macmillian.

Health Impact Project. HIA in the United States. Retrieved March 28, 2014), from www.healthimpactproject.org/hia/us

Health Impact Project. (2014). Grantees. Retrieved May 6, 2014, from www.healthimpactproject.org/project/grantees

Hebert, K. A., Wendel, A. M., Kennedy, S. K., \& Dannenberg, A. L. (2012). Health impact assessment: A comparison of 45 local, national, and international guidelines. Environmental Impact Assessment Review, 34, 74-82.

Heller, J., Malakafzali, S., Todman, L. C., \& Wier, M. (2013). Promoting Equity through the Practice of Health Impact Assessment. Oakland, CA: PolicyLink.

Hoch, C. (1994). What Planners Do: Power, Politics, and Persuasion. Chicago, Illinois: Planners Press.

Hofrichter, R., \& Bhatia, R. (2010). Tackling Health Inequities through Public Health Practice: Theory to Action. New York: Oxford University Press.

Hourdequin, M., Landres, P., Hanson, M. J., \& Craig, D. R. (2012). Ethical Implications of Democratic Thoery for U.S. Public Participation in Environmental Impact Assessment. Environmental Impact Assessment Review, 35, 37-44.

Huang, V. (2011). Building Transit Oriented Community in Oakland's Chinatown. Race, Poverty, and the Environment, 18(1), 63-67. 
Huberman, A. M., \& Miles, M. B. (1998). Data management and Analysis Methods. In N. K. Denzin \& Y. S. Lincoln (Eds.), Collecting and Interpreting Qualitative Materials (pp. 246-273). Thousand Oaks, CA: Sage.

Human Impact Partners. (2012). A Case Study of the I-710 HIA.

Innes, J. E. (1995). Planning Theory's Emerging Paradigm: Communicative Action and Interactive Practice. Journal of Planning Education and Research, 14(3), 128135.

Innes, J. E. (1996/2004). Planning Through Consensus Building: A New View of the Comprehensive Planning Ideal. In J. M. Stein (Ed.), Classic Readings in Urban Planning - 2nd Edition (pp. 147-161). Chicago, IL: Planners Press.

Innes, J. E., \& Booher, D. E. (2010). Planning with Complexity: An introduction to collaborative rationality for public policy. New York: Routledge.

Innes, J. E., \& Booher, D. E. (2014). A Turning Point for Planning Theory? Overcoming Dividing Discourses. Planning Theory, OnlineFirst.

Israel, B. A., Schulz, A. J., Parker, E. A., \& Becker, A. B. (1998). Review of Community Based Research: Assessing Partnership Approaches to Improve Public Health. Annual Review of Public Health, 19, 173-202.

Isreal, B. A., Schulz, A. J., Parker, E. A., Becker, A. B., Allen III, A. J., \& Guzman, R. J. (2003). Critical Issues in Developing and Following Community Based Participatory Research Principles. In M. Minkler \& N. Wallerstein (Eds.), Community-Based Participatory Research for Health (pp. 53-76). San Francisco, CA: Jossey-Bass.

Jackson, R. J. (2003). Editorial: The Impact of the Built Environment on Health - An Emerging Field. American Journal of Public Health, 93(9), 1382-21383.

Kearney, M. (2004). Walking the walk? Community participation in HIA: A qualitative interview study. Environmental Impact Assessment Review, 24, 217-229.

Kemm, J. (2005). The Future Challenges for HIA. Environmental Impact Assessment Review, 25, 799-807.

Kemm, J. (2013). Health Impact Assessment: Past Achievements, Current Understanding, and Future Progress. Oxford, United Kingdom: Oxford University Press.

Kent, J. L., \& Thompson, S. (2014). The Three Domains of Urban Planning for Health and Well-Being. Journal of Planning Literature, OnlineFirst.

Kenzer, M. (1999). Healthy Cities: A Guide to the Literature. Environment and Urbanization, 11(1), 201-220.

Krumholz, N. (1999/2003). Equitable Approaches to Local Economic Development. In S. Campbell \& S. Fainstein (Eds.), Readings in Planning Theory - 2nd Edition. Malden, MA: Blackwell.

Krumholz, N., \& Forester, J. (1990). Making Equity Planning Work. Philadelphia, PA: Temple University Press.

LACEEN. (2014). L.A. Community Environmental Enforcement Network. 2014, from www.laceen.org

LACMTA. (2014a). I-710 Corridor Participation Participation Framework. Retrieved March 30, 2014), from

//ebb.metro.net/projects_studies/I710/community/default.htm 
LACMTA. (2014b). I-710 Corridor Project EIR/EIS Maps. Retrieved March 30, 2014), from media.metro.net/projects_studies/I710/images/710_projectmap.pdf

Lara, R. (2013, October 11). Bill to Improve Health and Traffic Conditions Along I-710 Corridor Vetoed; Yet Hope Not Lost. Press Release. Retrieved from http://sd33.senate.ca.gov/news/2013-10-11-bill-improve-health-and-trafficconditions-along-i-710-corridor-vetoed-yet-hope-not-

Lasker, R. D., \& Guidry, J. A. (2009). Engaging the Community in Decision Making: Case Studies Tracking Participation, Voice and Influence. Jefferson, North Carolina: McFarland \& Company, Inc.

Laurian, L., \& Shaw, M. M. (2009). Evaluation of Public Participation: The Practices of Certified Planners. Journal of Planning Education and Research, 28(3), 293-309.

Lawrence, R. (1999). Urban Health: An Ecological Perspective. Review of Environmental Health, 14(1), 1-10.

Laws, D. (1999). Representation of Stakeholding Interests. In L. Susskind, S. McKearnan \& J. Thomas-Larmer (Eds.), The Consensus Building Handbook. Thousand Oaks, CA: Sage.

LBACA. (2014a). Long Beach Alliance for Children with Asthma: About. 2014, from http://lbaca.org/about-lbaca/about/

LBACA. (2014b). Long Beach Alliance for Children with Asthma: Outdoor Air Pollution. 2014, from http://lbaca.org/policy/outdoor-air-pollution

LBACA. (2014c). Long Beach Alliance for Children with Asthma: Policy. 2014, from http://lbaca.org/policy/policy/

Mahoney, M. E., Potter, J.-L. L., \& Marsh, R. S. (2007). Community participation in HIA: Discords in teleology and terminology. Critical Public Health, 17(3), 229241.

Malizia, E. E. (2006). Planning and Public Health: Research Options for an Emerging Field. Journal of Planning Education and Research, 25(4), 428-432.

Marmot, M., \& Wilkinson, W. (2003). Social Determinants of Health: The Solid Facts. 2nd Edition, . Denmark: World Health Organization.

Melnick, A. (2010). PAWN - Planning for Active Walkable Neighborhoods. Clark County, WA: Robert Wood Johnson Foundation - Active Living Reserch Round 9.

Melosi, M. V. (2000). The sanitary city: urban infrastructure in America from colonial times to the present. Baltimore: John Hopkins University Press.

Metzger, J. T. (1996). The Theory and Practice of Equity Planning: An Annotated Bibliography. Journal of Planning Literature, 11(1), 112-126.

Miles, M. B., \& Huberman, A. M. (1994). Qualitative Data Analysis: An Expanded Sourcebook, 2nd Edition. Thousand Oaks, CA: Sage.

Minkler, M. (1999). Personal Responsibility for Health? A Review of the Arguments and the Evidence at Century's End. Health Education \& Behavior, 26(1), 121-140.

Minkler, M. (2010). Linking Science and Policy Through Community-Based Participatory Reserach to Study and Address Health Disparities. American Journal of Public Health, 100(S1), S81-S87.

Minkler, M. (Ed.). (1997). Community organizing and community building for health. New Brunswick, NJ: Rutgers University Press. 
Minkler, M., Breechwich Vasquez, V., Chang, C., Miller, J., Rubin, V., Glover Blackwell, A., et al. (2008). Promoting Healthy Public Policy Through Community-Based Participatory Research: Ten Case Studies. Oakland, CA: PolicyLink.

Minkler, M., \& Wallerstein, N. (2008). Community-Based Participatory Research for Health (2nd ed.). San Fransisco, CA: Jossey-Bass.

Minkler, M., Wallerstein, N., \& Wilson, N. (2008). Improving Health Through Community Organizing and Community Building. In K. Glanz, B. K. Rimer \& K. Viswanath (Eds.), Health Behavior and Health Education (4th ed., pp. 287-312). San Francisco: Jossey-Bass.

National Research Council. (2011). Improving Health in the United States: the Role of Health Impact Assessment. Washington DC: The National Academies Press.

Negev, M. (2012). Knowledge, Data and Interests: Challenges in Participation of Diverse Stakeholders in HIA. Environmental Impact Assessment Review, 33, 48-54.

North American HIA Practice Standards Working Group. (2009). Practice Standards for Health Impact Assessment (HIA).

North American HIA Practice Standards Working Group. (2010). Minimum Elements and Practice Standards for Health Impact Assessment, Version 2. Oakland, CA.

Northridge, M., \& Sclar, E. (2003). A joint urban planning and public health framework: Contributions to health impact assessment. American Journal of Public Health, 93(1), 118-121.

Northridge, M. E., Sclar, E. D., \& Biswas, P. (2003). Sorting out the connections between the built environment and health: A conceptual framework for navigating pathways and planning healthy cities. Journal of Urban Health - Bulletin of the New York Academy of Medicine, 80(4), 556-568.

O'Faircheallaigh, C. (2010). Public Participation and Environmental Impact Assessment: Purposes, Implications, and Lessons for Public Policy Making. Environmental Impact Assessment Review, 30, 19-27.

Ozawa, C. (1993). Improving Citizen Participation in Environmental Decisionmaking: The Use of Transformative Mediator Techniques. Environment and Planning $C$ : Government and Policy, 11, 103-117.

Parry, J., \& Kemm, J. (2005). Criteria for Use in the Evaluation of Health Impact Assessment. Public Health, 119(12), 1122-1129.

Piven, F. F. (1970). Whom does the advocate planner serve? Social Policy(May/June).

Polidori, A., \& Fine, P. M. (2012). Ambient Concentrations of Criteria and Air Toxic Pollutants in Close Proximity to a Freeway with Heavy Diesel Traffic. Retrieved from http://www.aqmd.gov/tao/AQ-Reports/I710Fwy_Study.pdf.

Pollack, K. M. (2013, 09/25/2013). Impacts of Health Impact Assessments: A Multiple Case Study of the U.S. Experience. Paper presented at the 2nd National HIA Meeting, Washington, DC.

Potapchuk, W. R., \& Crocker, J. (1999). Implementing Consensus-Based Agreements. In L. Susskind, S. McKearnan \& J. Thomas-Larmer (Eds.), The Consensus Building Handbook. Thousand Oaks, CA: Sage.

Putters, K. (2005). HIA, the next step: Defining models and roles. Environmental Impact Assessment Review, 25, 693-701. 
Quick, K. S., \& Feldman, M. S. (2011). Distinguishing Participation and Inclusion. Journal of Planning Education and Research, 31(3), 272-290.

Quigley, R., \& Taylor, L. (2003). Evaluation as a key part of health impact assessment: the English experience. Bulletin of the World Health Organization, 81(6), 415419.

Rajotte, B. R., Ross, C. L., Ekechi, C. O., \& Cadet, V. N. (2011). Health in All Policies: addressing the legal and policy foundations of health impact assessment. Journal of Law, Medicine, \& Ethics, 39(27-29).

Rauschmayer, F., \& Risse, N. (2005). A framework for the selection of participatory approaches for SEA. Environmental Impact Assessment Review, 25, 650-666.

Rhodus, J., Fulk, F., Autrey, B., O'Shea, S., \& Roth, A. (2013). A Review of Health Impact Assesments in the U.S.: Current State-of-Science, Best Practices, and Areas for Improvement.

Rice, S. (2010, November 24, 2010). County approves 20-year cycling, pedestrian plan. Columbian.

Ricklin, A., Musiol, E., \& Klein, W. (2012). Healthy Planning: An Evaluation of Comprehensive and Sustainability Plans Addressing Public Health. Chicago: American Planning Association.

Rosner, D. (2006). Public health in U.S. cities: a historical perspective. In N. Freudenberg, S. Galea \& D. Vlahov (Eds.), Cities and the Health of the Public (pp. 129-142). Nashville, Tenn: Vanderbilt University Press.

Ross, C. L., Orenstein, M., \& Botchwey, N. (2014). Health Impact Assessment in the United States. New York: Springer.

Ross, C. L., \& Rao, A. (2013). Health impact assessment in the USA: practice, policy and legal underpinnings. In M. O'Mulan (Ed.), Integrating Health Impact Assessment with the Policy Process: Lessons and experiences from around the world (pp. 8898). Oxford, UK: Oxford.

Rudolph, L., Caplan, J., Ben-Moshe, K., \& Dillon, L. (2013). Health in All Policies: A Guide for State and Local Governments. Washington, DC and Oakland, CA: American Public Health Association and Public

Health Institute.

Sallis, J., Owen, N., \& Fisher, E. B. (2008). Ecological Models of Health Behavior. In K. Glanz, B. K. Rimer \& K. Viswanath (Eds.), Health Behavior and Health Education: Theory, Research and Practice. San Francisco: Jossey-Bass.

Sallis, J. F., Cervero, R. B., Ascher, W., Henderson, K. A., Kraft, M. K., \& Kerr, J. (2006). An Ecological Approach to Creating Active Living Communities. Annual review of public health, 27(1), 297-322.

Salomons, G. H., \& Hoberg, G. (2014). Setting Boundaries of Participation in Environmental Impact Assessment. Environmental Impact Assessment Review, $45,69-75$.

Sandercock, L. (2000). When Strangers Become Neighborhours: Managing Cities of Difference. Planning Theory and Practice, 1(1), 13-20.

Schulz, A. J., Israel, B. A., Zimmerman, M. A., \& Checkoway, B. N. (1995). Empowerment as a multi-level construct: perceived control at the individual, 
organizational and community levels. Health Education Research, 10(3), 309327.

Sloane, D. C. (2006). From Congestion to Sprawl: Planning and Health in Historical Context. Journal of the American Planning Association, 72(1), 10-18.

Smith, D. (2013, August 15, 2013). Angelenos' vision of their river is created from a made-up memory. Los Angeles Times. Retrieved from http://www.latimes .com/news/local/la-me-smith-river20130816,0,6866286.story?page=1\#axzz2rL4D4OVM

Srinivasan, S., O'Fallon, L. R., \& Dearry, A. (2003). Creating Healthy Communities, Healthy Homes, Healthy People: Initiating a Research Agenda on the Built Environment and Public Health. American Journal of Public Health, 93(9), 14461450.

St-Pierre, L. (2013). Canadian Experiences in Institutionalizing Health Impact Assessment (HIA. Montreal, Quebec: National Collaborating Centre for Healthy Public Policy,.

Stakeholder Participation Working Group. (2012). Guidance and Best Practices for Stakeholder Participation in Health Impact Assessments. Oakland, CA: 2010 HIA in the Americas Workshop.

Steinemann, A. (2001). Improving Alternatives for Environmental Impact Assessment. Environmental Impact Assessment Review, 21, 3-21.

Stoecker, R. (2003). Are Academics Irrelevant? Approaches and Roles for Scholars in Community Based Participatory Research. In M. Minkler \& N. Wallerstein (Eds.), Community-Based Participatory Research for Health (pp. 98-112). San Francisco, CA: Jossey-Bass.

Sullivan, M., Chao, S. S., Allen, C. A., Kone, A., Pierre-Louis, M., \& Krieger, J. (2003). Community-Researcher Partnerships: Perspectives from the Field. In M. Minkler \& N. Wallerstein (Eds.), Community-Based Participatory Research for Health (pp. 113-130). San Francisco, CA: Jossey-Bass.

Tarr, J. A. (1996). The Search for the Ultiate Sink: Urban Pollution in Historical Perpective. Akron, Ohio: University of Akron Press.

Taylor, L., Gowman, N., \& Quiigley, R. (2003). Evaluating Health Impact Assessment.

Taylor, N. (1998). Mistaken Interests and the Discourse of Planning. Journal of the American Planning Association, 64(1), 64-75.

Tier 2 Community Advisory Committee. (2004). Major Opportunity/Strategy Recommendations and Conditions.

TransForm. (2012). Great Communities Collaborative. Retrieved 02/07/2012, 2012, from http://transformca.org/campaign/great-communities

U.S. Environmental Protection Agency Region IX. (2008). Scoping Comments for Interstate 710 (I710) Corridor Project from Ocean Boulevard in the City of Long Beach to State Route 60 (SR60) in Los Angeles County, California.

U.S. Environmental Protection Agency Region IX. (September 28, 2012). Comments on the Draft Environmental Impact Statement for the Interstate 710 Corridor Project from Ocean Boulevard to State Route 60, Los Angeles County, California (CEQ\# 20120229). Retrieved from http://www.epa.gov/region9/nepa/letters/ca/losangeles/i710Corridor-OceanBlvd-rte60-deis.pdf. 
UCLA School of Public Health. (2014). Methodology: Models (Taxonomy of HIA) Health Impact Assessment. from http://www.ph.ucla.edu/hs/healthimpact/models.htm

Wallerstein, N., \& Duran, B. (2003). The Conceptual, Historical, and Practice Roots of Community Based Research and Related Participatory Traditions. In M. Minkler \& N. Wallerstein (Eds.), Community-Based Participatory Research for Health (pp. 27-52). San Francisco, CA: Jossey-Bass.

Wendel, A. (2013, 09/25/2013). Endeavors in Health Impact Assessment Evaluation. Paper presented at the 2nd National HIA Meeting, Washington, DC.

Werna, E., Harpham, T., Blue, I., \& Goldstein, G. (1999). From Healthy City Projects to Healthy Cities. Environment and Urbanization, 11(1), 27-40.

Wilkinson, R., \& Marmont, M. (2003). Social determinents of health: the solid facts. 2nd edition. Copenhagen, Denmark: World Health Organization.

Wismar, M., Blau, J., Ernst, K., \& Figueras, J. (2007). The Effectiveness of Health Impact Assessment: Scope and Limitations of Supporting Decision-Making in Europe. United Kingdom: Cromwell Press.

World Health Organization. (1946, 19-22 June). Preamble to the Constitution of the World Health Organization. Paper presented at the International Health Conference, New York.

World Health Organization. (1986, November 21, 1986). The Ottawa Charter for Health Promotion. Paper presented at the An International Conference on Health PRomotion, Ottawa, Canada.

World Health Organization. (1999). Health Impact Assessment: Main Concepts and Suggested Approaches. Retrieved from www.euro.who.int/document/PAE/Gothenburgpaper.pdf.

World Health Organization. (2008a). Closing the Gap in a Generation: Health Equity through Action on the Social Determinents of Health Retrieved March 30, 2014, from http://whqlibdoc.who.int/publications/2008/9789241563703_eng.pdf

World Health Organization. (2008b). The HIA Procedure. Retrieved November 27, 2008), from http://www.who.int/hia/tools/process/en/index.html

World Health Organization. (2013). Review of evidence on health aspects of air pollution - REVIHAAP Project. Retrieved from http://www.euro.who.int/_data/assets/pdf_file/0004/193108/REVIHAAP-Finaltechnical-report-final-version.pdf.

World Health Organization. (2014). Types of Healthy Settings: Healthy Cities. Retrieved May 1, 2014, from www.who.int/healthy_settings/types/cities/en/

Yin, R. K. (1994). Case Study Research: Design and Methods - 2nd Edition. Thousand Oaks, CA: Sage Publications.

Zimmerman, E., Evans, B. F., Woolf, S. H., \& Haley, A. D. (2012). Social Capital and Health Outcomes in Boston. Richmond, Virginia: Center on Human Needs, Virginia Commonwealth University. 


\section{APPENDICES}

Appendix A - Semi-structured Interview Guide

Appendix B - Informed Consent

Appendix C - Guiding Principles Governing Lake Merritt BART Station Area Plan 
Appendix A

\section{Semi-Structured Interview Guide}

Code:

Case:

Date:

D1. Professional Title:

D2. Professional degree:

D2. Accredited?

D3. Years of professional experience:

D4. Years with this organization:

D5. Previous training/experience in planning/health cross-discipline practice?

D6. Previous training and experience with HIA?

D7. Previous training and experience with community outreach?

1. What motivated you (and your organization) to be involved in (name of plan/project)? $R 2, R 4$,

2. [For those structuring the process] Was a community participation or engagement strategy considered? Prompt both HIA and general plan if appropriate. $\mathbf{R} \mathbf{I}$

3. [For those structuring the processes] What were the goals of the strategy? $\boldsymbol{R} \mathbf{I}$

4. What were your initial views on health issues associated with project? $\boldsymbol{R} 2, \boldsymbol{R} 5$

5. Have those views changed over the course of the project? $R \mathbf{5}$

6. Who did you think needed to be present to make sure the health issues associated with the project could be adequately addressed? $\boldsymbol{R} \boldsymbol{I}$

7. Was anyone missing? $\boldsymbol{R} \boldsymbol{I}$

8. [For those structuring the process] Were resources provided to help participants participate in the process?

[For community stakeholders] Did you have access to enough resources to full participate in the HIA? RI R4

9. Do/did you have relationships with these people/organizations outside of this project? R6

10. Describe your involvement in identifying and deciding which health issues were addressed in this project. $\boldsymbol{R} 2$ 
11. Were there differences among participants about which health issues should be addressed? $\boldsymbol{R} 2$

12. How were these differences resolved? $\boldsymbol{R} 2$

13. Describe your involvement in providing information and/or analyzing information associated with health impacts. $\boldsymbol{R} 4$

14. Were there differences among participants about which information should be used and how? $\mathbf{R} 4$

15. How were these differences resolved? $\boldsymbol{R} 4$

16. Do you recall any external events that were important in shaping the direction of the HIA process and document? Context control

17. How was the information and work on the HIA fed back to members of your organization/community? $\boldsymbol{R} \boldsymbol{I}$

18. Does the HIA reflect your concerns about health issues for this project? $\boldsymbol{R 5}$

19. Does [planning document] reflect your concerns about health issues for this project? R5

20. What other key participants in the HIA process should I interview? Interview sampling control 
Appendix B

\title{
INFORMED CONSENT INFORMATION FOR SEMI-STRUCTURED INTERVIEWS
}

\author{
Dear Participant,
}

As a student in the Urban Studies and Planning doctoral program at Portland State University, I am researching the potential of health impact assessments to allow for additional community participation. I am contacting you based on your association with the _ plan and the connected health impact assessment work. Your interview responses will help me better understand how health impact assessments can address community needs.

Your participation is voluntary. You do not have to take part in this project and participation will not affect the outcome of the health impact assessment, plan, or relationships with organizations and people associated with this plan. If you decide to take part in this research, I will ask you to respond to approximately 20 interview questions in person, or if required, over the phone. This interview will likely take 45 minutes, depending on your responses.

Your privacy is very important to me. The information you share with me will be kept confidential through assigning your name a numerical code. The code will be used to identify your interview recording and transcripts and will only be shared with my advisor, Dr. Connie Ozawa at Portland State University. In order to make sure I have accurately captured your input, I will send you a written summary of our interview; transcriptions of the interviews will available upon request. All materials (tapes and transcripts) will be identified only by the numerical code. The file containing your numerical code assignment will be kept in a locked filing cabinet separate from the tapes and transcripts. Electronic files of the transcripts will only be saved on a firewall protected Portland State University server.

If you have any questions, please contact me - Nicole Iroz-Elardo - at (XXX)XXX$\mathrm{XXXX}$. If you have questions concerning the use of human subjects in research, please contact the Research and Sponsored Projects Office at (503)725-4288.

Your oral consent means:

- You understand the risks and benefits of participation

- You are willing to take part in the interview

- You understand that your participation in the interview is voluntary and you can agree at any point to stop and change your mind.

Thank you for your time and consideration,

Nicole Iroz-Elardo 
Appendix C

\section{Guiding Principles Governing Lake Merritt BART Station Area Plan}

\section{Community Engagement}

Ensure opportunities for effective community participation by all stakeholders, including residents, property owners, businesses, students, employees, and organizations in the further development and implementation of the Plan.

\section{Public Safety}

- Create safe public spaces by increasing foot traffic, improving lighting, and strengthening linkages.

- Promote safer Streets with traffic calming, improved lighting, improved signage, improvements that address the needs of non-English speaking residents and visitors, and improved sidewalks and intersections

- Improve community police services

\section{Business}

- Strengthen and expand business in Chinatown, through City zoning, permits, marketing, redevelopment, infrastructure improvements, and other city tools.

- Attract and promote a variety of new businesses, including small businesses and start-ups, larger businesses that provide professional-level jobs (e.g., engineers, attorneys, accountants, etc.), and businesses that serve the local community (such as grocery stores, farmers markets, restaurants, pharmacies, banks, and bookstores).

- Promote more businesses near the Lake Merritt BART Station to activate the streets, serve Chinatown, Laney College, and the Oakland Museum of California, and increase the number of jobs.

\section{Jobs}

- Attract development of new office and business space that provide jobs and promote economic development for both and small businesses

- Increase job and career opportunities, including permanent, well-paying, and green jobs. Ensure that these jobs provide work for local residents.

- Support the provision of job training opportunities; ensure that local training opportunities (including vocational English as a second language opportunities) exist for jobs being developed both in the planning area and the region, particularly those accessible via the transit network. Coordinate with Laney College to provide job-training opportunities.

- Employ local and/or targeted hiring for contracting and construction jobs for implementation of the plan (i.e., construction of infrastructure). 


\section{Housing}

- Accommodate and promote new rental and for sale housing within the project area for individuals and families of all sizes and all income levels (from affordable to market rate housing).

- Prevent involuntary displacement of residents.

- Maintain, preserve, and improve existing housing in the project area and prevent loss of housing that is affordable to residents (subsidized and unsubsidized), and senior housing. Promote healthful homes that are environmentally friendly and that incorporate green building methods.

\section{Community Facilities and Open Space}

- Improve existing parks and recreation centers, including improving access to existing parks; and add new parks and recreation centers to serve higher-density housing and increased number of jobs.

- Ensure all parks are safe, accessible to all age groups, clean, well maintained, and provide public restrooms and trash containers.

- Create a multi-use, multi-generational recreational facility, either in addition to or including a youth center.

- Provide space for community and cultural programs and activities such as multiuse neighborhood parks, athletic fields, areas for cultural activities such as tai chi, community gardens, and expanded library programs for youth families, and seniors.

- Work with the Oakland Unified School District to ensure adequate capacity of school and children's recreational facilities.

\section{Transportation}

- Expand, preserve, and strengthen the neighborhood's access to public transit, walkability, and bicycle access.

- Ensure safety and compatibility of pedestrians, cyclists, and autos through improvements that calm traffic, improve sidewalks, improve intersection crossings, and improve traffic flow and pattern, including reevaluating one-way streets, considering narrowing streets, and reducing speeds. In particular address the flow of traffic using Posey and Webster tubes.

- Improve connections between existing assets and destinations, including between Chinatown, Lake Merritt, the 12th Street and 19th Street BART stations, Alameda County facilities, and Laney College and between the BART Stations and the Jack London District, including improving the I-880 undercrossings.

- Develop a parking strategy that includes shared parking and allows access to the area, and particularly to local retail, while also promoting non-auto modes of transportation and makes best use of available land.

- Increase walk, bike, and transit trips.

- Preserve and reinvest in transit services and facilities to make sure operators can continue to provide reliable services. 


\section{Community and Cultural Anchor and Regional Destination}

- Establish a sense of place and clear identity for the area as a cultural and community anchor and a regional destination, building on existing assets such as Chinatown, the Oakland Museum of California, Laney College, the Kaiser Convention Center, Jack London Square, and Lake Merritt and the Lake Merritt Channel.

- Preserve, celebrate, and enhance the historic cultural resources and heritage of Chinatown as a regional anchor for businesses, housing, and community services, and highlight cultural and historic resources in the planning area through signage (both wayfinding signage and by developing sign regulations that allow the display of items in store windows), historic walks, and reuse of historic buildings. Ensure that public services and spaces proposed preserve and reflect the cultural history and aspects of Chinatown's historic geography.

- Promote a more diverse mix of uses near the BART Station, such as cafes, restaurants, music venues, retail stores, nightlife, etc., that activate the area as a lively and vibrant district.

- Preserve existing designated historic resources per all federal, State and City regulations and encourage restoration of designated historic structures that would achieve priority Chinatown and/or City goals.

- Consider a cultural heritage district or related tools for preserving, enhancing, and strengthening Chinatown.

- Make connections to the Historic Jack London Warehouse District as a key asset in the Planning Area.

\section{Health}

Establish the area as a healthier place to live and work, through a range of strategies including:

- Promoting health awareness and education

- Improving environmental quality, including improving air quality as a public health measure

- Ensuring access to healthy food and housing

- Increasing health and medical services available to the community

- Cleaning up air, soil, and water contamination (including trash on the streets)

- Reducing noise levels where permitted noise levels are exceeded.

- Proving clean and well maintained public outdoor places that provide public restrooms and trash containers.

\section{Redevelopment of Key Publicly Owned Blocks Near BART}

- Establish a long-term plan for redevelopment of the four publicly owned blocks, including the two BART blocks, the MTC/ABAG block, and Madison Square Park to meet identified plan goals, including accommodating improved open 
spaces, new housing development, more jobs, more retail, and improved BART access.

- Recognize, incorporate, and reflect Chinatown's historic role in the redevelopment of the four publicly owned blocks, including the two BART blocks, the MTC/ABAG block, and Madison Square Park.

\section{Green and Sustainable Urban Design}

- Establish high quality, distinctive, and green urban design proposals, standards, and/or guidelines for new private development and public infrastructure, that are placed-based and include building design, street design, and park design.

- Build on the existing urban fabric and further promote high density and mixed use building design that promotes active and safe spaces.

- Promote green and sustainable design in concert with the City's Emerald City initiative.

- Identify landmarks and views at key locations such as the Lake Merritt BART station plaza, and promote improvements such as lights and public art, etc., and consider preservation of key views as new development is proposed (e.g., along 14th Street to Lake Merritt).

- Promote active and safe public spaces and streets by ensuring that design activates the public realm and increases the safety of streets and pedestrian crossings.

- Identify and enhance gateways between the planning area and other neighborhoods such as on 12th/14th Street which connects the planning area to the East Lake Neighborhood. 